\title{
Familienmodelle in Video-on-Demand-Serien: Analyse der Beispiele
}

Das Gesamtbild einer TV-Familie konstituiert sich aus diversen Faktoren. Anhand dieser Faktoren möchte ich den folgenden analytischen Teil strukturieren. Der weitreichenden Analyse meines Korpus geht dabei die exemplarische Analyse der Serie Ozark voran (3.1), die strukturell von der Untersuchung des Korpus abweicht. Zu Beginn der Korpusanalyse sollen die familiären Rollenmuster und geschlechtlichen Konstruktionen analysiert werden, also die Positionen, die eine Figur innerhalb eines Familiengefüges bzw. innerhalb einer familienzentrierten Serienhandlung einnehmen kann (3.2). Dabei unterscheide ich zwischen weiblichen und männlichen Rollen und thematisiere zudem Bedeutung sowie textinterne Wertung von Rollen, die von heteronormativen Strukturen abweichen. Bezüglich meiner Beispiele bedeutet dies konkret, die Darstellung homo- und transsexueller Charaktere zu untersuchen. Diese Charaktere zählen zwar auch in die Rollenbereiche der Mütter, Töchter, Söhne und Väter (und werden in diesem Rahmen auch genannt), nehmen in den analysierten Serien jedoch eine offenkundige Sonderrolle ein. Ohne dabei in irgendeiner Weise eine ausgrenzende oder abwertende Strategie verfolgen $\mathrm{zu}$ wollen, ist dementsprechend eine eigenständige Untersuchung notwendig. Nach dieser Analyse isolierter Rollen werde ich die möglichen Verhältnisse der Charaktere zueinander untersuchen (3.3). Dies schließt sowohl innerfamiliäre Beziehungen ein als auch Beziehungen von Familienmitgliedern zu außerfamiliären Charakteren. Aus den Beziehungen der Charaktere zueinander ergeben sich diverse Modelle von Familie, die durch die Texte ebenfalls unterschiedlich gewichtet werden (3.4). Über die Rollen, Beziehungsgeflechte und

Elektronisches Zusatzmaterial Die elektronische Version dieses Kapitels enthält Zusatzmaterial, das berechtigten Benutzern zur Verfügung steht https://doi.org/10.1007/978-3-658-34766-6_3. 
die daraus resultierenden Modelle hinaus werden die Darstellungen von Familie, welche - wie oben (vgl. 1) bereits angemerkt - gleichsam als Keimzelle bzw. verkleinertes Abbild der Gesellschaft gelten können, auch von den Paradigmen bestimmt, die an das familiäre Leben angelagert werden und als deren Merkmalsträger/innen die Einzelcharaktere fungieren (3.5). Abschließend beleuchte ich die Raum- und Handlungsstrukturen der jeweiligen Formate und deren Aussage über die Stellung der Familie innerhalb der Formate (3.6). Am Ende des Kapitels steht eine zusammenfassende Abstraktion der zuvor abgeleiteten Schlüsse und Thesen (3.7). Eine Übersicht über die Charaktere in Form einer Personenkonstellation und die Handlung der jeweiligen Serienfolgen ist in Anhang 2 (im elektronischen Zusatzmaterial) zu finden.

\subsection{Serienanalyse: Ozark}

Die Handlung von Ozark ergibt sich in ihrer Gesamtheit aus der vielseitigen Verknüpfung verschiedener familiärer Verbände und nur weniger nicht familiär eingebundener Einzelcharaktere. Aufgrund der gezeigten Familien, die sowohl hinsichtlich ihrer Modellierung (z. B. traditionelle Kernfamilie vs. alleinerziehendes Elternteil), der Verortung in sozialen Milieus (z. B. obere Mittelschicht vs. Unterschicht, weltlich/kriminell vs. religiös/rechtschaffen) und anderer Faktoren sehr divers sind, ist Ozark nicht nur inhaltlich und analytisch ergiebig, es eignet sich auch dazu, die dieser Untersuchung zugrunde liegende Arbeitsweise beispielhaft nachzuvollziehen. Da sich die Analyse von Ozark konkreter am Gegenstand bewegt als die umfassendere Korpusanalyse liegen ihr zunächst keine abstrakten Strukturen zugrunde. Stattdessen gehe ich von einer Analyse der unterschiedlichen Familienverbände und der weiteren Charaktere der Serie aus. Wie in der Korpusanalyse folgt eine Untersuchung der Leitparadigmen des Formats ebenso wie der Raum- und Handlungsstruktur. Hieraus ziehe ich Schlüsse über die Darstellung von Familie in Ozark.

\subsubsection{Kurze Inhaltsangabe}

Um die Orientierung zu erleichtern und der folgenden Analyse ein Fundament zu schaffen, möchte ich eine kurze Einführung in Inhalt und Handlungsverlauf von Ozark geben. 
Der dominante Handlungsstrang der Serie ist das Geschehen um die Chicagoer Familie Byrde. Der Familienvater Marty, ein selbstständiger Finanz- und Anlageberater, wurde, nur halb freiwillig, in die Geldwäschegeschäfte des mexikanischen Drogenbarons Camino Del Rio verwickelt. Als Byrdes Geschäftspartner Bruce Liddell von Del Rio erschossen wird, da er einen größeren Geldbetrag unterschlagen hat, droht auch Marty der Tod. Byrde kann Del Rio überzeugen, dass er für ihn als Geldwäscher von höherem Nutzen ist, und schlägt vor, in den Ozarks einen Geldwäschebetrieb aufzubauen. Hierbei handelt es sich um eine Wald- und Seenregion im südlichen Missouri sowie in Teilen Arkansas, Oklahomas und Kansas. Die Region - besonders die Seengebiete - ist zwar touristisch gut erschlossen, aber in großen Teilen doch sehr rural geprägt und weist viele recht isolierte Ortschaften auf. ${ }^{1}$ Die Ozarks gelten u. a. als Heimat der Hillbillys, also des Stereotyps des ungebildeten, US-amerikanischen Hinterwäldlers, und sind somit - für eine Familie aus der Großstadt - das sprichwörtliche „Ende der Welt". ${ }^{2}$ Die gesamte Familie zieht - verfolgt von Beamten des misstrauisch gewordenen FBIs - in die Ozarks. Hier werden sie mit den größtenteils antagonistischen Einwohnern konfrontiert und - unter Martys Federführung - durch die Geldwäschegeschäfte in diverse Konkurrenzkampf- und Bedrohungssituationen mit potenziell tödlichem Ausgang verwickelt. Den Byrdes stehen als Antagonisten zunächst der Hillbilly-Clan der Langmores gegenüber, die versuchen an

\footnotetext{
${ }^{1}$ Vgl. „New World Encyclopedia“" zu „The Ozarks“:

http://www.newworldencyclopedia.org/entry/The_Ozarks (zuletzt abgerufen am 21.04.2020).

${ }^{2}$ Anthony Harkins stellt fest, dass die Darstellung von ,southern mountain people as premodern and ignorant ,hillbillies “" ein fest verankerter und bis heute bestehender Teil der US-amerikanischen Populärkultur in allen Bereichen ist (vgl. Harkins 2004: 3). Neben den Bewohnern der Appalachen dienen auch die Bewohner der Ozarks als Vorlage für dieses Klischee, obgleich sich der Herkunftsraum der Hillbillys zu einem eher amorphen Gebilde entwickelte, das alle rural geprägten Räume abseits ökonomischer Zentren umfasst (vgl. Harkins 2004: 4). Als Merkmale der Hillbillys zählt Harkins ,a diet rooted in scarcity [...], physical appearance and clothing that denoted hard and specifically working-class laboring conditions [...], an animal-like existence on the economic and physical fringes of society [...], ignorance and racism, and in all cases, economic, genetic and cultural impoverishment " (Harkins 2004: 4) auf. In Hilbilly Hellraisers. Federal power and populist defiance in the Ozarks. charakterisiert J. Blake Perkins die Ozarks zudem als rurales, stark konservativ-geprägtes Gebiet mit deutlichen ,antigovernment“ Tendenzen innerhalb der Bevölkerung (vgl. Perkins 2017: 2 f.). Ozark arbeitet hier also in doppelter Hinsicht mit einem Klischee: Die Byrdes werden aus dem hochmodernen Chicago, einem Inbegriff großstädtischen Lebens, in eine Gegend versetzt, die geradezu stereotypisch einen Gegensatz zur modernen bzw. ,fortschrittlichen “ Welt bildet und deren Bewohner ihnen - den aufgeschlossenen, liberalen Stadtmenschen - im direkten Gegensatz gegenüberstehen. Mehr zu dieser Grenzüberschreitung unter 3.1.4.
} 
das Vermögen der Byrdes zu gelangen. Während die Langmores sich als geringe Bedrohung herausstellen bzw. in ihren Versuchen erfolglos bleiben, durchkreuzt Marty versehentlich im späteren Verlauf des Formats die Geschäfte des Ehepaars Snell, das in der Gegend - getarnt als Farmer bzw. Mohn-Bauern - über ein Heroin-Imperium gebietet. Diese werden zu einer ähnlichen Bedrohung wie Del Rio. Letztlich findet sich Marty in einem Machtkampf zwischen einheimischem und mexikanischem Drogenkartell wieder. Hinzu kommt, dass die langjährige Ehe Martys durch einen Betrug seiner Ehefrau gefährdet ist, somit gilt es nicht nur das Leben der Byrdes vor der Bedrohung durch Del Rio zu schützen, sondern auch die Familie vor dem Auseinanderbrechen durch den Ehebruch zu bewahren. Familiäre Konflikte nehmen innerhalb der Handlung des Formats eine oft so zentrale Stellung ein, dass sie der zentralen Handlungslinie - Geldwäsche und Kriminalität - an Relevanz ebenbürtig sind.

\subsubsection{Charakteranalysen}

Da Ozark über ein recht umfassendes Figureninventar verfügt (vgl. Abb. 3.1), wurden die Charaktere des Formats in Gruppen zusammengefasst. Dabei ist bereits im Vorhinein auffällig, dass die Figuren überwiegend in Familienverbänden organisiert sind. Nur wenige Neben und lediglich ein zentraler Charakter sind bzw. ist nicht in ein zumindest familienähnliches Verhältnis eingebettet. Welche Aussagen sich bereits aus diesem Grundcharakteristikum des Formats in Bezug auf mein Forschungsinteresse ableiten lassen, soll im Folgenden erörtert werden, lässt aber bereits die offenkundige Tendenz erahnen, Familie narrativ zu zentrieren. Da in vielen Fällen eine enge Verknüpfung bestimmter Charaktere mit bestimmten Paradigmen vorliegt, soll die Charakteranalyse der abstrakteren Untersuchung der zentralen Paradigmen des Formats vorausgehen und dieser als Fundament dienen. Während ich also im Rahmen der Charakteranalyse wiederholt auf beispielhafte Textstellen Bezug nehme, wird dies bei der Paradigmenanalyse weniger der Fall sein. Die Analyse der Charaktere ist nach dem Rang bzw. der Bedeutung geordnet, welche/n die jeweiligen Gruppen in der Narration von Ozark einnehmen, zentraler Bezugspunkt ist dabei - wie aus dem obigen Schema ersichtlich - die Familie Byrde.

\subsubsection{Familie Byrde}

Dreh- und Angelpunkt der Serie ist die Familie Byrde, die neben Marty Byrde aus seiner Ehefrau Wendy, mit der er zu Beginn der diegetischen Gegenwart seit 


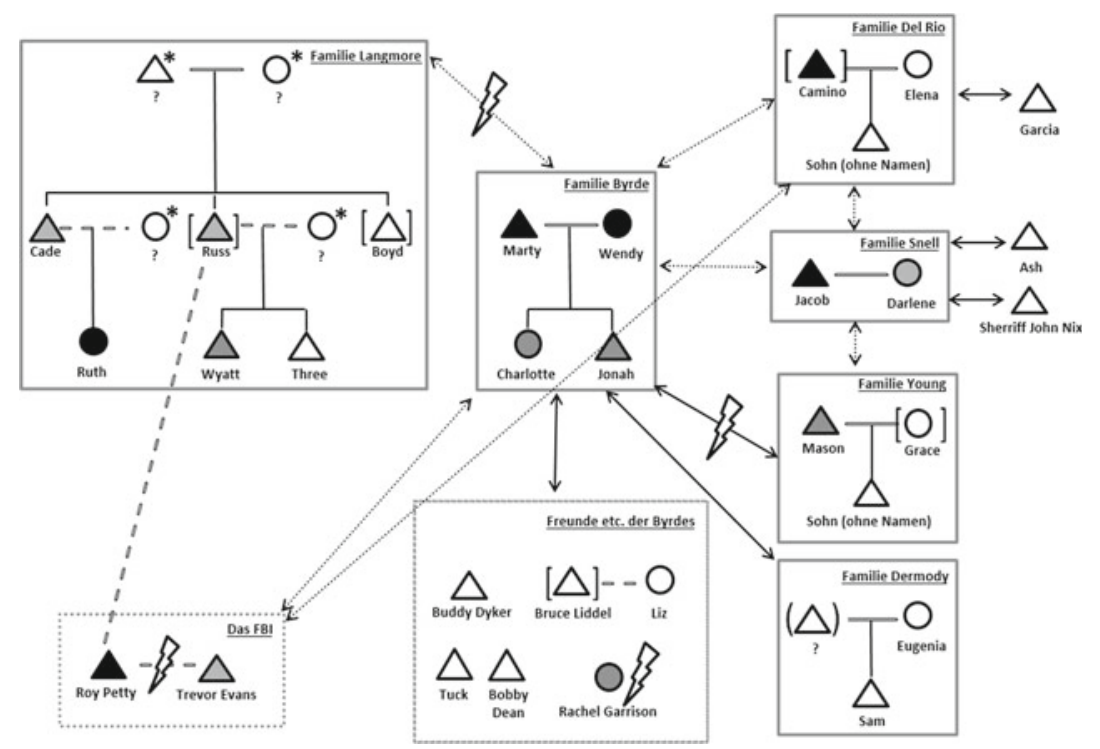

Abb. 3.1 Personenkonstellation zu Ozark (für eine Erklärung der verwendeten Zeichen, siehe Anhang 2 im elektronischen Zusatzmaterial)

22 Jahren verheiratet ist, der fünfzehnjährigen Tochter Charlotte und dem dreizehnjährigen Sohn Jonah besteht. Betrachtet man die Struktur der Familie Byrde, ist festzustellen, dass es sich um ein relativ traditionelles Familienmodell handelt, das an das Familienideal der 1950er Jahre erinnert: Marty verdient den Lebensunterhalt der Familie, während Wendy als Hausfrau und Mutter die Arbeit im Haus und die Betreuung der Kinder übernimmt.

Doch ist Marty Byrdes Position nicht vergleichbar mit der des allmächtigen, allwissenden Patriarchen der Serien der 1950er und 1960er Jahre, welcher über jeden Zweifel erhaben ist: Martys Position darf angezweifelt, seine Standpunkte dürfen kritisiert werden. Dies zeigt sich bereits in einer Szene der ersten Episode: Als ihr Vater Charlotte zehn Dollar verweigert, um damit eine Aktion an der Schule zu unterstützen, reagiert sie nicht nur kritisch, sondern beleidigend: „I am not calling you one but why are you acting so dickish?“ (Ozark I/1: 09:00). An der gelassenen Reaktion Martys lässt sich erkennen, dass dies keine unerwartete oder ungewöhnliche Verhaltensweise seiner Tochter ist. Es handelt sich eher um 
eine impulsive Reaktion ohne besondere Schwere als um eine tiefgreifende Kritik. Seine innerfamiliär dominante Position bleibt unangetastet, wird sogar noch bestätigt, als Wendy, nachdem sie kurz Partei für ihre Tochter ergriffen hat, letztlich doch Martys Argumentation zustimmt. Er ist und bleibt derjenige, der die zentralen Entscheidungen innerhalb der Familie Byrde trifft und der - bis zur letzten Episode der Staffel - über das Leben seiner Frau und vor allem seiner Kinder verfügt, wenn auch stets mit der Absicht ihnen ein stabiles und (finanziell) sorgenfreies Leben zu ermöglichen. Tatsächlich findet eine gewisse Stilisierung Martys in seiner Vaterrolle statt: Seine Liebe zu seinen Kindern ist absolut und unbedingt und seine Opferbereitschaft für die Familie grenzenlos. ${ }^{3}$ Auch die Schuld am Auseinandergehen der Ehe wird im Verlauf der Narration eindeutig Wendy zugeschrieben. Marty, so wird schon in der ersten Episode deutlich, ist selbst nach Wendys Betrug zu treu, zu integer, um selbst zum Betrüger zu werden: Als er aus Rache an seiner Ehefrau eine Sexarbeiterin aufsuchen will, imaginiert er das Zusammentreffen bloß in einem Wachtraum, in welchem die Frau ihn in seinen Werten und Vorstellungen bestätigt (vgl. Ozark I/1: 12:00). Er ist zwar offensichtlich wütend und zutiefst enttäuscht von seiner Ehefrau, sagt, dass sie ihm das „Herz gebrochen“ habe (Ozark I/7: 53), doch er übt nie vergleichbare Rache. Selbst der zentrale negative Charakteraspekt Martys - seine verbrecherische Tätigkeit - wird relativiert: Letztlich lässt er sich nur unter deutlichem Druck und durch die Überredungskünste Del Rios zur Geldwäsche überreden. Martys Ziel ist es dabei vor allem, seine Familie zu beschützen und für sie zu sorgen (Ozark I/8:21:00 sowie I/8: 24:00 „To protect and provide for my family.“). ${ }^{4}$ Seine Entscheidung macht Marty dabei zusätzlich von der Zustimmung seiner Frau abhängig, die sich einverstanden erklärt (Ozark I/8: 38:00). Zweifel an der

\footnotetext{
${ }^{3}$ Die Liebe zu seinen Kindern äußert sich u. a. wiederholt in Szenen, in denen Marty ihnen einen Gutenachtkuss gibt und sie seines väterlichen Stolzes versichert (u. a. Ozark I/1: 12:00, I/2: 40:00, I/3: 51:00), wird aber auch aus der Gesamthandlung mehr als hinlänglich ersichtlich. So ist er in der zweiten Episode entschlossen, Selbstmord zu begehen, um damit seine Familie vor der Bedrohung zu retten. Er sieht von diesem Plan ab, da er erfährt, dass seine Lebensversicherung unter den verdächtigen Umständen seines Todes nicht ausgezahlt werden würde und seine Familie somit unversorgt bliebe (vgl. Ozark I/2: 44:00). Selbst im vermeintlich letzten Moment seines Lebens, als Del Rio ihn mit der Waffe bedroht, denkt er nur an seine Kinder und sieht vor seinem inneren Auge glückliche Familienerinnerungen (vgl. I/1: 28:00).

${ }^{4}$ Durch die Verknüpfung von Verbrechen und Familie entsteht dementsprechend eine Struktur, die das Verbrechen einerseits legitimiert, andererseits dem Familienaspekt eine gewisse negative Implikation - die des Verbrecher-Clans oder der kriminellen Familie - verleiht. Dies erinnert nicht nur an Serien wie Breaking Bad, sondern auch an bekannte filmische Erzählungen wie Francis Ford Coppolas The Godfather (USA, 1972).
} 
positiven Rolle Marty Byrdes entsteht aus seiner beruflichen Position als harter Kapitalist und Geschäftsmann. Dieser Zwiespalt - Geschäftsmann auf der einen, emotionaler Familienvater auf der anderen Seite - zeigt sich immer wieder aufs Neue: Die Serie wird mit einem Monolog Martys darüber eröffnet, dass der finanzielle Erfolg der Maßstab der Lebensentscheidungen eines Mannes sei (vgl. Ozark I/1: 00:00), später vergleicht er bei einer väterlichen Ansprache eine Familie mit einem Kleinunternehmen (vgl. Ozark I/2: 00:00) und zeigt sich gegenüber familiären Belangen oft kalt und ablehnend, letzteres allerdings nur in Gesprächen mit seiner Frau. ${ }^{5}$ Diese emotionale Kälte kann entsprechend nicht als tatsächliche Ablehnung der Familie, sondern vielmehr als Ablehnung seiner Ehefrau verstanden werden. Irritierend sind ebenso Szenen, die seine Tätigkeiten in der kriminellen Zwischenwelt direkt neben seine Rolle als Familienvater stellen, so beispielsweise, wenn er liebevoll mit seiner Tochter spricht, nachdem er bei einer jugendlichen Stripperin war, um von ihr Informationen zu erlangen (vgl. Ozark I/3: 49:00, 51:00). Zunächst wird hier die Begegnung Martys im Stripclub gezeigt, es folgt eine Szene, in welcher der FBI-Agent Roy Petty von einem anderen Mann oral befriedigt wird, und dann eine Szene, in der Ruth Langmore erkennt, dass ihre Onkel Geld entwendet haben und sich ein Konflikt anbahnt. Es handelt sich in allen drei Fällen um nächtliche Szenen mit düsterer Beleuchtung und gewalttätiger und/oder sexueller Atmosphäre. Das Gespräch Martys mit seiner Tochter findet zwar ebenfalls in nächtlicher Dunkelheit statt, steht aber durch die friedvolle Geborgenheit der Szenerie im Gegensatz zu den vorangehenden Szenen und auch dem nachfolgenden Konflikt der Langmores, der durch das Geräusch eines gespannten Pistolenhahns eingeleitet wird. Durch diese Nebeneinanderstellung wird die Unvereinbarkeit von Martys Lebensbereichen deutlich ebenso wie sein zunehmendes Abgleiten in die Kriminalität. Die Dunkelheit - stellvertretend für Verbrechen und Unterwelt - hat Martys Leben vollständig erfasst und droht seine Familie, den ,Anker der Menschlichkeit', der ihn bisher von der Verrohung anderer Charaktere abgegrenzt hat, zu vereinnahmen. Martys Rolle als Familienvater wird somit allerdings nicht relativiert. Vielmehr wird sie durch die Gegenüberstellung positiv bestätigt und es wird darauf verwiesen, dass eine dauerhafte Koexistenz beider Sphären nicht möglich ist. Ausschlaggebend für die Charakterisierung Martys ist hier, dass er im Raum des Verbrechens zwar ,funktioniert', also die notwendigen Handlungen zielstrebig und gekonnt ausführt, dies allerdings nie mit Freude oder anderen positiven Emotionen tut. Er handelt hier vielmehr mit

\footnotetext{
${ }^{5}$ So ist er betont unberührt davon, dass die Spielzeugkiste (,toy chest“) seiner Tochter beim Umzug in die Ozarks vergessen wurde (Ozark I/3: 01:00), und davon, dass sie das Haus verkaufen müssen, in dem Jonah geboren wurde (vgl. Ozark I/4: 04:00).
} 
einer gewissen Verbitterung, Resignation oder mit kalter Entschlossenheit, welche ihm die Extremsituation eines gnadenlosen Handlungsraumes abverlangt. Geborgenheit und Zufriedenheit findet er in der Familie. Die Figur wird somit zwar kontrastiert, seine Rolle als Familienvater jedoch nicht relativiert. Zweifelsohne bleibt der Charakter moralisch indifferent, denn faktisch liegt die Entscheidung, sich der Kriminalität zuzuwenden bei ihm, ist die gesamte Bedrohungssituation doch Konsequenz seines Handelns - objektiv ist Marty Byrde ein Verbrecher -, dennoch findet keine explizite Negativcharakterisierung der Figur statt, schließlich war die handlungsinterne Tätigkeit als Geldwäscher die Alternative zum sicheren Tod.

Bei Wendy Byrde hingegen handelt es sich, auch wenn sie nicht ohne positive Eigenschaften ist, um einen negativ inszenierten Charakter. ${ }^{6}$ Auch sie verfügt über Familiensinn und ist bereit ihre Kinder gegenüber jeder Bedrohung zu verteidigen. Dieses Handeln ist allerdings weniger emotional begründet, sondern entspringt vielmehr einem animalischen Mutterinstinkt. ${ }^{7}$ Wie Marty hält sie am familiären Zusammenhalt fest, auch in Anbetracht der massiven Bedrohungssituation durch Del Rio: „We're a family, so we are... We're making this move as a family.“ (vgl. Ozark I/1: 32:00). Vor allem aber - und dies kann als ausschlaggebender Punkt betrachtet werden - ist sie diejenige, die vor Einsetzen der Handlung den Ehebruch begeht und somit eine Spaltung der Familie provoziert. Zudem weiht sie die Kinder in die Geldwäschegeschäfte des Vaters ein. Zwar handelt es sich hierbei um einen Akt der Ehrlichkeit, der das weitere Leben erleichtert, da er Geheimhaltung und Lügen unnötig macht, sie setzt die Kinder damit allerdings auch unmittelbar dem Stress der akuten Bedrohungssituation aus und lässt sie Teil der kriminellen Tätigkeiten werden (vgl. Ozark I/2: 53:00). ${ }^{8}$ Auch wenn es sich bei der Mutter der Familie Byrde nicht um eine positiv charakterisierte

\footnotetext{
${ }^{6}$ Die Äquivalenzen der Charakterinszenierung zum populären US-amerikanischen Serienformat Breaking Bad (2008-2013) sind überdeutlich. Unabhängig von inhaltlichen Ähnlichkeiten - in beiden Formaten geht es im weitesten Sinne um Drogenkriminalität - ähnelt das Ehepaar Byrde dem Ehepaar White aus Breaking Bad. Nicht nur sehen sich Skyler White und Wendy Byrde rein äußerlich ähnlich, auch findet eine Negativcharakterisierung statt. Beide Frauen sind ihrem Ehemann (eingeschränkt) antagonistisch gegenübergestellt.

${ }^{7}$ Als sie Charlotte von den Langmore-Jungen bedroht glaubt, fährt sie wütend auf das Grundstück der Langmores und droht ihnen mit dem Tod, falls sie ihre Tochter nicht in Ruhe lassen oder sich noch einmal ihrem Haus nähern (vgl. Ozark I/3: 45:00).

${ }^{8}$ Dies ist nicht explizit negativ zu bewerten: Zwar kommt dieses Geständnis am Ende der zweiten Episode überraschend für die Rezipierenden, schafft aber die notwendige Vertrauensbasis für die weitere Koexistenz der Familie: Ohne eine Einweihung würden die Kinder wohl endgültig das Vertrauen in die Familie verlieren, welches im Gesamtverlauf der Formats ohnehin wiederholt erschüttert wird.
} 
Figur handelt, so kommuniziert der Text die Motive, die zum Bruch der Ehe führen, als nachvollziehbar. Als sie in der ersten Episode eingeführt wird, berichtet sie mit leichter Ironie von ihrem Tagesverlauf: „My day was very exciting. I went to Costco. And then I went and got groceries. And then I dropped off the recyclables. And then I took Jonah to the dentist." (Ozark I/1: 08:00). Ihre Aussage, ihr Tag sei ,aufregend“ gewesen, widerspricht hier dem zwar gefüllten, doch äußerst gewöhnlichen Tagesplan. Über Wendys Vorgeschichte wissen wir, dass sie sich zuvor beruflich in politischen Kampagnen engagiert hat (vgl. Ozark I/8: 14:00). Im filmischen Jetzt hingegen ist sie ausschließlich mit Haushaltsaufgaben und den Kindern beschäftigt, d. h., all ihre Tätigkeiten sind familiäre, genuin eigene Interessen kommen nicht mehr vor. Sowohl als Mutter als auch auf beruflichem Terrain musste sie wiederholt Rückschläge hinnehmen, die in der achten Episode „Kaleidoscope“ dargestellt werden, einer Episode, die zeitlich vor dem Geschehen der Serie spielt: Sie wird nur wegen ihres Alters bei einem Vorstellungsgespräch für einen Job abgelehnt, für den sie klar qualifiziert wäre (vgl. Ozark I/8: 04:00), vor allem aber führt ein Autounfall zu einer Fehlgeburt, kurz nachdem sie sich entschieden hatte, das Kind zu behalten (vgl. Ozark I/8: 43:00). Gegenüber Marty äußert sie, sie habe den Ehebruch begangen, weil sie seine Zuneigung vermisse und sich von ihm ausgeschlossen gefühlt habe, seitdem er mit der Geldwäsche anfing (vgl. Ozark I/7 53:00). Es ist also ein langwieriger, frustrierender Prozess der Enttäuschungen, der Wendy zu ihrem Betrug an Marty treibt. Ebenso wie Marty - Geschäftsmann und Familienvater - befindet sie sich in einem Rollenkonflikt: Zum einen hat sie die traditionelle Rolle der Hausfrau und Mutter auszufüllen und tut dies auch, nicht unbedingt widerwillig, mit scheinbarer Mühelosigkeit, zum anderen ist sie intellektuell unterfordert und sehnt sich nach beruflicher Anerkennung, nach einer Ernsthaftigkeit jenseits der Häuslichkeit. Zudem ist sie in der Beziehung mit Marty emotional und sexuell unbefriedigt. Der Ehebruch ist Ventil ihrer aufgestauten Emotionen. Während des Lebens in Ozark zwingt sie schließlich dem Immobilienmakler Sam Dermody regelrecht ihre Mitarbeit auf (vgl. Ozark I/3: 42:00) und forscht hier nach Möglichkeiten zur Geldwäsche. Sie sucht einen Weg nach beruflicher Erfüllung, nach aktiver und relevanter Einbindung in Martys Geschäfte und somit nach eben jener Anerkennung, die ihr bisher verweigert blieb. Ihre beruflichen Bemühungen haben jedoch nie die Tragweite und Effizienz wie Martys Anstrengungen zur Geldwäsche. ${ }^{9}$ Auch wenn sie sich für den Zusammenhalt der Familie einsetzt, ist

\footnotetext{
${ }^{9}$ Sie ist zwar diejenige, die Marty auf die Idee bringt, Geld über den Bau einer Kirche zu waschen, die letztendliche Ausführung dieses Planes obliegt allerdings Marty. Zudem trägt eben dieses Bauvorhaben massiv zur Eskalation der Situation bei (vgl. Ozark I/5: 33:00). Ihre Beteiligung am Immobiliengeschäft ist zum Teil Kompensation für die eigene defiziente
} 
Wendy im Familiengefüge der Byrdes somit stets eher Risikofaktor als tragendes Familienmitglied. ${ }^{10}$

Wie ihre Mutter kann Charlotte als tendenziell negativer Charakter gewertet werden. Von ihrer Seite regt sich der aktivste Widerstand gegen den Umzug der Byrdes. Als sie davon erfährt, besteht ihre erste Reaktion aus rüder Zurückweisung: „No fucking way am I going.“ (vgl. Ozark I/1: 32:00). Diese Einstellung ändert sich faktisch im weiteren Verlauf der Serie nicht. Wiederholt versucht sie sich von der Familie zu lösen, sei es durch einen Fluchtversuch zurück nach Chicago (vgl. Ozark I/3: 26:00, 33:00), durch einen angedeuteten Selbstmordversuch (vgl. Ozark I/7: 55:00) und durch die ostentative Abkehr von ihrer Kindlichkeit und damit der Bindung an ihre Eltern. ${ }^{11}$ Letztlich scheitern all ihre Emanzipationsversuche: Sie bleibt ihrer Familie verhaftet, eine Loslösung ist nicht möglich. ${ }^{12}$

Familiensituation: „I know how to sell the idea of a happy family.“ (vgl. Ozark I/3: 42:00). Kann sie schon nicht selbst in einer glücklichen Familie leben, so will sie diese Situation doch zumindest zeitweise vortäuschen.

${ }^{10}$ Wendy ist auch diejenige, die dazu anregt, die Kinder - ohne ihre Eltern - zurück nach Chicago zu schicken, um ihnen ihr altes Leben wiederzugeben. Glaubhaft vermittelt sie, dass sie als Eltern hier versagt und die Kinder entwurzelt hätten (vgl. Ozark I/7: 50:00). Eine Äußerung, die zwar objektiv korrekt ist, die jedoch innerhalb des Seriengefüges als negativ gelten kann: Eine Trennung der Familie kommt hier nicht in Frage.

${ }^{11}$ Dies beginnt damit, dass sie ihre Eltern mit ihren Vornamen anspricht, anstatt sie „Mom“ und ,Dad“" zu nennen - ein Verhalten, das Marty sofort verbietet (vgl. Ozark I/3: 01:00, sowie 14:00). Als zentraler Loslösungsversuch kann ihr Verhalten in der sechsten Episode „Book of Ruth" gelten: Hier schläft sie mit dem attraktiven jungen Chicagoer Zach und verliert ihre Jungfräulichkeit (vgl. Ozark I/6: 36:00). Dieser Versuch das Kind-Sein hinter sich zu lassen, scheitert: Zach geht und lässt Charlotte mit Liebeskummer zurück. Zuletzt flüchtet sie sich zu ihrer Mutter (vgl. Ozark I/6: 51:00).

${ }^{12}$ Interessant ist Charlottes nur wenig thematisierte Inszenierung ihrer Situation nach außen. Als Vermittler zur Welt außerhalb der Ozarks dient ihr ihr Smartphone: In einer markanten Szene nimmt sie ein Selfie von sich auf, das sie mit dem Kommentar „Loving the Ozarks“ in einem sozialen Netzwerk postet. Die Inszenierung nach außen, das Bild, das sie ihren außerfamiliären Freunden und Bekannten vermittelt, steht im direkten Gegensatz zu ihrer tatsächlichen Gemütsverfassung. Explizit wird hier die Divergenz von öffentlicher Inszenierung und tatsächlicher Befindlichkeit eröffnet. Charlotte betrachtet ihre Selbstinszenierung über das Smartphone bzw. den Zugang zur Außenwelt, den ihr das Gerät bietet, allerdings als tragenden Bestandteil ihres Lebens: Als sie es - um nicht aufgespürt werden zu können - abgeben soll, lehnt sie dies zunächst mit den Worten „No fucking way. My whole life is in there." ab (vgl. Ozark I/10: 39:00). Das Digitale dient Charlotte als Ausgleichs- und Ermächtigungsraum: Während ihre physischen Lebensumstände von Entwurzelung, Kontrollverlust und familiären Konflikten bestimmt werden, also deutlich defizient sind, kann sie im Digitalen ein Leben nach eigenen Wünschen und Vorstellungen inszenieren. Das Weltmodell der 
Jonah bildet ein Gegenstück zu seiner Schwester und ist ein eher positiver Charakter. Der Junge ist zutiefst verunsichert von der Situation, insbesondere als er erfährt, dass sein Vater für ein Drogenkartell arbeitet. Indem er sich Videos über die Gewalttaten mexikanischer Drogenkartelle ansieht, schürt er seine Furcht weiter und steigert sich in die Situation hinein (vgl. Ozark I/3: 16:00). Seine Verunsicherung wächst und er entwickelt eine diffuse Faszination für den Tod und das Sterben. ${ }^{13}$ Im weiteren Verlauf beginnt er sich für Schusswaffen zu interessieren, lässt sich von Buddy Dyker das Schießen beibringen (vgl. Ozark I/5: 13:00) und beschafft sich letztlich selbst Waffen (vgl. Ozark I/9: 00:00). Seine Intention ist hier eindeutig, seine Familie zu schützen und seine Machtlosigkeit $\mathrm{zu}$ überwinden. Letztlich ist er nie gezwungen einen Mord $\mathrm{zu}$ begehen, seine kindliche Naivität bleibt unberührt, die Schwelle zur Verrohung wird nicht überschritten. ${ }^{14}$ Wie Marty versucht Jonah also die Familie gegen die Bedrohung zu verteidigen. Dabei ist auffällig, dass er sich - im Gegensatz zu seiner Schwester - nicht von der Gewalt zu lösen versucht, sondern sich ihr sogar zuwendet. Direkte Gewaltausübung, insbesondere Gewalt durch Schusswaffen, werden hier innerfamiliär zu männlichen Aspekten.

Der Aufbau der Familie Byrde folgt einer konservativen Hierarchie: Marty Byrde hat über die gesamte Serie hinweg stets das letzte Wort. Er und sein Sohn übernehmen die männliche Schutzfunktion, auch wenn es sich in Jonahs Fall

Serie steht dem entgegen: Angesichts ,realer' Probleme - u. a. der familiären Konflikte ist Charlottes Inszenierung im digitalen Raum irrelevant. Nicht in der Öffentlichkeit werden genuin private, in diesem Falle emotionale Problematiken verhandelt, sondern in der Familie. Bei dieser handelt es sich um den Raum größter persönlicher Privatheit, und nur hier kann diese Privatheit gebührend verhandelt werden. Dieser Absolutheitsanspruch der Familie als einziger Raum der effektiven Problemlösung - ein historisches Kontinuum in Serien - bleibt auch von der Digitalisierung unangetastet.

${ }^{13}$ So unterhält er sich mit dem schwerkranken Buddy Dyker über dessen Leiden (vgl. Ozark I/4: 05:00) und beschäftigt sich mit einem toten Waldtier, schneidet es auf und zieht seine Eingeweide heraus (vgl. Ozark I/4: 20:00). Dies geschieht seiner Aussage nach aus naturwissenschaftlichem Interesse (vgl. Ozark I/4: 25:00), tatsächlich wohl aber eher aus einer momentanen Todesfixierung.

${ }^{14}$ Mehrmals bedroht er Eindringlinge auf dem Grundstück der Byrdes mit Waffen oder hat es zumindest vor, sei es Ash - ein Handlanger der Snells (vgl. Ozark I/5: 46:00), der FBI-Agent Roy Petty (vgl. Ozark I/6: 39:00) oder Del Rios Handlanger Garcia (vgl. Ozark I/10: 18:00). Letztlich ist es die großväterliche Mentorenfigur Buddy Dyker, die Garcia erschießt, Wendy und den Kindern somit die Flucht ermöglicht und Jonah - durch das vorherige Entladen seiner Waffe - vor einem Mord bewahrt (vgl. Ozark I/10: 19:00). Kennzeichnenderweise ist es Wendy, die kurz zuvor Jonahs Schießen mit einem kaum sichtbaren Nicken legitimiert. Sie ist also bereit hinzunehmen, dass ihr Sohn endgültig ins Verbrechen verstrickt wird - ein weiterer Aspekt ihrer Negativcharakterisierung. 
um den Verteidigungsversuch und lediglich die Imitation prototypischer männlicher Verhaltensweisen handelt. Die Frauen der Familie, Wendy und Charlotte, sind diejenigen, die eine Spaltung entweder provozieren oder durch ihr Verhalten zumindest begünstigen. Eine Gleichberechtigung der Geschlechter auf Ebene der Erwachsenen existiert nur pro forma: Die Hierarchien sind zweifellos flacher als innerhalb eines strengen Patriarchats, letztendlich liegt die Entscheidungsgewalt jedoch immer bei Marty. ${ }^{15}$ Diese Struktur ist keinesfalls unproblematisch, vielmehr wird das familiäre Zusammenleben bereits in der ersten Episode als konfliktreich und angespannt dargestellt: Das gemeinsame Abendessen wird zuerst vom geschwisterlichen Streit Jonahs und Charlottes dominiert und wendet sich anschließend einer Auseinandersetzung zwischen Charlotte und ihrem Vater zu (vgl. Ozark I/1: 07:00). Das Abendessen ebenso wie der gesamte Abend werden zudem von Martys Wissen um den Betrug seiner Frau überschattet. Auch wenn der Streit eine nebensächliche, alltägliche Angelegenheit ist, so ist es doch kennzeichnend, dass die Familie als dysfunktional und konfliktreich eingeführt wird. Vor allem sind die Byrdes ab Beginn der Serie durch einen tiefen Vertrauensverlust gespalten, der nicht nur die Ehepartner immer weiter voneinander entfremdet (vgl. Abb. 3.2 - hier wird die Entfremdung konkret bildlich sichtbar), sondern auch die Kinder an der moralischen Integrität und Autorität ihrer Eltern zweifeln lässt. ${ }^{16}$ Von allen Seiten zerbricht das Gefüge.

\footnotetext{
${ }^{15}$ Marty nimmt - so explizit in der Serie geäußert - die Position des „Deciders“ ein, der bestimmt, wie die Familie handelt. Wendy muss, als sie für die Familie ein Haus in den Ozarks sucht, erst die Bestätigung ihres Mannes - eben des „Deciders“, wie Buddy Dyker es formuliert - einholen (vgl. Ozark I/2: 19:00).

${ }^{16}$ Der Vertrauensbruch zwischen Marty und Wendy geschieht offensichtlich durch Wendys Ehebruch. Allerdings bestand bereits zuvor von Martys Seite Misstrauen und Paranoia, schließlich setzte er einen Privatdetektiv auf seine Ehefrau an (vgl. Ozark I/1: 36:00). Schon vorher muss also Anlass für Misstrauen bestanden haben. Die Distanzierung der Ehepartner äußert sich im Verlauf des Formats überdeutlich: Marty erklärt Wendy offen, dass sie nicht mehr Mann und Frau, sondern nur noch Geschäftspartner seien (vgl. Ozark I/2: 03:00). Es herrscht eine tiefgehende Ablehnung, ja sogar Hass Martys auf seine Frau. In Bezug auf ihren von Del Rio ermordeten Liebhaber erklärt er ihr: „In fact, the satisfying sound of your lover smacking the pavement is the only thing that gets me to sleep every night." Als Reaktion auf diese Äußerung schlägt Wendy ihm zweimal ins Gesicht (vgl. Ozark I/2: 04:00). Die Spaltung der Ehe scheint an dieser Stelle unüberwindbar.

Auch Charlotte und Jonah erleben eine Krise in der Vertrauensbeziehung zu ihren Eltern: Als Jonah von Charlotte erfährt, dass seine Eltern ihn - wegen seiner Faszination für tote Tiere für seltsam und vielleicht gefährlich halten - ist er entsetzt: „Why should I believe anything you say when you've been lying to me my entire life?" (vgl. Ozark I/4: 36:00). Ebenso spricht Charlotte ihrer Mutter ihre elterliche Qualifikation ab: „Oh, is my money-laundering mother
} 


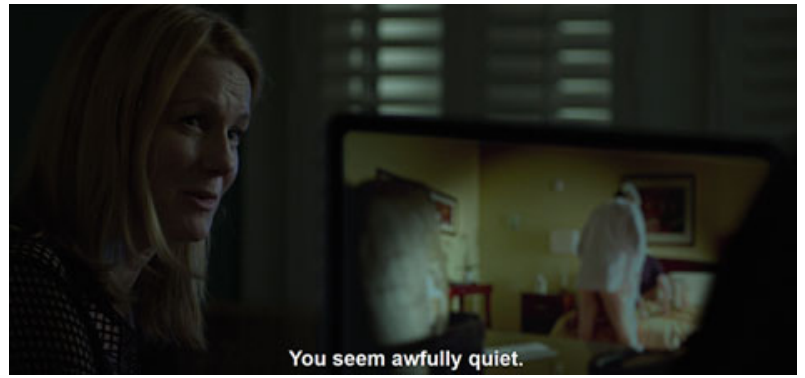

Abb. 3.2 Marty sieht sich im Gespräch mit Wendy den Beweis ihres Ehebruchs an (Ozark $\mathrm{I} / 1: 11: 00)$

Ist der genuine Grund dafür nun aber tatsächlich Wendys Untreue, ihre Charakterschwäche? Auf den ersten Blick mag dies der Fall sein, doch trifft diese Erklärung nur oberflächlich zu: Letztlich liegt die Ursache für den drohenden Bruch bei den Rollenzwängen, denen sich die Familienmitglieder unterordnen müssen. Marty sieht sich als einziger Erwerbstätiger der Familie gezwungen, den Deal mit Del Rio einzugehen. Könnte er seiner Familie nicht weiterhin einen relativ hohen Lebensstandard finanzieren, so würde er einem gesellschaftlich verankerten Männerbild nicht gerecht werden, das eng mit finanzieller Absicherung und einem karrieristischen, aufstiegsorientierten Arbeitsethos verbunden ist. ${ }^{17}$ Wendy hingegen versucht zwar die Hausfrauen- und Mutterrolle auszufüllen, erlebt diese jedoch nicht als sinntragenden Lebenszweck oder erfüllende Tätigkeit, sondern als einengend und wenig erfüllend. Hinzu kommt der Mangel an Zeit, die Marty - aufgrund seiner beruflichen Einbindung - Wendy widmet. Die Struktur

really playing morality police here?“ (vgl. Ozark I/2: 41:00). Wendy kann dies nur resigniert zur Kenntnis nehmen, sie hat ihre Autorität als Mutter verloren.

${ }^{17}$ Obgleich die Rede von finanziellen Einschränkungen der Byrdes ist (vgl. Ozark I/8: 34:00), wird die ursprüngliche Entscheidung für eine kriminelle Tätigkeit Martys nie vollkommen legitimiert. Die Familie war auch vor Martys Zusammenarbeit mit Del Rio nicht in besonderer wirtschaftlicher Not. Es scheint vor allem der Wunsch nach wirtschaftlichem Aufstieg - im Endeffekt also finanzielle Gier - zu sein, die Marty dazu motiviert, Del Rios Angebot anzunehmen (vgl. Ozark I/8: 39:00). Dieser Wunsch nach Aufstieg basiert auf Marthys Vorstellung von Geld als ,measure of a man's choices“ (Ozark I/1: 00:00), also darauf, dass er in einem Anwachsen des Geldes eine Legitimation seiner Entscheidungen sieht. Dass die groß angelegte Geldwäsche und die endgültige Hinwendung zum gewaltsamen Verbrechen nicht mehr seine freie Entscheidung ist, stellt eine Art Ehrenrettung des Charakters dar. 
der Familie, die sich aus ehelichen Grenzen und konventionell-traditionellen Rollenbildern zusammensetzt, scheint ein Gefängnis zu sein, das seine Mitglieder einschränkt und zu negativen Taten treibt. Dennoch ist es Wendy, die den zentralen Normbruch begeht und sich damit gegen die Familie richtet, während Marty deren Zerfall aktiv entgegengewirkt. Zwar geht er zu seiner Ehefrau auf Distanz, will aber seinen Kindern weiterhin ein annähernd stabiles Umfeld bieten und das Vertrauen wiederherstellen. ${ }^{18}$ Auch wenn er - im Selbstgespräch - Wendy mit einer „schmutzigen“ Scheidung droht (vgl. Ozark I/1: 39:00), kommt es nie zu einem ernsthaften Gespräch darüber. Das Zusammenleben Martys und Wendys zeichnet sich - trotz der ständigen Konfrontation mit ihren Eheproblemen - durch ein Vermeidungsverhalten aus: Es findet bis zur siebten Episode keine tatsächliche Aussprache, kein klärendes Gespräch statt, das ein endgültiges Zerbrechen der Familie bedeuten könnte. Erst nachdem Marty das Verhalten nachahmt, das Wendys Liebhaber beim Geschlechtsakt auf dem Beweisvideo zeigt (vgl. Ozark I/6: 41:00), erst nachdem er also durch einen Akt direkter körperlicher Erniedrigung Rache genommen hat und Wendys Betrug symbolisch wiederholt wurde, kann eine Aussprache erfolgen (vgl. Ozark I/7: 53:00). Mag diese zunächst auch erfolglos sein, dauern die Konflikte noch an, so ist hier doch der Grundstein für eine Versöhnung gelegt. Diese Versöhnung kann letztlich erfolgen, nachdem die Instabilität der Familie in der letzten Episode einen Höhepunkt erreicht: Nachdem Marty Frau und Kinder fortgeschickt hat, um sie vor Del Rio zu schützen, nachdem sie bereits neue Identitäten haben und sich so mit der absoluten Auflösung ihres vorherigen Lebens konfrontiert sehen (vgl. Ozark I/10: 38:00) - erst nach dieser Extremsituation kann die Familie wieder zusammenkommen. Auf Ebene der Raumstruktur wird der Extremraum höchster Bedrohung betreten. AnschlieBend ist ein Übertritt in einen Raum der familiären Restrukturierung sowie der - zumindest relativen - Ordnung wieder möglich. Nun erfolgt ein Schuldeingeständnis Wendys - „I'm so sorry I hurt you, Marty. I should never have done that." -, welches Marty unter Eingeständnis seiner eigenen Verfehlungen annimmt (vgl. Ozark I/10: 01:08:00). Während Wendy geneigt ist, Martys Anweisungen Folge zu leisten und mit falschen Identitäten zu fliehen, sind es Charlotte und Jonah, die sich weigern, den Vater zurückzulassen und ihr Leben, ihre Familie aufzugeben (vgl. Ozark I/10: 01:10:00). Dies ist insofern bedeutsam, da Wendy sich in ihre Marty unterlegene Rolle fügt und seinem Urteil gehorcht. Nur die Kinder dürfen an dieser Stelle widersprechen, um nicht erneut einen Bruch der

\footnotetext{
${ }^{18}$ Der Versuch, die Vertrauensbasis zwischen ihm und Jonah wiederherzustellen, ist bizarr: Er weiht ihn in das Geldwäschegeschäft ein und erklärt ihm die Abläufe (vgl. Ozark I/4: 55:00). Dies ist zwar moralisch fragwürdig, kann aber - als Beweis absoluter Offenheit und Ehrlichkeit - die Beziehung zwischen Vater und Sohn wieder kitten.
} 
Struktur zu riskieren. Letztlich kommen die Byrdes wieder zusammen, Martys und Wendys Versöhnung ist wahrscheinlich: Beide schenken sich ein Lächeln (vgl. Ozark I/10: 1:16:00). Trotz aller Konflikte und scheinbar unüberbrückbaren Spaltungen , siegt' der familiäre Zusammenhalt. Die Familie bleibt unantastbares und sinnstiftendes Dogma. Die dysfunktionalen Faktoren und das Leid innerhalb der Familie stellen diesen Schluss nicht in Frage, vielmehr bestätigen sie ihn: Die Familie wird als Gemeinschaft in allen Lebenslagen betrachtet, deren Bedeutung auch in problematischen Situationen nicht aufgegeben werden darf, es handelt sich um ein „Gemeinsam durch dick und dünn gehen“. Die positiven Erfahrungen und idealen Momente wiegen die negativen Seiten - so scheint es - auf. ${ }^{19}$

\subsubsection{Familie Langmore}

In vielerlei Hinsicht kann die Familie Langmore als Gegenstück zur Familie Byrde gelten: Das Leben der Byrdes ist klar hierarchisiert und strukturiert, ihr räumliches Umfeld ist sauber und gepflegt, sie sind wohlhabend und gebildet. Die Byrdes weisen somit alle signifikanten Merkmale einer weißen Familie der oberen Mittelschicht auf. Für jeden der genannten Aspekte trifft im Falle der Langmores das Gegenteil zu: All ihre Merkmale charakterisieren sie als Hillbillys bzw. als „white trash“, d. h. als Angehörige einer ungebildeten, armen Unterschicht, wobei die verwendeten Begriffe auf kulturell überzeichnete Stereotypen verweisen. Von ihrem ersten Auftreten in der zweiten Episode an, in der sie Marty Geld stehlen, stehen sie unter den Paradigmen offener Verkommenheit und Kriminalität.

Bereits die Verwandtschaftsverhältnisse, welche auf den ersten Blick kaum zu durchschauen sind, offenbaren familiäres Chaos: Eine Art Oberhaupt ist Russ Langmore, ein grobschlächtiger Mann, der sich - zusammen mit seinem jüngeren Bruder Boyd - den Lebensunterhalt mit Gelegenheitsjobs und Kleinkriminalität verdient. Der älteste der erwachsenen Langmore-Brüder befindet sich aus unbekannten Gründen im Gefängnis, seine 19-jährige Tochter Ruth ist ebenfalls Teil der Familie. Zudem hat Russ zwei Söhne: den 17-jährigen Wyatt und den 14- oder 15-jährigen Three. Die Mütter von Ruth, Wyatt und Three sind nicht anwesend und werden nicht thematisiert. Die Hierarchie innerhalb der Familie unterliegt einer chaotischen Dynamik, die mit dem statisch-konservativen Modell der Byrdes nicht zu vergleichen ist, und baut am ehesten auf körperlicher und gewaltsamer Überlegenheit bzw. beständigen Machtkämpfen auf. Durch das ungleichmäßige Geschlechterverhältnis sind die Langmores auch deutlich männlich geprägt.

\footnotetext{
${ }^{19}$ So ist für Marty die Erinnerung an glückliche Familienmomente zentrales sinnstiftendes Element, die in den größten Bedrohungssituationen bzw. in Momenten der Hoffnungslosigkeit in Erscheinung treten (vgl. Ozark I/1: 28:00 sowie Ozark I/10: 01:15:00 - hier dient beide Male das Trampolin der Kinder als Symbol für glückliche Momente).
} 
Die drei erwachsenen Brüder Cade, Russ und Boyd sind untereinander eindeutig hierarchisiert: Cade, eine düster inszenierte Nebenfigur, ist der dominante der drei Brüder. Es handelt sich um einen kriminellen Despoten, der selbst aus dem Gefängnis heraus Druck auf seine Tochter ausübt, sie für seine Pläne einspannt und seine Brüder in Furcht versetzt. ${ }^{20}$ Er ist derjenige, der das Leben der Langmores vor seiner Inhaftierung organisiert hat. Weder Russ noch Boyd verfügen über besondere Intelligenz oder Organisationstalent. Vor allem Boyd, ebenfalls ein wenig bedeutender Nebencharakter, zeigt eher impulsives Verhalten als Reife oder Besonnenheit und wirkt dadurch häufig infantil. Beispielsweise betrinkt er sich und spielt zusammen mit Three ein Spiel, bei dem sich beide mit Feuerwerkskörpern beschießen (vgl. Ozark I/5: 44:00). Russ agiert nur unwesentlich kontrollierter oder besonnener. Er ist naiv und es mangelt ihm an Selbstreflexion: Der FBI-Ermittler Roy Petty macht sich mühelos Russ unterdrückte Homosexualität und die damit einhergehende Suche nach Zuneigung zunutze, um ihn für seine Pläne einzuspannen (vgl. Ozark I/6: 13:00). Die Chancen der Langmores unter Russ' Anleitung jemals das soziale und finanzielle Tief zu verlassen, sind mehr als gering. Three, der jüngste Langmore, ähnelt seinem Onkel Boyd: Er trinkt trotz seines jungen Alters bereits Alkohol und ist ebenfalls äußert unreif (vgl. Ozark I/3: 18:00). Es ist klar zu sehen, dass er die Verhaltensweisen seines Vaters und seines Onkels adaptiert. Die größte Reife und höchste Intelligenz unter den Langmore-Männern zeigt Wyatt: Er zieht sich vor der omnipräsenten Gewalt (vgl. Ozark I/3: 13:00) und den infantilen Spielen seines Bruders und Onkels wiederholt auf das Dach des Trailers zurück und zeigt eine Begeisterung für Literatur, deren Inhalt und Botschaft er bewusst reflektiert (vgl. Ozark I/5: 44:00). Dieser ,Flucht' nach oben liegt eine simple räumliche Semantik zugrunde: Wyatt ist seinen Onkeln, seinem Bruder und auch seiner Cousine geistig überlegen, steht gewissermaßen über ihnen. Sowohl auf kognitiv-intellektueller als auch auf emotionaler Ebene hebt er sich deutlich von ihnen ab. Seine Charakterisierung folgt dem Stereotyp des ,ungeschliffenen Diamanten', des feinfühligen, intelligenten

\footnotetext{
${ }^{20}$ Boyd, der sich in einem Streit gegen Ruth, wendet meint zu ihr: „,You know, you're not your daddy.“, worauf Ruth erwidert: „That's right. And if daddy were here, he would have hung you out by your ball sack already. You want me to tell him that you're disrespecting me?" Boyd und Russ geben klein bei und widersprechen ihr nicht mehr (vgl. Ozark I/3: 06:00). Boyds Vormachtstellung unter den drei Brüdern ist also offensichtlich ebenso wie sein herablassender Umgang mit seiner Tochter: Ruth besucht ihren Vater wiederholt im Gefängnis, sehnt sich offensichtlich nach seiner Zuneigung. Ihr Vater beleidigt seine Tochter jedoch lediglich und nutzt ihre Ergebenheit aus. So spannt er sie ein, um Marty Byrde zu ermorden, um an sein Geld zu gelangen (vgl. Ozark I/6: 12:00). Als ihr dies nicht gelingt, bedroht er sie und beleidigt seine eigene Tochter als Hure (vgl. Ozark I/7: 39:00).
} 
jungen Mannes, der in ein Umfeld geboren wurde, das nicht seiner Natur entspricht. Selbst dem Rest der Familie ist bewusst, dass er auf einem College besser aufgehoben wäre als in ihrem Umfeld (vgl. Ozark I/9: 38:00). ${ }^{21}$

Ruth Langmore, die einzige weibliche Figur der Langmore-Familie, ist zugleich der bedeutendste Langmore-Charakter innerhalb des Seriengefüges. Gewissermaßen ist die intelligente und schlagkräftige junge Frau Oberhaupt der Familie. Durch deren Respekt vor ihrem Vater kann sie Einfluss auf ihre Onkel ausüben und zeigt auch keine Skrupel, sie mit einer Waffe zu bedrohen. ${ }^{22}$ Sie ist diejenige, die in Marty Byrdes Geschäfte einsteigt und Pläne zum finanziellen Aufstieg schmiedet. Tatsächlich ist ihre vermeintliche Überlegenheit angreifbar, sie unterliegt dem körperlich überlegenen Russ, als sie ihn zu sehr reizt (vgl. Ozark I/6: 44:00). Allerdings ist dies nur vorläufig der Fall: Letztlich behauptet Ruth ihre Stellung durch die Ermordung ihrer Onkel in der neunten Episode mittels eines elektrisierten Bootsstegs, also durch ein Vorgehen, für das Verstand und Geschick anstatt Körperkraft nötig sind (vgl. Ozark I/9: 49:00). Sie plant die Vormundschaft für ihre Cousins zu übernehmen und festigt somit nicht nur ihre Position, sondern bestätigt auch ihre Mutterrolle, die sie ihnen gegenüber im Verlauf der Serie wiederholt einnimmt (vgl. Ozark I/10: 44:00). Ruths Versuch, die Familie vom destruktiven Einfluss ihrer Onkel zu befreien, ist ein vornehmlich kompensatorisches Verhalten: Obgleich taff, schlau und selbstständig, wird Ruth ebenso über die starke Bindung an ihren Vater charakterisiert. Ihm gegenüber schwindet ihre Selbstständigkeit, wandelt sich in ein diametral

${ }^{21}$ Dabei ist er sich der Ausweglosigkeit seiner Situation bewusst: Zum einen liest er zwar Science-Fiction-Literatur, beschäftigt sich mit Zukunftsvisionen und anderen Welten, zum anderen wird dieses eskapistische Verhalten durch sein Bewusstsein relativiert, dass auch in einer zukünftigen Welt, auch auf anderen Planeten die Menschen nach wie vor die gleichen Probleme haben werden (hier bezieht er sich auf die Kurzgeschichtensammlung The Martian Chronicles von Ray Bradburry aus dem Jahre 1950): „We're the aliens. We go to Mars, take the place over, wipe out all the Martians and, like, try to make it our own. But then we realize it can never really be ours, like, even the people that were born, there, never known any other place, they'll still always be aliens. And the best part is, like, all these people move to mars, try to escape their problems on Earth and they get there and it's like life on Mars isn't any different. Like, they just bring all their old problems with them." (Ozark I/5: 44:00). Gewissermaßen reflektiert er hier seine eigene Situation und zeigt einen deutlichen Minderwertigkeitskomplex: Er ist in seiner Schicht, seiner als negativ empfundenen sozialen Stellung verhaftet - und selbst wenn er ihr entkommen sollte, bedeutet dies nicht die Auflösung seiner Probleme, vielmehr wird er außerhalb seiner Schicht stets ein Fremdkörper bleiben.

${ }^{22}$ Nachdem Russ und Boyd das Geld, das sie von Marty Byrde gestohlen haben, für Luchse ausgegeben haben, um sie zu züchten und deren Fell zu verkaufen, reagiert Ruth wütend: Sie bedroht ihre Onkel mit einer Pistole und sperrt sie zu den Luchsen - beides Weibchen - in den Käfig (vgl. Ozark I/3: 53:00). 
gegensätzliches Verhalten: Sie verehrt ihn und bringt ihm - um ihm zu gefallen - absolute Hörigkeit entgegen. In Gegenwart ihres Vaters ist sie eher kleines Mädchen als emanzipierte Frau. Cade Langmore indes begegnet seiner Tochter abschätzig, beleidigend und kalt (vgl. Ozark I/6: 11:00 sowie I/7: 39:00). Sie ist für ihn ein Werkzeug zur Umsetzung seiner kriminellen Interessen, zur Kontrollausübung aus dem Gefängnis hinaus. Seine Komplimente und Bestätigungen - wie z. B. „You're the smartest person this side of Mississippi. Anything you don't know yet, you'll figure." - gegenüber seiner Tochter, sind weniger positive Zusprache als eindeutige Forderung, die keinen Widerspruch duldet (vgl. Ozark I/6: 11:00). Dennoch idealisiert Ruth ihren Vater und wird vom Wunsch nach einer perfekten und funktionierenden Familie angetrieben. ${ }^{23}$ Der Mangel an einer funktionierenden Familie, an einem bestätigenden Umfeld oder menschlicher Wärme führt im Fall von Ruth einerseits zu emotionaler Abhärtung und anderseits zum Wunsch bzw. Drang, dieses Defizit in irgendeiner Weise auszugleichen. Dementsprechend schwankt sie zwischen skrupellosem kompensatorischem Aktionismus und Verleugnung der Wahrheit über ihren Vater, der genau das Gegenteil des von ihr imaginierten Ideals ist. Dennoch ist ihr erfolgreiches Durchsetzungsvermögen, wenn dies auch zwischenzeitlich durch ihre physische Überlegenheit entmystifiziert wird, ein signifikantes Charaktermerkmal. Ruth ist der einzige, annähernd positiv besetzte weibliche Charakter der Serie. Diese positive Konnotation resultiert vor allem daraus, dass sie - im Gegensatz zu den Byrdes - keine realistische Alternative zu gewaltsamem und verbrecherischem Handeln hat. Obgleich sie für ihr Ziel, den familiären Raum zu schützen (oder vielmehr überhaupt erst herzustellen), über Leichen geht, wird diese Tat über ihr Umfeld legitimiert: In einem Raum brutaler Machtkämpfe gibt es keinen anderen Ausweg als selbst Gewalt anzuwenden. Sie ist Produkt und Opfer eines Umfeldes, das keine alternativen Handlungsweisen zulässt. Die Byrdes hingehen ziehen eine Kooperation mit der Polizei und eine Abkehr vom Verbrechen nie ernsthaft in Betracht, obwohl diese möglich wäre. Ruth bleibt in ihren Handlungsweisen also charakterlich integer. Zwar erscheint ein Konflikt zwischen ihr und ihren Cousins wahrscheinlich, wenn diese erfahren, dass sie für die Ermordung ihres Vaters verantwortlich ist. Dies ist jedoch innerhalb der ersten Staffel nicht relevant. Tatsächlich beschwört sie Wyatt, das Andenken an ihren Vater zu bewahren (vgl. Ozark I/10: 35:00). Ihre Tat ist die

\footnotetext{
${ }^{23}$ Offensichtlich neidisch beobachtet sie eine glückliche Familie, die sich an einem Tisch in der „Blue Cat Lodge“ niederlässt (vgl. Ozark I/4: 09:00). Sie verteidigt die Ehre ihres Vaters sogar gewaltsam gegen Beleidigungen (vgl. Ozark I/5: 25:00).
} 
Ultima Ratio, die Ermordung der unfähigen und selbstgezogenen Onkel ein notwendiges Opfer, um überhaupt erst eine funktionierende Familie herzustellen. ${ }^{24}$ In Bezug auf das Weltmodell der Serie ist es hier auffällig, dass ein weiblicher Charakter nur dann in eine tatsächlich einflussreiche Position - z. B. die des Familienoberhauptes - gelangen kann, wenn er männliche Verhaltensweisen (in diesem Fall Gewalt) adaptiert und männliche Charaktere endgültig beseitigt. Nur dadurch, dass sie sich nicht wie Wendy und Charlotte Byrde verhält, keine Vermeidungsoder Betrugshandlungen vornimmt, sondern - wie Marty und Jonah - die Familie in den Mittelpunkt ihres Handelns stellt, ist die positive Konnotation Ruths überhaupt möglich.

Das Leben der Familie Langmore ist von ständigen physischen und psychischen Machtkämpfen ebenso bestimmt wie von nahezu offener Kriminalität. In jedem Lebensaspekt, sei es Alkoholkonsum, soziales Umfeld, Beruf und Verhalten, werden sie als Hillbillys, als Außenseiter der Gesellschaft dargestellt. ${ }^{25}$ Innerhalb des gewaltdominierten Umfeldes der Langmores ist physische Dominanz effektiver als geistige, falls diese nicht besteht, muss auf einem anderen Weg Gewalt ausgeübt werden. Sie ist das einzige Mittel zur Durchsetzung und drängt somit auch per se ,gute` Menschen zu destruktiven, moralisch höchst verwerflichen Taten. Diese gesellschaftliche Unterschicht wird in Ozark vorrangig über eine ausweglose Gewaltspirale semantisiert, die den Angehörigen unterer sozialer Schichten einen Ausweg, wenn nicht unmöglich macht, so doch zumindest enorm erschwert. Trotz der instabilen und chaotischen Lebensumstände ist das tragende Paradigma dennoch identisch mit dem der Byrdes: Familiärer Zusammenhalt und eine Sicherung der Existenz, die nur im Miteinander erreicht werden kann, ist das zentrale Motiv eines jeden Langmores, vielleicht mit Ausnahme des außenstehenden Cade, über dessen Motivation wenig bekannt ist. Selbst Boyd, ansonsten infantil und asozial, entscheidet sich - unter Hinweis auf familiäre Werte - dafür, seinen Bruder beim Mord an Marty Byrde zu unterstützen, und

\footnotetext{
${ }^{24}$ Russ plant Marty Byrde zu ermorden und mit seinen Söhnen die Ozarks zu verlassen. Ruth - eine wichtige Bezugsperson für die Jungen - soll zurückgelassen werden (vgl. I/9: 38:00). Dies würde eine Spaltung der Familie bedeuten, die Ruth durch ihr Handeln verhindert, zumal sie sicherlich die geeignetere Leit- und Erziehungsfigur für die Jungen ist als deren kaum zurechnungsfähiger Vater. Zudem verhindert sie mit ihrer Tat die Zerstörung der Familie Byrde.

${ }^{25}$ Dies wird auch im Sprachgebrauch deutlich: In fast jedem Wortwechsel unter den Langmores fällt wiederholt das Wort „fuck“ oder äquivalente Beleidigungen und Flüche. Zudem sprechen sie mit einem ausgeprägten Hillbilly-Akzent, der ihre Herkunft aus einem geographisch abgelegenen Gebiet betont.
} 
geht, wenn auch unfreiwillig, mit ihm gemeinsam in den Tod (,You're my brother. What the fuck have I got here, anyway?“ - Ozark I/9: 36:00). Der Gegensatz der Byrdes und Langmores, von Ober- und Unterschicht, besteht also lediglich auf einer oberflächlichen Ebene ${ }^{26}$. Der zentrale Unterschied besteht darin, dass die Kriminalität und moralische Fragwürdigkeit ebenso wie die innerfamiliären Konflikte der Langmores offen zu Tage treten, während diese in der Familie Byrde unter der Oberfläche liegen und hinter verschlossenen Türen ausgehandelt werden. Tatsächlich wiegen Martys moralische Verfehlungen schwerer als die Kleinkriminalität der Langmores, schließlich ist es Marty, der im großen Ausmaß die Drogenkriminalität unterstützt, die mehr Menschenleben kostet als das Handeln der Langmores. Zudem sind beide Familien durch das dominante Paradigma des Familiensinns miteinander verbunden. In der Tiefenstruktur des Formats werden daher Klassengegensätze relativiert. Eine zuvor konstatierbare Kultur-Natur-Dichotomie, die sich aus dem Gegensatz der zivilisiert-beherrschten Byrdes und der emotionalen, ,barbarischen' Langmores ergibt, besteht auf einer tieferen Text- und Charakterebene nicht mehr: Unabhängig von Klasse, Herkunft, Beruf oder moralischem Bewusstsein ist eine Familie unabdingbar für Glück und Erfolg eines jeden Menschen.

\subsubsection{Familie Snell}

Wenn auch die Byrde-Familie und der Langmore-Clan zweifellos die zentralen Personenverbände in Ozark sind, so bilden Jacob und Darlene Snell, ein Ehepaar zwischen 60 und 70 Jahren, doch ein interessantes familiäres Gegenmodell. Durch ihr Vermögen, den sukzessiven Landerwerb, Drohungen und Schuldverhältnisse, z. B. gegenüber dem lokalen Sheriff (vgl. Ozark I/10: 20:00), sichern sie sich eine unumstößliche Machtposition innerhalb der Region. ${ }^{27}$ Die Snells werden als ,böse Macht" semantisiert, die tief in der Region verwurzelt ist. Sie identifizieren sich zentral über ihre Abstammung aus der Region, definieren sich als „Hillbillys“ (vgl. Ozark I/4: 52:00). Diese Selbstidentifikation geht über simple Heimatverbundenheit hinaus, vielmehr sind Jacob und Darlene besessen von ihrer Familiengeschichte, die sie zu einem Mythos überhöhen. Die Snells wurden 1929 von ihrem fruchtbaren Land in die unfruchtbaren bergigen Regionen vertrieben - als Stromunternehmer das Land überfluteten - und richten seitdem ihr ganzes

\footnotetext{
${ }^{26}$ Hier ist nicht die Oberflächenstruktur im Sinne des Discours gemeint, sondern eine vordergründige inhaltliche Ebene des Textes, die der Kernstruktur des Weltmodells vorgelagert ist.

${ }^{27}$ Dabei ist ihr Vorgehen äußerst skrupellos. Ein Beispiel: Um den Pastor Mason Young dafür $\mathrm{zu}$ bestrafen, dass er sich weigert bei seinen Predigten Heroin zu vertreiben, ermorden sie seine schwangere Frau und hinterlassen ihm das Kind (vgl. Ozark I/10: 20:00).
} 
Handeln darauf aus, ihren gesellschaftlichen und lokalpolitischen Einfluss zurückzugewinnen (Ozark I/6: 4:00). Dabei ist nicht eindeutig, ob nun Jacob, Darlene oder beide gebürtige Snells sind. Die Besessenheit für die Wiedergutmachung des an der Familie angerichteten ökonomischen wie emotionalen Schadens - wohlgemerkt eines Schadens, der längere Zeit vor der Geburt Jacobs und Darlenes entstanden sein muss - ist in beiden gleichermaßen präsent. Dogmatisch halten sie an ihrer Familiengeschichte und dem damit verbundenen Vergeltungsgedanken fest. Dieses Streben wird, durch das Festhalten an bestimmten Prinzipien und Symboliken, zu einem Antrieb mythischen Ausmaßes: „Symbolism matters Mr. Byrde. Maybe not to people who have no pride, no history. But to us." (vgl. Ozark I/10: 52:00).

Bei eingehender Betrachtung entpuppt sich der wiederholte Bezug der Snells auf ihre Familiengeschichte als Versuch, die eigenen Verbrechen durch mythische Überhöhung als Racheakt zu legitimieren, keinesfalls als eine rational stimmige Rechtfertigung: Die Selbstdefinition der Snells als „Hillbillys“ ergibt sich auch durch eine Opposition zum „Redneck“, die vage bleibt. Durch eine Erzählung über einen Redneck und einen Hillbilly, die Jacob Snell an Bobby Dean, Besitzer eines Stripclubs und Untergebener der Snells, weitergibt, wird diese Selbstidentifikation zuerst transportiert. Die wirre Parabel führt auf eine Charakterisierung des Rednecks als aggressiv und arrogant und des Hillbillys als bescheiden, fleiBig und ruhig hinaus (vgl. Ozark I/4: 52:00). Aus narrativer Sicht soll diese Erzählung ein Gefühl der Tiefgründigkeit erzeugen, verfehlt aber eine kohärente Moral und bleibt weitestgehend inhaltslos. Am Ende des Gesprächs wird Dean von Darlene vergiftet und Jacob kommentiert dessen Tod mit „Fucking Redneck“ (Ozark I/4: 54:00). Besonders deutlich wird die Ablehnung von Rednecks, als Darlene den Drogenboss Camino Del Rio erschießt, weil dieser sie als solche bezeichnet (vgl. Ozark I/10: 57:00). Der Gegensatz zwischen „Redneck“ und „Hillbilly“, den Snell hier aufstellt, ist in dieser Absolutheit konstruiert. Der Literaturwissenschaftler Matthew Ferrence konstatiert, dass beide Begriffe aus einer ideologischen Sicht ununterscheidbar sind:

Each designates a rural underclass, and each is dependant on a fixed sense of geographic and historical specificity, even though the actual ,meaning ' of the term constantly changes. The uses and definitions of these identities move to satisfy national need. As such, the terms become empty signifiers referencing ideas that correspond to no one. Yet they shift to allow the individual or group using the identity to shape the image into what is needed. (Ferrence 2014: 45 f.) 
Beide Begriffe sind also hochgradig kulturell und medial aufgeladen und werden je nach Kontext stets aufs Neue mit verschiedenen Bedeutungen und Konnotationen besetzt - man denke an die zahlreichen medialen Redneck- und Hillbilly-Klischees, sei es in Horror oder Komödie. Versucht man sich an einer allgemeinen, abgrenzenden Definition der fluiden Begriffe, so bezeichnet „Redneck“ männliche Angehörige der Arbeiterklasse in den US-amerikanischen Südstaaten. Der Begriff „Hillbilly“ schließt diese Merkmale zwar mit ein, bezieht sich aber vor allem auf die Bewohner bergiger Regionen, gleich welchen Geschlechts. „Hillbilly“ ist zudem identitätsstiftender als Redneck und ist eng mit einem Stolz auf die Unabhängigkeit und die Verteidigung und Bewahrung einer spezifischen Bergbewohner-Identität verbunden (vgl. Harkins 2004: 212). Allgemein ergibt sich die Hillbilly-Mentalität und Selbstdefinition aus zahlreichen Attributen:

Through as yet unheralded, the Hill Billy has a traditional history, reaching onto the dim and distant past. [...] The Hill Billy, ever true to his principle of exclusiveness, never looks beyond his own beloved hills for his bride. As a result, the species has remained pure and undefiled. ... The Hill Billy is proud in his poverty, contented with his environment, happy in his seclusion. (Harkins 2004: 51, hier als Zitat aus der Schrift Down in Arkansas des Humoristen Charles S. Hibler)

Am wahrscheinlichsten ist es, dass die Snells als Hillbillys, Dean als Redneck wegen seiner Heimatlosigkeit und seinem Mangel an Werten, seiner schieren Identitätslosigkeit, ablehnen. Für sie ist er eine Last, ein unverlässlicher, da geschichtsloser und gieriger Mensch, der beseitigt werden muss. In der Gesamtschau bleibt Jacob Snells Parabel weitgehend nichtssagend und effekthascherisch, fügt sich aber - in Verbindung mit dem Familienmythos - in das allgemeine Familienbild von Ozark ein.

Durch diese massive Rückwärtsgewandtheit wird zudem jede Reflexion des Zukünftigen irrelevant: Die Snells sind alt und kinderlos. Alles Streben der Snells ist somit, wenn auch momentan äußerst erfolgreich, auf längere Sicht vergebens. Nach ihrem Tod wird all ihr Handeln in letzter Instanz ziellos sein, da es keinen Erben gibt, der es weiterführen könnte. Auch hier lässt sich eine Verhandlung der Familienthematik deutlich ausmachen: Zwar sind Jacob und Darlene ein Ehepaar, aber keine vollständige Familie. Sie richten sich - durch die Ermordung der Frau des Pastors und durch die konstante Bedrohung der Byrdes - sogar bewusst gegen die Familie. Durch diese Doppelcharakterisierung der Snells, in der das Festhalten an der Familiengeschichte der Vernachlässigung der Familie im Hier und Jetzt gegenübergestellt wird, wird innerhalb des Weltmodells ein weiterer Aspekt von Familie aufgezeigt: $\mathrm{Zu}$ der Funktion als Schutzraum kommt eine Funktion als 
Vermächtnisträger. Ohne Kinder, an die man das eigene Vermächtnis weitergeben kann, verliert das Konzept Familie den Sinn. ${ }^{28}$

\subsubsection{Das FBI und andere Charaktere ohne Familie}

Wird das FBI auch durch zwei Charaktere - Roy Petty und seinen Partner Trevor Evans - vertreten, so ist es doch fast ausschließlich Petty, der als alleinstehender und in der Diegese deutlich abgegrenzter Charakter diese Fraktion vertritt. Petty ist der einzige Hauptcharakter und einer der wenigen Charaktere überhaupt, der nicht Teil einer Familie oder zumindest eines familienähnlichen Verbandes ist: Seine Beziehung zu Evans ist bereits vor Beginn der Serie beendet (vgl. Ozark I/3: 33:00) und seine Beziehung zu Russ Langmore ist ausschließlich manipulativer Natur. Petty zeigt ein gestörtes Verhältnis zu Bindungen. Dieses Verhalten wird durch eine gescheiterte Partnerschaft und eine problematische Beziehung zu seiner Mutter bedingt, die in der achten Episode der ersten Staffel beleuchtet werden: Vor der eigentlichen Diegese führte er eine glückliche, homosexuelle Beziehung. Dreh- und Angelpunkt seines Lebens war seine Mutter, die zuvor durch Tablettensucht aufgefallen war (vgl. Ozark I/10: 9:00), die er vom Heroinkonsum abzuhalten versuchte (vgl. Ozark I/10: 30:00) und die er nach einem Unfall gesundpflegen musste (vgl. Ozark I/10: 37:00). Wie die Beziehung endete und ob Pettys Mutter noch am Leben ist, bleibt unklar, kann jedoch vermutet werden. Durch die Drogenabhängigkeit seiner Mutter erklärt sich seine Besessenheit für den Fall der Byrdes. Innerhalb der Serienhandlung bleibt Petty ein Einzelgänger. Er ist unfähig, Nähe zu anderen Menschen zu entwickeln - eine Tatsache, die durch die Art und Weise unterstrichen wird, wie er den infantilen Russ Langmore in seiner Suche nach Zuneigung ausnutzt. Zudem ist Petty in höchstem Maße emotional instabil. Beispielsweise gerät er außer sich, als seine Ermittlungen scheitern (vgl. Ozark I/10: 1:03:00). Evans bezeichnet ihn als Soziopathen (vgl. Ozark I/3: 33:00) und ein Sexarbeiter stellt fest, dass Petty Probleme (,issues") habe (vgl. Ozark I/3: 49:00). Ein entsprechendes Verhalten zeigt sich im Rückblick der achten Episode noch nicht, eine negative Entwicklung seines Lebens in seiner Vergangenheit liegt dementsprechend nahe.

Die Ursache für die instabile Persönlichkeit Pettys und seine soziopathischen Tendenzen erklärt sich im vorliegenden Weltmodell recht einfach: Ein Mensch ohne Rückhalt in einer Familie ist angreifbar und ungeschützt, nicht nur der Außenwelt, sondern auch sich selbst gegenüber. Familie dient als Raum der Ruhe

\footnotetext{
${ }^{28}$ Als die Snells dem Vorschlag Martys zustimmen, Land zu fluten, um über ein Fluss-Kasino Geld zu waschen, stellt sich die Frage, ob es sich bei der oft beschworenen Familiengeschichte der Snells um deren tatsächliche Motivation oder vielmehr um eine vorgeschobene Legitimierung ihrer kriminellen Machenschaften handelt (vgl. Ozark I/10: 52:00).
} 
und Selbstreflexion, als Ausgleich zum harten Berufsleben, das Private fungiert als Schutzraum vor dem Öffentlichen. Pettys negative emotionale und geistige Situation ist eine Folge seiner Einsamkeit und eventuell einer problematischen familiären Vorprägung durch seine drogenabhängige Mutter.

Bei den anderen familienlosen Figuren, die eine nennenswerte Rolle spielen, handelt es sich um den Stripclub-Besitzer Bobby Dean, der als äußerst unsympathisch und moralisch verkommen charakterisiert wird (vgl. Ozark I/4: 17:00; hier erwartet er, dass ihn Ruth Langmore als Teil eines Bewerbungsgesprächs oral befriedigt), und um Tuck, einen jungen Mann mit Down-Syndrom. Dieser wird zwar deutlich positiv charakterisiert und scheint nicht unglücklich oder besonders isoliert, nimmt aber durch seine Behinderung eine Außenseiterrolle ein. Ebenso steht Buddy Dyker, der todkranke, alleinstehende alte Mann, dessen Haus die Byrdes erwerben und der anschließend im Keller wohnt, außerhalb der Gesellschaft, obwohl es sich um eine positive Mentoren-Figur handelt. Auch Rachel Garrison, die Besitzerin der „Blue Cat Lodge“, führt ein promiskuitives Leben als alleinstehende Frau ohne Angehörige (vgl. Ozark I/4: 46:00; an dieser Stelle wird thematisiert, dass sie sich jede Woche einen „fuck of the week“ sucht). Rachel scheint - obgleich sie das Single-Dasein vordergründig genießt - einsam zu sein (vgl. Ozark I/4: 23:00) und verlässt die Ozarks in der letzten Episode (vgl. Ozark I/10: 37:00). Alle Charaktere, die nicht in einem Familienverband eingebettet sind, führen in Ozark ein emotional defizientes Leben, werden negativ charakterisiert oder nehmen eine Außenseiterrolle ein.

\subsubsection{Camino Del Rio}

Camino Del Rio, ein skrupelloser mexikanischer Drogenbaron, tritt zunächst als Antagonist der Familie Byrde, insbesondere Martys, auf, indem er sie mit dem Tode bedroht. Er schreckt vor der Zerstörung von Familien nicht zurück und erschießt beispielsweise die Betreiber eines Fuhrunternehmens, über das Bruce Liddell, Martys Kollege, Geld gewaschen und einiges davon unterschlagen hat. Dabei befiehlt er zuerst den Vater zu erschießen, da kein Vater sein Kind sterben sehen sollte - eine Parodie bzw. Verzerrung eines Verbrecher-Ethos (vgl. Ozark I/1: 23:00). Auffällig ist, dass er bis zu einem gewissen Grad als Familienmensch dargestellt wird: Bei seinem ersten Auftritt nimmt er Bezug auf den Familienbetrieb seines Vaters, wenn auch um Druck auf Bruce Liddell auszuüben (vgl. Ozark I/1: 18:00). ${ }^{29}$ Vor allem wird er in der Folge „Kaleidoscope“ zusammen mit Frau

\footnotetext{
${ }^{29}$ Er erzählt von einer Angestellten, die Geld aus dem Laden seiner Eltern stahl, um Medikamente für ihren Sohn zu kaufen, und fragt, wie sein Vater mit ihr hätte verfahren sollen (vgl. Ozark I/1: 18:00).
} 
und Sohn gezeigt (vgl. Ozark I/8: 14:00). Entweder dient Del Rio seine Familie als Fassade, um ein Bild als seriöser Geschäftsmann aufrechtzuerhalten, oder und dies ist in der Logik des Textes wahrscheinlicher - sie bildet einen Ausgleich und Rückzugsort, der es ihm ermöglicht, sein berufliches Leben zu meistern. Es ergibt sich dieselbe Aussage wie bezüglich des Gegensatzes zwischen den Byrdes und den Langmores: Die Bedeutung der Familie ist unabhängig von sozialer und gesellschaftlicher Verortung.

\subsubsection{Familie Young}

Der Pastor Mason Young und seine schwangere Ehefrau Grace repräsentieren nicht nur als einzige Figuren in Ozark ein religiös geprägtes Leben - alle weiteren Charaktere haben keinen tiefergehenden Bezug zu Religion -, sie sind zudem die einzige moralisch und kriminell unbelastete und hoffnungsvolle, funktionierende Familie in der Serie. Mit ihrem Gottvertrauen, das zumindest der Pastor auch in akuten Bedrohungssituationen zeigt (vgl. Ozark I/7: 23:00), und ihrer hoffnungsvollen Vorwärtsgewandtheit bilden sie ein Gegenstück zu den Snells. Die Youngs sind - auf einer vereinfachten und abstrahierten Ebene - das Gute, die Snells das Böse.

Das Paradigma ,Hoffnung ' wird hier, in Verbindung mit religiösen Motiviken, an die Familie angelagert: Anstatt sich der Trauer um seine Frau, seiner Hilflosigkeit als Vater und somit der Vergangenheit zu ergeben und seinen neugeborenen Sohn, wie es zunächst scheint, zu ertränken, tauft er ihn im Wasser des Sees (vgl. Ozark I/10: 1:13:00; vgl. Abb. 3.3). Der Sohn erscheint somit als Hoffnungsträger, als Licht in den dunklen Lebensumständen des Pastors. Solange Familie besteht, besteht Hoffnung. Dies gilt für Mason Young ebenso wie für die Byrdes oder die Langmores, die sich ohne ihre Angehörigen ebenfalls in einer hoffnungsund ziellosen Situation befänden. Marty äußert dies explizit, als Young sich selbst fragt, warum er seinen Sohn ,in einer solchen Welt“ überhaupt am Leben lassen sollte: „Because kids are hope. You know, that... that maybe things can get better.“ (Ozark I/10: 1:04:00).

\subsubsection{Familie Dermody}

Der alleinstehende Immobilienmakler Sam Dermody, der sein Geschäft zusammen mit seiner verwitweten Mutter Eugenia führt, nimmt in der Narration der Serie eine untergeordnete Rolle ein. Das Verhältnis von Mutter und Sohn ist dennoch interessant: Bereits durch ihr Aussehen und ihr grundlegendes Verhalten werden die Dermodys als seltsam und abweichend charakterisiert: Sam ist zurückhaltend, schüchtern und schmächtig und zeigt skurrile Verhaltensweisen, wenn er 


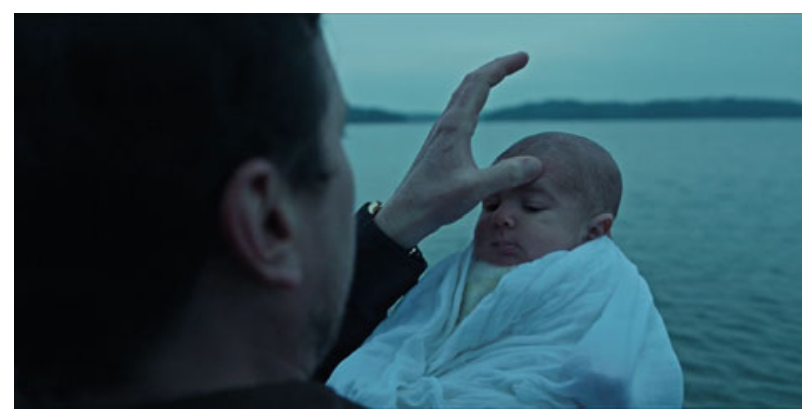

Abb. 3.3 Mason Young tauft seinen Sohn (Ozark I/10: 1:14:00)

sich z. B. - bei seinem ersten Auftritt in der Serie - von seinem Hund Erdnussbutter von den Füßen lecken lässt und dadurch anscheinend eine Art sexuelle Befriedigung erfährt (vgl. Ozark, I/2: 05:00). Dermody wird direkt zu Beginn als Sonderling mit harmlosen sexuell-perversen Neigungen eingeführt. Seine Mutter ist voluminös, laut, dominant und weist einen Hang zu äußerst geschmackloser Kunst auf (vgl. Ozark, I/7: 43:00). Sam ist es, trotz fortgeschrittenen Alters, nicht gelungen, sich von seiner Mutter zu lösen, von der er offensichtlich in den meisten Bereichen seines Lebens dominiert wird. Voll und ganz ist der erwachsene Mann von seiner Mutter abhängig, lebt sogar in einer gewissen Furcht davor sie zu verärgern (vgl. Ozark, I/6: 18:00). Eugenia findet ihr Ende, als sie während eines Streits wütend und unaufmerksam vor einen Lastwagen läuft (vgl. Ozark I/7: 43:00). Obwohl er sie während des Streits als ,constant, 24/7, nagging, incessant fucking bitch" bezeichnete und sie ihn offensichtlich während seines ganzen Lebens von der Verwirklichung seiner tatsächlichen Träume abhielt, ist Sam wegen des Todes seiner Mutter am Boden zerstört (vgl. Ozark, I/9: 14:00). Er betreibt sogar eine Art verklärenden Totenkult, indem er eine besonders extravagante und kostenaufwändige Bestattungsmethode für seine Mutter durchsetzen will, bei der ihre Asche zu einem Diamanten gepresst wird, den er - nach Wunsch seiner Mutter - für einen Ehering verwenden kann (vgl. Ozark, I/9: 25:00).

Zwar leben die beiden Dermodys in einem familiären Verhältnis, allerdings erfährt dieses keinesfalls eine positive Charakterisierung. Statt der mütterlichen Fürsorge, die Eugenia ihrem Sohn entgegenbringen sollte, übt sie zwanghaft Kontrolle über ihn aus und macht ihn von sich abhängig. Sam ist ein Charakter, dem eine Initiation ins Erwachsenenleben oder Mannsein nie gelungen ist, der nie eine 
eigene Familie gegründet hat, auch da seine Mutter ihn mit größter Wahrscheinlichkeit daran gehindert hat. Dementsprechend ist Sam in seiner Herkunftsfamilie wie in einer Zwangsstruktur gefangen. Familie ist also ein Konzept, das innerhalb des Weltmodells von Ozark bewusst angestrebt werden muss. Ein Verweilen im Ausgangsraum, in dem das Leben mit der Geburt seinen Anfang nimmt und der während der Kindheit und frühen Jugend zentraler Bezugspunkt bleibt, ist nicht sinnvoll und glückbringend, kann sogar zu negativen Strukturen führen. Ein jedes Individuum muss - auch damit Familie überhaupt bestehen bleibt und nicht ausstirbt - bestrebt sein, eine eigene Familie zu gründen, die wiederum zur Gründung weiterer Familien führt. Wie fatal die Folgen eines Festhaltens sein können, wird am Beispiel von Sam Dermody gezeigt, der selbst nach dem Tod seiner Mutter, also mit dem Ende der Ausgangsfamilie, unfähig zu eigenständiger Weiterentwicklung, an ihr festhält.

\subsubsection{Bruce Liddell}

Die Beziehung von Martys Arbeitskollegen und gutem Freund Bruce Liddell zu seiner Freundin Liz stellt in der ersten Episode ein Gegenmodell zu Martys Ehe dar. Zwischen ihm und Liz besteht offensichtlich eine große sexuelle Anziehung, unverhohlen spricht er mit Marty darüber: „Liz...Liz...Nothing's off-menu. This girl's got a wink like a fox trap." (vgl. Ozark I/1: 5:00; in der deutschen Synchronisation: „Liz...Oh, Liz ist unglaublich. Das versaute Luder geht sowas von ab.“). Zu Martys 22-jähriger Ehe meint er „Holy Christ, those threads are stripped!“ (vgl. Ozark I/1: 5:00; in der deutschen Synchronisation: „Heilige Scheiße, da ist der Lack wohl ab!"). Marty weist diese Anzüglichkeiten zurück und verweist Bruce darauf, dass es sich bei Liz um Bruces zukünftige Ehefrau handle, was dieser abtut.

Die offensichtlich befriedigende Beziehung zwischen Bruce und Liz hat im Rahmen der Narration die Funktion, Marty die Mängel seiner eigenen defizienten Beziehung vor Augen zu führen. Auch in langjährigen Beziehungen ist demnach ein befriedigendes Sexualleben integraler Bestandteil, der notwendig für die Funktionalität des Verhältnisses ist. Besteht dieser nicht mehr, kann es - wie im Falle der Byrdes - zu Untreue und Spaltung kommen. Die physische Ebene einer Beziehung wird in diesem Sinne der emotionalen Ebene annähernd gleichgestellt, wobei die physische Ebene jedoch schwerer wiegt. Obgleich die emotionale Vereinsamung und die zermürbende Unterforderung und Langeweile Wendys ausschlaggebende Faktoren für ihren Ehebruch sind, stellt ihre konkrete Tat den eigentlichen Grenzübertritt dar. 


\subsubsection{Grundparadigmen}

Im Folgenden möchte ich auf die dominanten Paradigmen der Serie Ozark eingehen bzw. darauf, welche Paradigmen über die Familie - als zentraler Handlungsort des Formats - dominant verhandelt und welche Inhalte und Aussagen somit vermittelt werden.

\subsubsection{Familie und Geschlechterrollen}

Zwangsläufig werden im medialen Umgang mit Familie stets Familien- und Geschlechterrollen verhandelt und problematisiert. Wie sich bereits im Verlauf der vorangegangenen Analyse herausgestellt hat, ist der Blick der Serie Ozark auf das Geschehen ein deutlich männlicher: Frauen werden fast durchgehend als Antagonistinnen eines starken Protagonisten inszeniert, der zugleich als zentrale Identifikationsfigur fungiert. Wendy Byrde provoziert eine in höchstem Maße emotional belastende Spaltung der Familie, zudem kann ihr - durch ihre Zustimmung zu Martys Plänen - die partielle Schuld an den kriminellen Verwicklungen der Familie gegeben werden. Charlotte Byrde behindert entweder das familiäre Leben oder distanziert sich aktiv davon. Darlene Snell ist nicht nur deutlich ihrem Mann untergeordnet, sondern bringt mit ihrem impulsiven Handeln die Pläne der Familie in Gefahr, wenn sie z. B. Camino Del Rio erschießt. ${ }^{30}$ Eugenia Dermody schließlich terrorisiert ihren Sohn und hindert ihn an jeglicher Selbstverwirklichung.

Die männlichen Charaktere des Formats sind nicht durchgehend positive Charaktere, allerdings erfahren sie keine vergleichbar konsequente Negativcharakterisierung. Zudem werden nicht nur ihre Gefühlswelten dominant fokussiert, sie nehmen innerhalb des hierarchischen Gefüges stets eine dominante Position ein. Es sind Marty und Jonah Byrde, welche die Familie - den Mittelpunkt der Serie - verteidigen, ebenso wie Buddy Dyker als Mentoren-Figur bzw. GroßvaterErsatz. Jacob Snell - wenn auch ein inhumaner und skrupelloser Charakter - führt seine Geschäfte mit einem gewissen Ehrenkodex. Mason Young bewahrt seine moralische bzw. religiöse Integrität, während seine Frau ihm zur Flucht rät (vgl. Ozark I/7: 23:00), sich also gegen ,männliche' Standhaftigkeit und Kampfeswillen richtet. Eine Flucht würde hier ein Aufgeben, ein Zurücklassen der Prinzipien bedeuten. Selbst Roy Pettys soziopathisches Verhalten wird durch die Geschehnisse in seiner Vergangenheit, wenn nicht legitimiert, so doch zumindest

\footnotetext{
${ }^{30}$ Sie folgt, in der Rolle einer Hausfrau, Jacobs Anweisungen, z. B. „Darlene. Could we have a couple of glasses, please? Lemonade. Thank You.“ (Ozark I/4: 50:00) und hat allgemein den deutlich geringeren Redeanteil.
} 
verstehbar gemacht - ebenso wie Russ und Boyd Langmores schwere charakterliche Mängel als Konsequenzen sozialer Verwahrlosung zumindest nachvollziehbar sind. Obwohl Snell und Del Rio auch Antagonisten sind, so nehmen sie doch innerhalb ihrer Familie eine Führungsposition ein. Dass Sam Dermody dazu nicht in der Lage ist, liegt an der Unterdrückung durch seine Mutter - ein Vater, der regulierend eingreifen könnte, ist abwesend.

Nur durch die Übertragung männlicher Attribute kann Ruth Langmore - als einziger weiblicher Charakter - positiv semantisiert werden. Durch die Abwesenheit einer männlichen Schutzfigur ist sie nicht nur Werkzeug ihres Vaters und somit Stellvertreterin eines Mannes, sie muss auch die Abwesenheit einer männlichen Leitfigur für ihre Cousins kompensieren, da Russ durch sein geringes geistiges Potenzial, seine Manipulierbarkeit, die mit einem Mangel an Eigenständigkeit einhergeht, und seine Homosexualität nicht als solche fungieren kann. Boyd Langmore ist hier schlichtweg nicht als Mann, sondern - in seiner Infantilität - als Kind zu betrachten. Er kann ebenfalls keine Vorbildfunktion einnehmen. Die Aufladung der Figur Ruth mit männlichen Merkmalen ist überdeutlich: Sie übernimmt die Geschäftsführung des Stripclubs und gewinnt somit Dominanz auf einem Terrain, das typischerweise durch weibliche Unterwerfung gekennzeichnet ist. Zudem greift sie zu Waffengewalt und ermordet letztlich die älteren Männer der Familie. ${ }^{31}$ Dennoch gelingt es ihr, sich - durch die Verweigerung des Mordes an Marty Byrde - von ihrem Vater zu emanzipieren. Simplifizierend könnte man an dieser Stelle davon sprechen, dass Ruth über die Zuweisung männlicher Attribute auf Ebene des sozialen Geschlechts nicht als weiblicher Charakter betrachtet werden kann. Tatsächlich jedoch ist diese Attributszuweisung nicht derart vollumfänglich. Ruth ist die Ausnahme, die die Regel negativer charakterisierter Weiblichkeit in Ozark bestätigt. Nur in Abwesenheit einer geeigneten männlichen Führungsfigur gelingt es Frauen, das Heft in die Hand zu nehmen. Eine Eignung zur Führungsfigur ergibt sich dabei nicht aus moralischer oder charakterlicher Integrität, sondern schlicht aus der Fähigkeit, die Familie zu beschützen. Russ und Boyd Langmore sind dazu nicht in der Lage und müssen weichen.

Der Blickwinkel der Serie ist also zunächst eindeutig konservativ, ja sogar sexistisch: Fast naturgesetzlich ordnen sich Frauen Männern unter, die - wie Alphamännchen - eine Schutzfunktion für das ,Rudel' erfüllen. Nur in dem daraus resultierenden Patriarchat kann so etwas wie Ordnung entstehen. Dabei handelt es sich um eine Ordnung, in der Kriminalität, Mord etc. existieren, welche

${ }^{31}$ Zwar sind in Texten auch gegenläufige Deutungsansätze möglich, in denen gerade Stripclubs Orte weiblicher Dominanz sind, an denen Männer durch weibliche Reize gefügig gemacht werden, dies ist in Ozark allerdings nicht der Fall. 
aber dennoch eine rational erklärbare bzw. regelgeleitete Ordnung ist, in der eine destruktive weibliche Impulsivität eingedämmt werden kann. Diesen Blickwinkel als Endpunkt der Analyse zu bestätigen, hieße wiederum zu kurz zu greifen: Die Negativrolle der Frau ist keine unveränderliche, unbedingte und ursprüngliche Position, sie ist Produkt der männlichen Dominanz. Zeigen die Frauen in Ozark auch negativ charakterisiertes Verhalten, so ist dies doch ein unweigerliches Produkt der Einengung durch patriarchale Strukturen. Wendy Byrde versucht einer gefühlsarmen und zur Routine verkommenen Ehe zu entkommen, Charlotte lehnt sich gegen das für sie undurchsichtige und irrationale Verhalten ihrer Eltern auf, Darlene Snell versucht ihren Mann in gewisser Weise zu übertrumpfen und Eugenia Dermody scheint eine lieblose Ehe in der Vergangenheit verarbeiten zu müssen. ${ }^{32}$

Wenn auch implizit - und wohl kaum intendiert -, so wird in Ozark durchaus die Problematik des Beharrens auf konservativen, patriarchalen Familienstrukturen verhandelt. Besonders innerhalb der Byrdes werden diese Strukturen als Faktum akzeptiert. In der Familie Byrde kommt es jedoch niemals zu einem tatsächlichen Bruch, niemals - und dies ist ein zentraler Punkt - zu einer tiefgehenden Aussprache der Ehepartner. Die Aussprache, die erfolgt, führt letztlich zu einem Schuldeingeständnis Wendys, die angedeutete Versöhnung am Ende der Staffel zu einer Festigung der Rolle Marty Byrdes. Ruth Langmore gelingt der Ausbruch. Wie sich die Situation nach einer möglichen Entlassung ihres Vaters aus dem Gefängnis verändert, ist fraglich - eine mögliche Entwicklung für eine zweite Staffel, denn Cade Langmore wird als Antagonist grundlegend etabliert. ${ }^{33}$ In ihrer Substanz bleiben die vorhandenen Geschlechterrollen und -normen unangetastet. Gelegentlich brechen sich Frauen in impulsiver und radikaler Weise Bahn, diese Handlungen werden aber - in ihrer Aggressivität - stets als Störung des Status quo angesehen und niemals vollumfänglich verarbeitet oder analysiert. Nur auf einer sekundären Ebene wird klar, dass die genuine Schuld für die Missverhältnisse, für die Störungen in der friedlichen Koexistenz der Menschen, bei den männlichen Charakteren liegt. Dies wird gemeinhin übergangen, da auf der sichtbareren Oberflächenebene die Schuld bei den weiblichen Charakteren liegt. Eine Gleichberechtigung der Geschlechter existiert nur pro forma als

\footnotetext{
${ }^{32}$ Sam meint zu der aufwendigen und kostspieligen Beerdigungsplanung seiner Mutter: „Well, she always swore that she'd throw a funeral better than her wedding. Stick it to my father." (vgl. Ozark I/9: 26:00).

33 Tatsächlich übt Cade in der zweiten Staffel unterdrückerischen Einfluss auf seine Tochter aus und nimmt ihr teilweise ihre Eigenständigkeit, kommt aber letztlich zu Tode.
} 
notweniges Element einer modernen, aufgeklärten Gesellschaft, letztlich werden althergebrachte Rollenbilder eingehalten und perpetuiert. ${ }^{34}$

\subsubsection{Sexualität}

Trotz seines engen Zusammenhangs mit dem Bereich der Familie und insbesondere der Geschlechterrollen soll der Aspekt der Sexualität hier gesondert hervorgehoben werden, auch in Bezug auf die Darstellung homosexueller Charaktere. Wird Roy Pettys ehemalige Beziehung in der achten Episode der ersten Staffel als liebevoll und glückbringend charakterisiert, kann dies nur in sehr begrenztem Maße die Charakterisierung von Homosexualität als abweichend und anormal relativieren, die das Format allgemein vornimmt. Allein die Tatsache, dass die zwei homosexuellen Charaktere des Formats ein soziopathischer Außenseiter und ein kleinkrimineller Hinterwäldler sind, beide also außerhalb der Gesellschaft stehen, ist überaus kritisch zu betrachten: Homosexualität wird in Ozark keinesfalls als normal, gewöhnlich oder natürlich gekennzeichnet. Sie trägt den Stempel des Ungewöhnlichen: Wer homosexuell ist, steht in Ozark außerhalb der Gesellschaft. Dass Roy Pettys ehemalige Lebenspartner als Arzt/Krankenpfleger (vgl. Ozark I/8) bzw. FBI-Agent (Trevor Evans) voll in die Gesellschaft integriert sind, relativiert dies wiederum nur in geringem Maße, da es sich bei beiden um nahezu irrelevante Nebencharaktere handelt.

Gekoppelt an familiäre Zusammenhänge hat Sexualität in der Serie einen hohen Stellenwert. Gewissermaßen fungiert sie hier als Macht- und Druckmittel: Wendys außerehelicher Geschlechtsakt wird als ultimativer Bruch der Treue, d. h. als Beweis und Höhepunkt der Untreue, angesehen. Nur durch die Nachahmung dieses Aktes durch ihren Mann kann dieser Treuebruch kompensiert werden. Sexualität ist also nicht nur wichtiger Bestandteil einer ehelichen Beziehung, um die Spannung und die emotionale Nähe aufrechtzuerhalten, sondern untrennbar mit dem Vertrauen und der Treue innerhalb einer Beziehung verbunden. Sie ist ausschließlich den Ehepartnern vorbehalten und kann - ohne einen Bruch des Verhältnisses zu provozieren - nicht außerhalb dieser Beziehung stattfinden. Ozark legitimiert Sexualität damit ausschließlich über monogame Partnerschaften und

\footnotetext{
${ }^{34}$ Zwar werden Frauen in Ozark nicht im Sinne eines „,male gaze“ durchgehend als passive, sexuelle bzw. erotisierte Objekte präsentiert werden (vgl. Mulvey 2010: 203 f.). Allerdings stellt die Diegese Männer, allen voran Marty Byrde, in den Mittelpunkt des Geschehens. Männliche Figuren kontrollieren die Handlung und treiben dieselbe voran. Auch Ruth Langmores Rolle als herausragend starker weiblicher Charakter wird durch ihre hierarchische Unterordnung ihrem Vater gegenüber relativiert. Obgleich in Ozark keine bedeutsame bildliche Erotisierung oder Herabsetzung der Frauenrollen erfolgt, so werden sie im Gesamtzusammenhang stets den Männern untergeordnet.
} 
bestärkt - in heterosexuellen Beziehungen - die männliche Dominanz auch auf dieser Ebene.

\subsubsection{Geld}

Scratch. Wampum. Dough. Sugar. Clams. Loot. Bills. Bones. Bread. Bucks. Money. That which seperates the haves from the have-nots. But what is money? [...] Is it simply an agreed-upon unit of exchange for goods and services? $\$ 3,70$ for a gallon of milk? Thirty bucks to cut your grass? Or is it an intangible? Security or happiness. Peace of mind. Let me propose a third option. Money as a measuring device. You see, the hard reality is how much money we accumulate in life is not a function of who's president or the economy or bubbles bursting or bad breaks or bosses. It's about the American work ethic. The one that made us the greatest country on Earth. It's about bucking the media's opinion as to what constitutes a good parent. Deciding to miss the ball game, the play, the concert, because you've resolved to work and invest in your family's future. And taking responsibility for the consequences of those actions. Patience. Frugality. Sacrifice. When you boil it down, what do those three things have in common? Those are choices. Money is not peace of mind. Money's not happiness. Money is, at its essence that measure of a man's choices. (Ozark I/1: 00:00)

Dieser Monolog über das Geld bildet die Einleitung der Serie und ist somit das erste, mit dem die Rezipierenden konfrontiert werden. Tatsächlich ist es kaum verwunderlich, dass eine Serie, deren zentraler Handlungsknoten ein GeldwäscheGeschäft ist, das Geld zum vordergründig zentralen Paradigma der Serie macht - dass de facto die Familie diesen Rang einnimmt, sollte sich bereits herausgestellt haben. Martys Aussage, die sich nur scheinbar an eine rezipierende Instanz richtet, sich aber letztlich als Kund/innengespräch mit einem Ehepaar herausstellt, wird rasch auf ironische Weise konterkariert: Marty sieht sich, direkt in Folge auf seinen Monolog, zum ersten Mal das Video an, das seine Frau beim Ehebruch zeigt. Obgleich er also eine große Menge Geld erwirtschaftet hat und finanziell gut für seine Familie sorgen kann, hat Marty durch seine emotionale Abwesenheit einen Bruch der Familie mitprovoziert. Martys Streben nach Geld mag anfangs im Dienste der Familie gestanden haben. Seine Zustimmung zu den Geldwäschegeschäften jedoch geschieht aus Gier, geht über das lebensnotwendige hinaus und führte letztlich zur desaströsen Lage, in der sich die Byrdes zu Beginn der Serie befinden. Es wird dementsprechend deutlich, dass Reichtum nicht automatisch Glück und Seelenfrieden bedeutet. Als Messinstrument für Lebensentscheidungen im positiven Sinne versagt Geld vollkommen, funktioniert vielmehr im negativen Sinne: Mit dem Anstieg des Geldes mindert sich die emotionale Lebensqualität Martys, es halten neue Sorgen und Nöte Einzug in den Haushalt der Byrdes. „Money's not happiness“ ist - im Gesamtzusammenhang des Formats - wohl 
der zutreffendste Satz in Martys Aussage. Geld ist höchstens ein Maßstab für das finanzielle Geschick eines Menschen. Der von ihm mehrmals beschworene amerikanische Arbeitsethos (vgl. Ozark I/1: 00:00 sowie 32:00) und die Gleichsetzung der Familie mit einem Kleinunternehmen (vgl. Ozark I/2: 00:00) entpuppen sich als Selbstschutzmechanismen: Da Marty auf familiärem Terrain die Kontrolle verloren hat, flüchtet er sich in die ihm vertraute Finanzwelt. Durch nüchternen Geschäftssinn versucht er die emotional belastende Lage zu verarbeiten, auch wenn er Wendy erklärt, sie seien nicht mehr Mann und Frau, sondern Geschäftspartner (vgl. Ozark I/2: 03:00) oder wenn er zu Wendy - in Bezug auf den Verkauf ihres alten Hauses - meint, dass Sentimentalität nur dem Gewinn im Wege stünde (vgl. Ozark I/4: 04:00). Den Kampf, den Marty und seine Familie führen müssen, ist weniger ein Kampf für, sondern ein Kampf gegen das Geld: Die Unmengen von Geld, die Marty und seine Frau mühsam waschen, stehen der Familie antagonistisch gegenüber. Das Geld ist nicht Maßstab von Lebensentscheidungen, sondern Gegenspieler, eine Art negative Macht, die das Schlechte in den Menschen hervorruft. Geld bzw. Geldgier ist der Grund für den Mord Ruth Langmores an ihren Onkeln. Des Geldes wegen werden Bruce Liddell sowie der Fuhrunternehmer und sein Sohn in der ersten Episode erschossen. Camino Del Rio handelt aus reiner Profitgier und selbst die Snells stellen ihren Familienmythos, in Aussicht auf eine große Profitmöglichkeit, hinten an (vgl. Ozark I/10: 51:00). Es lässt sich also kaum ein positiver Effekt des Geldes in Ozark beobachten, dennoch betrachten viele der Charaktere die Mehrung des eigenen Vermögens als Leitmotiv. Positive Gegenmodelle sind sowohl das Gottvertrauen und der Glauben Mason Youngs als auch der Familiensinn, der sich innerhalb der Byrdes und Langmores - mit dem Tod von Russ und Boyd - durchsetzt. Auch wenn Geld und Familie in der Logik der Serie untrennbar miteinander verknüpft sind - nahezu jedes Unternehmen ist ein Familienunternehmen (das Fuhrunternehmen, die Snells, die Dermodys und gewissermaßen die Byrdes) -, so muss doch gemeinschaftlicher Zusammenhalt unabhängig vom Vermögen bestehen bleiben. Überlagert das Streben nach Profit das Bewusstsein für das Wohl der Familie, hat dies unweigerlich negative Konsequenzen. Ist diese paradigmatische Gewichtung der Serie als Kapitalismuskritik zu verstehen? Lediglich partiell, denn das Wirtschaftssystem der USA wird nicht an sich angegriffen. Vielmehr wird demonstriert, dass die übermäßige Gier nach Profit das moralische Bewusstsein eines Menschen überschattet und in die Kriminalität und/oder zur Vernachlässigung bedeutenderer Lebensbereiche führen kann. Wie Marty es formuliert, geht es darum, das Kapital in den Dienst der Familie zu stellen und nicht andersherum. Geld bzw. der Beruf, durch den Geld erwirtschaftet wird, sind stets nur Lebensgrundlage und dürfen 
nie zum Selbstzweck werden. ${ }^{35}$ Solange diese Grenzen eingehalten werden, ist der Kapitalismus an sich unproblematisch - problematisch sind die Versuchungen des Geldes.

\subsubsection{Gewalt}

Durch die Ansiedlung des Formats in einem kriminellen Umfeld ist Gewalt - oft als Resultat der zuvor genannten Geldgier - ein häufig wiederkehrender Bestandteil von Ozark. Del Rios Morde, u. a. an Bruce Liddell und Wendys Liebhaber, und die Gewaltdrohungen, die er gegen die Byrdes ausspricht, Jonahs Todes- und Waffenobsession, Wyatt Langmores Flucht vor den Prügeleien seiner Onkel und deren Ermordung, die Vergiftung Bobby Deans oder die Ermordung Del Rios sind nur einige Beispiele für den omnipräsenten Gewalteinsatz in der Diegese.

Gewalt ist in Ozark nur in sehr eingeschränktem Maße eine praktikable Problemlösungsstrategie: Alle gewaltsamen ,Lösungen ' ziehen unweigerlich schwere, oft noch problematischere Konsequenzen nach sich: Die Ermordung Liddells und der Fuhrunternehmer verschärft den Verdacht des FBI (vgl. Ozark I/2: 35:00). Jonahs Wunsch, die Familie gewaltsam zu verteidigen, bedeutet eher Schwierigkeit als Schutz. Die Prügeleien der Langmores sind fruchtlos und der Mord an Russ und Boyd wird mit hoher Wahrscheinlichkeit nicht ohne Konsequenzen bleiben ebenso wie die Ermordung Del Rios und seiner Handlanger sicherlich nicht folgenlos bleiben und das Kartell nach ihm suchen wird (vgl. Ozark I/10: 58:00). Gewalt ist in der Logik der Serie stets nur eine punktuelle und keine dauerhafte Lösung - sie erzeugt stets Gegengewalt und somit eine Gewaltspirale.

Vor allem bildet Gewalt einen elementaren Bestandteil der Narration. Sie trägt zur Schaffung der düsteren Atmosphäre der Serie bei: Schon ab der ersten Episode wird etabliert, dass es sich nicht um ein Spiel, sondern um eine Welt des schwerwiegenden Verbrechens handelt, in welche die Byrdes hineingeraten. Übertreten sie gewisse Grenzen oder gehen sie zu hohe Risiken ein, droht ihnen und allen anderen Personen in ihrem Umfeld das gleiche todbringende Schicksal. Von außen, aber auch von innen sind die Familien einer Bedrohung ausgesetzt, z. B. Jonahs Verrohung, die Konflikte der Langmores. Diese Bedrohung erzeugt den Druck, der notwendig ist, um die Byrdes wieder zusammenzubringen: Ohne die Gefährdung des eigenen Lebens und des Lebens ihrer Nächsten wäre die Scheidung der Eheleute mehr als wahrscheinlich und ein Auseinanderdriften

\footnotetext{
35 In Martys Falle dient das Geld zudem als Festigung patriarchaler Strukturen: Er verdient den Unterhalt, von dem seine Frau und seine Kinder leben. Mittels des Geldes kann Marty daher seine familiäre Vormachtstellung sichern.
} 
somit vorprogrammiert, der zentrale Dreh- und Angelpunkt der Serie ginge verloren. Die Folgen eines Familienverlustes wären für alle Beteiligen desaströs. Die Gewalt in der Serie dient also dazu, die Bedeutung der Familie zu betonen: Nur die Familie, wenn auch in sich nicht unbedingt funktional, bietet einen Schutzraum vor äußeren Bedrohungen, Rückhalt und Geborgenheit. Der Kampf um den Erhalt der Familie dient als vordringlichstes, sinnstiftendes Ziel.

\subsubsection{Abstraktion einer Raum- und Handlungsstruktur}
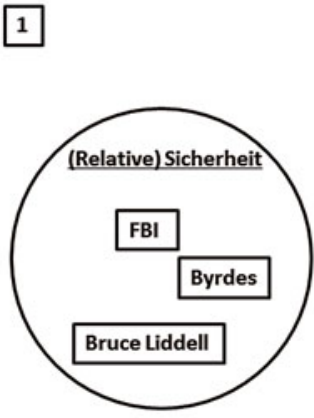

Raummerkmale:

- Routiniertes/Geordnetes Familienleben

- Geregeltes und legales Berufsleben

- Gewaltlosigkeit/Keine bzw. geringe Gefahr physischer Angriffe

- Kultiviertheit

GeordneteVerhältnisse

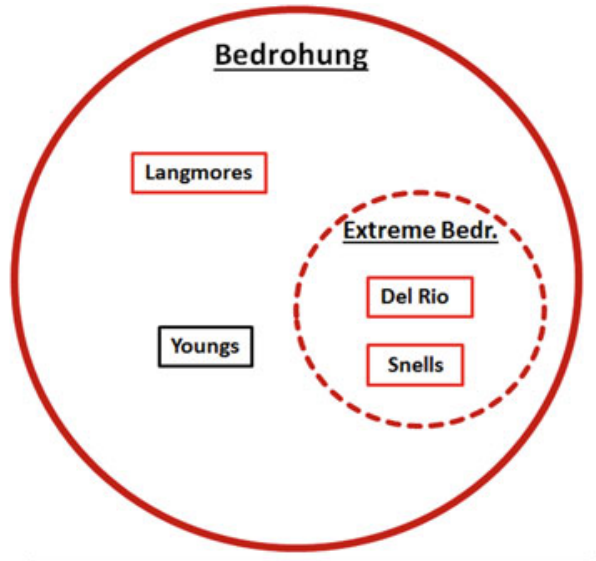

Raummerkmale:

- Zerbrechen familiärerStrukturen/massive familiäre Konflikte

- Kriminelle Geschäfte

- Gewalt und konkrete physische Bedrohung

- Verwahrlosung/Verrohung

Chaotische Verhältnisse

Abb.3.4 Ozark Handlungsschema - Situation 1 (Ausgangssituation)

Die Handlung der Serie ist recht einfach strukturiert und verläuft nach einem Prinzip der sukzessiven Steigerung, welches ich anhand einiger Abbildungen verdeutlichen möchte. Ozark weist eine klare Raumtrennung auf. Dabei steht ein Raum der zumindest relativen Sicherheit einem Raum der Bedrohung gegenüber (vgl. Abb. 3.4). Ersterer bietet Merkmale der Stabilität, d. h. ein routiniertes und 
gesichertes Familienleben ebenso wie ein Berufsleben ohne jede Kriminalität oder die Gefahr physischer Angriffe. Die Figuren, die in diesem Raum beheimatet sind, sind allgemein kultiviert, die Verhältnisse für Marty Byrde und seine Familie sind weitestgehend geordnet. Dieser Ausgangsraum ebenso wie die oben abgebildete Ausgangssituation der Serie sind aber faktisch nicht Teil der Handlung. Selbst im Rückblick in die Vergangenheit der Byrdes und anderer Charaktere in „Kaleidoscope" (vgl. Ozark I/8) wird deutlich, dass die Sicherheit und die Ordnung der Familie bereits länger gefährdet ist: Martys Ehefrau ist wegen eines Mangels an beruflichem Erfolg deprimiert (vgl. Ozark I/8: 04:00), sie verliert ein Kind (vgl. Ozark I/8: 43:00). Marty rutscht in die Welt der Kriminalität ab und wird dort sofort mit brutaler körperlicher Gewalt konfrontiert (vgl. Ozark I/8: 46:00). Die Ordnung des Ausgangsraumes ist demzufolge nie ideal gewesen, sondern war bereits vor Beginn der Handlung brüchig, eine ideale Stabilität bestand u. U. nie. Nichtsdestotrotz ist der Gegenraum, hier mit „Bedrohung“ benannt, wesentlich extremer in seiner Merkmalsausprägung: Hier dominieren Instabilität und Chaos im Gegensatz zu geordneten Verhältnissen. Die Familie Byrde droht zu zerbrechen, Kriminalität herrscht vor und bringt die ständige Gefahr physischer Angriffe mit sich. Zudem sind die Bewohner dieses Raums - repräsentiert vor allem durch die Langmores - unkultiviert und pflegen einen chaotisch-ungeordneten Lebensstil. In diesen Raum der Bedrohung oder auch des Chaos werden die Byrdes im Rahmen einer eigentlichen Grenzüberschreitung versetzt. Diese Grenzüberschreitung wird zum einen durch Wendy Byrdes Ehebruch bedingt, zum anderen durch die Einwilligung Marty Byrdes in die Geldwäschegeschäfte und letztlich durch die Ermordung Liddells als einen Akt absoluter Gewalt (vgl. Abb. 3.5).

Die Räume von Sicherheit und Bedrohung sind topographisch weitgehend entkoppelt, schließlich sind die Byrdes bereits in Chicago der Bedrohung ausgesetzt, auch wenn diese in den Ozarks ihren Höhepunkt findet. Den Extremraum dieses Raumes personifizieren Camino Del Rio und die Snells. Hier verdichtet sich moralische Verkommenheit, bedenkenlose Gewaltanwendung und schwerwiegendes Verbrechen. Auf anderer Ebene ist indes eine Kopplung von Topographie und Topologie durchaus vorhanden. Wie eingangs (vgl. 3.1.1) bereits angesprochen, gelten die Ozarks als allgemein rückständig und antimodern (vgl. Perkins 2017: 2 f.), die Bewohner als Hillbillys (vgl. Harkins 2004: 3). Mit dem Übertritt vom modernen, großstädtischen und fortschrittlichen Raum Chicago in die zumindest qua Klischee - rückständigen Ozarks wird eine topologisch gebundene Kultur-Natur-Opposition errichtet. Geordnete und bekannte Strukturen, kühler, berechnender Verstand und gemäßigte Emotionen, also stereotype Merkmale eines Kultur-Raumes, weichen unüberschaubaren Verhältnissen, ungebremster Emotionalität, Triebhaftigkeit und Gewalt. Dieser Natur-Raum bietet vor allem die 


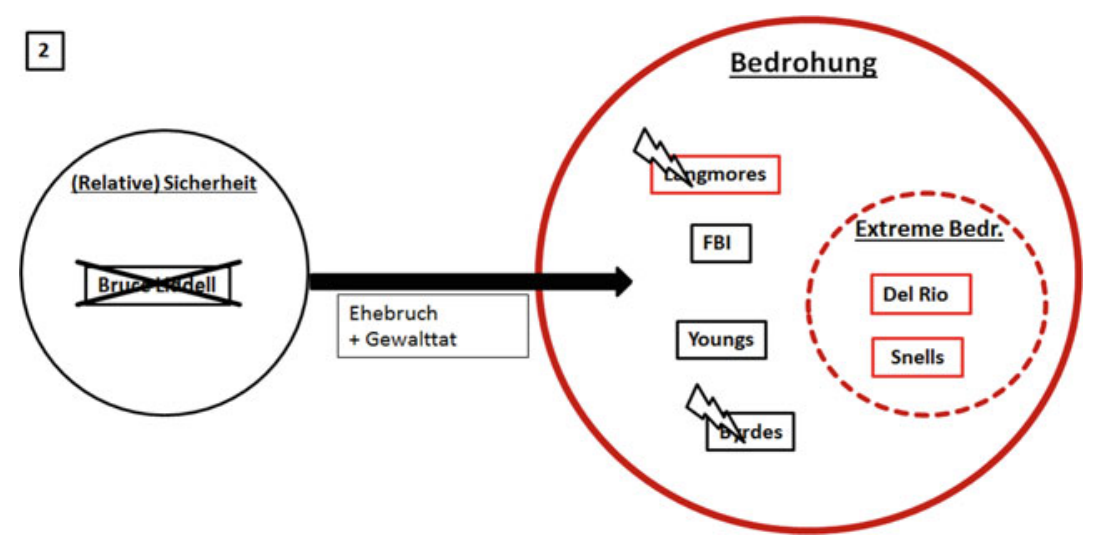

Abb.3.5 Ozark Handlungsschema - Situation 2

Möglichkeit, die Familie als natürlich gegebene Form menschlichen Zusammenlebens zu inszenieren. Erst hier, ohne die klaren Zügel des Kultur-Raumes, können die bisher unterdrückten Emotionen ausgelebt, besagte Strukturen in Frage gestellt und dekonstruiert werden - natürlich nur um letztlich wieder eine Bestätigung zu erfahren.

Spätestens mit dem Umzug in die Ozarks, in diesen chaotischen NaturRaum, beginnt die eigentliche Handlung des Formats. Die Byrdes sind nun in sich gespalten und in ihrer Zusammengehörigkeit gefährdet - und werden hier nur der Einfachheit halber als Gruppe dargestellt. Sie bleiben dennoch in ihren Merkmalen konstant, bewahren also ihre Kultiviertheit, ihren Ordnungsdrang, ihre moralischen Ansprüche und sind wohlhabender als der Durchschnitt der Region. Somit stellen sie einen Störfaktor im Gegenraum dar. Mit ihrem Übertritt provozieren sie eine Reihe an Konflikten, u. a. die zunehmende Spaltung der Langmores. Die Handlung Episode für Episode aufzuschlüsseln wäre wenig zielführend, da ein recht eindeutiges Schema zu abstrahieren ist: Typisch für den narrativen Verlauf einer Serie findet eine sukzessive Steigerung statt.

Zum einen werden die Charaktere immer mehr miteinander verknüpft, so dass zuletzt - zumindest über die Byrdes als Mittler - alle Charaktere in irgendeiner Form von Beziehung zueinander stehen (vgl. Abb. 3.6). ${ }^{36}$ Zum anderen nähern sich die Figuren dem Extremraum an und adaptieren dessen Merkmale.

\footnotetext{
${ }^{36}$ Die Familie Dermody (mehr unter 3.1.2.7) wurde in diesem Schema außen vorgelassen, da sie eine untergeordnete und wenig handlungsrelevante Rolle spielten. Tatsächlich ließen sich
} 


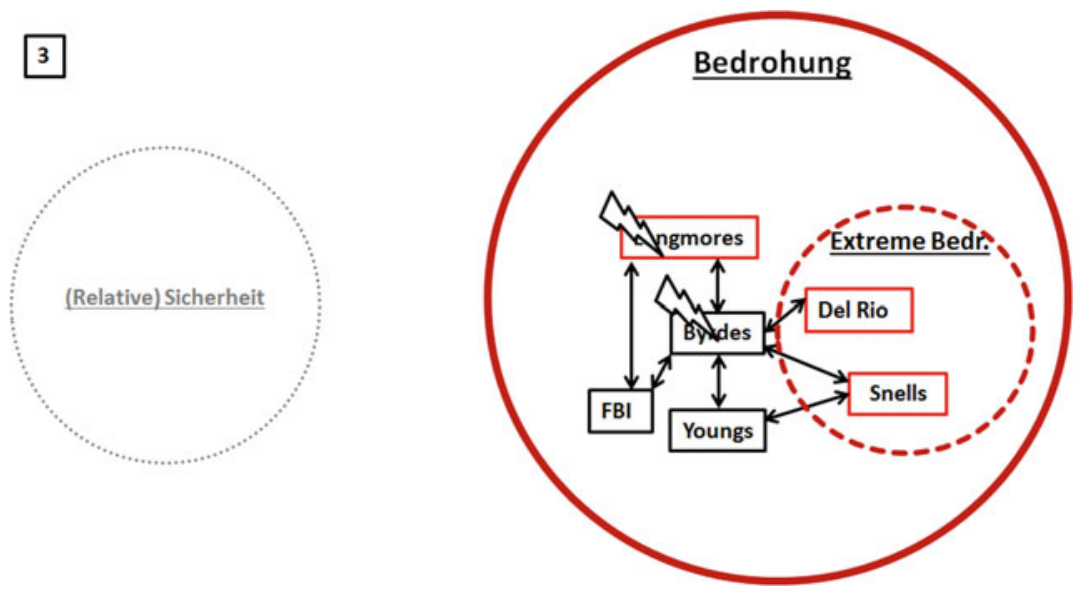

Abb. 3.6 Ozark Handlungsschema - Situation 3

Sie werden mehr und mehr Teil krimineller Machenschaften und amoralischer, gewalttätiger Verstrickungen: Nach einer anfänglichen morbiden Todesfaszination erwirbt Jonah schwere Waffen, das kriminelle Potenzial der Langmores wächst von Diebstahl zu Mordplänen heran und vor allem Marty gerät im Verlauf der Serie zunehmend unter den Einfluss bzw. Druck der Snells.

Höhepunkt und gleichzeitig Auflösung findet die erste Staffel mit dem Ende der neunten und der gesamten letzten Episode. Hier betreten die Byrdes den Extremraum (vgl. Abb. 3.7): Die Familie trennt sich zeitweilig, Marty Byrde sieht sich direkt mit den Snells und Del Rio konfrontiert und auch andere Figuren nähern sie dem Extrem an, z. B. der Mord Ruth Langmores an ihren Onkeln, die Ermordung Grace Youngs, das manipulative Spiel Roy Pettys.

Mit der Ermordung Del Rios und der Langmores relativiert sich die Bedrohung und Marty wird das Verlassen des Extremraums gestattet (vgl. Abb. 3.8). Der Höhepunkt der äußeren Bedrohung ermöglicht es den Familien, wieder zusammen zu finden. Es ist der äußere Druck, der die zerbrechenden Strukturen erneut verdichtet. Obwohl es zum Ende der ersten Staffel nicht zutreffend wäre, im Falle der Byrdes von einem vollständigen Verlust des konstitutiven Merkmals und der Annahme der Merkmale des Gegenraumes zu sprechen, so haben sie sich doch teilweise assimiliert und stellen keine Fremdkörper mehr in ihrem jetzigen Raum

diese Charaktere vollkommen aussparen, ohne bedeutende Änderungen am Handlungsverlauf vornehmen zu müssen. 


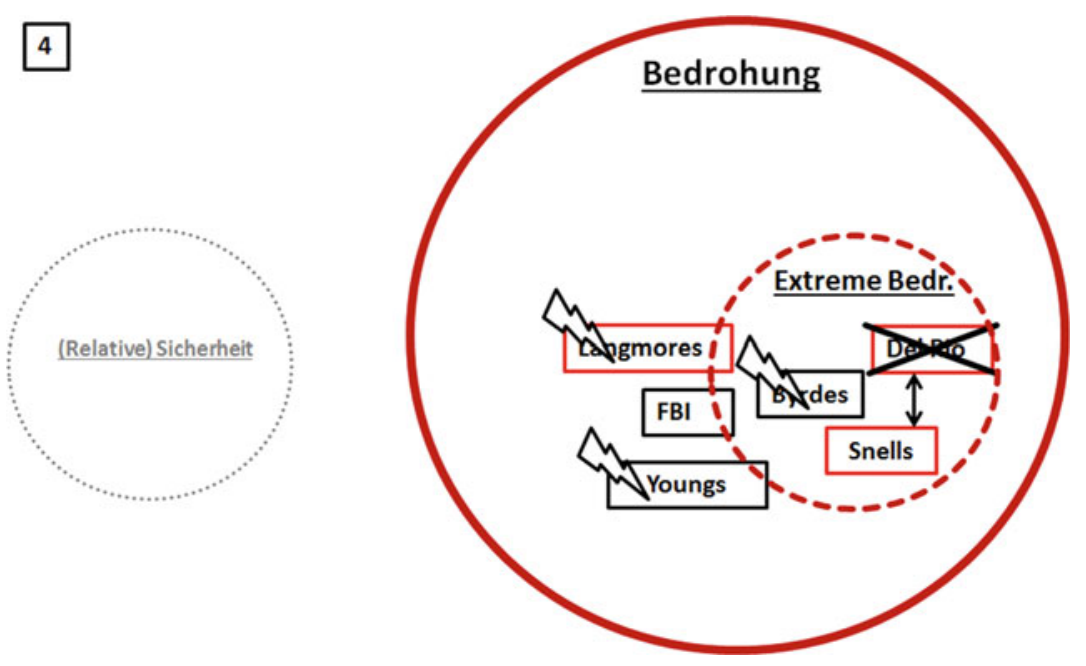

Abb.3.7 Ozark Handlungsschema - Situation 4

dar. Sie sind mit den Regeln und Gegebenheiten vertraut und in sich erneut stark und geschlossen genug, um die Handlung einer neuen Staffel bestreiten zu können. Serientypisch ist die Handlung nur relativ, aber nicht ganz abgeschlossen: Die Byrdes kehren nicht in ihren Ausgangsraum zurück, sind weiterhin mit Bedrohung und Unsicherheit konfrontiert. Die Offenheit der Handlungsfäden und die zahlreichen ungelösten Problematiken ermöglichen es, mit einer zweiten Staffel anzuknüpfen: Finden Marty und Wendy wieder zusammen? Welche Konsequenzen zieht das mexikanische Kartell aus der Ermordung Del Rios? Können die Langmores - trotz Ruths Handeln - als Familie zusammenleben? Zu welchen Mitteln greift der gescheiterte Roy Petty?

In Bezug auf die Familienthematik vermittelt die narrative Struktur ein in der Gesamtschau wenig überraschendes Bild: In doppelter Hinsicht wird die Bedeutung von Familie als einzig glückbringenden und optimal schützenden Raum des menschlichen Zusammenlebens bekräftigt. Zum einen wird deutlich, dass Familien selbst in größten Not- und Bedrohungssituationen aufrechtzuerhalten sind. Jede äußere Bedrohung stärkt den inneren Zusammenhalt. Den Widrigkeiten trotzt man gemeinsam. Außerfamiliäre Fährnisse helfen sogar dabei, sich auf die Bedeutung des schützenden Zusammenhaltes zu besinnen. Zum anderen ist der Natur-Raum der Ozarks ein Terrain, auf dem vermeintlich elementar 


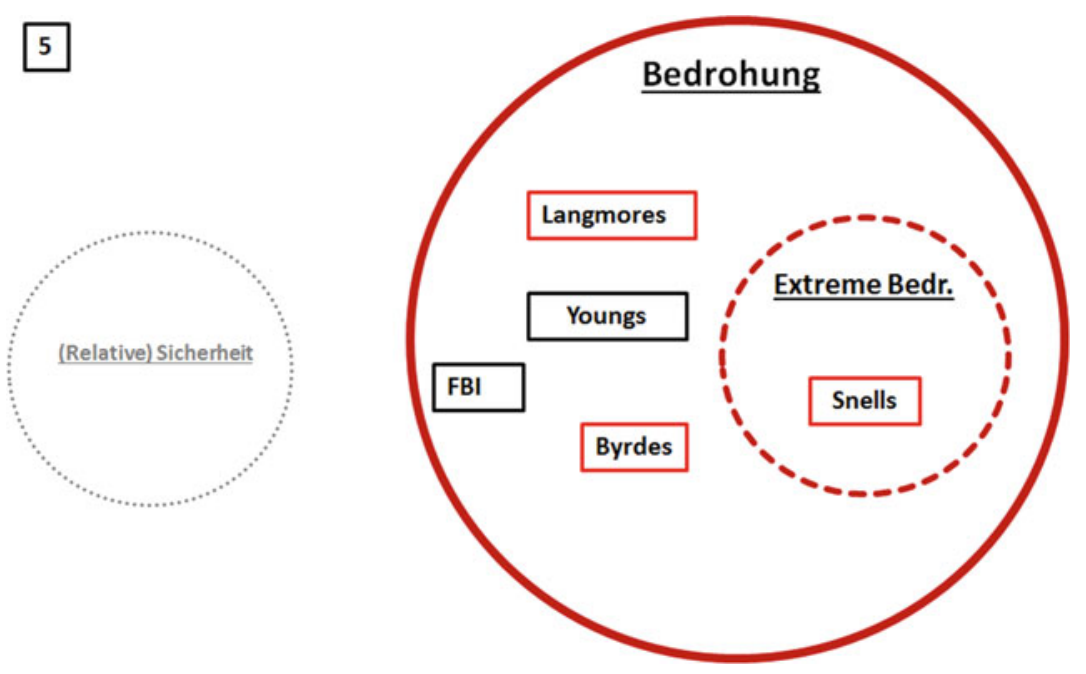

Abb. 3.8 Ozark Handlungsschema - Situation 5 (Endsituation)

anthropologische Lebens- und Verhaltensformen deutlicher zu Tage treten als im reglementierten Kultur-Raum, dem die Byrdes entstammen und dessen Merkmale sie tragen. Kulturell tief verankerte Bilder, wie der Hillbilly und die Ozarks als rückständige Region, dienen der Serie als Ausgangspunkt dieser impliziten Argumentation: Alle Menschen, ungeachtet von Herkunft und soziokulturellem Hintergrund - ob städtisch oder ländlich -, zeigen letztlich ähnliche Verhaltensweisen. Ebenso wie für die Byrdes sind auch für die Langmores und Pastor Young die Ozarks der Ort, an dem sich herausstellt, worauf es , ankommt': Die Familie ist der natürliche Zustand der Koexistenz außerhalb dessen die Einzelnen der Bedrohung hilflos ausgesetzt sind und kaum zu ihren Zielen gelangen. Die Familie wird in Ozark als durch die menschliche Natur diktiertes Dogma inszeniert.

\subsubsection{Resümee zu Ozark: Aufrechterhaltung eines leeren Mythos}

Vergleichen wir die Familienverbände in Ozark, so stellt sich heraus, dass die gesellschaftlich etablierten Grenzen von Klasse, Herkunft, sozialen Umstände etc. 
mehr Schein als Sein sind. Es handelt sich um eine Struktur, um die Lebensumstände der Menschen zu charakterisieren und einschätzen zu können. Der Wesenskern des Menschen, das tatsächliche Sein, ist unabhängig von diesen Konstrukten. Gegensätze innerhalb der Gesellschaft bestehen zwar auf der Oberfläche, keinesfalls ist aber die gesellschaftliche Herkunft mit der moralischen Integrität eines Menschen gleichzusetzen. Familie ist in Ozark der Kern einer jeden erfolgreichen menschlichen Koexistenz, keine gesellschaftlich geschaffene Form, sondern eine anthropologische Determinante.

Dennoch fällt es schwerer, den endgültigen Standpunkt der Serie gegenüber der Familie in seiner kompletten Bandbreite zu ermitteln, als vielleicht anzunehmen wäre. Familiäres Leben bleibt keinesfalls unproblematisch, vielmehr spielen sich die zentralen Konflikte des Formats in und zwischen Familien ab. Der erste Eindruck der Familie Byrde ist von Streit (Streit am Abendbrottisch, vgl. Ozark, I/1: 07:40) und Vertrauensverlust geprägt, von Gräben, die sich im Verlauf der Serie eher vertiefen als schließen. Die Dysfunktionalität der Familie scheint irreparabel. Sukzessive entfremden sich die Byrdes, in Teilen auch die Langmores und die Dermodys voneinander. Das Leben in diesen Verbänden - ein Leben, das in dieser Form nicht selbst gewählt ist - hat etwas Quälendes und Zwanghaftes, schließlich ist es die Hauptquelle der belastendsten Konflikte in ihrer aller Leben. Auch dient die Familie als Stütze und Basis konservativer Hierarchien und Rollenbilder, die - zumindest für die weiblichen Charaktere - eine große Belastung darstellen.

Betrachtet man jedoch die durchgehend erfolglosen Versuche, den familiären Rahmen zu verlassen, und diejenigen Charaktere, die ein glückloses AußenseiterDasein ohne schützende Gemeinschaft führen, verlieren die problematisierten Aspekte und zentralen Konflikte an Schärfe und büßen diese mit der Wiederversöhnung der Byrdes und der Langmores sowie der Trauer Sam Dermodys um seine Mutter nahezu vollkommen ein. Die Charaktere und somit notwendigerweise die Serie, die distanzlos deren Blickwinkel einnimmt, verklären das Geschehene und das Zusammenleben mit den Menschen, die ihnen im Großteil der Narration oft antagonistisch oder zumindest im Streit gegenüberstehen.

Die letzten Momente der ersten Staffel betonen dies überdeutlich: Sie werden von emotionaler klassischer Musik (Beethovens zweites Klavierkonzert) unterlegt. Marty liegt auf dem Trampolin, auf dem er früher mit seinen Kindern spielte. Als er das Auto hört, in dem Wendy, Charlotte und Jonah zurückkehren, öffnet er die Augen, springt vom Trampolin, rennt auf seine Kinder zu und fällt ihnen in die Arme. Über sie hinweg lächelt ihm Wendy zu, er lächelt zurück, beide sind offensichtlich gerührt, Wendy weint eine einzelne Träne. Die Kamera stellt dabei stets die Charaktere - vor allem Marty - in den Mittelpunkt des Bildes. Zuletzt werden 
Martys und Wendys Gesicht in Großaufnahme gezeigt, wodurch ein Fokus auf deren Emotionen gesetzt wird. Diese Versöhnung steht im deutlichen Gegensatz zum Beginn der Serie: Hier wird der erfolglose Ausbruchsversuch Wendys, d. h. ihr Ehebruch, durch den Tod ihres neuen, außerfamiliären Partners sanktioniert (vgl. Ozark I/1: 39:00).

In der Konzeption der Familiendarstellung stellt sich Ozark nicht in die Tradition der Familienserie der 1950er Jahre, welche Dysfunktionalität und tiefgehende Konflikte unberührt lässt. Es wird betont, dass jede Familie eine Familie mit Konflikten ist und es keine idealen Väter, Mütter, Kinder - keine idealen Menschen - gibt. Dennoch verlieren sich die problematisierten Aspekte in Redundanz und verblassen vor der dogmatischen Notwendigkeit des familiären Raumes. Selbst Ruths Ausbruch aus einem Patriarchat dient - durch die Tilgung des destruktiven Potenzials, das von ihren Onkeln ausgeht - dem Erhalt von Familienstrukturen. Ozark erweist sich nach eingehender Analyse als ein Format, das zwar durchaus Problematiken des familiären Lebens aufgreift, dies jedoch nur oberflächlich tut und letztlich stets auf eine konservative Moral verweist. Die ,Beweisführung der Serie ist dabei unzulänglich. Es ist die Frage zu stellen, ob nicht viele der Charaktere letztlich ein glücklicheres und sorgloseres Leben führen könnten, vor allem ein Leben, das ihren Bedürfnissen und Wünschen eher entspräche, wenn sie den familiären Rahmen verließen. Die Darstellung der Familie als unbedingt notwendiger Raum des Rückhalts sowie als Schutzraum vor äußeren Bedrohungen ist eine bloße Behauptung, die aus konstruierten Beispielen gespeist wird. Da ein glückliches Leben ohne Familie in Ozark nicht präsentiert wird, existiert es im vorgestellten Weltentwurf nicht. Eine Sinnsuche auf eigene Faust - als einzelner, individueller Mensch - kann hier nie zielführend sein. Es existieren ausschließlich Negativbeispiele für diesen Lebensstil und für jeden Charakter eröffnet sich lediglich die Wahl, ein einsamer, glückloser Paria oder Teil einer Gemeinschaft zu sein - auch wenn diese Gemeinschaft nicht wirklich vor äußeren Bedrohungen schützt, sondern vor allem weitere Belastungen mit sich bringt. Die Serie hält an einem alternativlosen Dogma fest, ohne dessen Sinn tatsächlich belegen zu können: Familie existiert in Ozark um ihrer selbst willen, ihre Funktionen erfüllt sie zweifelhaft. Ein mythisiertes ${ }^{37}$ Bild von Familie existiert in diesem Format zwar weiter, hat aufgrund eines gesellschaftlichen Wandels die Funktion der Versorgung und des Schutzes von Frau und Kindern jedoch verloren. Dieses Bild

\footnotetext{
${ }^{37}$ Mythen verstehe ich im Sinne von Roland Barthes als ,,von der Geschichte gewählte Rede“ (Barthes 2016: 252), also als (massen-)medial erzeugte „sekundäre konnotative Systeme“, in deren Natur bzw. Intention es liegt, ihren konnotativen und ideologisch aufgeladenen Charakter zu verschleiern und als denotativ, d. h. als natürlich und unwandelbar, gegeben zu erscheinen (vgl. Nöth 2000: 108 f., 411 f.).
} 
von Familie dominiert - wie sich in der folgenden Analyse zeigen wird - die Gesamtheit des Analysekorpus.

\subsection{Familiäre Rollenmuster und Geschlechterkonstruktionen}

Bei der Untersuchung des Gesamtkorpus (über Ozark hinaus) liegt bezüglich der innerfamiliären Rollenverteilung eine Gliederung in männliche und weibliche Rollen nahe. Sowohl an weibliche als auch an männliche Charaktere sind bestimmte Charaktereigenschaften ebenso wie bestimmte Erwartungen gebunden, die eine Kategorisierung ermöglichen. Innerhalb einer Familie kann eine Frau entweder die Rolle der Mutter, Ehefrau oder die der Tochter einnehmen, ein Mann - komplementär dazu - die Rolle des Vaters, Ehemannes oder Sohnes. Hinzu kommen Charaktere, welche außerhalb oder am Rande des in der Serie fokussierten, familiären Verbandes stehen und unterschiedliche Funktionen in Bezug auf diesen einnehmen. Wie sich im Verlauf dieses Kapitels zeigen wird, liegt in der Regel eine deutliche Fokussierung auf eine Kernfamilie vor, so dass Mitglieder der erweiterten Familie, z. B. Großeltern, Tanten, Onkel, Cousins, Cousinen etc., diesem äußeren Familienkreis zuzuordnen sind. Überschreitungen der genannten Rollenmuster treten selten auf und sind dem Bereich homo und vor allem transsexueller Charaktere zuzuordnen. Bei der folgenden Analyse werden nicht ausnahmslos alle Charaktere der Serien des Analysekorpus analysiert, sondern lediglich diejenigen, die innerhalb der Handlung eine besonders relevante Funktion einnehmen, d. h. sämtliche Haupt- und einige relevante Nebencharaktere.

\subsubsection{Darstellung und figurative Konzeption weiblicher Charaktere}

\subsubsection{Mütter und Ehefrauen}

„I mean, women are supposed to be mothers. It's supposed to be natural. It comes with the tits, right? The equipment is pre-installed." (The Marvelous Mrs. Maisel I/3: 35:50). So charakterisiert Miriam Maisel das Rollenbild der Frau in den 1950er Jahren. Übertreibt sie auch bewusst, trifft diese Aussage auch auf Serien zu, die über 50 Jahre später in der Gegenwart spielen. Wendy Byrde (Ozark) mit ihrer deutlichen Bindung an Heim und Herd und ihrer Stellung als Mutter ohne relevanten oder produktiven Bezug zur Arbeitswelt lebt zwar in einer anderen 
Gesellschaft als Miriam Maisel, sieht sich aber nach wie vor mit der formulierten Anforderung konfrontiert.

Aus dem Vergleich der Video-on-Demand-Serien meines Korpus - insbesondere derjenigen, die in der Vergangenheit spielen - mit den medialen Rollendarstellungen der entsprechenden Jahrzehnte lässt sich die Tendenz erkennen, den jeweiligen Zeitgeist kritisch zu reflektieren und zu kommentieren. Der heutige Blickwinkel auf die Vergangenheit ist dabei von gegenwärtigen Norm- und Wertvorstellungen ebenso wie von aktuellem kulturellem Wissen geprägt. Eine Untersuchung dessen, wie die Vergangenheit und ihre gesellschaftlichen Strukturen und Rollenbilder aus aktueller Sicht reflektiert werden, ermöglicht, Aussagen über aktuelle Wertvorstellungen zu treffen. Die Serie The Marvelous Mrs. Mai$\mathrm{sel}$, welche im New York der 1950er Jahre verortet ist, also in der Zeit, in der das dominante Bild der Serien-Familie geprägt wurde, eignet sich hier als analytischer Ausgangspunkt.

Bevor sie vom Ehebruch ihres Ehemannes erfährt, lebt Miriam Maisel das geordnete Leben einer Ehefrau und Mutter der oberen Mittelschicht. ${ }^{38}$ Dass es sich hierbei um eine Fassade handelt, um den Versuch einem vorgeprägten Geschlechterbild zu genügen, wird bereits zu Beginn der Serie in einer Ansprache Miriams auf ihrer Hochzeit deutlich, in der ihre verklärte Erzählung mit den realen Geschehnissen kontrastiert wird, die deutlich weniger glamourös sind. ${ }^{39}$ Penibel achtet sie darauf, eine perfekte Erscheinung zu präsentieren. Ohne dass ihr Ehemann dies bemerkt, unterzieht sie sich, nachdem dieser eingeschlafen ist und bevor dieser aufwacht, einer aufwändigen Kosmetikroutine und legt sich anschließend wieder ins Bett, um den Anschein von äußerer Makellosigkeit zu erwecken (vgl. The Marvelous Mrs. Maisel I/1: 16:05). Zudem misst sie jeden Tag ihre Körpermaße, um sich selbst in ihrer Entwicklung zu überwachen (vgl. The Marvelous Mrs. Maisel I/1: 21:10). All dies verdeutlicht, dass der äußere Anschein von Perfektion ein illusionärer ist, der mühsam aufrechterhalten wird. Diese Illusion, die Miriam Maisel als Teil ihres Lebens verinnerlicht hat - sicherlich auch durch

\footnotetext{
${ }^{38}$ Unterlegt von dem Song „On a wonderful day like today“ (Johnny Mathis) erledigt sie ihre Einkäufe für das anstehende Jom Kippur, überglücklich darüber, dass der Rabbi die häusliche Feier besuchen wird, anschließend wird sie beim Zubereiten eines Bratens in der in hellen Pastellfarben gehaltenen Küche gezeigt (vgl. The Marvelous Mrs. Maisel I/1: 05:41).

${ }^{39}$ So redet sie einerseits davon, dass der Tag perfekt sei, verweist aber zugleich auf die finanziellen Bedenken ihres Vaters. Sie verklärt ihr Studium auf dem „Bryn Mawr“-Frauen-College, gleichzeitig wird sie in ihrer Studienzeit gezeigt, wie sie mit Freundinnen ihr Schamhaar bleicht. Sie romantisiert ihr Aufeinandertreffen mit Joel und erzählt davon, wie er sie in Galerien, Gedichtlesungen und griechische Dramen mitnahm. Tatsächlich besuchten sie weniger intellektuelle Vergnügungen wie eine Burlesque- und eine Comedy-Show. Zudem hatten sie bereits vor der Ehe Sex (vgl. The Marvelous Mrs. Maisel I/1: 0:11-5:09).
} 
die Erziehung der konservativen Mutter ${ }^{40}$ und des ignorant-autoritären Vaters -, zerbricht mit dem Ehebruch ihres Mannes Joel und ihrer anschließenden Trennung. Sie distanziert sich zunehmend von den gesellschaftlichen und familiären Erwartungen, verweigert sich Joels erneuten Annäherungs- und Wiedergutmachungsversuchen (vgl. The Marvelous Mrs. Maisel I/4: 23:50) und beginnt sogar $\mathrm{zu}$ arbeiten, worauf ihre Eltern mit Entsetzen und Ablehnung reagieren (vgl. The Marvelous Mrs. Maisel I/5: 5:00, 29:01). In ihrer Stand-Up-Comedy reflektiert sie die gesellschaftlichen Anforderungen an Frauen:

Why do women have to pretend to be something that they're not? Why do we have to pretend to be stupid when we're not stupid? Why do we have to pretend to be helpless when we're not helpless? Why do we have to pretend to be sorry when we have nothing to be sorry about? Why do we have to pretend to be not hungry when we're hungry? (The Marvelous Mrs. Maisel I/7: 47:48)

Wie Wendy Byrde versucht Miriam Maisel, sich von einer Struktur zu emanzipieren, die als einengend wahrgenommen wird und Frauen auf eine einzige Rolle reduziert, welche nicht ihren tatsächlichen Wünschen oder Fähigkeiten entspricht. Miriams Befreiungsversuch wird im Unterschied zu Wendys Ehebruch allerdings eher positiv bewertet. Einerseits erlaubt der kritische Blick auf die als restriktiv wahrgenommenen Strukturen der 19590er Jahre Miriam, sich denselben zu verweigern, andererseits wird sie durch den Ehebruch ihres Mannes, d. h. dessen destruktiven Akt, dazu legitimiert.

Dennoch suchen ihre Eltern die Schuld am Zerbrechen der Ehe zunächst bei Miriam. Mit einem veritablen Nervenzusammenbruch reagieren sie auf die Nachricht von der Trennung. ${ }^{41}$ Auch in der Gruppierung mit anderen Frauen werden geschiedene Frauen stets ausgegrenzt (vgl. The Marvelous Mrs. Maisel I/2: 7:50). Miriams Entscheidung, einen Beruf zu ergreifen, wird von ihren Eltern ebenso

${ }^{40}$ Diese vollzieht kennzeichnenderweise eine nächtliche Routine, die deckungsgleich mit Miriams ist, einschließlich der Tatsache, dass ihr Ehemann es nicht bemerken soll. Beide Szenen werden mit derselben Musik unterlegt und folgen einem nahezu identischen Ablauf (vgl. The Marvelous Mrs. Maisel I/3: 12:43). Dies unterstreicht, dass die Mutter offensichtlich Verhaltensweisen an ihre Tochter weitergegeben hat. Selbst über das Aussehen von Miriams Tochter im Säuglingsalter macht sie sich Sorgen: „I just want her to be happy. It's easier to be happy when you're pretty.“ (The Marvelous Mrs. Maisel I/1: 19:18).

${ }^{41} \mathrm{Ihr}$ Vater zerstört sein Arbeitszimmer und die Mutter bricht in Tränen aus (vgl. The Marvelous Mrs. Maisel I/1: 37:47). Abraham Weissman, ihr Vater, meint zudem, es sei ihre Schuld, dass sie einen schwachen Mann geheiratet habe (vgl. The Marvelous Mrs. Maisel I/1: 38:32). Ebenso ist Joels Mutter verstört wegen der Trennung (vgl. The Marvelous Mrs. Maisel I/2: 26:08) und Rose Weissman leugnet lange Zeit die Möglichkeit einer Scheidung (vgl. The Marvelous Mrs. Maisel I/7: 25:03). 
mit Unverständnis und Unglauben aufgenommen (vgl. The Marvelous Mrs. Maisel I/5: 29:01). Das gesellschaftliche Ansehen einer Frau ergibt sich im dargestellten Weltmodell aus ihrer Stellung als Hausfrau und Mutter, insbesondere, wenn es sich um Frauen der gehobenen Mittelschicht handelt, welche heute weiterhin von den meisten Serien fokussiert werden.

Wirft man nun einen Blick auf die Repräsentation von Frauen als Ehefrauen und Mütter in Serien, welche die 1970er, 1980er und 1990er abbilden, so fällt eine gewisse Differenz auf. ${ }^{42}$ In meinem Korpus werden die 1970er Jahre in den Serien The Get Down und $F$ is for Family aufgegriffen.

The Get Down zeigt zwei relevante Mutterfiguren der afroamerikanischen Arbeiterklasse und stellt damit im Gesamtkorpus eine Ausnahme dar. Bei Wanda, der Tante des Protagonisten Ezekiel und dessen Ziehmutter nach dem Tod seiner Eltern, handelt es sich um einen Charakter, der vor allem durch seine Funktion als Mutterfigur für die Vermittlung positiver Werte definiert wird. ${ }^{43}$ Die Figur ist dabei eher ein Randcharakter und steht für einen traditionellen Frauentypus, dessen Leben um Häuslichkeit und Mutterschaft kreist. Ähnlich, aber interessanter und in Bezug auf die Diegese relevanter ist Lydia Cruz, die Frau des hochreligiösen und autoritären Pastors Ramon Cruz. Sie verkörpert einen konservativen und devoten Frauentypus, in dessen Lebensmittelpunkt das Hinnehmen der Autorität des Ehemannes steht. ${ }^{44}$ Erst später in der Serie widersetzt sie sich ihrem Ehemann. Dazu wird sie durch die Loslösung ihrer Tochter von der Familie und ihrer Liebe zu Francisco, dem Bruder ihres Ehemannes, der auch Lydias Vater ist, motiviert. Sie erlaubt ihrer Tochter eine Gesangskarriere, riskiert einen offenen Streit mit ihrem Ehemann (vgl. The Get Down I/10: 15:00), gesteht ihm, dass Lydia nicht seine Tochter ist, und entscheidet sich für Francisco (vgl. The Get Down I/10: 39:00). Hier handelt es sich zwar um einen Akt der Emanzipation, der durch den anschließenden Selbstmord ihres Mannes noch weiter hervorgehoben wird (vgl. The Get Down I/10: 47:00). Dieser wird allerdings durch den Umstand geschmälert, dass sie sich von der Autorität eines Mannes in die Autorität eines anderen begibt, auch wenn dieser sie deutlich besser behandelt. Sie emanzipiert

42 Die 1960er Jahre werden in Serien weitgehend ausgespart. Grund hierfür könnte die mediale Nähe zu den 1950er Jahren sein, vor allem wohl aber die problematische politische Lage, die sich nicht als Grundlage für komisch-unterhaltende Formate eignet.

${ }^{43}$ Beispielsweise will Wanda, dass Ezekiel lernt, was es heißt, richtig zu arbeiten (vgl. The Get Down I/3: 4:00), und möchte ihn um jeden Preis vor dem Kontakt mit Drogen bewahren (vgl. The Get Down I/3: 11:00).

${ }^{44}$ Sie leugnet im Gespräch mit ihrer Tochter Lydia, je große Träume gehabt zu haben. Letztlich gibt sie im selben Gespräch zu, dass sie Tierärztin werden wollte (vgl. The Get Down I/2: 15:00). 
sich zwar, um ihrer Funktion als beschützende Mutter gerecht zu werden, gibt den Status der Ehefrau aber nicht auf. Dies wäre ihr als erwerbsloser Frau auch kaum möglich.

F is for Family, eine Zeichentricksitcom, dekonstruiert bzw. entmystifiziert satirisch gesellschaftliche Mythen (vgl. Kelsch 2019: 151 f.). Sue Murphy hat hier unter dem Diktat ihres Ehemannes Frank zu leiden. Ihr Leben ist von ihren häuslichen Pflichten und der Erziehung der Kinder bestimmt. Sie kocht, macht den Haushalt und arbeitet in ihrer freien Zeit als Vertreterin für „Plast-a-Ware“ (die Serienversion von Tupperware). Diese Tätigkeit, die sie als relevanten Teil ihres Lebens sehen möchte, betrachtet ihr Ehemann als „little hobby“ und spricht auch sonst äußerst herablassend davon (vgl. $F$ is for Family I/2: 6:00). Tatsächlich handelt es sich vor allem um einen Versuch, die Eindimensionalität ihres Lebens zu kompensieren, indem sie etwas jenseits des Haushalts tut. Sie versucht, Missstände zu leugnen und sich einzureden, glücklich zu sein (vgl. $F$ is for Family I/2: 22:00), erkennt aber bald ihre tatsächliche Situation: „My life isn't perfect, okay? Outside of being a wife and a mother, I've got nothing! I sell plastic that I cry into! [...] Sometimes I wish I'd never got married!“ (vgl. $F$ is for Family I/3: 17:00). Trotz einer stärkeren beruflichen Einbindung im Verlauf der Serie, unter der die Familie ein wenig leidet (vgl. $F$ is for Family I/5: 3:00), bleibt Sue - auch aufgrund der Widrigkeiten und Geringschätzungen - ihrer Rolle verhaftet. Obgleich ihr Leben von Verzweiflung und Depression bestimmt ist, scheint eine Loslösung von ihrem Ehemann aufgrund emotionaler und finanzieller Abhängigkeit nicht möglich - u. U. auch aufgrund der narrativen Zwänge des Sitcom Formats, die eine gleichbleibende Personenkonstellation diktieren. Letztlich entschließt sich Sue, beruflich aktiver zu werden, und befreit sich zumindest teilweise aus ihrer Einengung.

The Get Down und $F$ is for Family porträtieren die 1970er Jahre als ein Jahrzehnt, in dem väterliche Autorität und die Verhaftung der Frau in ihrer Rolle als Hausfrau und Mutter dominieren. Nichtsdestotrotz zeigen sowohl Lydia Cruz als auch Sue Murphy Tendenzen zu einer Loslösung: Lydia, indem sie ihren Ehemann verlässt und sich seiner Autorität aus eigenem Antrieb wiedersetzt, und Sue, indem sie beruflich aktiver wird und damit zugunsten einer gewissen Selbstverwirklichung die Familie zurückstellt.

Ähnlich verhält es sich in den modellierten 1980er Jahren in der Serie Red Oaks. Wie Wendy Byrde oder Sue Murphy fühlt sich Judy Myers, Ehefrau von Sam Myers und Mutter des Protagonisten David, von ihrem Alltag vollkommen eingeengt. Die frühe Ehe, die vor allem aufgrund ihrer Schwangerschaft zustande kam, und die damit einhergehenden häuslichen Aufgaben verhinderten eine experimentelle Phase des Abenteuers und der Selbstfindung (vgl. Red Oaks I/4: 9:00). 
Das Resultat ist ein Gefühl der Nicht-Existenz bzw. einer charakterlichen Irrelevanz: „I feel invisible, like I barely exist, except as this person who cooks and cleans and picks up after them." (Red Oaks I/7: 10:26). Trotz der Befürchtungen bezüglich ihrer finanziellen Eigenständigkeit (vgl. Red Oaks I/7: 12:46) entschließt sie sich zur Scheidung und strebt eine Karriere als Immobilienmaklerin an (vgl. Red Oaks I/3: 3:10). ${ }^{45}$ Bei dieser Scheidung handelt es sich um einen als mutig dargestellten Akt der Selbstüberwindung und der Überwindung gesellschaftlicher Anforderungen, die - in der Logik der Serie - der Vergangenheit angehören und eine Selbstfindung verhinderten. Im Gegensatz zur Scheidung Miriam Maisels bedeutet die Scheidung von Judy und Sam keinen besonderen Verlust gesellschaftlichen Ansehens und ist im Vergleich zu Sue und Lydia als Figuren der modellierten 1970er auch eine positive Option, die von einem weiblichen Charakter gewählt werden kann - auch ohne Hilfestellung anderer männlicher Charaktere.

In den 1990er Jahren spielend, zeigt Everything Sucks! die alleinerziehende, berufstätige Mutter Sherry O'Neil als eigenständigen Charakter, der ohne Ehemann den Herausforderungen des Lebens gewachsen ist. Auch sie wurde - wie Judy Myers - früh schwanger und zudem von ihrem als infantil und verantwortungslos dargestellten Ehemann verlassen, als ihr Sohn Luke sieben Jahre alt war (vgl. Everything Sucks! I/1: 15, I/2: 3:00). Dennoch gelingt es ihr, den Sohn liebevoll $\mathrm{zu}$ versorgen und den Haushalt zu führen. Ihre Mutterrolle ist ihr dabei sehr wichtig $^{46}$, sie verliert allerdings nie ihre Unternehmungslust oder ihre Persönlichkeit. ${ }^{47}$ Auch wenn sie letztlich die Beziehung zum Schuldirektor Ken Messner sucht und damit der Versuch einer Wiederherstellung, vollständiger' familiärer Verhältnisse angedeutet wird, wird sie nicht allein über die Suche nach einer Beziehung definiert. Ein eigenständiges Leben als alleinerziehende Mutter ist offensichtlich möglich.

\footnotetext{
45 Zudem wird eine eigentliche Homo- oder Bisexualität Judys angedeutet, die ihre Einengung in der Ehe weiter unterstreicht (vgl. Red Oaks I/1: 1:59).

${ }^{46}$ Sie ist bei einem Gespräch mit dem Direktor besorgt, die Beziehung zu ihrem Sohn und den Blick darauf, wie er sich entwickelt zu verlieren (vgl. Everything Sucks! I/3: 10:00). Allgemein besteht zwischen beiden ein enges Vertrauensverhältnis - sie sieht sich und ihren Sohn als „Team“ (vgl. Everything Sucks! I/3: 16:00).

${ }^{47}$ Sie raucht auf einem Date mit dem Schuldirektor ihres Sohnes konfisziertes Marihuana (vgl. Everything Sucks! I/6: 6:00), plündert mit ihm den Snackautomaten der Schule (vgl. Everything Sucks! I/1: 10:00) und geht mit ihm im Pool der Schule schwimmen (vgl. Everything Sucks! I/6: 14:00).
} 
Nun ist bei der Reflexion der medialen Darstellung vergangener Jahrzehnte, zumindest in den hier untersuchten Einzelbeispielen, eine Liberalisierungstendenz feststellbar. Zieht man die allgemeine gesellschaftliche Entwicklung seit den 1950er Jahren in Betracht, ist dies wenig überraschend. Es läge der Schluss nahe, dass sich - unter Fortführung der liberalen Tendenzen - patriarchale Strukturen in Serien mittlerweile weiter aufgelöst haben und die Autonomie der Frau zur Selbstverwirklichung fern von Rollenzwängen gestiegen sei. Dies ist nur teilweise der Fall. Selbst die TV-Frauen in Szenarien in der Gegenwart, z. B. Wendy Byrde, sehen sich mit ähnlichen Problemen konfrontiert wie Miriam Maisel, Lydia Cruz, Sue Murphy oder Judy Myers. Elsa Gardner aus Atypical ist ebenfalls vollkommen von ihren häuslichen Tätigkeiten eingenommen. ${ }^{48}$ Dass ihr Sohn Sam Autist ist und damit besonderer Aufmerksamkeit bedarf, trägt zu ihrer Selbstdefinition über die Mutterschaft besonders bei. Überbesorgt und sehr beschützend versucht sie über dessen Leben zu verfügen. ${ }^{49}$ Als die Notwendigkeit dieser Fürsorge aufgrund der Adoleszenz ihres Sohnes abnimmt, sieht sie sich sukzessive mit der Inhaltsleere ihres Lebens jenseits ihrer Mutterschaft konfrontiert. ${ }^{50}$ Sie unternimmt einen Ausbruchsversuch aus den festgefahrenen Strukturen, indem sie eine sexuelle Affäre beginnt (vgl. Atypical I/3: 27:00). Obwohl Sam besondere Fürsorge benötigt, hat Elsas Selbstdefinition als Mutter also überhandgenommen. Selbst ihr Ehemann Doug zweifelt daran, ob sie noch eine Persönlichkeit jenseits der Mutterschaft habe (vgl. Atypical I/5: 27:00). Die Affäre wird im späteren Verlauf der Serie eindeutig negativ bewertet, da sie die Stabilität der Familie in Gefahr bringt, auf die Sam nach wie vor angewiesen ist. ${ }^{51}$

Die Serien des Korpus bilden keine Ausnahme darin, dass weibliche Seriencharaktere, die keine Kinder haben, sich vornehmlich über eine Berufung zur Mutterschaft definieren. Diese bringt dabei die Notwendigkeit einer Aufopferung

\footnotetext{
${ }^{48}$ In der Szene, in der sie als Charakter eingeführt wird, stellt sie das Essen für die Familie auf den Tisch, erzählt davon, wie sie Kleidung für ihren autistischen Sohn Sam eingekauft hat, und fragt ihren Sohn nach seinem Tagesverlauf (vgl. Atypical I/1: 2:00).

${ }^{49}$ Sie fordert Sams Therapeutin Julia dazu auf, Sam nicht mehr dazu anzuregen, eine Freundin zu finden, da er noch nicht bereit dafür sei (vgl. Atypical I/1: 9:00).

${ }^{50}$ Als sie - mehr durch Zufall - mit Bekannten in eine Bar geht, um dort einen Drink zu nehmen, nimmt sie dies als Flucht aus ihrem, wahren Leben' wahr, nur um anschließend - gegenüber dem Barkeeper - rasch zu beteuern, dass sie ihr Leben liebe (vgl. Atypical I/1: 26:00). Bei einem Treffen in einer Selbsthilfegruppe für Eltern mit autistischen Kindern stellt sie fest, dass sie sich beim Flirten mit dem Barkeeper zum ersten Mal seit langer Zeit sorgenfrei gefühlt hat (vgl. Atypical I/2: 6:00).

${ }^{51}$ Elsa entfremdet sich von ihrem Ehemann, kann seine Liebe nicht mehr erwidern (vgl. Atypical I/6: 27:00) und lügt ihn bezüglich ihrer Gefühle an (vgl. Atypical I/7: 16:00).
} 
für die Kinder mit sich, die bis zum Selbstverlust führt. ${ }^{52}$ Die Rolle der Mutter dominiert dabei deutlich die Rolle der Ehefrau: Eine Mutter ist zunächst diejenige, die ihren Kindern Wärme und Fürsorge zuteilwerden lässt. Unter diesem Aspekt erledigt sie auch den Haushalt. Die Rolle als Ehefrau, auch in dem Sinne, dass sie sich der Autorität der Eltern oder des Ehemannes zu fügen hat, verliert an Relevanz. Ebenso ist es weniger der gesellschaftliche Druck, der die Mutter zu dieser Aufopferung verpflichtet - auch wenn dieser nach wie vor besteht ${ }^{53}$-, sondern vielmehr eine Art natürliche Veranlagung der Frau. Die weibliche Selbstdefinition als Mutter ist also integrales Merkmal weiblicher Charaktere, die innerhalb eines Familienverhältnisses verortet sind.

Diesen ,natürlichen Drang' versuchen auch Frauen zu erfüllen, die kinderlos sind, sich aber in einer Ehe oder eheähnlichen Beziehung befinden. ${ }^{54}$ Problematisch ist dies, wenn Frauen auf biologischem Wege keine Kinder bekommen

\footnotetext{
${ }^{52}$ So opfert sich die Mutter Victoria Hayward aus der Anthologie-Serie The Romanoffs für ihren schwer erkrankten Sohn auf und stellt dabei jedes Verlangen nach individueller Erfüllung, z. B. durch eine Liebesbeziehung, zurück. Beispielsweise stellt sie sich der Forderung ihres Ehemannes entgegen, die kostspieligen, aber fruchtlosen Behandlungen ihres Sohnes nicht fortzuführen (vgl. The Romanoffs I/6: 44:00), und macht sich Vorwürfe, dass sie ihrem Sohn nicht genug Zeit schenkt, obwohl sie ihr Leben nach ihm ausrichtet (vgl. The Romanoffs I/6: 1:11:00). Ebenfalls in The Romanoffs lebt Anastasia La Charnay, eine ältere Dame, vollkommen in der Vergangenheit, da sie vom Verlust ihres Sohnes stark gezeichnet wurde (vgl. The Romanoffs I/1: 23:15, 46:30, 47:02), und findet erst Frieden mit sich selbst, als sich ankündigt, dass ihre Familienlinie - durch ein Kind ihres Neffen - nicht enden wird und sie somit - auch wenn dies lediglich impliziert wird - die Rolle einer Großmutter einnehmen kann (vgl. The Romanoffs I/1: 1:21:04). Diese Freude empfindet sie, obwohl das Kind von ihrer muslimischen Haushälterin stammt, die sie zuvor aus rassistischen Bedenken ablehnte. Sie verkörpert somit den Typus der verbitterten Witwe, deren ,Panzer` durch eine Wiederherstellung eines familiären Gefüges durchbrochen wird.

${ }^{53}$ So ist Shelly Pfefferman in Transparent in der Regel weniger um ihre Kinder bemüht als um das Aufrechterhalten einer gesellschaftlich akzeptablen Fassade: Als ihr seniler zweiter Ehemann verschwindet, sorgt sie sich vor allem darum, dass die Leute darüber reden werden (vgl. Transparent I/5: 3:42). Zudem versucht sie ihren promiskuitiven Sohn Joshua mit einer Rabbinerin zu verkuppeln, um der gesellschaftlichen Norm gerecht zu werden (vgl. Transparent I/5: 15:00). Innerfamiliär handelt es sich um einen relativ liberalen Charakter, für den Rollenbilder und angemessenes Verhalten eine eher geringe Bedeutung haben. Dies gilt allerdings nur, solange der äußere Schein gewahrt bleibt.

${ }^{54}$ Der Charakter Ondine aus The Romanoffs ermordet - so impliziert es die Handlung der Episode - die Ehefrau des wohlhabenden George Burrows, in den sie entweder verliebt ist oder ihn schlicht als Ehemann gewinnen will. Sie zielt vermutlich auch darauf ab, dessen Sohn Simon zu ermorden, was misslingt. Anschließend heiratet sie Burrows, setzt ein eigenes Kind in die Welt und drängt Simon aus der Familie. Ihr Name rückt sie in die Nähe von Undinen, d. h. teils verführerischen, schwer fassbaren Sirenengestalten der europäischen Sagenliteratur, und charakterisiert sie als negative Gestalt, als Typus verführerischer Weiblichkeit.
} 
können. Anka Garner (The Romanoffs) definiert sich zentral über ihren Wunsch Mutter zu sein und verzweifelt an ihrer mangelnden Befähigung dazu (vgl. The Romanoffs I/7: 58:20). Frances Bergstein bzw. Frankie aus Grace and Frankie nimmt es als persönlichen Makel wahr, dass sie nie biologische Mutter sein konnte und ihre Söhne adoptieren ,musste' (vgl. Grace and Frankie I/10: 14:00). ${ }^{55}$ Kennzeichnenderweise wird die Geburt eines Kindes in derselben Episode als unproblematischer, klinisch sauberer Akt dargestellt (vgl. Grace and Frankie I/10: 18:00). Auch wenn dies mit dem unterhaltsamen und seichten Charakter der Serie in Verbindung steht, legt diese Darstellungsweise den Grundstein für eine allgemeine Marginalisierung belastender Aspekte der Mutterschaft.

Dass die Rolle der Mutter eine exklusive Aufopferung verlangt, zeigt sich bereits an der Tatsache, welche beruflichen Tätigkeiten die Figuren in den untersuchten Serien ausüben:

\section{Berufliche Einbindung von Müttern/Ehefrauen}

\begin{tabular}{l|l|l}
\hline Serie & Charakter & Beruf \\
\hline XXX 1. Atypical & Elsa Gardner & $\begin{array}{l}\text { Keine berufliche Tätigkeit } \\
\text { (Friseurin) }\end{array}$ \\
\hline 2. Everything Sucks! & Sherry O'Neil & Stewardess \\
\hline 3. F is for Family & Sue Murphy & $\begin{array}{l}\text { Zunächst } \\
\text { Tupperware-Vertreterin als } \\
\text { Nebenbeschäftigung, später } \\
\text { Vollzeit-Job }\end{array}$ \\
\hline 4. Grace and Frankie & Grace Hanson & $\begin{array}{l}\text { Leiterin eines } \\
\text { Kosmetik-Unternehmens }\end{array}$ \\
\hline 5. Grace and Frankie & $\begin{array}{l}\text { Frances ,Frankie“ } \\
\text { Bergstein }\end{array}$ & $\begin{array}{l}\text { Kunstlehrerin als } \\
\text { Nebenbeschäftigung }\end{array}$ \\
\hline XXX 6. Ozark & Wendy Byrde & Keine berufliche Tätigkeit \\
\hline XXX 7. Red Oaks & Judy Myers & Keine berufliche Tätigkeit \\
\hline XXX 8. Red Oaks & Fay Getty & Keine berufliche Tätigkeit \\
\hline XXX 9. The Get Down & Lydia Cruz & Keine berufliche Tätigkeit \\
\hline XXX 10. The Get Down & Wanda & Keine berufliche Tätigkeit \\
\hline 11. The Marvelous Mrs. & Miriam Maisel & $\begin{array}{l}\text { Zunächst kein Beruf, nach } \\
\text { Trennung von ihrem } \\
\text { Ehemann Kosmetikerin }\end{array}$ \\
\hline
\end{tabular}

${ }^{55}$ Dementsprechend zeigt sie sich begeistert von der Schwangerschaft anderer Frauen (vgl. Grace and Frankie I/10: 4:00) und leidet darunter, als Grace ihr sagt, dass sie von ihr nie als Mutter wahrgenommen wurde (vgl. Grace and Frankie I/10: 17:00). 


\begin{tabular}{|c|c|c|}
\hline \multicolumn{3}{|c|}{ Berufliche Einbindung von Müttern/Ehefrauen } \\
\hline Serie & Charakter & Beruf \\
\hline $\begin{array}{l}\text { XXX 12. The Marvelous Mrs. } \\
\text { Maisel }\end{array}$ & Rose Weissman & Keine berufliche Tätigkeit \\
\hline $\begin{array}{l}\text { 13. The Marvelous Mrs. } \\
\text { Maisel }\end{array}$ & Shirley Maisel & $\begin{array}{l}\text { Buchhalterin ihres } \\
\text { Ehemannes (eher aus } \\
\text { Duldung) }\end{array}$ \\
\hline 14. The Ranch & Maggie Bennett & Barfrau \\
\hline XXX 15. The Romanoffs I/1 & $\begin{array}{l}\text { Anastasia „Anushka“ La } \\
\text { Charnay }\end{array}$ & Keine berufliche Tätigkeit \\
\hline XXX 16. The Romanoffs I/2 & Shelly Romanoff & $\begin{array}{l}\text { Unklar/Keine berufliche } \\
\text { Tätigkeit }\end{array}$ \\
\hline 17. The Romanoffs I/4 & Julia Wells & $\begin{array}{l}\text { Arbeit in einem Heim für } \\
\text { Obdachlose (eher als } \\
\text { Nebenbeschäftigung) }\end{array}$ \\
\hline 18. The Romanoffs I/5 & Katherine Ford & Literaturprofessorin \\
\hline XXX 19. The Romanoffs I/6 & Victoria Hayward & Keine berufliche Tätigkeit \\
\hline XXX 20. The Romanoffs I/7 & Anka Garner & $\begin{array}{l}\text { Unklar/Keine berufliche } \\
\text { Tätigkeit }\end{array}$ \\
\hline XXX 21. The Romanoffs I/8 & Ondine & Keine berufliche Tätigkeit \\
\hline XXX 22. Transparent & $\begin{array}{l}\text { Shelly Pfefferman, geb. } \\
\text { Lipkind }\end{array}$ & Keine berufliche Tätigkeit \\
\hline
\end{tabular}

Von den 22 hier untersuchten Müttern und Ehefrauen üben 13 (ca. $60 \%$ ) keinen Beruf aus oder werden intradiegetisch zumindest nicht mit einer beruflichen Tätigkeit verknüpft (mit $\mathbf{X X X}$ gekennzeichnete Felder). Sechs von ihnen haben Berufe, die einer ehrenamtlichen Beschäftigung bzw. einem Hobby gleichen und keine finanzielle Relevanz haben (Sue Murphy, Frances Bergstein, Shirley Maisel und Julia Wells). ${ }^{56}$ Allein Sue Murphy und Miriam Maisel ergreifen erst im weiteren Serienverlauf als Akt der Emanzipation einen Beruf. Die weiteren Charaktere haben deutlich weiblich konnotierte Berufe: Sherry O'Neil ist Stewardess, Grace Hanson Leiterin eines Kosmetik-Unternehmens. Damit hat sie zwar unter den untersuchten weiblichen Charakteren die einflussreichste berufliche Stellung, bleibt aber mit Weiblichkeit und Ästhetik verknüpft. Julia Wells übt den Beruf einer College-Professorin für russische Literatur aus - ein Beruf, der nur am Rande thematisiert wird und wenn nicht mit Weiblichkeit, so doch mit Ästhetik

\footnotetext{
${ }^{56}$ Elsa Gardners Tätigkeit als Friseurin kann nicht als aktiver Beruf bezeichnet werden und tritt eher in einem privaten Rahmen zu Tage.
} 
und Feingefühl verknüpft ist. Es ist dabei zusätzlich von Relevanz, inwiefern eine Frau - im Vergleich zum Ehemann - in ihrem beruflichen Umfeld bzw. bei der Ausübung ihrer Tätigkeit gezeigt wird oder wie oft deren Tätigkeit thematisiert wird. Das häusliche Umfeld dominiert hier eindeutig.

Maggie Bennett (The Ranch) stellt als Barbesitzerin, einem an sich männlich konnotierten Beruf, eine Ausnahme dar. Diesen Beruf hat sie nach der Trennung von ihrem Ehemann ergriffen. Sie ist deutlich wärmer und fürsorglicher als ihr Ehemann. Da ihre erwachsenen Söhne diese Fürsorge nicht mehr benötigen, kann sie ohne Weiteres berufstätig sein. Allgemein wird sie zwar als starker und eigenständiger Charakter dargestellt, während ihrer Ehe litt sie allerdings, wie zahlreiche andere Serien-Ehefrauen, unter der Ignoranz und Arbeitsfixierung ihres Ehemannes (vgl. The Ranch I/4: 18:00). Die Verweigerung, eine erneute Beziehung zu Beau einzugehen (vgl. The Ranch I/7: 25:00), stellt also ebenso wie ihr Beruf eine Emanzipation von einengenden ehelichen Strukturen dar. Damit ist sie mit Sue Murphy oder Miriam Maisel vergleichbar.

Die einzige Mutter und Ehefrau des Korpus, die eigenständig und in einem relevanten Ausmaß berufstätig ist, ist Grace Hanson, die dementsprechend als erfolgreiche Karrierefrau präsentiert wird. Die starke Bindung an die Karriere wird teilweise negativ konnotiert, da sie in der Vergangenheit die Zeit für die Familie und für ihre Rolle als Mutter deutlich reduzierte. ${ }^{57}$ Die Konsequenz ist ein distanziertes Verhältnis zu ihrem Ehemann und eine tendenziell autoritäre Haltung gegenüber ihren Töchtern. Dieses Verhältnis wird mit dem weniger strukturierten, engen und antiautoritären Familiengefüge der Bergsteins kontrastiert, der Familie von Graces Freundin Frankie. Grace verkörpert gesellschaftliche Konventionen, Frankie natürliche und esoterisch-spirituelle Aspekte. ${ }^{58}$ Die Gegenüberstellung beider Lebensstile und deren Konsequenzen ist ein Schlüssel zum Verständnis der Erwartungen, die an Serien-Ehefrauen gestellt werden: Zwar haben beide Ehefrauen einen Nachkommen, der gesellschaftlichen Erwartungen entspricht, doch

\footnotetext{
${ }^{57}$ So arbeitet sie in einer Rückblende am kompletten Labor-Day-Wochenende und verpasst somit fast die Geburt ihrer Enkelin (vgl. Grace and Frankie I/10: 2:00).

${ }^{58}$ Grace achtet penibel auf ihr Äußeres, das stets adrett und betont weiblich ist (vgl. Grace and Frankie I/1: 1:00). Ihr Haus ist elegant und steril (vgl. Grace and Frankie I/1:10). Ihre Probleme verdrängt sie durch den Konsum von Alkohol (vgl. Grace and Frankie I/1: 5:00, I/8: 16:00) und Beruhigungsmitteln (vgl. Grace and Frankie I/1: 13:00, I/10: 2:00). Sie bemüht sich um jeden Preis eine gesellschaftlich akzeptable Fassade aufrechtzuerhalten. Im Gegensatz dazu steht Frankie mit einem spirituell-esoterischen Gebaren (vgl. Grace and Frankie I/1: 19:00) und allgemein alternativem Auftreten, das sie in die Nähe der Hippie-Szene stellt. Ihr Haus ist eher offen, hell, von zahlreichen Pflanzen umgeben und in Holz- und Erdtönen gehalten (vgl. Grace and Frankie I/1: 9:00). Grace and Frankie stellt also Klischees klassischer Bürgerlichkeit den Klischees eines alternativen Lebensstils gegenüber.
} 
haben beide auch negative Charaktereigenschaften an ihre Kinder weitergegeben: Graces Tochter Brianna lebt vor allem für ihren Beruf, sie leitet das Unternehmen ihrer Mutter, hält nur oberflächlich Kontakt mit ihrer Mutter (vgl. Grace and Frankie I/2: 13:00) und bemüht sich schon länger erfolglos um eine Beziehung (vgl. Grace and Frankie I/1: 11:00). Frankies Sohn Coyote hatte in der Vergangenheit ein Drogenproblem (vgl. Grace and Frankie I/1: 10:00, I/12: 19:00) und ist nicht im Stande ein geregeltes Leben zu führen. Während Grace also ihren familienfernen Karrierismus und das kühle Verhältnis zum Familiären an Brianna weitergegeben hat, vererbte Frankie ihren Hang zu Strukturlosigkeit und einem ungeregelten Lebensstil. Weder die strikte Einhaltung von Normen und die Bindung an beruflichen Erfolg noch eine vollkommene Abkehr von Konventionen werden also positiv bewertet. Um eine erfolgreiche Mutter und Ehefrau zu sein, um dem Ehemann und vor allem den Kindern zu genügen, muss ebenso menschliche Wärme und ein Wille zur Selbstverwirklichung wie Disziplin und gesellschaftliches Bewusstsein vorhanden sein. Das Ziel ist eine Balance. Keiner dieser Aspekte darf überhandnehmen, da sonst ein ,glückliches' Leben nicht mehr gegeben ist. Hinzu kommt die unbedingte Notwendigkeit zur Paarbindung. Sobald Grace und Frankie sich von ihren Ehemännern getrennt haben, noch vor der eigentlichen Scheidung, beginnen sie mit der Suche nach einem neuen Partner, versuchen also familiäre Strukturen wiederherzustellen.

Nach dieser umfassenden Auswertung der Rollen der Ehefrauen und Mütter in meinem Analysekorpus lassen sich deutliche Gemeinsamkeiten der einzelnen Charaktere ableiten. Zunächst ist bezüglich der beruflichen Beschäftigungsverhältnisse der einzelnen Charaktere eine deutliche Diskrepanz zur Realität festzustellen. Klammert man Serien aus, die nicht in einem Äquivalent der Gegenwart spielen, gehen 61,54\% (8 von 13) der Frauen im Analysekorpus keiner Beschäftigung nach. 15,38 \% (2 von 13) gehen einem Beruf ohne finanzielle Relevanz nach. Nur 23,08 \% (3 von 13) der Frauen arbeiten tatsächlich, während im realen Jahr 2018 54,9 \% der US-amerikanischen Frauen erwerbstätig waren (vgl. Statista 2019 II). Selbst die Werktätigkeit von Maggie Bennett (The Ranch), Grace Hanson (Grace and Frankie) und Katherine Ford (The Romanoffs) ist zu relativieren, da Maggie Bennetts Söhne nicht mehr auf ihre mütterliche Fürsorge angewiesen sind, Grace Hanson einerseits in einem weiblich konnotierten Bereich (Kosmetik) arbeitet und andererseits ihre Tätigkeit in Bezug auf die Familie negativ besetzt ist und Katherine Ford - neben ihrem ästhetisch konnotierten Beruf - vor allem in ihrer Rolle als Mutter gezeigt wird. Ehefrauen und Mütter werden also nach wie vor im häuslichen Bereich verortet. Üben sie eine berufliche Tätigkeit aus, wird diese entweder nicht thematisiert, als Hobby bzw. Nebenbeschäftigung gewertet oder negativ besetzt. Sie erfüllen mit relativer Exklusivität 
ihre entsprechenden Rollen, die vor allem in der Erziehung der Kinder und der häuslichen Fürsorge liegen.

Wie ein gesellschaftlicher Erwartungsdruck, der Scheidung oder (berufliche) Selbstverwirklichung verbietet, hat die Autorität bzw. Überordnung familiärer Instanzen wie Eltern oder Ehemännern im Vergleich zu den Serien vergangener Jahrzehnte abgenommen und schwindet auch in den Video-on-Demand-Serien, welche in den 1950er bis 1990er Jahren spielen. Die Notwendigkeit der absoluten Hingabe einer Frau an ihre Rolle als Ehefrau und Mutter kann nicht mehr aus einem gesellschaftlichen Zwang heraus begründet werden. An die Stelle dieser Erklärung tritt das Diktum, dass jede Frau, die sich in einer stabilen Paarbeziehung befindet, mit hoher bis absoluter Wahrscheinlichkeit die Mutterschaft anstrebt. Der Drang zu Fürsorge, menschlicher Wärme und Fortpflanzung ist - überspitzt formuliert - eine biologische Determination der auftretenden Charaktere. ${ }^{59}$ Auch die Bindung innerhalb einer Paarbeziehung wird nicht nur als Grundlage eines funktionierenden familiären Ablaufes, sondern als bedeutend für ein gelungenes Leben gesetzt - schon allein deshalb, weil sie die Grundlage für die spätere Mutterschaft bildet.

Ehe und Mutterschaft bedeuten nichtsdestotrotz für die Mehrheit der Charaktere eine Belastung, die zu einem zentralen Konflikt führt. Die Mütter finden aufgrund ihrer umfangreichen familiären Verpflichtungen und der impliziten Forderung nach exklusiver Aufopferung für die Familie keinen Raum zur Selbstverwirklichung oder Selbstfindung. Besonders deutlich wird dies, wenn die Ehe früh geschlossen wurde und die Mutterschaft in jungem Alter zustande kam und somit nie eine Selbstfindungsphase außerhalb häuslicher Bindungen stattfinden konnte. Entsprechend suchen die Mütter nach einer eigenen Identität und einer persönlichen Erfüllung jenseits des als belastend wahrgenommenen Haushalts. Gipfelt diese Identitätssuche in einem Ehebruch der Frau, so wird dies deutlich negativ bewertet. Männliche Untreue oder die Ignoranz des Ehemannes gegenüber seiner Ehefrau geben ihr indes das Recht zu einer Loslösung vom Ehemann bzw. zur Scheidung der Ehe. Sollten die Kinder bereits erwachsen und daher nicht

\footnotetext{
${ }^{59}$ Miriam Maisel stellt insofern eine Ausnahme dar, da ihre Position als Ehefrau die Mutterschaft dominiert. Obwohl sie zwei kleine Kinder hat, eines davon ein Säugling, und dementsprechend viel Zeit mit ihnen verbringen müsste, bewegt sie sich die meiste Zeit recht autonom, ohne dass ihre Rolle als Mutter fokussiert würde. Die Kinder befinden sich dann entweder in der Obhut der Eltern, eines Hausmädchens oder später des Vaters. Als Teil der gehobenen Mittelklasse, so der implizite Tenor der Serie, kann sie sich eine Beaufsichtigung der Kinder rund um die Uhr leisten und somit ihrer gesellschaftlichen Rolle gerecht werden. Es liegt auch nahe, dass Miriam, für die die Rolle als Ehefrau und Mutter stets mehr Zwang denn eigener Antrieb war, die Kinder eher als Belastung wahrnimmt, als Teil des Systems, dem sie sich unterordnen muss.
} 
mehr auf mütterliche Fürsorge angewiesen sein, wird dieser Loslösungsprozess erleichtert.

Die Tatsache, dass Mutterschaft und Paarbindung nach wie vor als grundlegende Antriebe und Merkmale erwachsener weiblicher Charaktere dargestellt werden, gleichzeitig aber die Quelle der primären Lebenskonflikte sind, erklärt sich zunächst aus der narrativen Situierung der analysierten Serien, die sich vornehmlich im familiären Bereich abspielen. Der Mangel an Müttern und Ehefrauen, die sich in Video-on-Demand-Serien beruflich verwirklichen, ebenso wie der Mangel an alternativen Modellen des Zusammenlebens in einer Paarbeziehung, z. B. ehelose Beziehung, kinderlose Beziehung, offene Beziehung, polyamore Beziehung, lassen eine kritische Perspektivierung zu. Ehe und Mutterschaft werden im Rahmen meines Analysekorpus nach wie vor als Norm inszeniert. Da diese Norm aufgrund relativ liberaler gesellschaftlicher Verhältnisse keine logische Begründung erfahren kann, wird sie als notwendig gesetzt und gleichsam mythisiert. Mutter in einer Video-on-Demand-Serie zu sein bedeutet, Teil eines Mythos zu sein, der an konservative Werte und Strukturen anknüpft und nur unter gewissen Bedingungen gebrochen werden kann, nämlich dann, wenn das familiäre Gefüge nicht unmittelbar verletzt wird bzw. ein ,Überleben' desselben gewährleistet ist.

\subsubsection{Töchter}

Besonders bei erwachsenen Frauen mit eigener Familie ist es innerhalb eines Serien-Familiengefüges nicht ohne Weiteres zu bestimmen, ob der Charakter die Rolle der Tochter oder der Mutter und Ehefrau einnimmt. Zwar sind die Figuren nicht notwendigerweise auf eine Rolle beschränkt, in der Regel liegt aber eine Zentrierung auf einen kernfamiliären Verband vor, sodass Charaktere als Töchter fokussiert werden, selbst wenn sie bereits Ehefrauen und Mütter sind. Deren Ehepartner und Kinder sind dann als Nebencharaktere zur erweiterten Familie zu rechnen. Dies lässt sich beispielsweise daran erkennen, dass die Charaktere öfter ohne ihren Ehepartner oder ihre Kinder auftreten bzw. generell öfter in ihrer Rolle als Tochter adressiert werden. So ist dies beispielsweise bei Sarah Pfefferman in Transparent der Fall: Die erste Staffel legt einen Fokus auf den Umgang der Kinder mit dem Outing ihres Vaters als transsexuell oder deren Versuch, eine Familie zu gründen bzw. die Basis für eine Familiengründung zu schaffen, falls - wie im Falle der Kinder Alexandra und Joshua - keine solche vorhanden ist. Ebenso ist Mallory in Grace and Frankie verheiratet und hat zwei Kinder, da hier jedoch weiterhin Grace und Frankie sowie deren Ehemänner als Protagonist/inn/en auftreten, befindet sie sich in der Rolle der Tochter. 
Betrachtet man nun die Rolle der Tochter im familiären Gefüge lässt sich grob zwischen erwachsenen bzw. dem Elternhaus entwachsenen Töchtern, adoleszenten Töchtern und Charakteren im Kindesalter differenzieren, die bei ihren Eltern leben. Zu letzterer Kategorie zählen Casey Gardner (Atypical), Kate Messner (Everything Sucks!), Maureen Murphy ( $F$ is for Family), Charlotte Byrde und Ruth Langmore (Ozark), Skye Getty (Red Oaks), Mylene Cruz (The Get Down) und Hajar Azim (The Romanoffs). Allen jüngeren Töchtern ist gemein, dass sie eine Phase der Selbstfindung durchleben und - im Falle der adoleszenten Charaktere - versuchen, sich von den Eltern zu lösen. Abhängig vom Szenario und den Verhältnissen, in denen sich die Charaktere befinden, ergeben sich daraus unterschiedliche Problematiken und Spezifika. Während Miriam Maisel in deutlich konservativen Strukturen aufgewachsen ist, ihre spätere Rolle als erwachsene Frau klar definiert und ein Ausbruch und eine Emanzipation von den Eltern unwahrscheinlich ist, verhält sich dies bei Mylene Cruz und Maureen Murphy, Charakteren in 1970er-Jahre-Szenarien, anders. Um ihren Traum einer Karriere als Sängerin zu verwirklichen, muss sich Mylene ihres Vaters, einem traditionalistischen Priester, erwehren. Da dieser ihren Gesang strikt ablehnt (vgl. The Get Down I/1: 9:00) und sie für ihre Abweichungen sogar körperlich bestraft (vgl. The Get Down I/1: 1:09:00), gleicht dieser Prozess einem mühsamen Kampf. ${ }^{60}$ Es gelingt ihr letztlich, geht aber mit dem Selbstmord ihres Vaters einher, der symbolisch für den Tod einer vergangenen, konservativeren Ära steht. Zudem ist sie weiterhin deutlich sexistischen Geschlechterbildern ausgesetzt, welche die Selbstbestimmtheit ihrer Entwicklung in Frage stellen. ${ }^{61}$ Maureen Murphy sieht sich in $F$ is for Family mit einer ähnlichen Problematik konfrontiert. Immer wieder zeigt das jüngste Familienmitglied deutliche Ambitionen bezüglich ihrer Zukunft. So will sie sich zu Halloween als Astronautin verkleiden, ihr Vater erklärt ihr jedoch, dass es keine weiblichen Astronauten gibt und auch nie geben werde (vgl. $F$ is for Family I/4: 8:00), zudem verbietet er ihr weitere männlich konnotierte Kostüme (vgl. F is for Family I/4: 16:00). Gegen ihren Willen drängt er sie in konservative Rollenmuster, will, dass sie sich wie eine „Lady“ benimmt (vgl. $F$ is for Family

${ }^{60}$ Mylenes Pop- und Disco-Musik, zu der freizügige Shows gehören (vgl. The Get Down I/10: 27:00), wird der vom Vater unterstützten geistlichen Gospel-Musik gegenübergestellt und steht, einhergehend mit der starken Musikfokussierung der Serie, für gesellschaftlichen Fortschritt bzw. Liberalisierung.

${ }^{61}$ Ihr musikalischer Aufstieg gelingt nur anhand sexuell aufgeladener Auftritte (vgl. The Get Down I/9: 28:00, I/10: 27:00). Nachdem sie zum ersten Mal mit ihrem Freund geschlafen hat, meint eine Freundin, dass sie nun eine Frau sei (vgl. The Get Down I/4: 4:00). Die Karriere und Selbstverwirklichung Mylenes sind also auch jenseits der Autorität ihres Vaters männlichen Bedürfnissen unterworfen. 
II/1: 15:00). Maureen gibt ihre Vorstellungen und Träume allerdings nie auf und bewahrt als einzige innerhalb der Familie ihren Optimismus und ihre Ambitionen. Dass beide Serien, die in den 1970er Jahren spielen, ambitionierte Charaktere in der Töchter-Rolle zeigen, die darauf abzielen, konservative Strukturen zu überwinden, trägt zur Charakterisierung des Jahrzehnts als Zeit des Umbruchs und der Liberalisierung bei, in dem Autoritäten schwinden. Mylene und Maureen sind Vertreterinnen einer neuen Generation, die sich sukzessive von männlichen Vorgaben emanzipiert.

Skye Getty in Red Oaks zielt bewusst darauf ab, sich von ihren Eltern und von der männlichen Dominanz zu lösen. Sie inszeniert sich selbst als erotisch, intellektuell, künstlerisch veranlagt und feministisch. ${ }^{62}$ Allgemein bleibt sie in ihren Intentionen relativ schwer fassbar und erscheint als feenhafte Frauengestalt. Am Ende der ersten Staffel kündigt sie einen einjährigen Aufenthalt in Paris an und entzieht sich somit einer ernsthaften Beziehung mit dem Protagonisten David (vgl. Red Oaks I/10: 24:50). Skyes Selbstbestimmung ist partiell zweifelhaft: Ihre wohlhabenden Eltern dulden ihr Verhalten und sie erweckt häufig den Eindruck einer gelangweilten ,höheren Tochter'. An ihrem Beispiel und dem Freiraum, den sie genießt, wird deutlich, dass im 1980er-Jahre-Weltmodell von Red Oaks eine Selbstbestimmung der Frauen gegeben ist, dies wird auch durch Judy Myers Scheidung unterstrichen (vgl. 3.2.1.1). Zudem wird aufgezeigt, dass die Adoleszenz eine Phase der Selbstfindung und des Einfindens in gesellschaftliche Strukturen ist.

Im Zentrum von Kate Messners Leben in Everything Sucks! steht hauptsächlich die sexuelle Selbstdefinition. Kate Messner muss nicht nur einerseits mit ihrem Köper zurechtkommen, der nicht dem stereotypen Weiblichkeitsideal entspricht, sie entdeckt auch ihre Homosexualität (vgl. Everything Sucks! I/1: 19:00) und muss dementsprechend ihren eigenen Ängsten und gesellschaftlichen Ressentiments die Stirn bieten. Die Tatsache, dass Kates Mutter früh Selbstmord beging und ihr keine weibliche Leitfigur mehr zur Seite steht, empfindet sie offensichtlich als Trauma (vgl. Everything Sucks! I/9: 19:00). Hinzu kommt die pubertäre Ablehnung der Fürsorge ihres Vaters (vgl. Everything Sucks! I/1: 6:00). Ihre Kindheit in den 1990er Jahren entspricht dabei in Darstellung und Abläufen, bis auf gewisse technische Unterschiede und gesellschaftliche wie mediale Trends, weitgehend gegenwärtigen Verhältnissen.

${ }^{62}$ Bei einem ihrer ersten Auftritte liest sie das Buch Delta of Venus von Anaïs Nin, einen Band mit erotischen Kurzgeschichten (Red Oaks I/1: 27:54). Zudem malt sie männliche Akte (vgl. Red Oaks I/2: 7:45). Durch die Wahl eines schwarzen Kleides auf einer Hochzeit demonstriert sie, dass sie eheliche Strukturen ablehnt (vgl. Red Oaks I/4: 4:00). 
Casey Gardner (Atypical) lehnt sich zunächst durch burschikoses und bewusst unweibliches Verhalten gegen die Wunschvorstellung ihrer Mutter auf, die sich eine femininere Tochter wünscht (vgl. Atypical I/5: 9:00, I/7: 7:00). Zudem sieht sie sich als Beschützerin ihres autistischen Bruders (vgl. Atypical I/8: 26:00) und tritt generell für Schwächere ein, wenn sie diese in Bedrängnis sieht (vgl. Atypical I/1: 13:00). Als sie eine Beziehung zu einem Jungen eingeht, schwindet ihr maskulines Auftreten. Sie kleidet sich für ihn weiblicher, was - durch den aus zahlreichen Formaten bekannten ,Ballkleid-Effekt ${ }^{*}$ - deutlich ästhetisch inszeniert wird (vgl. Atypical I/10: 21:00). In Anbetracht einer potenziellen Paarbindung schwinden also emanzipatorische Tendenzen, eine Hinwendung zu rollentypischerem Verhalten findet statt.

Auch Hajar Azim (The Romanoffs I/1) sucht zumindest partiell die Loslösung von ihrer Familie. Zwar handelt es sich um einen erwachsenen Charakter, der bereits als Hausmädchen arbeitet, sie wohnt aber weiterhin bei ihrer Familie und wird dort von ihrer Mutter in häusliche Tätigkeiten eingebunden (vgl. The Romanoffs I/1: 33:50). Ihre Ausbildung zur Krankenpflegehelferin, welche sie zeitgleich bewältigt (vgl. The Romanoffs I/1: 1:01:09), bedeutet eine Loslösung von der Familie. Doch bereits während des Lebens bei ihrer Familie ist sie weitgehend eigenständig. Dies wird vom muslimischen Hintergrund der Familie nicht geschmälert, obwohl sie angibt, sich gegen ihre traditionellen Eltern durchsetzen zu müssen (vgl. The Romanoffs I/1: 1:04:26). Letztlich verliebt sie sich in den Charakter Greg, den Neffen Anushkas, bei der sie als Hausmädchen arbeitet, und wird ungewollt schwanger. Sie und Greg gestehen sich ihre Liebe und es scheint beiden eine gemeinsame Zukunft bevorzustehen (The Romanoffs I/1: 1:19:15).

Wie oben bereits beschrieben, besteht die Rolle der Tochter, die den häuslichen Raum noch nicht verlassen hat, darin, eine Loslösung anzustreben und damit u. U. von Strukturen, die als belastend oder unterdrückerisch wahrgenommen werden, beispielsweise das Patriarchat oder restriktive Traditionen. Bevor dies abschließend erfolgen kann, müssen die Figuren eine Phase der allgemeinen Selbstfindung durchlaufen. Dies betrifft sowohl das sexuelle Selbstbild als auch die gesellschaftliche Rolle und Position. Die Selbstfindung der Charaktere ist eng an die Beziehungsfindung gekoppelt - eine Ausnahme stellen Charaktere im Kindesalter dar wie Maureen Murphy. Casey Gardner findet einen Freund und verhält sich daraufhin weiblicher, Hajar Azim wird von Greg schwanger und verliebt sich in ihn, Charlotte Byrde versucht sich über den Verlust ihrer Jungfräulichkeit zu emanzipieren - auch wenn dies fehlschlägt - und Mylene Cruz muss sich männlich dominierten Strukturen anpassen. Trotz ihres anstehenden Aufbruchs nach Paris bindet sich Skye Getty zumindest partiell an David. Paradoxerweise bedeuten Emanzipation und Loslösung in der Mehrheit der Fälle gleichzeitig Bindung 
an einen meist männlichen Gegenpart, auch wenn dieser - und dies muss betont werden - in keinem der Beispiele eine Autoritätsperson ist.

Bevor eine Bindung stattgefunden hat, erscheint auch das Leben derjenigen Charaktere defizient, die bereits erwachsen sind und nicht mehr in elterlicher Obhut leben. Dies betrifft im Rahmen meines Korpus Brianna Hanson (Grace and Frankie) und Alexandra „Ali“ Pfefferman (Transparent). Während Mallory Hanson und Sarah Pfefferman bereits geheiratet und ihre eigene Familie gegründet haben, wird das Leben ihrer Schwestern durch den Mangel daran bestimmt. Brianna verkörpert den Karriere-Aspekt ihrer Mutter. Ihre Berufsfixierung, ihre emanzipierte und selbstbestimmte Art und ein Mangel an hausfraulichen Fähigkeiten - z. B. das Zubereiten von Essen für ein Date (vgl. Grace and Frankie I/7: 3:00) - verhindern zunächst eine Paarbindung. Sie nimmt ihre eigene Existenz ohne Paarbindung offensichtlich als unvollständig und unbefriedigend wahr. Frankies Sohn Nwabudike beschreibt ihre Situation und den Grund für ihre Resignation folgendermaßen: ,You want what everyone wants. You wanna come home at the end of the day to someone who's happy to see you." (Grace and Frankie I/7: 4:00). Ali Pfeffermans Leben ist ebenso defizient, in ihrem Falle ist die Problematik allerdings weiterreichender. Als jüngstes Kind der Familie scheint sie regelrecht , verzogen' worden zu sein. Im Gegensatz zu Brianna hat sie weder Beruf noch eine andere feste Beschäftigung. Da keine Identitätsfindung stattgefunden hat, kann es weder zu einer gesellschaftlichen Einordnung noch zu einer gelungenen Beziehung kommen. ${ }^{63}$ Offensichtlich leidet auch sie unter ihrer Einsamkeit und der Instabilität ihres Lebens. ${ }^{64}$ Nach dem Outing ihres Vaters als transsexuell will sie rasch eine Beziehung zu einer transsexuellen Frau eingehen (vgl. Transparent I/6), sucht insofern weniger nach einem eigenen Selbstbild, als dass sie versucht, dies durch Imitation zu erreichen - eine infantile Verhaltensweise, die ihrer Charakterisierung als wankelmütig und unbeständig entspricht. Das Leben von Sarah Pfefferman und Mallory Hanson wird deutlich durch deren Rolle als Hausfrau und Mutter geprägt und erfährt durchaus eine Inszenierung als belastend und entbehrungsreich, was der obigen Charakterisierung dieser Rolle

\footnotetext{
${ }^{63}$ Sie hat keine eigene Einkommensquelle, sondern leiht sich stets aufs Neue Geld von ihrem Vater (vgl. Transparent I/1: 13:30). Wiederholt versucht sie Kontrolle über ihr Leben zu erlangen, sei es über vermehrten Sport (Transparent I/1: 24:00) oder durch den Beginn eines neuen Studiums (vgl. Transparent I/7: 4:51). Zeitgleich konsumiert sie Drogen (vgl. Transparent I/2: 25:08, I/3: 6:40) und findet keine stabile Beziehung.

${ }^{64}$ Sie wird als erster Charakter der Serie gezeigt, doch im Gegensatz zu ihren Geschwistern allein in ihrer unordentlichen, dämmrigen Wohnung (vgl. Transparent I/1: 0:51).
} 
entspricht. ${ }^{65}$ Dennoch werden die Lebensentwürfe beider Charaktere zunächst als Gegenbeispiel zu ihren alleinstehenden Schwestern etabliert, die innerhalb des Serienverlaufs nach einer gefestigten Beziehung suchen. Diese Beziehungen sind, folgt man der Logik der Ehefrau- und Mutterrolle, Basis für eine möglichst stabile Ehe mit Kindern. Andere Beziehungen, die auf dem Weg dorthin eingegangen werden, haben dementsprechend wenig eigenen Wert und fungieren als Stufen zum Ziel.

Ruth Langmore in Ozark stellt ein Bindeglied zwischen der Adoleszenz und dem Erwachsenenalter dar, steht zwischen Tochter und Mutter. Sie steht unter dem Einfluss ihres Vaters und teilweise ihrer Onkel. Als einzige Frau in der Familie Langmore ist es - trotz ihres jungen Alters - ihre Aufgabe, als Mutterersatz für ihre Cousins zu agieren. In dieser Rolle und als einziger tatsächlich rationaler und vernünftiger Charakter des Langmore-Clans kann sie Autorität über die männlichen Figuren, mit Ausnahme ihres Vaters, ausüben. Sie strebt zudem nicht nach einer Paarbeziehung. Somit stellt sie eine Ausnahme dar - jedoch eine Ausnahme, welche die Regel bestätigt: Die dargestellte Familie Langmore ist, durch den Mangel tatsächlicher Mütter defizient, hierzu trägt auch das infantile Verhalten der anwesenden Langmore-Männer bei. Ruth ist als einzige Frau verpflichtet, als Mutter zu agieren. Eine Paarbeziehung wird durch die unterdrückerische Bindung an ihren Vater verhindert, der sie als einziger Mann in ihrem Leben in Anspruch nimmt. Zwar ist hier nicht von Inzest auszugehen - das deutet die Serie nicht an -, in jedem Falle aber von einer missbräuchlichen Beziehung, die Ruths Entwicklung unterbindet.

Abstrahiert man die Tochterrollen, so können sie in der Logik der Weltentwürfe nur eine Vorstufe zur späteren Mutterschaft sein, zumindest in dem Fall, dass Selbstfindung und Paarbindung gelingen. Diese Paarbindung folgt zwar nicht mehr autoritären Mustern, die mit den 1950er Jahren vergleichbar wären, verlangt aber doch eine exklusive Hingabe an die Mutterschaft und teilweise eine

${ }^{65}$ Sarah Pfefferman wird zuerst dabei gezeigt, wie sie ihre Kinder auf die Schule vorbereitet und der Haushälterin die Aufgaben des Tages überträgt. Dabei ist sie zwar routiniert, aber deutlich gestresst - u. a. auch, da ihr Ehemann in die Arbeit geht, ohne sich zu verabschieden (Transparent I/1: 2:00). Sarah bricht später durch eine homosexuelle Beziehung die Ehe und konsumiert Marihuana, um den Stress und die Belastung durch die Gesamtsituation zu verarbeiten (vgl. Transparent I/7: 7:00). Sie versucht allerdings weiter, die Familie in ihrer Gesamtheit aufrechtzuerhalten und zu verteidigen - beispielsweise indem sie ihren Vater bei seinem öffentlichen Outing unterstützt (Transparent I/4: 18:30) oder indem sie auf regelmäßige gemeinsame Familienessen besteht (vgl. Transparent I/6: 19:30). Mallorys Leben als Mutter ist vergleichbar stresserfüllt. Sie wird beim Erledigen häuslicher Tätigkeiten gezeigt, zum Bewältigen des Stresses nimmt sie Beruhigungsmittel (vgl. Grace and Frankie I/2: 11:00). Generell ist sie der Situation jedoch gewachsen. 
Aufgabe persönlichen Freiraums (weder Mallory Hanson noch Sarah Pfefferman sind berufstätig). ${ }^{66}$ Wenn diese Entwicklung bis zum Erwachsenenalter nicht stattgefunden hat, ist der Versuch der Charaktere dies nachzuholen elementarer Teil der Diegese. Ein Leben als alleinstehende Frau wird als offenbar defizient empfunden, die potenziellen Probleme des Ehelebens werden nicht reflektiert, selbst wenn diese am Beispiel der Geschwister oder Eltern deutlich werden. Die Rolle der Tochter besteht ergo elementar darin, zunächst Emanzipation zu erlangen, um diese später erfolgreich aufzugeben. ${ }^{67}$

\subsubsection{Alleinstehende/der Familie assoziierte Frauen}

\begin{tabular}{l|l|l}
\hline \multicolumn{2}{l}{ Frauen außerhalb der Familie } \\
\hline Serie & Charakter & Charaktertyp \\
\hline 1. Atypical & Julia Sasaki & $\begin{array}{l}\text { - Psychotherapeutin des Protagonisten Sam } \\
\text { Gardner } \\
\text { - Adjuvantin des Protagonisten } \\
\text { - In einer festen Beziehung }\end{array}$ \\
\hline 2. Atypical & X Paige & $\begin{array}{l}\text { - Schülerin } \\
\text { - Freundin/Liebesbeziehung des } \\
\text { Protagonisten David }\end{array}$ \\
\hline 3. Everything Sucks! & X Emaline & $\begin{array}{l}\text { - Schülerin } \\
\text { - Zunächst Opponentin, dann } \\
\text { Freundin/Love-Interest einer } \\
\text { Protagonistin (Kater Messner) }\end{array}$ \\
\hline
\end{tabular}

${ }^{66}$ So wird Sarah Pfefferman als Jugendliche mit rebellischer Attitüde gezeigt und fährt auf eine politische Demonstration (vgl. Transparent I/8: 8:30). Vergleichbares politisches Engagement wird später nicht mehr thematisiert und war somit entweder Teil einer Entwicklungsphase oder wurde aufgrund ihrer späteren gesellschaftlichen Rolle abgelegt.

${ }^{67}$ Eine interessante Thematisierung dieser Problematik erfolgt in der dritten Folge von The Romanoffs (Expectation). Der Charakter Ella Hopkins ist hochschwanger. Ihre Mutter ist empört darüber, dass Ellas Ehemann während dieser kritischen Phase auf Geschäftsreise ist (vgl. The Romanoffs I/3: 07:22), und auch darüber, dass Ella keinen eigenen Beruf anstrebt. Sie wirft ihr vor, sich durch ein Leben als Hausfrau zu erniedrigen und keine eigenständige Person zu sein (vgl. Romanoffs I/3: 08:30). Ella legitimiert dieses Leben als einen Akt bewusster Entscheidung. Die Thematisierung der Annahme der Hausfrauenrolle als selbstständige, nicht gesellschaftlich vorgegebene Rolle ist innerhalb des Analysekorpus einzigartig. Zudem wird sie ihrer Mutter Julia gegenübergestellt, die sich selbst permanent an zwei Männer gebunden hat - einen Ehemann und eine ehemalige Affäre (Ellas Vater) - und beruflich in einem Obdachlosenheim arbeitet, eher ehrenamtliche Tätigkeit als tatsächlicher Beruf. Ihre Mutter erfüllt daher selbst nicht die Forderungen, die sie an ihre Tochter stellt, und steht im negativen Gegensatz zu ihrer wohlüberlegten und reflektierten Tochter. So finden eine Legitimation und eine positive Konnotation der absoluten Hingabe an die Rolle als Hausfrau statt. 


\section{Frauen außerhalb der Familie}

\begin{tabular}{|c|c|c|}
\hline Serie & Charakter & Charaktertyp \\
\hline 4. F is for Family & $\begin{array}{l}\text { X Bridget } \\
\text { Fitzsimmons }\end{array}$ & $\begin{array}{l}\text { - Schülerin } \\
\text { - Love-Interest eines Protagonisten (Bill } \\
\text { Murphy) }\end{array}$ \\
\hline 5. Ozark & $\begin{array}{l}\text { Rachel } \\
\text { Garrison }\end{array}$ & $\begin{array}{l}\text { - Restaurant-/Hotelbetreiberin } \\
\text { - Überwiegend) Adjuvantin } \\
\text { - Ledig }\end{array}$ \\
\hline 6. Red Oaks & X Karen & $\begin{array}{l}\text { - Gerade Schule } \\
\text { abgeschlossen/Gymnastik-Lehrerin } \\
\text { - Freundin/Liebesbeziehung des } \\
\text { Protagonisten David Myers - später } \\
\text { Ex-Freundin }\end{array}$ \\
\hline XXX 7. The Get Down & Fat Annie & $\begin{array}{l}\text { - Kriminelle } \\
\text { - Opponentin der Charaktere } \\
\text { - Ledig }\end{array}$ \\
\hline 8. The Get Down & $\begin{array}{l}\text { Yolanda } \\
\text { Kipling }\end{array}$ & $\begin{array}{l}\text { - Jugendliche } \\
\text { - Freundin der Protagonistin Mylene Cruz }\end{array}$ \\
\hline 9. The Get Down & Regina & $\begin{array}{l}\text { - Jugendliche } \\
\text { - Freundin der Protagonistin Mylene Cruz }\end{array}$ \\
\hline $\begin{array}{l}\text { 10. The Marvelous Mrs. } \\
\text { Maisel }\end{array}$ & Susie Myerson & $\begin{array}{l}\text { - Künstler-Agentin/Angestellte eines Clubs } \\
\text { - Freundin und Agentin der Protagonistin } \\
\text { Miriam Maisel } \\
\text { - Ledig }\end{array}$ \\
\hline $\begin{array}{l}\text { 11. The Marvelous Mrs. } \\
\text { Maisel }\end{array}$ & $\begin{array}{l}\text { Imogene } \\
\text { Cleary }\end{array}$ & $\begin{array}{l}\text { - Hausfrau und Mutter } \\
\text { - Freundin der Protagonistin Miriam Maisel } \\
\text { - Verheiratet }\end{array}$ \\
\hline $\begin{array}{l}\text { XXX 12. The Marvelous } \\
\text { Mrs. Maisel }\end{array}$ & Sophie Lennon & $\begin{array}{l}\text { - Komikerin } \\
\text { - Opponentin/berufliche Konkurrentin der } \\
\text { Protagonistin Miriam Maisel } \\
\text { - Ledig } \\
\end{array}$ \\
\hline $\begin{array}{l}\text { XXX 13. The Marvelous } \\
\text { Mrs. Maisel }\end{array}$ & Penny Pan ${ }^{68}$ & $\begin{array}{l}\text { - Sekretärin } \\
\text { - Opponentin von Miriam Maisel: Ehemann } \\
\text { Joel Maisel beginnt eine Affäre mit ihr } \\
\text { - Ledig }\end{array}$ \\
\hline
\end{tabular}

${ }^{68}$ Penny Pan, die junge Sekretärin, mit der Miriams Ehemann eine Affäre beginnt, ist ein Nebencharakter, der weniger in direkte Konkurrenz zur Protagonistin tritt. Vielmehr wird Joel als der Schuldige inszeniert und Penny als naive, junge Frau, die sich Hoffnungen auf eine ernsthafte Beziehung macht - selbst nachdem Joel sie bereits verlassen hat (vgl. The 


\begin{tabular}{|c|c|c|}
\hline \multicolumn{3}{|c|}{ Frauen außerhalb der Familie } \\
\hline Serie & Charakter & Charaktertyp \\
\hline 14. The Ranch & X Heather & $\begin{array}{l}\text { - Unbekannter Beruf } \\
\text { - Freundin/Liebesbeziehung des } \\
\text { Protagonisten Colt Bennett } \\
\text { - Verlobt }\end{array}$ \\
\hline 15. The Ranch & $\begin{array}{l}\text { X Abby } \\
\text { Philipps }\end{array}$ & $\begin{array}{l}\text { - Unbekannter Beruf } \\
\text { - Freundin/Liebesbeziehung des } \\
\text { Protagonisten Colt Bennett }\end{array}$ \\
\hline 16. The Romanoffs I/1 & X Sophie & $\begin{array}{l}\text { - Unbekannter Beruf } \\
\text { - Freundin/Liebesbeziehung des } \\
\text { Protagonisten Greg Moffat - später } \\
\text { Ex-Freundin } \\
\text { - In einer festen Beziehung }\end{array}$ \\
\hline 17. The Romanoffs I/2 & $\begin{array}{l}\text { X Michelle } \\
\text { Westbrook }\end{array}$ & $\begin{array}{l}\text { - Ehemalige Ballerina/Ehefrau } \\
\text { - Affäre mit dem Protagonisten der Folge } \\
\text { Michael Romanoff } \\
\text { - Verheiratet }\end{array}$ \\
\hline 18. The Romanoffs I/3 & Olivia Rogers & $\begin{array}{l}\text { - Schauspielerin } \\
\text { Protagonistin der Folge } \\
\text { - Ledig }\end{array}$ \\
\hline $\begin{array}{l}\text { XXX 19. The Romanoffs } \\
\text { I/3 }\end{array}$ & $\begin{array}{l}\text { Jacqueline } \\
\text { Gerard }\end{array}$ & $\begin{array}{l}\text { - Regisseurin } \\
\text { - Opponentin der Protagonistin Olivia } \\
\text { Rogers } \\
\text { - Ledig }\end{array}$ \\
\hline 20. The Romanoffs I/7 & $\begin{array}{l}\text { Elena } \\
\text { Evanovich }^{69}\end{array}$ & $\begin{array}{l}\text { - Agentin eines Waisenhauses } \\
\text { - Adjuvantin der Protagonisten Joe und } \\
\text { Anka Garner } \\
\text { - (Vermutlich) Ledig }\end{array}$ \\
\hline $\begin{array}{l}\text { XXX 21. The Romanoffs } \\
\text { I/8 }\end{array}$ & Ondine & $\begin{array}{l}\text { - Hausfrau und Mutter } \\
\text { - Opponentin des Protagonisten } \\
\text { (Simon/Candice Burrows) } \\
\text { - Verheiratet }\end{array}$ \\
\hline
\end{tabular}

Marvelous Mrs. Maisel I/8 34:35). Sie ist somit nur im eingeschränkten Sinne eine Opponentin, eher Opfer der Umstände und notwendiger Handlungsaspekt und soll im Folgenden nicht mehr aufgeführt werden.

${ }^{69}$ Da innerhalb der Episode kein Ehemann, Freund oder Ähnliches des Charakters auftaucht und sie stets eigenständig agiert, wurde Elena Evanovich als alleinstehend kategorisiert. 


\begin{tabular}{|c|c|c|}
\hline \multicolumn{3}{|c|}{ Frauen außerhalb der Familie } \\
\hline Serie & Charakter & Charaktertyp \\
\hline 22. Transparent & $\begin{array}{l}\text { Davina } \\
\text { Rejennae }\end{array}$ & $\begin{array}{l}\text { - Kein Beruf } \\
\text { - Freundin der Protagonistin Maura } \\
\text { Pfefferman } \\
\text { - Ledig }\end{array}$ \\
\hline 23. Transparent & X Kaya & $\begin{array}{l}\text { - Musikerin } \\
\text { - Affäre eines Charakters (Joshua } \\
\text { Pfefferman) }\end{array}$ \\
\hline 24. Transparent & X Rita Holt & $\begin{array}{l}\text { - Babysitterin } \\
\text { - Affäre eines Charakters (Joshua } \\
\text { Pfefferman) } \\
\text { Ledig }\end{array}$ \\
\hline 25. Transparent & X Raquel Fein & $\begin{array}{l}\text { - Rabbinerin } \\
\text { Freundin/Liebesbeziehung eines Charakters } \\
\text { (Joshua Pfefferman) } \\
\text { - Ledig }\end{array}$ \\
\hline 26. Transparent & $\begin{array}{l}\text { X Tammy } \\
\text { Cashman }\end{array}$ & $\begin{array}{l}\text { - Innenarchitektin } \\
\text { - Freundin/Liebesbeziehung eines } \\
\text { Charakters (Sarah Pfefferman) } \\
\text { - Verheiratet }\end{array}$ \\
\hline
\end{tabular}

Mit Blick auf obige Tabelle möchte ich weibliche Charaktere außerhalb der in den Serien fokussierten Familien in zwei Kategorien aufteilen: Opponentinnen und Charaktere, die nicht in negativer Beziehung zu den Protagonist/inn/en stehen. In obiger Tabelle habe ich dabei stets die berufliche Beschäftigung bzw. Lebensphase des Charakters, deren Beziehung zu den Hauptcharakteren und ihren Beziehungsstatus festgehalten. Mit XXX gekennzeichnete Felder kennzeichnen Opponentinnen, ein $\mathbf{X}$ vor dem Charakternamen weist auf eine amouröse und/oder sexuelle Beziehung hin. Alle anderen Felder kennzeichnen Adjuvantinnen.

Die Gruppe der Opponentinnen ist die kleinste. Von den oben gelisteten 26 Figuren treten nur fünf in direkte Opposition zu den Charakteren der Serien. Das Ziel der skrupellosen Verbrecher-Anführerin Fat Annie aus The Get Down ist es vor allem, ihren Einfluss zu vergrößern und ihre Drogengeschäfte zu erweitern. Die Komikerin Sophie Lennon tritt in The Marvelous Mrs. Maisel in Konkurrenz zu Miriam Maisel und will deren Karriere blockieren. Jacqueline Gerard, eine ältere Regisseurin, manipuliert und terrorisiert in der dritten Folge von The Romanoffs die Protagonistin Olivia Rogers. Ondine aus der achten Folge von The 
Romanoffs verdrängt den Protagonisten Simon Burrows aus seiner Familie, nachdem sie dessen Mutter ermordet hat. Bei Fat Anni, Jacqueline Gerard und Sophie Lennon handelt es sich um alleinstehende Frauen, von denen jede eine autoritäre Rolle einnimmt bzw. einen Beruf ausübt, der im jeweiligen Szenario eher männlich konnotiert ist: Verbrecher-Anführerin, Regisseurin und Komikerin. Alle drei Charaktere sind nicht familiär eingebettet. Fat Annie tritt als Matriarchin eines kriminellen Clans auf, den sie selbst als „Family“ bezeichnet (vgl. The Get Down I/3: 16:00). Dabei ist nur der Charakter Cadillac tatsächlich ihr Sohn. Diesen unterdrückt sie (vgl. The Get Down I/1: 1:00:00) ebenso wie den Charakter Shaolin Fantastic, den sie nicht nur sexuell ausnutzt (vgl. The Get Down I/3: 16:00), sondern auch zum Mord zwingt (vgl. The Get Down I/6: 11:00). Sie fungiert daher als negative Übermutter, die eine Zwangsstruktur statt einer Familie schafft. Sophie Lennon, die auf der Bühne eine burschikose Hausfrau mimt (vgl. The Marvelous Mrs. Maisel I/7: 15:13), wohnt allein mit Dienstboten in einem aristokratischen Anwesen und gibt sich kühl und gewählt (vgl. The Marvelous Mrs. Maisel I/7: 32:53). Jacqueline Gerard gibt vor von der Zarenfamilie Romanow abzustammen, um bei einer Serie über die Familie Regie führen zu dürfen (vgl. The Romanoffs I/3: 1:07:02). Am Set ist sie betont autoritär, exzentrisch und herablassend. So greift sie beispielsweise einem der Schauspieler in den Schritt und fordert ihn auf ein „fucking man“ zu sein (vgl. The Romanoffs I/3: 34:20). Auch sie instrumentalisiert familiäre Strukturen, um ihre Ziele zu erreichen, und errichtet eine Aura männlicher Dominanz. Ondine greift als einzige der vier Opponentinnen auf keine entsprechende Strategie zurück und distanziert sich nicht von der Familie. Vielmehr versucht sie durch Verführung, sexuelle Avancen und heimtückische Handlungen eine eigene Familie zu errichten. Zu diesem Zweck zerstört sie eine bereits bestehende Familie.

Von drei Charakteren (und Ondine als Abweichung) eine allgemeine Regel ableiten zu können, ist nun kaum möglich. Dennoch lässt sich feststellen, dass im Fall von Fat Annie, Sophie Lennon und Jacqueline Gerard männlich konnotierte Autorität dazu genutzt wird, die weiblichen Charaktere als eindeutig negativ zu inszenieren. Zudem wird Familie entweder eindeutig abgelehnt oder als Mittel zum Zweck instrumentalisiert. Die Negativcharakterisierung der Figuren ergibt sich also aus einer deutlichen Abweichung bzw. Perversion klassischer Rollenmuster (Fat Annie) ebenso wie aus dem Bruch allgemein positiv konnotierter familiärer Strukturen. Während bestimmte Ehefrauen und Mütter das Scheitern einer Selbstfindung verkörpern, verkörpern die vier hier aufgeführten Opponentinnen einen ,Überfluss' an Emanzipation bzw. einen nicht gesellschaftskonformen Charakter, der für diejenigen Figuren eine Bedrohung darstellt, die versuchen, innerhalb eines gesellschaftlichen Rahmens eine Rolle zu finden. 
Die Gruppe der Figuren, die nicht in Opposition zu den zentralen Charakteren stehen, ist deutlich größer. Neun davon stellen Adujvantinnen der Hauptcharaktere oder eines Hauptcharakters dar. Hier kann es sich um Freundinnen handeln, welche die Charaktere unterstützen (Yolanda Kipling, Regina, Susie Myerson, Imogene Cleary und Davina Rejennae). Eine entsprechende Freundschaft mit einer Frau besteht dabei nur zwischen Frauen. In meinem Korpus ist somit keine nicht sexuell konnotierte (platonische) oder nicht verwandtschaftliche Beziehung zwischen einem Mann und einer Frau gegeben. Dass es in keinem der analysierten Weltmodelle eine relevante Freundschaft zwischen einer erwachsenen Frau und einem erwachsenen Mann gibt, unterstreicht die absolute Einengung auf bestimmte Rolle und trennt die Geschlechter disjunkt: Beziehungen zwischen männlichen Charakteren scheinen allein der Aufrechterhaltung familiärer Strukturen zu dienen.

Die meisten der hier analysierten Charaktere sind von tertiärer Bedeutung, zählen also zu den Nebenrollen mit geringer oder punktueller Handlungsrelevanz. Charaktere wie u. a. Imogene Cleary, eine Hausfrau, Mutter und Freundin von Miriam Maisel in The Marvelous Mrs. Maisel, oder Yolanda Kipling und Regina, zwei Freundinnen von Mylene Cruz in The Get Down, bieten vor allem die Möglichkeit dazu, in Gesprächen mit der Protagonistin die Normvorstellungen, Konflikte und Gedanken der Charaktere zu etablieren und zu problematisieren (vgl. The Marvelous Mrs. Maisel I/1: 20:38, I/2: 06:07; The Get Down I/1: 10:30, I/2: 29:00). Sie sind mehr Träger und Katalysatoren der Handlung als aktive Elemente. Eine Ausnahme stellen Susie Myerson und Davina Rejennae dar. Susie Myerson, Freundin und Agentin von Miriam Maisel, gehört selbst zu den Hauptcharakteren der Serie und initiiert Miriams Comedy-Karriere. Davina unterstützt Maura Pfefferman bei ihrer Einfindung in die Transsexuellen-Szene und vor allem in ihr Leben als Frau (vgl. Transparent I/4: 4:30), womit sie eine besondere Rolle innerhalb der Serie einnimmt. Bei diesen Charakteren handelt es sich ebenfalls um Adjuvantinnen, allerdings - im Gegensatz zu obigen Beispielen - mit individueller und kontinuierlicher Relevanz sowie aktiver Rolle.

Andere Adjuvantinnen unterstützen die Charaktere auf professioneller Ebene. Julia Sasaki ist als Psychotherapeutin des autistischen Protagonisten Sam Gardner in Atypical ein bedeutender Teil in dessen Leben. Rachel Garrison hilft den Byrdes in Ozark bei ihren Geschäften und Elena Evanovich (The Romanoffs) hilft dem US-amerikanischen Ehepaar Garner bei der Adoption eines russischen Kindes. Ebenso wie obenstehende „Freundinnen“ ermöglichen sie gewisse Handlungen der Charaktere bzw. allgemeine Handlungsstränge.

Die Mehrzahl (zwölf von vierundzwanzig) der nicht oppositionellen Charaktere wird indes von Frauen gestellt, die sich in einer Liebesbeziehung oder 
einer sexuellen Beziehung zumeist zu männlichen Protagonisten befinden. Dabei lässt sich grob zwischen einer längeren Beziehung, einer Affäre (eine rein sexuelle Beziehung von begrenzter Dauer) und einem Love-Interest (eine Person von sexuellem und/oder amourösen Interesse, mit der keine Beziehung zustande kommt) unterscheiden. Zu erster Gruppe zählen Paige, Karen, Heather, Sophie und Tammy Cashman, während Abby Philipps eine ehemalige Beziehung des The Ranch-Protagonisten Colt Bennett ist. Affären von Charakteren sind Michelle Westbrook, Kaya und Rita Holt. Emaline Addario und Bridget Fitzsimmons zählen zu den Love-Interests. Diese Charaktere haben trotz der unterschiedlichen Art und Weise, auf die sie mit den Protagonist/inn/en zusammentreffen, Gemeinsamkeiten. Zunächst handelt es sich nicht um Protagonistinnen, sondern um sekundäre und tertiäre Charaktere. Ohne jeder der zahlreichen Figuren eine gesonderte Analyse zuteilwerden zu lassen, lässt sich feststellen, dass alle in Hinblick auf die Figur, zu der sie in Beziehung stehen, eine ähnliche Funktion erfüllen. In welche konkrete Richtung diese Funktion geht, hängt von der Art der Beziehung ab. Paige vermittelt dem Protagonisten Sam in Atypical einen Eindruck davon, wie es ist in einer Beziehung zu sein, z. B. von der Notwendigkeit von Kompromissen und dem Eingestehen eigener Fehler (vgl. Atypical I/5: 28:00). Karen, David Myers Freundin in Red Oaks, steht - weiblich und sexualisiert - im Gegensatz zu Skye Getty. Sie verkörpert mit ihrem sehr konventionellen und traditionellen Blick auf eine gemeinsame Zukunft (vgl. Red Oaks I/1: 18:49) einen Lebensentwurf, den David ablehnt, und motiviert ihn dazu, sich von eingefahrenen Strukturen zu lösen. Heather ist scheinbar die erste ernsthafte Beziehung Colt Bennetts in Red Oaks und führt ihn somit in Richtung eines gefestigten Lebens. Tammy Cashmans Auftreten in Transparent führt zum Outing von Sarah Pfefferman als homosexuell. Joshua Pfeffermans Kurzzeitbeziehung bzw. Affäre Kaya verdeutlicht Joshua seinen Wunsch nach Heirat und Kindern (vgl. Transparent I/3: 4:45). Michelle Westbrook (The Romanoffs I/2), eine verheiratete Frau, die außerhalb der Ehe nach Abwechslung sucht, verkörpert das, was sich Michael Romanoff eigentlich wünscht: ein Ausbrechen aus seinem als eintönig empfundenen Ehe- und Familienleben. Emaline Addario bringt Kate Messner ihre Homosexualität näher und schenkt ihr Selbstvertrauen. Aus dieser beispielhaften Aufzählung ergibt sich, dass außerfamiliäre weibliche Charaktere, welche mit den Protagonist/inn/en in eine amouröse und/oder sexuelle Beziehung treten, die vornehmliche Aufgabe haben, diese bei ihrem Selbstfindungsprozess zu unterstützen - sei es in Bezug auf die sexuelle Selbstfindung, das ,Erlernen' von Beziehungssituationen oder eine allgemeine gesellschaftliche Orientierung. Auch wenn sich Beziehungen im Verlauf der Handlung trennen und die Figuren sich in Abneigung gegenüberstehen, bieten sie eine Hilfestellung für die Hauptcharaktere auf ihrem Weg zu einer 
gefestigten gesellschaftlichen und familiären Position. Dabei handelt es sich nicht zwingend um eine adoleszente Selbstfindung. Auch ein erwachsener Charakter kann erkennen, dass seine aktuelle Lebenslage nicht, optimal ' ist. Damit unterstützen sie, wie obenstehende Adjuvantinnen, die Protagonist/inn/en und ermöglichen Charakterentwicklung und die damit einhergehende Handlung.

Abschließend ist es von Interesse einen Blick auf die Beziehungssituation der außerfamiliären Charaktere zu werfen. Wenn jugendliche oder sehr junge Charaktere ledig sind, ist dem natürlich keine besondere Bedeutung zuzumessen. Interessanter ist die Lebenssituation erwachsener Charaktere. Verheiratete Charaktere bzw. Charaktere in einer eheähnlichen Beziehung unterliegen dabei weitgehend den gleichen Strukturen wie Ehefrauen und Mütter bzw. werden in ihrer Situation nicht besonders thematisiert, da eheliche Probleme in der Regel am Beispiel der Protagonist/inn/en verhandelt werden. Charaktere, die nicht in einer Beziehung leben, nehmen deutlich häufiger einen Sonderstatus ein. Zunächst sind - wie oben angesprochen - sämtliche Antagonistinnen bzw. Opponentinnen, mit Ausnahme von Ondine, weder verheiratet noch in einer Beziehung. Es verbleiben Susie Myerson sowie Rachel Garrison, Olivia Rogers, Elena Evanovich, Davina Rejennae und Rita Holt. Susie Myerson, die mit Kleidung und Verhalten sehr maskulin anmutet, kann bzw. will als mutmaßlich homosexueller oder u. U. asexueller Charakter in den 1950er Jahren keine offene Beziehung eingehen. Ebenso hat Davina Rejennae als älterer transsexueller Mann eine besondere Position inne, denn auch für sie ist das Eingehen einer Beziehung kompliziert. Rachel Garrisons promiskuitive Existenz macht sie offensichtlich einsam und angreifbar (vgl. 3.1.2.4). Rita Holt, Joshua Pfeffermans ehemalige Babysitterin, ist eine immer wiederkehrende Beziehung des Charakters und eher ein Irritationsfaktor in seinem Leben - dies wird spätestens deutlich, als sie ihm seinen Sohn, den Teenager Colton, vorstellt und damit sein Leben weiter destabilisiert (vgl. Transparent I/10: 17:52). Die Russin Elena Evanovich, die dem Ehepaar Garner eine Adoptivtochter vermitteln soll, gibt sich als kühler und eigenständiger Charakter, wird aber vor allem von dem Wunsch getrieben, verwaisten Kindern ein Zuhause zu bieten (vgl. The Romanoffs I/7: 1:17:58). Einen Sonderfall hinsichtlich der allgemeinen Einordnung stellt Olivia Rogers dar, eine junge Schauspielerin in der dritten Folge von The Romanoffs. Sie ist innerhalb der gesamten Serie die einzige weibliche Protagonistin ohne Beziehung bzw. familiäre Anbindung. Olivia ist eine alleinstehende Frau ohne Familie - ihre Mutter ist kurz vor Einsetzen der Handlung gestorben (vgl. The Romanoffs I/3: 40:40). Sie versucht sich vor der autoritären Regisseurin Jacqueline Gerard und unter den männlichen Schauspielern am Set zu behaupten und blickt auf eine längere Geschichte von Diskriminierung aufgrund ihres Geschlechts zurück (vgl. The Romanoffs I/3: 
1:08:27). Sie schläft mit ihrem Schauspielerkollegen Samuel (vgl. The Romanoffs I/3: 28:54), erhält von ihm aber später keine moralische Unterstützung mehr. Die alleinstehende Olivia muss sich auf ihren Agenten verlassen, der sie in ihren Sorgen und Nöten allerdings wenig ernstnimmt. Letztlich stirbt die völlig überlastete und gestresste Olivia - wohl aufgrund eines Schocks - während der Dreharbeiten. Die Absenz moralischer Unterstützung durch Familie oder Partner ist eine der Ursachen für die Situation. Die Konsequenzen des fehlenden familiären Rückzugsraums betonen im Umkehrschluss dessen Bedeutung.

Alleinstehende weibliche Charaktere nehmen in den Serien des Korpus eine Sonderrolle ein, die im Gegensatz zu Charakteren in Paarbeziehungen steht. Häufig stechen sie durch bestimmte Merkmale heraus, die sich von anderen Figuren abheben. Am auffälligsten sind dabei die Opponentinnen, die durch eine Absenz von Familie und/oder Liebe in ihrem Leben auffallen. Dieser Mangel kennzeichnet sie als unnatürlich gegenüber den Protagonist/inn/en, die stets nach familiärer oder amouröser Anbindung suchen oder diese bereits gefunden haben.

Neben mehrheitlich sekundären und tertiären Adjuvantinnen-Figuren treten außerfamiliäre Frauen überwiegend als sexuell oder romantisch attraktive Charaktere auf. Sie nehmen damit wichtige Positionen im Leben der Protagonist/inn/en ein und beeinflussen deren Entwicklung. Trotz dieser bedeutsamen Positionen findet aber letztlich eine Definition dieser Charaktere über ihre weibliche Attraktivität bzw. ihre Eignung als potenziell dauerhafte Partnerinnen statt. Frauen ohne Beziehung nehmen eine spezielle Rolle ein, wenn sie nicht als Antagonistinnen fungieren. Die analysierten Serien nehmen also weitestgehend eine Reduzierung auf konservative Rollenmuster vor: Frauen, die nicht in einer Beziehung sind und damit die (mehrheitlich männlichen) Protagonist/inn/en in ihrer Entwicklung hin zu einer gefestigten gesellschaftlichen und familiären Rolle unterstützen sei es als zwischenzeitliche Weggefährtinnen oder spätere Ehefrauen -, müssen zwar nicht unbedingt negativ konnotiert sein, stehen aber in der Regel außerhalb einer dominanten Norm. Eine Selbstverwirklichung außerhalb familiärer Strukturen oder ohne die (zumindest emotionale) Abhängigkeit von einem Partner - wobei hier Heterosexualität die Norm ist - ist entweder entbehrungsreich oder wird genuin negativ konnotiert. Das Leben innerhalb der Familie wird durch die Setzung als Norm als einzig möglicher Raum eines gelungenen Lebens für weibliche Charaktere gesetzt. 


\subsubsection{Darstellung und figurative Konzeption männlicher Charaktere}

\subsubsection{Väter und Ehemänner}

Bezüglich der Darstellung der Väter und Ehemänner möchte ich mit einer ,historischen Chronologie', angefangen beim Weltmodell der 1950er Jahre in The Marvelous Mrs. Maisel, beginnen. Die älteren Patriarchen Abraham Weissman und Moishe Maisel verfügen über eine nahezu uneingeschränkte Verfügungsgewalt bzw. die oberste Autorität über die Familie. Vor allem Abraham Weissman sticht als klassischer Patriarch heraus. Auch wenn Mutter und Tochter ihm mit begrenztem Respekt begegnen und er in vielen seiner Verhaltensweisen verschroben und neurotisch wirkt ${ }^{70}$, so stellt er doch innerhalb der Familie Weissman die zentrale Autorität dar, nach der sich die meisten Abläufe ausrichten, zumal er den Lebensunterhalt der Familie verdient. Er ist dabei nicht bereit, sein Leben auch nur in Details den Bedürfnissen anderer anzupassen. ${ }^{71}$ Seiner Ehefrau und seiner Tochter begegnet er mit Ignoranz, in manchen Fällen sogar Herablassung - eine Attitüde, die er generell auf Frauen überträgt. ${ }^{72}$ Allgemein ist er der Meinung, über das Leben seiner Tochter verfügen zu können, und behandelt sie, als sei sie weiterhin ein Kind. ${ }^{73}$ Moishe Maisel, Joels Vater, tritt weniger in Erscheinung, zeigt aber ähnliche Verhaltensweisen, wenn er sich beispielsweise mit Abraham Weissman verbündet, um die Kinder wieder zusammenzubringen (vgl. The Marvelous Mrs. Maisel I/3: 24:30). Abraham, und am Rande Moishe, treten mit großer

\footnotetext{
${ }^{70}$ Das Ausmaß seines Wutausbruchs, als er von der Trennung seiner Tochter erfährt nimmt absurde Züge an, als er sein Büro zerstört und wild auf dem Klavier spielt (vgl. The Marvelous Mrs. Maisel I/1: 37:56). Prinzipiell legt er neurotisches Verhalten an den Tag, wenn er z. B. verzweifelt nach Alltagsgegenständen sucht und dabei seine Frau, die mit ihm spricht, weitgehend ignoriert (vgl. The Marvelous Mrs. Maisel I/3: 06:30).

${ }^{71}$ Beispielsweise will er seinem Enkelsohn nach dem Abendessen nicht zugestehen, dass dieser fernsieht, da er jeden Abend nach dem Essen im Wohnzimmer liest. Auch nur einmalig von dieser Gewohnheit abzuweichen, ist für ihn undenkbar (vgl. The Marvelous Mrs. Maisel I/4: 08:37).

${ }^{72}$ Er gibt beispielsweise Miriam die Schuld an ihrer Trennung, da sie sich einen schwachen Mann ausgesucht hat (vgl. The Marvelous Mrs. Maisel I/1: 38:22), und will später nicht glauben, dass sie tatsächlich einen Beruf ergriffen hat (vgl. The Marvelous Mrs. Maisel I/5: 29:01). U. a. äußert er den Gedanken, dass alle hochintelligenten Menschen, besonders Frauen, hässlich seien (vgl. The Marvelous Mrs. Maisel I/4: 22:44).

${ }^{73}$ So will er sie gegen ihren Willen dazu bringen, die Ehe mit Joel wiederherzustellen (vgl. The Marvelous Mrs. Maisel I/2: 41:55). Als Miriam spätabends nach Hause kommt, verhört er sie und stellt drakonische Verhaltensregeln auf (vgl. The Marvelous Mrs. Maisel I/4: 50:09).
} 
Selbstverständlichkeit als Familienoberhäupter und als ,Vorgesetzte' ihrer Ehefrauen und Töchter auf. Dass Abraham kein per se negativer Charakter ist, sondern bei Zeiten eher hilflos erscheint, verdeutlicht, dass es sich hier nicht um eine bösartige Autoritätsausübung oder den Wunsch handelt, die Frauen der Familie zu unterdrücken. Vielmehr ist die Verfügung über die Ehefrau und insbesondere die Tochter und den Sohn, gepaart mit der Ignoranz gegenüber weiblichen Bedürfnissen, natürlicher Teil des Weltbildes der Charaktere. Sie sehen sich in der Rolle des Patriarchen, welche die Gesellschaft ihnen zugewiesen hat, und reflektieren in keiner Weise alternative Verhaltensmodelle bzw. ziehen keine Änderungen ihres Verhaltens in Betracht.

Joel Maisel, Angehöriger einer jüngeren Generation, ähnelt in seinem Verhalten seinem Vater und Schwiegervater. So macht er beispielsweise seine Ehefrau für sein persönliches Scheitern als Comedian verantwortlich (vgl. The Marvelous Mrs. Maisel I/1: 31:07), lässt sie und ihre beiden gemeinsamen Kinder ohne Weiteres zurück, um mit seiner Sekretärin zusammenzuleben, und richtet sich mit dieser ein Leben ein, das dem mit Miriam entspricht (vgl. The Marvelous Mrs. Maisel I/4: 30:35). Letztlich entscheidet er sich dafür, Miriam und die Kinder weiterhin finanziell zu versorgen (vgl. The Marvelous Mrs. Maisel I/7: 31:00). Er verprügelt sogar einen Mann, der sie bei einem ihrer Auftritte beleidigt (vgl. The Marvelous Mrs. Maisel I/8: 58:27). Verantwortungsgefühl ebenso wie Zuneigung und eine Art Ehrbegriff bleiben also trotz der Trennung, die vor allem Miriam als endgültig vertritt, vorhanden. Er kann Miriam allerdings nicht zurückgewinnen und ist auch nicht imstande, ausreichend Autorität über sie auszuüben, um sie zu einer erneuten Beziehung zu zwingen. An seinem Charakter wird bereits ein Schwinden männlicher Autorität deutlich. Er versucht die vorangegangene Generation autoritärer und ignoranter Ehemänner/Väter zu imitieren, scheitert aber an der Eigenständigkeit seiner Ehefrau. Dabei muss deutlich sein, dass es sich bei Miriam Maisel um eine Ausnahme-Frau inmitten devoter weiblicher Charaktere handelt.

Frank Murphy, Ehemann von Sue Murphy und Vater von Kevin, Bill und Maurreen in $F$ is for Family, besteht - wie Abraham Weissman - darauf, dass sein häusliches Leben unangetastet von den Belangen seiner Ehefrau oder seiner Kinder bleibt. Frank wird zu Beginn der Serie als missgelaunter Choleriker etabliert. Eine belanglose Störung wie ein Werbeanruf beim Abendessen genügt, um einen enormen Wutausbruch zu provozieren, der ihn dazu verleitet, sich nicht nur abfällig gegenüber seiner Ehefrau zu äußern, sondern auch einen Nachbarsjungen zu beschimpfen (vgl. F is for Family I/1: 1:00). Wie dies bei bewusst überzeichneten Zeichentricksitcom-Charakteren häufig der Fall ist, ändert sich sein Verhalten 
im weiteren Serienverlauf nicht. Er zeigt kaum Zuneigung gegenüber seinen Kindern, es kann sogar von Verachtung die Rede sein. ${ }^{74}$ Die Elternschaft nimmt Frank als Last wahr und versucht sie vor allem seiner Ehefrau zu überlassen, der er - obwohl er sie allem Anschein nach liebt - ebenfalls mit weitgehender Ignoranz und Ablehnung begegnet. ${ }^{75}$ Kinder wie Ehefrau müssen dabei unter seinen restriktiven Moralvorstellungen leiden. Diese Haltung, welche dazu führt, dass die Familie in einem ständigen Klima der Angst vor ihm lebt (vgl. $F$ is for Family I/2: 2:00), resultiert aus einer grundlegenden Unzufriedenheit mit seinem Leben und seinem Beruf. Explizit äußert er, nicht glücklich zu sein (vgl. $F$ is for Family I/2: 2:00). Seine eigene Familie nimmt er im Alltag als mangelhaft wahr (vgl. $F$ is for Family I/3: 23:00). Grund für seine Unzufriedenheit, die er an Frau und Kindern auslässt, ist vor allem ein Korsett gesellschaftlicher und beruflicher Erwartungen, dem er nicht gerecht werden kann und das ihn überlastet. ${ }^{76}$ Im Inneren scheint er eine tiefe Zuneigung für seine Frau und seine Kinder zu empfinden. Wenn es notwendig ist, verteidigt er sie sogar mit Gewalt (vgl. $F$ is for Family I/6: 15:00). Nur in entsprechenden Extremsituationen, ist es ihm möglich, seine Emotionen zu äußern: „I got the best family in this whole goddamn town!“ (vgl. F is for Family I/6: 16:00). Das alltägliche Verhalten Murphys gegenüber Frau und Kindern ist indes von negativer Ablehnung geprägt.

Ramon Cruz, Vater von Mylene und Ehemann von Lydia in The Get Down, unterdrückt mit absoluter Autorität und großem christlichen Fanatismus Ehefrau und Tochter. Sein Selbstmord stellt ein Scheitern hyperpatriarchaler Strukturen dar. Winston Kipling, Vater von vier Charakteren in The Get Down, übt ebenfalls deutliche Autorität über seine Söhne aus. So müssen sie den Gehweg vor seinem Friseursalon fegen (vgl. The Get Down I/1: 6:00). Allgemein ist er aber ein positives Gegenmodell zu Cruz, wenn er die Liebe zu seinen Kindern und seiner

\footnotetext{
${ }^{74}$ Insbesondere der pubertäre und rebellische Sohn Kevin stellt einen Störfaktor für Frank dar. Dementsprechend beleidigt er ihn (vgl. $F$ is for Family I/1: 6:00) und trifft Entscheidungen wie die Ersparnisse für dessen College-Besuch für einen neuen Fernseher auszugeben (vgl. $F$ is for Family I/1 11:00). Als er einmal allein auf die Kinder achtgeben muss, fällt ihm nichts Besseres ein, als sie sofort ins Bett zu schicken (vgl. $F$ is for Family I/4: 9:00), und in ihrer Abwesenheit bedenkt er sie im Gespräch mit seiner Frau mit gefühllosen Beleidigungen (vgl. $F$ is for Family I/4: 14:00).

${ }^{75}$ So bezeichnet er ihren Beruf als Tupperware-Verkäuferin als „little hobby“ (vgl. $F$ is for Family I/2 6:00) und lehnt in ihrem Namen ein Jobangebot ab (vgl. F is for Family I/4: 9:00). ${ }^{76}$ Bereits im Vorspann sieht man, wie er rasch durch sein Leben fliegt vom Schulabgänger zum Soldaten in Korea und schließlich zum Angestellten wird - eine Entwicklung, die ihn offensichtlich deprimiert. Er wurde in seiner eigenen Wahrnehmung zu schnell durch die Stationen des Lebens geschleust.
} 
Familie nahezu überbetont (vgl. The Get Down I/3: 7:00) und diese bewusst nicht körperlich bestraft (vgl. The Get Down I/4: 20:00).

Die Darstellungen von Vätern in den 1970er Jahren zeigen ein durchwachsenes Bild, in dem patriarchale Strukturen wie in den 1950er Jahren vorherrschen, jedoch sukzessive ins Wanken geraten. Eine Fortführung dieses Verlaufs zeigt sich in Red Oaks. Sam Myers ist kein Extrem wie Ramon Cruz oder Frank Murphy, aber nach wie vor alleiniger Brotverdiener der Familie. Sein Leben basiert, ebenso wie Frank Murphys, auf einer als negativ und belastend empfundenen Entwicklung:

Sam: „Promise me that you won't make the same mistakes we did. [...] Your mother and I. We never loved each other. We should have split years ago except you came along. I should have married Sun Yi.“ - David: „Who's Sun Yi?"“ - Sam: „She's the girl I knew in Korea. Oh, she had such beautiful eyes [...] I think your mother's a lesbian or at least technically bisexual.“ (Red Oaks I/1: 1:59)

Sam empfindet sein Leben als Lüge - eine Erkenntnis, die er im Moment eines Herzanfalls seinem Sohn David mitteilt. Trotz dieser Einsicht - Ergebnis einer Extremsituation - bemüht er sich im Folgenden recht wenig um den Erhalt der Ehe oder um Einsicht gegenüber seinem Sohn. David soll nach seiner Vorstellung ebenso wie er Steuerberater werden. Dessen beruflicher Erfolg steht für ihn im absoluten Vordergrund (vgl. Red Oaks I/9: 10:40), auch wenn David die Pläne seines Vaters weitgehend ablehnt. Der Paartherapie mit seiner Frau steht Sam mit gelangweilter Ignoranz bzw. einer regelrechten Verweigerungshaltung gegenüber (vgl. Red Oaks I/4: 8:03) und schenkt ihr darüber hinaus wenig Aufmerksamkeit (vgl. Red Oaks I/3: 3:20). Diese Haltung entspringt - wie im Falle Abraham Weissmans oder Joel Maisels - keiner direkten Abneigung gegenüber seiner Familie, vielmehr zeigt sich in einigen Szenen eine große Zuneigung zu seiner Frau und seinem Sohn. ${ }^{77}$ Das oben geschilderte Empfinden, sein Leben sei von Grund auf falsch verlaufen, ebenso wie eine gewisse Engstirnigkeit, mit der er seine konservativen Werte vertritt, blockieren ihn in seinem Verhalten gegenüber der Familie. Allerdings sind die herrschenden negativen Verhältnisse derart Teil seines Alltags geworden, dass nur eine extreme Situation bzw. eine besondere Belastung

\footnotetext{
77 Als David auf der Couch einschläft, betrachtet er diesen liebevoll und küsst ihn auf die Stirn (vgl. Red Oaks I/3: 22:34). Später entwickelt er die Wunschvorstellung, der beste Freund seines Sohnes zu sein (vgl. Red Oaks I/7: 15:20). Er macht sich zudem ernsthafte Sorgen darüber, ob seine Frau ihn noch liebt (vgl. Red Oaks I/9: 12:49).
} 
Anlass dafür sein kann, sich dies einzugestehen. Sam scheitert an den Folgen seines autoritären Verhaltens: Sein Sohn ordnet sich nicht seinen Plänen unter und seine Frau lässt sich von ihm scheiden.

Bei Ken Messner in Everything Sucks! handelt es sich zusammen mit Russ Langmore um einen von zwei alleinerziehenden Vätern innerhalb des Korpus. ${ }^{78}$ Der Verlust seiner Ehefrau hat den Vater offensichtlich gezeichnet (vgl. Everything Sucks! I/1: 17:00) und er steht der Erziehung seiner Tochter, der es an einer Mutterfigur mangelt, mit einer gewissen Hilflosigkeit gegenüber. Dennoch beweist er sich als positive Vaterfigur. Er übt weder überzogene Autorität über seine Tochter aus noch versucht er ihr besondere Wertvorstellungen aufzuzwingen. Er will ihr vielmehr Offenheit und Toleranz sowie ein positives Selbstwertgefühl vermitteln und versucht ein Ansprechpartner für seine Tochter zu sein (vgl. Everything Sucks! I/1: 19:00). Fern jedes dramatisierten oder heroisierten Ehrbegriffs oder männlichen Machismo stellt er eine Ausnahme dar, auch unter den Videoon-Demand-Serien, welche Väter der Gegenwart zeigen. Liebe zu einer Tochter und das Bemühen um die Familie werden als natürliche Charaktermerkmale dargestellt und nicht als Akte romantisierter Selbstaufgabe oder Selbstgefährdung.

Russ Langmore steht zwar nicht im absoluten Gegensatz zu Ken Messner, schließlich ist auch er um seine Söhne und deren Wohlergehen besorgt. In seiner infantilen Unselbstständigkeit und seinem Hang zu Alkohol und Kontrollverlust stellt er aber kaum eine geeignete Vaterfigur dar. Seine Söhne verwahrlosen, die Absenz einer geeigneten Mutterfigur kann durch Ruth nur partiell kompensiert werden.

Wie mit Rückbezug auf Marty Byrde (Ozark) deutlich wird, behalten Väter und Ehemänner in Video-on-Demand-Serien über die Szenarien hinweg bestimmte Grundmerkmale bei. Die Grundlage eines väterlichen Idealbilds bildet dabei weiterhin der Familienvater der Serien der 1950er und 1960er Jahre. Im Gegensatz zu diesen wird das Zusammenleben der Familie in Video-on-Demand-Formaten problematisiert, die Väter nicht mehr als perfekt und omnipotent inszeniert.

Zunächst bestätigt sich in Marty Byrde und anderen Vaterfiguren des Korpus eine klare Geschlechterkonzeption hinsichtlich des allgemeinen Verhaltens und der Emotionalität der Figuren. Marty Byrde zeigt sich im Allgemeinen deutlich gelassener und kühler als seine Ehefrau Wendy. Ebenso wünscht sich Doug Gardner in Atypical mehr mit seinem Sohn teilen zu können und bemüht sich ein guter

\footnotetext{
${ }^{78}$ Mason Young in Ozark, der nach dem Tod seiner Frau sein Kind aufziehen muss, ist zwar ebenfalls ein alleinerziehender Vater. Da er diese Position erst mit Ende der letzten Episode der ersten Staffel einnimmt, soll er hier ausgenommen werden. Ebenso ist Cade Langmore alleinerziehend, kann diese Funktion allerdings aus dem Gefängnis heraus kaum wahrnehmen.
} 
Vater zu sein (vgl. Atypical I/1: 7:00, I/2: 4:00), distanziert sich aber vom übermäßigen Aufgehen seiner Frau in ihrer Mutterrolle (vgl. Atypical I/1: 19:00, I/5: 27:00). Zwar verließ er die Familie Jahre vor Einsetzen der Handlung für einige Zeit (vgl. Atypical I/3: 25:00), dies wird allerdings durch sein Zurückkehren und seine intensiven Versuche relativiert, sich mit seinem Sohn auseinanderzusetzen. Zudem beging er - im Gegensatz zu seiner Ehefrau - keinen Ehebruch, sondern suchte Zeit zur Selbstfindung ohne einen explizit destruktiven Akt. Einige Familienväter und Ehemänner in The Romanoffs zeigen ähnliche Verhaltensweisen. Eric Ford begegnet dem hochemotionalen Verhalten seiner Ehefrau gelassen und wirft ihr implizit Hysterie vor (vgl. The Romanoffs I/2: 11:10). Alex Myers äußert sich abfällig über nicht berufstätige Mütter, die übermäßig beschützend mit ihren Kindern umgehen (vgl. The Romanoffs I/5: 54:33), gegenüber seinen Kindern agiert er als moralische Instanz (vgl. The Romanoffs I/5: 1:03:30). Joe Garner (The Romanoffs I/7) agiert im Vergleich zu seiner deutlich emotionalen Ehefrau ebenfalls wesentlich nüchterner. Philipp Hayward wiederum versucht seine Frau davon abzubringen, dass sie ihren kranken Sohn immer neuen teuren, aber fruchtlosen Behandlungen aussetzt (vgl. The Romanoffs I/6: 1:02:30).

Beau Bennett, Vater des Protagonisten Colt Bennett in The Ranch, stellt ein Extrem dar. Er zeigt sich gegenüber seinen Söhnen nicht nur rational und nüchtern wie obige Charaktere, sondern geradezu kühl und oft ablehnend. ${ }^{79}$ Seine Ehe war von seiner emotionalen Abwesenheit gegenüber seiner Frau gekennzeichnet: Sie wirft ihm vor, er habe sich nur um seine Ranch gekümmert, nicht um sie (vgl. The Ranch I/4: 18:00). Auch wenn er diesen Fehler letztlich eingesteht (vgl. The Ranch I/4: 24:00), bleibt er doch hart, engstirnig und äußerst konservativ (vgl. The Ranch I/1: 14:00, I/7: 1:00) und weigert sich Hilfe und Unterstützung anzunehmen (vgl. The Ranch I/1: 24:00, I/8: 20:00). Dieses problematische Verhalten kann innerhalb der Sitcom-Dynamik von The Ranch als verschrobene Eigenheit, als Charakter-Extrem inmitten von Extremen gelten. Zudem legitimieren sich Beaus Verhaltensweisen über die Härte des Lebens als Rancher, das eine Hingabe an den Beruf notwendig macht (vgl. The Ranch I/1: 20:00, I/3: 28:00).

Häufig stellen Ehemänner und Väter folglich den rationalen bzw. emotional zurückgenommenen Teil des Ehepaares innerhalb der dargestellten Weltmodelle dar. Während Ehefrauen und Mütter in der Regel der fürsorgliche und ,weiche ${ }^{6}$ Teil der Beziehung sind, Emotionen zeigen und nicht selten von ihnen

\footnotetext{
${ }^{79}$ Er begrüßt seinen Sohn, der nach längerer Zeit nach Hause zurückkehrt, mit ,What the hell are you doing here?" (vgl. The Ranch I/1: 1:00), macht sich wiederholt über ihn lustig und würdigt ihn herab (vgl. The Ranch I/1: 5:00, I/2: 6:00, 21:00). Er lobt seine Söhne auch nicht, selbst wenn sie etwas nach seinen Vorstellungen erfüllen (vgl. The Ranch I/1: 16:00).
} 
bestimmt werden, ist es Aufgabe der Vaterfiguren moralische Richtlinien vorzugeben, die Kinder mit der Lebensrealität zu konfrontieren und auf die Härte des Lebens vorzubereiten. Eine Ausnahme bilden fürsorgliche Charaktere wie Mort/Maura Pfefferman (Transparent) oder Sol Bergstein, die Wärme und Zuneigung gegenüber ihren Kindern zeigen. Diese beiden Charaktere bestätigen jedoch die Regel: Sol ist homosexuell und Maura fühlt sich als Frau. Sie stehen also im Gegensatz zu den heterosexuellen Ehemännern, ihr emotionaleres Verhalten ist intradiegetisch als Abweichung von der heterosexuellen Norm gekennzeichnet. Ken Messner ist zwar ebenfalls ein emotionaler Charakter, dies wird ihm allerdings als alleinerziehender Vater einer Tochter und als Ersatz für die verstorbene Mutter abverlangt. Nur in extremen Belastungsfällen zeigen die männlichen Charaktere ihre Emotionen: Sei es der Wutanfall Abraham Weissmans, als er von der Trennung seiner Tochter erfährt, Frank Murphy, der seine Familie mit Gewalt verteidigt und danach offen seine Liebe äußert, oder Sam Getty, der einen Herzanfall erleidet und seinem Sohn seine Gefühle gesteht. Bisweilen bringt eine entsprechende Situation aufopferungsvolles und selbstloses Vaterverhalten zum Schutz der Familie mit sich.

\section{Berufliche Einbindung von Vätern/Ehemännern}

\begin{tabular}{l|l|l}
\hline Serie & Charakter & Beruf \\
\hline 1. Atypical & Doug Gardner & Rettungssanitäter \\
\hline 2. Everything Sucks! & Ken Messner & High-School-Direktor \\
\hline 3. F is for Family & Frank Murphy & Flughafen-Angestellter \\
\hline 4. Grace and Frankie & $\begin{array}{l}\text { Sol } \\
\text { Bergstein-Hanson }\end{array}$ & Anwalt \\
\hline XXX 5. Grace and Frankie & $\begin{array}{l}\text { Robert } \\
\text { Bergstein-Hanson }\end{array}$ & Anwalt \\
\hline 6. Ozark & Marty Byrde & Finanzberater \\
\hline 7. Ozark & Cade Langmore & Kleinkrimineller/Gefängnis-Insasse \\
\hline 8. Ozark & Russ Langmore & Kleinkrimineller/Tagelöhner \\
\hline 9. Ozark & Mason Young & Priester \\
\hline 10. Red Oaks & Sam Myers & Steuerberater \\
\hline 11. Red Oaks & Doug Getty & Aktienhändler \\
\hline 12. The Get Down & Ramon Cruz & Christlicher Priester \\
\hline XXX 13. The Get Down & Winston Kipling & Barbier/Friseur \\
\hline 14. The Marvelous Mrs. & Joel Maisel & $\begin{array}{l}\text { Angestellter eines } \\
\text { Plastik-Unternehmens, später Arbeit } \\
\text { Maisel }\end{array}$ \\
\hline
\end{tabular}




\begin{tabular}{l|l|l}
\hline $\begin{array}{l}\text { Berufliche Einbindung von Vätern/Ehemännern } \\
\text { Serie }\end{array}$ & Charakter & Beruf \\
\hline $\begin{array}{l}\text { 15. The Marvelous Mrs. } \\
\text { Maisel }\end{array}$ & $\begin{array}{l}\text { Abraham } \\
\text { Weissman }\end{array}$ & Mathematik-Professor \\
\hline $\begin{array}{l}\text { 16. The Marvelous Mrs. } \\
\text { Maisel }\end{array}$ & Moishe Maisel & $\begin{array}{l}\text { Leiter eines } \\
\text { Bekleidungsunternehmens }\end{array}$ \\
\hline 17. The Ranch & Beau Bennett & Rancher/Viehzüchter \\
\hline $\begin{array}{l}\text { 18. The Romanoffs } \\
\text { 19. The Romanoffs }\end{array}$ & $\begin{array}{l}\text { I/2 Michael } \\
\text { Romanoff }\end{array}$ & $\begin{array}{l}\text { Berater für } \\
\text { High-School-Absolventen (Wahl des } \\
\text { Colleges) }\end{array}$ \\
\hline 20. The Romanoffs & I/4 Eric Ford & Anwalt \\
\hline XXX 21. The Romanoffs & I/4 Ron Hopkins & Rentner (?) \\
\hline 22. The Romanoffs & I/6 Alex Myers & Manager (oder Ähnliches) \\
\hline 23. The Romanoffs & I/7 Joe Garner & Angestellter der Universal-Studios \\
\hline 24. The Romanoffs & I/8 George Burrows & Unbekannter Beruf \\
\hline 25. Transparent & $\begin{array}{l}\text { Maura/Morton } \\
\text { Pfefferman }\end{array}$ & Emeritierter Universitätsprofessor \\
\hline
\end{tabular}

Die Zeichnung des Mannes als ,harter und gestandener Mann', sozusagen als Verteidiger der Familie außerhalb des familiären Raumes, geht mit der dominanten Positionierung als alleiniger Familienversorger einher. Im Gegensatz zur Ehefrau bewegen sich Väter und Ehemänner außerhalb des geschützten familiären Raumes und müssen somit Härte und Rationalität beweisen. Während Ehefrauen und Mütter vor allem durch familiäre Konflikte belastet werden, ist es bei den Männern oft die Arbeitswelt und deren Anforderungen. Im Fall von Marty Byrde, dessen ,Arbeit" die gesamte Familie bedroht, handelt es sich um ein Extrem ebenso wie bei Beau Bennett, der sein ganzes Leben seiner Ranch verschrieben hat. Joel Maisel leidet unter der mangelnden Begeisterung, die er für seinen Beruf empfindet - ein Aspekt, der zu seinem Ehebruch beiträgt -, und unter seiner Erfolglosigkeit als Stand-Up-Comedian (The Marvelous Mrs. Maisel I/1:34:26). Ramon Cruz identifiziert sich über seinen Beruf, auch wenn es sich bei ihm eher um eine ,Berufung' handelt, unter der seine Familie leidet und an der er letztlich zugrunde geht. Frank Murphy muss die schlechte Behandlung erdulden, die er wiederholt an seinem Arbeitsplatz durch seine Vorgesetzten erfährt (vgl. $F$ is for Family: I/1: 1:00, I/2: 4:00, 13:00, I/3: 11:00). Die Frustration, welche sich in seiner beruflichen Situation aufbaut, lässt er an seiner Familie aus. Doug Getty, Präsident des Country-Clubs in Red Oaks und Skyes Vater, identifiziert 
sich über seine Arbeit an der Börse (vgl. Red Oaks I/8: 1:41) und wird wegen Insider-Handels festgenommen (vgl. Red Oaks I/10: 16:30). Michael Romanoff, der High-School-Abgänger bei der Wahl einer Universität berät, aber selbst seine Heimatstadt nie verlassen hat, fühlt sich als Versager (The Romanoffs I/2: 07:00) und überträgt diese Unzufriedenheit auf seine Ehe. Doug Gardner bemüht sich indes aktiv Familie und Beruf nicht zu vermischen, indem er seinen Kollegen nie davon berichtet, dass sein Sohn Autist ist (vgl. Atypical I/5: 26:00). Die berufliche Einbindung des Ehemannes hat folglich immer wieder negative Auswirkungen auf die Familie, sei es direkt, wenn der Beruf den Vater über Gebühr in Anspruch nimmt, oder indirekt, wenn sich die Belastung des Vaters negativ auf dessen psychische Verfassung und damit auf seinen Umgang mit der Familie ausübt. Obwohl negative Verhaltensweisen des Vaters gegenüber seiner Frau und seinen Kindern keinesfalls positiv konnotiert werden - schließlich haben sie direkte negative Konsequenzen auf das Leben der Ehefrau und der Kinder -, sind sie doch in der Logik der meisten Weltmodelle entschuldbar: Als Alleinverdiener ist es die unbedingte Verantwortung des Ehemannes, sich für den Beruf aufzuopfern. Wenn die Hingabe an den Beruf den Charakter zu sehr in Anspruch nimmt oder negative psychische Konsequenzen mit sich bringt, wird es als notwendiges Übel bzw. äußerer Zwang verstanden. Dadurch wird die Schuld des Mannes an seinen Verfehlungen relativiert.

Diese männliche Stellung hat allerdings nicht allein Auswirkungen auf das innerfamiliäre Verhalten und die charakterlich-emotionale Verfassung der Figuren, sondern bestimmt auch zentral deren Verortung in der familiären Autoritätsstruktur. Bis auf wenige Ausnahmen (mit XXX gekennzeichnete Felder in obiger Tabelle) ist die Mehrzahl der Familienväter in meinem Analysekorpus alleiniger Geldverdiener der Familie. Allein durch diesen Umstand üben sie Autorität auf den Rest der Familie aus, binden diese an sich, auch wenn dies nicht explizit verbalisiert wird. Bei der finanziellen Autorität des Ehemannes handelt es sich um ein tief verankertes narratives Muster, das bisweilen über die Handlungslogik hinausgeht. So sperren Sol Bergstein und Robert Hanson ihren Ehefrauen die Kreditkarten, um sich vor finanzieller Rache zu schützen (vgl. Grace and Frankie I/2: 8:00). Warum dies ohne weiteres möglich ist, warum die Ehemänner hier Verfügungsgewalt haben, ist nicht erklärbar, schließlich handelt es sich bei Grace Hanson um eine erfolgreiche Unternehmerin. Die Tatsache, dass die Ehemänner, obgleich sie sich von ihren Frauen getrennt und sich als homosexuelles Paar geoutet haben, weiterhin Autorität über ihre Ehefrauen ausüben, wird de facto nicht in Frage gestellt. Es findet eine klare Hierarchisierung des Männlichen über das Weibliche statt. 
Betrachtet man daher die Rolle der Ehemänner und Väter in Video-onDemand-Serien gesamtheitlich, lässt sich eine klare Ausrichtung an konservativen Geschlechter- und Rollenbildern erkennen. Der Ehemann ist in den meisten Fällen Alleinversorger der Familie, daraus erwächst eine negativ konnotierte Belastung für die Familie, die jedoch durch die schiere Notwendigkeit des Gelderwerbs relativiert wird. Zudem steht der Ehemann durch die finanzielle Verfügungsgewalt hierarchisch über der Ehefrau und kann damit weiterhin als Familienoberhaupt gelten, selbst wenn eine demokratische Familienstruktur behauptet wird. Diese Stellung wird auch durch die Inszenierung der männlichen Figuren als rationaler und weniger emotional im Vergleich zu weiblichen gefestigt. Durch Negativ-Charaktere wie Russ und Cade Langmore in Ozark, die ihre väterliche Verantwortung aus Impulsivität und Selbstsucht nicht wahrnehmen, wird eine dahingehende Rolle des Vaters als vernünftiger Versorger bestärkt. Die Differenz zwischen der Darstellung der Figuren in den Serien des Korpus und den Modellen der 1950er und 1960er Jahre besteht vor allem darin, dass die Autorität des Ehemannes nicht mehr absolut und weniger direkt ausgeübt wird. Ehemänner sind nicht einmal notwendigerweise sympathisch, sondern Menschen mit Schwächen und Makeln, die wiederholt (gravierende) Fehler begehen und somit ihre Familien gefährden. Es ist weniger die Stellung des Ehemannes und Vaters, die sich verändert hat, vielmehr dessen Darstellung.

\subsubsection{Söhne}

In vielerlei Hinsicht lässt sich die Rolle der Söhne meines Analysekorpus mit der Rolle der Töchter vergleichen. Auch sie lassen sich in zwei Gruppen aufteilen: erwachsene und jugendliche Söhne. ${ }^{80}$

Sam Gardner (Atypical), Luke O’Neil (Everything Sucks!), Kevin und Bill Murphy ( $F$ is for Family), Jonah Byrde, Wyatt und Russ Langmore (Ozark), David Myers (Red Oaks), Ezkiel Figuero (,Zeke“/,Books“), Marcus („Dizzee“), Ronald (Ra-Ra“) und Miles („Boo-Boo“) Kipling (The Get Down) teilen als jugendliche

\footnotetext{
${ }^{80}$ In diesem Abschnitt möchte ich die vier Söhne aus The Romanoffs ausschließen. Hier handelt es sich um Henry und Benji Myers (I/5), Nicholas Hayward (I/6) und Simon Burrows (I/8). Simon Burrows, ein transsexueller Mann, wird in 3.2.3 behandelt werden. Henry und Benji Myers, die ihren homosexuellen Klavierlehrer David Patton gegen Vorwürfe verteidigen, sind ein Beispiel für gelungene, tolerante Erziehung. An ihrem Beispiel wird auch demonstriert, wie leicht Kinder durch Gerüchte und üble Nachrede beeinflusst werden können. Nicholas Hayward, ein Junge mit Bluter-Krankheit, verkörpert den Typus des ,ernsten, kranken Jungen', dem durch den mangelnden Kontakt mit anderen Kindern gewissermaßen die Kindheit genommen wurde. Hier wird also die Notwendigkeit einer gewissen Unbeschwertheit in der Kindheit hervorgehoben. Es handelt sich allerdings um Randfiguren, aus denen sich keine allgemeine Regel ableiten lässt.
} 
Söhne mehrere Gemeinsamkeiten. Alle genannten Charaktere haben die Obhut ihrer Eltern bzw. den häuslichen Raum noch nicht verlassen, streben jedoch in den meisten Fällen nach einer Loslösung von diesem, nach Selbstverwirklichung und Selbstfindung jenseits elterlicher Aufsicht und Vorgaben.

Sam Gardner ist ein autistischer junger Mann und Protagonist der Serie Atypical. Die Serie wurde explizit ausgewählt, da hier das Leben einer Familie dargestellt wird, die sich in einer , besonderen' Situation befindet. Obwohl Sams Autismus eine tragende Rolle innerhalb der Handlung spielt, kann dessen tatsächliche Bedeutung stark eingeschränkt werden. Der Autismus ist weniger eine extreme Abweichung, die tiefergehend behandelt wird, sondern dient vielmehr als narrativer Katalysator: Die Familie Gardner erfährt Probleme, die nicht per se ungewöhnlich sind, lediglich etwas extremer ausgeprägt. Sams Leben als Teenager, seine Entwicklungen und Wünsche weichen in ihrer Essenz nicht von den anderen Beispielen meines Korpus ab, werden durch seinen besonderen Geisteszustand allerdings etwas verfremdet, somit besonders deutlich hervorgehoben und teilweise komisch überzeichnet. Die zentrale Motivation Sams in der ersten Staffel ist vor allem seine Suche nach einer Freundin und der Wunsch, sexuelle Erfahrungen zu machen. Obwohl er von sich behauptet, für Frauen seines Alters uninteressant zu sein (vgl. Atypical I/1: 4:00), findet er innerhalb der ersten Episode ein etwa gleichaltriges Mädchen, das mit ihm schlafen möchte (vgl. Atypical I/1: 27:00). Zwar findet hier kein Sex statt, da Sam mit der körperlichen Nähe nicht zurechtkommt (vgl. Atypical I/1: 29:00), doch bereits in der vierten Folge geht er eine längerfristige Beziehung ein (vgl. Atypical I/1: 26:00). Diese Beziehung ist von zahlreichen Problemen gekennzeichnet, kann aber innerhalb der ersten Staffel weitgehend aufrechterhalten werden, vor allem da Sam stets imstande ist, sich bei seiner Freundin für Verfehlungen zu entschuldigen. Der explizite Wunsch nach Loslösung von der Familie ist für Sam, auch aufgrund seines Alters, noch nicht relevant. Sein Erwachsenwerden, wird aber von seiner Mutter als Gefährdung des Sohnes bzw. des familiären Status quo wahrgenommen.

Frisch auf der High-School ist Luke O'Neil wesentlich jünger als der 18jährige Sam Gardner. Doch auch für ihn, ebenso wie seine gleichaltrigen Freunde, stehen vor allem die sexuellen Möglichkeiten des High-School-Lebens im Mittelpunkt ihres Interesses (vgl. Everything Sucks! I/1: 8:00). Er verliebt sich und strebt eine Beziehung mit Kate Messner an, die aufgrund ihrer Homosexualität nie tatsächlich zustande kommt. Für Luke spielt auch die Loslösung von seiner Mutter eine besondere Rolle. Nicht im Sinne eines Auszugs aus dem heimatlichen Raum, sondern dadurch, dass er sich mit seiner Mutter - trotz ihres guten Verhältnisses - auf eine Distanz, einen persönlichen Freiraum einigt. Konkret verständigen sie 
sich darauf, sich nicht mehr sämtliche Geheimnisse zu erzählen (vgl. Everything Sucks! I/10: 21:00).

Während Bill Murphys Leben vor allem ein Beispiel für fehlerhafte und traumatisierende Erziehung ist ${ }^{81}$, rebelliert Kevin, der älteste und pubertierende Sohn der Familie Murphy, offen gegen seine Eltern. Insbesondere sein Vater Frank ist für ihn, aufgrund der ständigen Herabwürdigungen, zur Hassfigur geworden. Er träumt davon, nicht zu seiner Familie zu gehören (vgl. $F$ is for Family I/2: 7:00), und konsumiert Drogen, anstatt sich um die Schule zu bemühen (vgl. $F$ is for Family I/3: 4:00). Letztlich sehnt er sich aber nach einer idealen Beziehung zu seinem Vater (vgl. F is for Family I/3: 13:00) und nach einer intakten und liebevollen Familiensituation. Er bewegt sich folglich zwischen dem kindlichen Wunsch nach familiärer Harmonie und Geborgenheit und dem dringenden Versuch, sich von Strukturen zu lösen, welche als Unterdrückung empfunden werden.

David Myers wird von seinem Vater Sam permanent unter Druck gesetzt und lehnt dessen Vorstellungen für sein weiteres Leben und vor allem dessen Wunsch, dass sein Sohn bei ihm arbeitet, strikt ab (vgl. Red Oaks I/1: 23:00). Er leidet zudem unter einem Mangel an Privatsphäre im häuslichen Bereich (vgl. Red Oaks I/4: 1:30) und unter einer eingefahrenen Beziehung zu seiner Freundin Karen. Die konservative Zukunft, die Karen sich für sie beide ausmalt (vgl. Red Oaks I/1: 18:49), läuft dabei seinen eigenen Ambitionen entgegen. Davids Bestrebungen und sein Handeln bewegen sich genau entgegengesetzt zu den Vorstellungen seines Vaters und seiner Freundin. Anstatt Steuerberater zu werden, wünscht er sich ein Studium an der New York University und eine Laufbahn im künstlerischfilmischen Bereich (vgl. Red Oaks I/1: 0:00) und verliebt sich in die ,wilde" und schwer fassbare Skye Getty. Er lehnt dabei seine Familie nicht gezielt ab, empfindet offensichtlich Zuneigung für seine Eltern, strebt aber entschieden nach einer Loslösung.

Ebenso streben Ezekiel Figuero und die Kipling-Brüder in The Get Down nach Loslösung von elterlichen Strukturen und konservativen gesellschaftlichen Vorgaben. Dabei steht die Selbstverwirklichung durch die Musik im Mittelpunkt. The Get Down stellt bezüglich der sozialen Verortung in der schwarzen Unterschicht der New Yorker Bronx eine Ausnahme innerhalb des Korpus dar. Selbst wenn die Jungen bzw. jungen Männer sozialen Rückhalt und moralische Festigung innerhalb der Familie erhalten wie die Kipling-Brüder, die im Gegensatz zum Waisen Zeke einem relativ gefestigten Elternhaus entspringen, können sie sich

\footnotetext{
${ }^{81}$ Er wird von seinem Vater meist ignoriert und bekommt nie die Möglichkeit, traumatisierende Erfahrungen - die er wiederholt macht - mit Hilfe seiner Eltern zu verarbeiten (vgl. $F$ is for Family I/5: 3:00, III/1: 8:00).
} 
dem negativen und kriminellen Einfluss des Umfeldes nicht entziehen. Bereitwillig konsumieren sie Alkohol und Drogen (vgl. The Get Down I/2: 8:00, I/3: 29:00, I/7: 12:00) und handeln im Falle von Miles sogar damit (vgl. The Get Down I/8: 19:00). Ezekiels Prozess der Loslösung weist widerstreitende Faktoren auf. Er löst sich von seiner Tante, die als Mutterfigur fungiert. Seine Freunde erklärt er zu seinen ,Brüdern“ (vgl. The Get Down I/3: 37:00), zur Ersatz-Familie, um den Verlust der eigentlichen Familie zu kompensieren. Zudem will er das Leben in der Unterschicht und der gefühlten Bedeutungslosigkeit hinter sich lassen. Dem talentierten jungen Mann steht dabei einerseits der experimentelle und risikoreiche künstlerische Weg oder andererseits die Aufnahme an einem Ivy-League-College offen (vgl. I/1: 21:00, I/7: 1:00)- eine enorme Chance für einen jungen Mann, der als Waise afroamerikanischer und puerto-ricanischer Herkunft gleich in vielerlei Hinsicht einer Randgruppe angehört. Mit der Wahl eines Colleges ließe er allerdings nicht nur seinen Herkunftsraum hinter sich, sondern würde sich auch der Oberschicht anschließen, derjenigen Gruppe also, die als maßgeblich verantwortlich für das Dasein der afroamerikanischen und hispanischen Bevölkerung am Rande der Gesellschaft wahrgenommen wird. Zeke entscheidet sich letztlich für die Musik, was deutlich wird, wenn er als mittlerweile erfolgreicher Rapper, seine Lebensgeschichte aus der Retrospektive erzählt (vgl. The Get Down I/1: 0:00).

Zwar sind die Lebensumstände von Ezekiel Figuero und David Myers verschieden, die Motivation ist im Kern jedoch identisch. Beide Charaktere lehnen die Strukturen, aus denen sie stammen, ab und wollen Träume verwirklichen, die diesen Strukturen entgegenlaufen. Dabei geraten sie in einen Zwiespalt zwischen dem Zugehörigkeitsgefühl zum Herkunftsraum und dem Wunsch nach Selbstverwirklichung - ein Zwiespalt, der etwas deutlicher inszeniert wird als im Fall der Töchter-Figuren. Auch die weiteren hier aufgeführten Charaktere entfernen sich in unterschiedlichem Maße von ihrer familiären Einbettung, sei es durch ein sexuelles Erwachen und eine damit einhergehende Entwicklung vom Kind zum Mann oder schlichtweg durch die pubertär-rebellische Ablehnung elterlicher Vorgaben. Wie die Töchter-Figuren streben Söhne nach größerer Eigenständigkeit und sexueller wie persönlicher Erfüllung. In den meisten Fällen spielt dabei eine Paarbeziehung eine besondere Rolle. Im Gegensatz zu den Töchtern nehmen sie den aktiven Part in Bezug auf die Partnersuche ein, müssen also eine geeignete Partnerin finden und nicht wie die Mehrzahl der Töchter gefunden bzw. erobert werden. Hier manifestieren sich wiederum konservative Denkweisen. Jonah Byrde strebt in Ozark zwar keine Loslösung von der Familie an und auch für ein sexuelles Erwachen ist er etwas zu kindlich. Indem er versucht, die Familie - nötigenfalls mit Waffengewalt - zu verteidigen, imitiert er allerdings klassisch männliche Rollenmuster. 
Wyatts und Russ Langmores Entwicklung stellt ein Negativbeispiel dar: Durch die Abwesenheit männlicher Vorbildfiguren und einer Mutter scheinen sie den Weg ihres verwahrlosten, kleinkriminellen Onkels einzuschlagen. Die Ambitionen des intelligenten Wyatt werden von den ungünstigen Umständen bedroht. Ein suboptimaler familiärer Raum, so die deutliche Implikation, hat negative Auswirkungen auf die Kinder.

Joel Maisel (The Marvelous Mrs. Maisel), Colt und Rooster Bennett (The Ranch), Coyote und Nwabudike Bergstein (Grace and Frankie), Greg Moffat (The Romanoffs I/1), Simon Burrows (The Romanoffs I/8) und Joshua „Josh“ Pfefferman (Transparent) sind dem Kindesalter entwachsen und haben sich bereits von ihren Eltern gelöst. Im Gegensatz zu einigen Töchtern befindet sich indes keiner von ihnen in einer stabilen oder dauerhaften Beziehung.

Nwabudike Bergstein, der afroamerikanische Adoptivsohn von Sol und Frankie Bergstein, bleibt über die Serie hinweg ein Charakter mit geringer Tiefe, der vor allem seinen Bruder und andere Charaktere mit Ratschlägen unterstützt. Seine Herkunft dient vor allem dazu, die Offenheit und Toleranz des Bergstein-Haushaltes darzulegen. Coyote ist ein exemplarisches Beispiel für gescheiterte Erziehung und einen erfolglosen Adoleszenz-Prozess. Zwar arbeitet er an einem College, hat aber sein Leben trotz der Bewältigung eines zurückliegenden Drogen-Problems (vgl. Grace and Frankie I/1: 10:00) nicht wirklich im Griff. Obgleich beide Charaktere alleinstehend sind, streben sie innerhalb der analysierten Episoden keine Paarbindung an.

Colt und Rooster Bennett sind wie Joshua Pfefferman bereits erwachsen. Keiner der drei Charaktere lebt allerdings in einer dauerhaften Beziehung. Joshua Pfefferman wird im Bett zusammen mit einer nackten jungen Frau in die Serie eingeführt (vgl. Transparent I/1: 1:00). Innerhalb der ersten Staffel steht Joshua in einer sexuellen Beziehung mit insgesamt vier Frauen unterschiedlichen Alters, darunter eine ehemalige Babysitterin, mit der er einen Sohn hat, von dem er in der letzten Episode der ersten Staffel erfährt. Joshuas häufig wechselnde Beziehungen können als die Suche nach menschlicher Wärme und Zuneigung ebenso wie nach einer dauerhaften Beziehung verstanden werden. Die Oberflächlichkeit der Verhältnisse wird diesem Wunsch nicht gerecht. Erst mit der Rabbinerin Raquel Feinman bahnt sich eine potenziell dauerhafte Beziehung an, die er ebenfalls rasch durch Sex zu festigen sucht (vgl. Transparent I/9: 13:40).

Rooster Bennett hat die väterliche Ranch nicht verlassen, wohingegen Colt Bennett dorthin zurückkehrt. Dieses Leben im elterlichen Raum wird nicht negativ konnotiert, denn schließlich werden sie als notwendige Arbeitskräfte benötigt. Wie sein Bruder Colt lebt er nicht in einer festen Beziehung und wird am ehesten durch seine Männlichkeit im Sinne eines unkontrollierten männlichen Verlangens 
charakterisiert, das ihn u. a. dazu verleitet, Frauen allein auf ihr Äußeres zu reduzieren (vgl. The Ranch I/4: 7:00). Laut eigener Aussage benutzt er bei seinen wechselnden sexuellen Kontakten keine Kondome (vgl. The Ranch I/9: 11:00). Zudem definiert er Alkohol als zentralen Teil seines Lebens (vgl. The Ranch I/2: 14:00, I/4: 1:00) und geht sorglos mit Schusswaffen um (vgl. The Ranch I/8: 0:00). Colt Bennett zeigt ebenso wie sein Bruder äußerst unkontrolliertes und infantiles Verhalten. Er versuchte sich lange erfolglos als Football-Spieler. Der Durchbruch ist ihm trotz seiner 34 Jahre noch nicht gelungen. Seinem Vater zufolge hat Colt seine Karriere durch Alkohol und Drogen selbst blockiert (vgl. The Ranch I/1: 6:00). Weiterhin definiert er sich über seine Erfolge als High-School-Footballer (vgl. The Ranch I/3: 10:00), obwohl diese Zeit lange hinter ihm liegt. Sein Alkoholkonsum bringt ihn in ungünstige Situationen (vgl. The Ranch I/3: 21:00). Dennoch wird Colt als im Kern positiver Charakter inszeniert: Er weist einen Annäherungsversuch einer Freundin zurück, da diese betrunken und verlobt ist (vgl. The Ranch I/4: 28:00), und offenbart klassisch-konservative Zukunftsvorstellungen. Auf die Frage, wo er sich in 20 Jahren sehe, antwortet er: „Probably sittin " on this porch watching Rooster and Mary's kids play with my kids." (The Ranch I/10: 29:00).

Sowohl Coyote Bergstein und Joshua Pfefferman als auch die Bennett-Brüder, insbesondere Colt, werden als erwachsene Männer dargestellt, die zwar körperlich erwachsen sind, den eigentlichen Prozess der Mannwerdung jedoch nicht durchlaufen haben. Insbesondere in der Serie The Ranch, die am deutlichsten eine konservative Familienmoral vertritt, wird eine klassisch-männliche Entwicklungsnorm aufgestellt. Männer durchlaufen in jüngeren Jahren eine Phase des unkontrollierten Verhaltens, dazu zählen sexuelle Promiskuität, der experimentellunkontrollierte Umgang mit Alkohol, Drogen und weitere ,unvernünftige ' und gesellschaftlich-destruktive Verhaltensweisen. Es handelt sich um einen Lebensabschnitt des ,Sich-die-Hörner-Abstoßens'. Diese Phase dient dazu, die Infantilität hinter sich zu lassen und letztlich mittels Paarbeziehung und gesicherter Lebensperspektive ein stabiles Leben als Ehemann und Vater zu führen. Charaktere wie Joshua, Rooster und Colt, die diese Lebensphase noch nicht erreicht haben bzw. sie bewusst sabotieren, werden dann negativ charakterisiert, wenn sie entsprechend destruktiv handeln, während stabilisierende Bestrebungen (hin zur dauerhaften Paarbindung) innerhalb der Handlung eindeutig positiv bewertet werden.

Die jüngeren Söhne, welche eine Loslösung von der Familie anstreben und ihren Wunsch nach Selbstverwirklichung in die Tat umsetzen wollen, stellen dabei eine Vorstufe zu den älteren Söhnen dar, die sich in einer auslaufenden Phase der Selbstfindung befinden. Diese darf in den dargestellten Weltmodellen 
nicht zu lange anhalten und muss in etwa bis Mitte 30 abgeschlossen sein, sonst drohen negative Konsequenzen oder konkreter: ein Dasein als Versager. Diese Existenz droht Joel, der seine Familie aufgibt, und Coyote, der keine Familienbildung anstrebt. Die Logik der dargestellten Weltmodelle lässt keine alternativen Verläufe zu: So wie auch die Väter ehemals Söhne waren, müssen sich die aktuellen Söhne zu Vätern entwickeln. Dies heißt, dass die Selbstverwirklichung der meisten Charaktere letztlich einem konventionellen Berufsleben und den damit einhergehenden Belastungen weichen wird - oder wie es Sam Myers in Red Oaks formuliert: „I was young once. First couple of years of college it's all about having fun. You go to keggers, you smoke a little reefer. ${ }^{82}$ You figure things out. But after a while you've got to buckle down. You've got to think about the future." (Red Oaks I/1: 1:00).

Im Vergleich zu den Töchtern ist auffällig, dass zwar ebenfalls eine Paarbindung angestrebt wird, allerdings keiner der erwachsenen Söhne bereits verheiratet ist - mit Ausnahme von Joel, der die Ehe auflöst. Den männlichen Charakteren wird ein längerer Zeitraum für den Prozess der Selbstfindung eingeräumt. Ebenso wird der Aspekt der Promiskuität deutlicher hervorgehoben. Die Töchter nehmen in einem vergleichsweise ruhigeren - wenn auch nicht unproblematischen - Prozess ihre gesellschaftliche Rolle ein, während diese Phase bei den Männern langfristiger und exzessiver ist. Von weiblichen Charakteren werden während dieser Entwicklung eine größere Vernunft und eine Selbstzurücknahme erwartet, während ihre männlichen Gegenstücke Emotionen und Trieben mit gesellschaftlicher Legitimation freien Lauf lassen. Mit Eintritt in die Ehe wandelt sich die Konstellation. Hier nimmt der Mann den dominanten rationalen Part, die Ehefrau die untergeordnete emotionale Rolle ein. Dies führt dazu, dass die männlichen Charaktere bereits in ihrer Zeit als Söhne die weiblichen Charaktere dominieren. Wieder konstruieren die analysierten Serien einen deutlich traditionellen Entwicklungsverlauf.

\subsubsection{Alleinstehende/der Familie assoziierte Männer}

\begin{tabular}{l|l|l}
\hline \multicolumn{2}{l}{ Männer außerhalb der Familie } \\
\hline Serie & Charakter & Status \\
\hline 1. Atypical & Zahid & $\begin{array}{l}\bullet \text { Schüler } \\
\bullet \text { Freund des Protagonisten (Sam Gardner) }\end{array}$ \\
\hline
\end{tabular}

${ }^{82}$ Bei Keggers handelt es sich um Partys, auf denen Bier aus „kegs“, also kleinen Fässern, ausgeschenkt wird. Diese werden üblicherweise mit High-School-Schülern und College-Studenten assoziiert. „Reefer“ ist ein Slang-Begriff für Marihuana. 


\begin{tabular}{|c|c|c|}
\hline \multicolumn{3}{|c|}{ Männer außerhalb der Familie } \\
\hline Serie & Charakter & Status \\
\hline 2. Atypical & X Nick & $\begin{array}{l}\text { - Barmann } \\
\text { - Affäre einer Protagonistin (Elsa Gardner) } \\
\text { - Ledig }\end{array}$ \\
\hline 3. Everything Sucks! & Tyler Bowen & $\begin{array}{l}\text { - Schüler } \\
\text { - Freund des Protagonisten (Luke O`Neil) } \\
\text { - Jugendliche Findungsphase }\end{array}$ \\
\hline 4. Everything Sucks! & McQuaid & $\begin{array}{l}\text { - Schüler } \\
\text { - Freund des Protagonisten (Luke O`Neil) }\end{array}$ \\
\hline $\begin{array}{l}\text { XXX 5. Everything } \\
\text { Sucks! }\end{array}$ & $\begin{array}{l}\text { Oliver } \\
\text { Schermerhorn }\end{array}$ & $\begin{array}{l}\text { - Schüler } \\
\text { - Opponent des Protagonisten (Luke O`Neil) }\end{array}$ \\
\hline XXX 6. F is for Family & $\begin{array}{l}\text { Jimmy } \\
\text { Fitzsimmons }\end{array}$ & $\begin{array}{l}\text { - Schüler } \\
\text { - Opponent eines Protagonisten (Bill Murphy) }\end{array}$ \\
\hline 7. Grace and Frankie & X Barry & $\begin{array}{l}\text { - Angestellter/Produktentwickler einer } \\
\text { Kosmetikfirma } \\
\text { - Geliebter eines Charakters (Brianna) } \\
\text { - Alleinstehend }\end{array}$ \\
\hline 8. Grace and Frankie & X Guy & $\begin{array}{l}\text { - Rentner (ehemaliger Abenteurer) } \\
\text { - Geliebter einer Protagonistin (Grace) } \\
\text { - Alleinstehend }\end{array}$ \\
\hline 9. Ozark & Buddy Dyker & $\begin{array}{l}\text { - Rentner } \\
\text { - Adjuvant der Familie Byrde } \\
\text { - Alleinstehend }\end{array}$ \\
\hline 10. Ozark & Tuck & $\begin{array}{l}\text { - Hilfskraft } \\
\text { - Adjuvant eines Protagonisten (Jonah Byrde) } \\
\text { - Alleinstehend }\end{array}$ \\
\hline 11. Ozark & Bruce Liddell & $\begin{array}{l}\text { - Anlageberater } \\
\text { - Freund eines Protagonisten (Marty Byrde) } \\
\text { - Verlobt }\end{array}$ \\
\hline XXX 12. Ozark & Camino Del Rio & $\begin{array}{l}\text { - Drogenhändler } \\
\text { - Opponent eines Protagonisten (Marty Byrde) } \\
\text { - Verheiratet }\end{array}$ \\
\hline XXX 13. Ozark & $\begin{array}{l}\text { Roy Petty (und } \\
\text { das FBI) }\end{array}$ & $\begin{array}{l}\text { - FBI-Agent } \\
\text { - Opponent der Protagonisten (Familie Byrde) } \\
\text { - Alleinstehend }\end{array}$ \\
\hline XXX 14. Ozark & Jacob Snell & $\begin{array}{l}\text { - Opiumbauer } \\
\text { - Opponent der der Protagonisten (Familie } \\
\text { Byrde) } \\
\text { - Verheiratet }\end{array}$ \\
\hline
\end{tabular}




\begin{tabular}{|c|c|c|}
\hline \multicolumn{3}{|c|}{ Männer außerhalb der Familie } \\
\hline Serie & Charakter & Status \\
\hline 15. Red Oaks & Nash Nasser & $\begin{array}{l}\text { - Tennislehrer } \\
\text { - Freund des Protagonisten (David Myers) } \\
\text { - Verheiratet }\end{array}$ \\
\hline 16. Red Oaks & Wheeler & $\begin{array}{l}\text { - High-School-Absolvent/Angestellter eines } \\
\text { Country-Clubs } \\
\text { - Freund des Protagonisten (David Myers) } \\
\text { - Jugendliche Findungsphase }\end{array}$ \\
\hline 17. Red Oaks & Herb & $\begin{array}{l}\text { - Rentner } \\
\text { - Adjuvant des Protagonisten (David Myers) } \\
\text { - Alleinstehend }\end{array}$ \\
\hline XXX 18. Red Oaks & Barry & $\begin{array}{l}\text { - Fotograf } \\
\text { - Opponent des Protagonisten (David Myers) } \\
\text { - Alleinstehend }\end{array}$ \\
\hline 19. The Get Down & $\begin{array}{l}\text { Shaolin } \\
\text { Fantastic }\end{array}$ & $\begin{array}{l}\text { - Drogendealer/Krimineller/DJ } \\
\text { - Freund des Protagonisten (Ezekiel Figuero) } \\
\text { - Alleinstehend/Beziehung zu Fat Annie }\end{array}$ \\
\hline 20. The Get Down & $\begin{array}{l}\text { Francisco „Papa } \\
\text { Fuerte“ Cruz }\end{array}$ & $\begin{array}{l}\text { - Politiker } \\
\text { - Adjuvant eines Protagonisten (Ezekiel Figuero) } \\
\text { sowie Onkel/Adjuvant einer Protagonistin } \\
\text { (Mylene Cruz) und Liebesbeziehung eines } \\
\text { Charakters (Lydia Cruz) } \\
\text { - Alleinstehend }\end{array}$ \\
\hline $\mathbf{X X X}$ 21. The Get Down & $\begin{array}{l}\text { Clarence } \\
\text { "Cadillac“" } \\
\text { Caldwell }\end{array}$ & $\begin{array}{l}\text { - Krimineller/Musikproduzent } \\
\text { - Opponent der Protagonisten (Ezekiel Figuero, } \\
\text { Shaolin und die Kiplings) } \\
\text { - Alleinstehend }\end{array}$ \\
\hline XXX 22. The Ranch & $\begin{array}{l}\text { Bankangestellter } \\
\text { (ohne Namen) }\end{array}$ & $\begin{array}{l}\text { - Bankangestellter } \\
\text { - Opponent eines Protagonisten (Beau Bennett) } \\
\text { - (Vermutlich verheiratet)/Tochter }\end{array}$ \\
\hline 23. The Romanoffs I/2 & X Ivan Novak & $\begin{array}{l}\text { - Unbekannter Beruf } \\
\text { - Love-Interest der Protagonistin (Shelly } \\
\text { Romanoff) } \\
\text { - Verheiratet }\end{array}$ \\
\hline $\begin{array}{l}\text { XXX 24. The } \\
\text { Romanoffs I/3 }\end{array}$ & X Samuel Ryan & $\begin{array}{l}\text { - Schauspieler } \\
\text { - Affäre/Opponent der Protagonistin (Olivia } \\
\text { Rogers) } \\
\text { - Alleinstehend }\end{array}$ \\
\hline $\begin{array}{l}\text { XXX 25. The } \\
\text { Romanoffs I/3 }\end{array}$ & Bob Isaacson & $\begin{array}{l}\text { - Schauspieler-Agent } \\
\text { - Opponent der Protagonistin (Olivia Rogers) } \\
\text { - Alleinstehend }\end{array}$ \\
\hline
\end{tabular}




\begin{tabular}{l|l|l}
\hline \multicolumn{2}{l}{ Männer außerhalb der Familie } \\
\hline Serie & Charakter & Status \\
\hline 26. The Romanoffs I/4 & X Daniel Reese & $\begin{array}{l}\text { - Autor } \\
\text { - Ehemalige Affäre der Protagonistin (Julia } \\
\text { Wells) } \\
\text { - In einer Beziehung oder Ehe }\end{array}$ \\
\hline 27. The Romanoffs I/5 & David Patton & $\begin{array}{l}\text { - Klavierlehrer } \\
\text { - Adjuvant/Freund der Protagonistin (Katherine } \\
\text { Ford/ihre Söhne) } \\
\text { - In einer Beziehung }\end{array}$ \\
\hline 28. The Romanoffs I/6 & Abel Erikson & $\begin{array}{l}\text { - Journalist } \\
\text { - Adjuvant der Protagonistin (Victoria Hayward) } \\
\text { - Alleinstehend }\end{array}$ \\
\hline 29. The Romanoffs I/6 & $\begin{array}{l}\text { X Christopher } \\
\text { Ming Aktienhändler } \\
\text { Affäre des Protagonisten (Simon Burrows) }\end{array}$ \\
\hline
\end{tabular}

Analog zu den weiblichen Charakteren außerhalb familiärer Verbände möchte ich hier eine Trennung in Opponenten und Adjuvanten bzw. nicht negative Charaktere vornehmen. Von 29 hier aufgeführten Charakteren handelt sich bei zehn um Opponenten (mit XXXX gekennzeichnete Felder). Die mit einem $\mathbf{X}$ gekennzeichneten Charaktere stehen in amouröser oder sexueller Beziehung zu den Protagonist/inn/en.

Bezüglich der Beziehungssituation der Opponenten lässt sich kein verallgemeinerbarer Status ableiten (- drei sind verheiratet, zwei der Charaktere sind Jugendliche und der Rest alleinstehend). Samuel Ryan (The Romanoffs I/3) ist dabei der einzige Antagonist, der eine sexuelle Beziehung mit einer Protagonistin aufbaut. Letztlich dient der Method-Actor, der sich am Filmset vollkommen in seine Rolle als Rasputin hineinsteigert und eine Besessenheit für die Schauspielerin Olivia Rogers entwickelt, nur ein Katalysator der Handlung. Er verunsichert Olivia Rogers weiter und demonstriert deren Angreifbarkeit auf sexueller Ebene.

Barry, ein Veranstaltungsfotograf in Red Oaks, versucht Davids Freundin Karen $\mathrm{zu}$ verführen und tritt damit in amouröse Konkurrenz zu ihm. Allgemein handelt es sich um einen narzisstischen Charakter mit sexistischen Neigungen (vgl. Red Oaks I/1: 15:55). Er verliert jedoch an Relevanz in Bezug auf den Protagonisten, da dieser sich Skye Getty zuwendet. Barry - eigentlich Opponent - wird somit nahezu zum Adjuvanten, da er David die Loslösung von Karen erleichtert.

Oliver Schermerhorn und Jimmy Fitzsimmons sind Opponenten im schulischen Umfeld der Protagonist/inn/en. Oliver Schermerhorn, ein von sich 
eingenommener ,Schauspieler', ist dabei nur zeitweilig Opponent der Protagonist/inn/en in Everything Sucks!, bis sie sich zu einer Gruppe zusammenschließen und er sich letztlich entscheidet, die Stadt zu verlassen. Jimmy Fitzsimmons ist ein recht archetypischer Schulschläger, mit dem Bill Murphy wiederholt aneinandergerät (vgl. $F$ is for Family I/5, I/6).

Die verbliebenen sechs Opponenten - Camino Del Rio, Roy Petty, Jacob Snell, Bob Isaacson, Clarence „Cadillac“ Caldwell und ein namenloser Bankangestellter in The Ranch - verkörpern bestimmte Paradigmen. Del Rio, Jacob Snell und Cadillac stehen für (Drogen-)Kriminalität, während Cadillac mit seinem Hang zur Disco-Musik darüber hinaus Verkörperung einer vergehenden Zeit ist. Roy Petty steht für staatliche Autorität, die in Ozark durchaus negativ konnotiert wird schließlich handelt es sich bei Petty selbst um einen problematischen Charakter. Der Bankangestellte, bei dem Beau Bennett um einen Kredit für die Ranch bittet (vgl. The Ranch I/8: 5:00), verkörpert das Finanzsystem. Bob Isaacson, der die Sorgen seiner Klientin Olivia Rogers nicht ernstnimmt und herablassend mit ihr umgeht (vgl. The Romanoffs I/3: 52:30), ist eine Verkörperung patriarchaler Verhaltensweisen.

Da eine gemeinsame Merkmalsmenge, welche eine kohärente Schlussfolgerung zuließe, nicht feststellbar ist, möchte ich die hier aufgeführten Charaktere als situative Opponenten bzw. Antagonisten charakterisieren.

Die Gruppe der männlichen, nicht negativen Figuren, die in einer amourösen Beziehung zu den Protagonist/inn/en stehen, ist mit sechs Charakteren deutlich kleiner als dieselbe Gruppe unter den weiblichen Charakteren. Eine Schematisierung ist problematisch. Barry, ein Angestellter Briannas in Grace and Frankie, stellt ihre erste potenziell dauerhafte Beziehung dar und eröffnet ihr einen Ausweg aus dem negativ konnotierten Single-Dasein. Guy, ein ehemaliger Abenteurer und Weltreisender, stellt in der ersten Staffel von Grace and Frankie den ersten Versuch Graces dar, nach der Trennung von ihrem langjährigen Ehemann wieder eine neue Beziehung einzugehen. Er ist die Personifizierung des ,Abenteuers“ bzw. des neuen Lebens, das Grace nun einschlagen kann, steht aber ebenso für ihren Wunsch nach Beständigkeit und einer stabilen Paarbeziehung.

Bezüglich der weiteren amourös-assoziierten Charaktere Ivan Novak, Daniel Reese und Christopher Ming aus The Romanoffs und Nick aus Atypical lässt sich erneut keine klare Gemeinsamkeit ableiten. Novak tritt als blasse VerführerFigur gegenüber der unglücklich verheirateten Shelly Romanoff auf. Eine sexuelle Affäre jenseits eines Flirts lehnt sie ab. Daniel Reese ist eine ehemalige Affäre von Julia Wells und Vater von deren Tochter. Christopher Ming, der eine homosexuelle Affäre mit Simon Burrows unterhält, dabei seine Verlobte betrügt und nicht 
zu seiner Liebe zu Simon stehen möchte, könnte als Antagonist gewertet werden (The Romanoffs I/8: 26:20). Simon reagiert auf Christophers Ablehnung mit Verzweiflung, findet aber nach der Trennung letztlich zu seiner, wahren' transsexuellen Persönlichkeit. Nick ist wiederum kein eigenständiger Charakter, sondern ermöglicht lediglich Elsas Ehebruch.

Die größte geschlossene Gruppe setzt sich aus Freunden (acht Charaktere) und weiteren Adjuvanten (fünf Charaktere) zusammen. Tuck ist in Ozark für die Protagonist/inn/en wenig mehr als ein Handlanger ohne besondere Bedeutung. Die Adjuvanten Buddy Dyker und Herb geben den Charakteren Jonah Byrde und David Myers Ratschläge, welche diesen dabei helfen, ihren weiteren Lebensweg zu bewältigen und Entscheidungen zu treffen. ${ }^{83}$ Die alleinstehenden, zynischen und rau-freundlichen alten Männer sind somit klassische Mentorenfiguren.

Abel Erikson, der bereits durch seinen Vornamen, der hier als Bezug zum biblischen „Abel“ verstanden werden kann, eine sanfte Opferrolle gegenüber dem autoritären Ehemann Nicholas Hayward einnimmt, tritt ebenfalls als Mentor auf (für Victoria Hayward). Als einer von zwei Protagonisten in dieser Personengruppe hilft er ihr uneigennützig ihr Leben mit ihrem kranken Sohn zu bewältigen, und erteilt ihr Lebensratschläge. Dabei nimmt er sich trotz amouröser Spannungen zurück und ermutigt Victoria die Situation mit ihrem Ehemann zu klären (vgl. The Romanoffs I/6: 1:10:30). Abel ist ein äußerst individueller Charakter, der oberflächlichen Beziehungen gelangweilt gegenübersteht ${ }^{84}$ und eine potenzielle Beziehung zu Victoria selbstlos aufgibt. Er entzieht sich gängigen Rollenoder Handlungsmustern und stellt somit eine Ausnahme innerhalb dieses Korpus dar.

Francisco Cruz, ebenfalls ein Protagonist, fungiert insbesondere für seine Nichte Mylene, aber auch für Ezekiel Figuero als bedeutende Helferfigur, indem er ihnen einen Weg aus ihren problematischen Lebensumständen ermöglicht. Zudem steht er in einer Liebesbeziehung mit Lydia Cruz. Da erst sehr spät innerhalb der Serie bekannt wird, dass es sich bei ihm eigentlich um Mylenes Vater handelt, möchte ich ihn nicht zur Gruppe der Väter- und Ehemänner zählen. Er lässt sich nur partiell einer Typisierung als skrupelloser Politiker unterziehen. De facto ist er daran interessiert, die Bronx, ein vollkommen verwahrlostes Stadtviertel mit miserablen Lebensumständen, lebenswert zu gestalten und somit den

\footnotetext{
${ }^{83}$ Herb erzählt David davon, dass er die Berufsvorgabe hasste, die sein Vater ihm machte, rät ihm explizit diese abzulehnen (vgl. Red Oaks I/2: 06:10, I/10: 19:49) und bestätigt ihn somit in seiner Ablehnung der Forderungen seines Vaters.

${ }^{84}$ In der Eröffnungsszene der sechsten Episode wird er dabei gezeigt, wie er in einer DatingApp gelangweilt Frauen bewertet (vgl. The Romanoffs I/6: 01:50).
} 
Menschen dort zu helfen (vgl. The Get Down I/1: 20:00). Auch wenn er letztlich wegen unlauterer Geschäfte inhaftiert wird (vgl. The Get Down I/10: 18:00), beweist er sich allgemein als moralisch integrer Charakter. Seine Ziele erscheinen aufrichtig und gegenüber Lydia Cruz, die er liebt, hat er sich - laut eigener Aussage - stets treu verhalten (vgl. The Get Down I/3: 44:00). Somit handelt es sich um eine Figur mit individuellen Eigenschaften und Handlungsrelevanz.

Die acht Charaktere innerhalb der Freundesgruppe lassen sich, wie die anderen Gruppen zuvor, wiederum schwer vereinheitlichen. Die Charaktere folgen relativ häufig stereotypen Charakterbildern, die ich im Folgenden mit überspitzten Schlagwörtern wiedergeben will. Tyler Bowen und McQuaid sind, ähnlich wie der Protagonist Luke, Nerds, die erfolglos versuchen, sexuelle Erfahrungen zu machen. Ähnlich verhält es sich bei Zahid, der sich als Frauenheld und wissend in sexuellen Dingen gibt, aber letztlich ein Aufschneider und ein Großmaul ist. Nash Nasser ist ein alternder Gigolo, der eine Eitelkeit zur Schau trägt, die seiner Lebensrealität nicht gerecht wird. Wheeler ist ein Versager und Faulpelz, dem es nicht gelingt, die Drogen hinter sich zu lassen und der - trotz hoher Intelligenz - nichts aus sich macht. Bruce Liddell ist ein Lebemann, der zu gierig ist und daran scheitert. Shaolin Fantastic ist ein Kleinkrimineller, der zwar große Ambitionen und Talente hat, den Zwängen seines Umfeldes aber nicht entkommen kann, und David Patton ist ein künstlerisch veranlagter Homosexueller, der zu Unrecht des unmoralischen Verhaltens und der Pädophilie beschuldigt wird. Diese Freunde, die den Charakteren meist zur Seite stehen, aber auch eigene Probleme haben, mit denen sich Konflikte entwickeln, haben dabei individuelle, handlungsabhängige Funktionen.

Außerfamiliäre, männliche Figuren lassen sich einer groben Einteilung in Personengruppen unterziehen. Dies ergibt sich notwendigerweise und ist allein nicht aussagekräftig. Wie sich anhand der obenstehenden Ausführungen nachvollziehen lässt, ist es eher eine lose Auflistung individueller Charaktere. Eine klare Kategorisierung kann deshalb nicht erfolgen. Auch wenn es sich nicht bei allen männlichen Figuren um differenziert-charakterisierte Figuren handelt (Typen mit Wiedererkennungswert sind häufig ${ }^{85}$ ), ergibt sich ihre Funktion in den meisten

\footnotetext{
${ }^{85}$ Charaktertypen werden dabei serienintern in der Regel individualisiert, indem ihnen bestimmte Verhaltensweisen oder ein charakterlicher Hintergrund zugewiesen werden. Sie fallen stets auf bestimmte, erwart- und einschätzbare Verhaltensweisen zurück und bleiben diesbezüglich relativ konstant. Ob ein ,Gigolo “ wie Nash an einer Tankstelle arbeiten würde, anstatt als Tennislehrer in einem Country-Club, ist weitgehend irrelevant, das Verhalten wäre - angepasst an das Umfeld - leicht unterschiedlich, Intention und Funktion des Charakters jedoch im Kern identisch.
} 
Fällen aus der jeweiligen Handlung der Serie. Die Bedeutung dieses Umstandes erschließt sich aus dem Vergleich mit den weiblichen Charakteren außerhalb der Familie, deren Rollenmuster und Handlungsfunktionen sich in der Regel klar ableiten lassen. Zunächst spielt es für einen männlichen Charakter eine eher geringe Rolle, ob dieser verheiratet ist oder nicht. Auch wenn dieser in einer Beziehung steht, wird dies nicht unbedingt thematisiert und die Abwesenheit einer Beziehung wird nicht unbedingt negativ bewertet. Männliche Charaktere genießen folglich eine größere individuelle ,Freiheit'. Dies ist auch bezüglich ihrer Aufgabe innerhalb der Handlung der Fall. Mit Ausnahme der Therapeutin Julia in Atypical treten keine positiven Mentorinnen auf - im Gegenteil: Frauen, die eine lehrende und weisungsbefugte Position einnehmen, sind in ihrer Gesamtheit Antagonistinnen. Es steht daher lediglich männlichen Figuren zu, Weisheit zu beanspruchen. Auch der Anteil der Love-Interests unter den männlichen Figuren ist geringer, was auf eine dominantere Sexualisierung bzw. Romantisierung der Frau schließen lässt.

Zudem werden die männlichen Charaktere im arbeitsfähigen Alter fast ausnahmslos berufstätig gezeigt, in Berufen wie Anlageberater (Bruce Liddell), Drogenhändler (Camino Del Rio, Cadillac), Tennislehrer (Nash Nasser), Politiker (Francisco Cruz), Bankangestellter (The Ranch), Autor (Daniel Reese) oder Aktienhändler (Christopher Ming). Frauen bekleiden, sollten sie überhaupt berufstätig sein, Berufe wie Sekretärin (Penny Pan), Ballerina (Michele Westbrook), Schauspielerin (Olivia Rogers), Angestellte eines Waisenhauses (Elena Evanovich), Musikerin (Kaya), Babysitterin (Rita Holt) oder Innenarchitektin (Tammy Cashman). Während Männer mehrheitlich in Feldern zu finden sind, die Entscheidungsfreudigkeit, Aggressivität und den Umgang mit Geld verlangen, werden weibliche Charaktere bis heute mit Hilfstätigkeiten, Fürsorge um Kinder oder ästhetisch-künstlerischen Aufgaben verknüpft. Diese Individualisierung und Profilierung männlicher Figuren bei gleichzeitiger Schematisierung weiblicher Charaktere ordnet diese den männlichen Figuren, wie auch im innerfamiliären Bereich und über Altersgrenzen hinweg, unter. Dies deckt sich mit der Feststellung, dass weibliche Charaktere wesentlich deutlicher an bestimmte Rollenzuschreibungen gebunden sind, während sich männliche Charaktere einer konkreten Rollenzuschreibung eher entziehen und durch ihren individuellen Handlungsbeitrag charakterisiert werden. 


\subsubsection{Darstellung und figurative Konzeption homo- und transsexueller Charaktere}

Sol: „Did we really spend all those years and fight our way out of one box just to climb into another?“"

Robert: „There are a lot of ways to be a couple. We just have to find the best way for us."

Sol: ,You don't think we're doing this wrong?“

Robert: „No, I don't think so.“

Sol: „So...you're fine never sleeping with anyone again, or Jeff?“

Robert: „Oh, God, yes!“

Sol: „But you're not just doing this for me?“

Robert: „I waited 20 years for you. I'd wait another 20 if I had to. There is no one else for me." (Grace and Frankie I/11: 23:00)

Die Beziehung von Robert Hanson und Sol Bergstein ist kennzeichnend für den seriellen Umgang mit homosexuellen Charakteren und Beziehungen zwischen diesen Charakteren. Robert und Sol outen sich als homosexuelles Paar und trennen sich von ihren Ehefrauen. Ihre folgende Beziehung wird im Sinne einer Angleichung an heteronormative Strukturen normalisiert. Nach der Trennung von ihren Ehefrauen leben sie miteinander und streben die baldige Scheidung und erneute Eheschließung an. Unabhängig von ihrem biologischen Geschlecht nehmen sie konventionelle eheliche Geschlechterrollen ein. Während Sol stets als emotional und gefühlvoll dargestellt wird, agiert Robert meist nüchtern und rational (vgl. Grace and Frankie I/1: 3:00, I/3: 3:00). Es kann somit eine Trennung in einen eher weiblichen und einen eher männlichen Part festgestellt werden. In ihrem Verhalten zueinander ähneln sie einem verheirateten Ehepaar, wenn sie sich etwa über alltägliche Nichtigkeiten streiten (vgl. Grace and Frankie I/6: 4:00). Tatsächlich wird die Beziehung zwischen beiden als besonders harmonisch dargestellt und so eindeutig positiv bewertet, da sie im Gegensatz zu den - besonders im Falle Roberts - angespannten vorherigen Ehen steht. Streiten sie sich auch wiederholt, so finden sie doch rasch mit dem Ende der Episode eine Lösung in einer versöhnlichen und vereinenden Aussprache (vgl. Grace and Frankie I/6: 24:00, I/11: 23:00). In der Quintessenz existiert bis auf das biologische Geschlecht der Ehepartner keine Differenz zwischen einer heterosexuellen Ehe und der homosexuellen Beziehung Roberts und Sols. Der obige Satz Roberts „There are a lot of 
ways to be a couple. We just have to find the best way for us" mag also die intendierte Aussage der Serie umschreiben, wird aber durch Handlungsverlauf und Serienhandlung insofern relativiert, da die klassische Form des ehelichen Zusammenlebens als optimal inszeniert wird, denn schließlich ist ihre Beziehung kaum von einer heterosexuellen zu unterscheiden. Diese Relativierung geschieht außerdem dadurch, dass andere Homosexuelle - Freunde von Robert und Sol - eher als wild und vergnügungssüchtig dargestellt werden. Sie können sich auf einer relativ konventionellen und gediegenen Party, welche die beiden veranstalten, nicht amüsieren und verlangen nach ausschweifender Unterhaltung (vgl. Grace and Frankie I/12: 11:00). Robert und Sol können dies nicht nachvollziehen. Sie streben gewissermaßen nach Hypernormalität, die den Alltag der meisten Ehepaare an Gewöhnlichkeit noch übertrifft.

Während heterosexueller Sex in Grace and Frankie zumindest angedeutet wird, geht die Beziehung zwischen Sol und Robert kaum über liebevolle Berührungen hinaus. Die sexuelle Ausprägung der Homosexualität, also deren konkrete Sichtbarkeit und Manifestation, wird ausgespart. Es lässt sich vermuten, dass dies aus der Intention heraus geschieht, die Zuschauer nicht mit Unbekanntem bzw. zu sehr ,Abweichendem' zu konfrontieren, welches die etablierte ,Normalität' gefährden könnte. Dahingehend wird Sexualität zwischen homosexuellen Charakteren in Transparent (vgl. I/2: 29:10, I/3: 9:30), Ozark (vgl. I/5: 40:00), Everything Sucks! (vgl. I/8: 9:00) und The Romanoffs (vgl. I/8: 25:50) durchaus angedeutet. Da sexuelle Handlungen generell selten gezeigt werden und homosexuelle Charaktere im Vergleich zu heterosexuellen Figuren selten sind, lässt sich hier keine allgemeine Regel ableiten.

Innerhalb des Korpus werden einige andere homosexuelle Beziehungen gezeigt, wobei ich die Annäherung von Kate Messner und Emaline Addario in Everything Sucks! ausklammern möchte, da diese lediglich angedeutet wird. Dizzee Kipling, selbst ein kreativer und künstlerisch veranlagter Charakter, geht eine Beziehung zum Sprayer Thor ein. Dies ist allerdings mehr ein Akt der sexuellen Selbsterkenntnis als eine ernsthafte Beziehung, denn Thor führt ihn in die Homo- und Transsexuellen-Szene New Yorks ein (vgl. The Get Down I/6: 21:00). Hinzu kommen die Beziehungen, die Roy Petty in Ozark führt: die zu seinem Kollegen Trevor Evans, die zu Russ Langmore und eine in der Vergangenheit liegende Beziehung (vgl. Ozark I/8). Mit Ausnahme der vergangenen Beziehung werden die gegenwärtigen negativ inszeniert: Petty hat sich von Evans getrennt und agiert im Umgang mit ihm ablehnend (vgl. Ozark I/3: 32:00) und Russ nutzt er schlichtweg für seine Pläne aus. Bei der Beziehung zwischen Simon Burrows und Christopher Ming in The Romanoffs handelt es sich lediglich um eine kurzzeitige Affäre, die zumindest für Christopher Ming rein sexueller Natur 
ist. Ozark ist dabei die einzige Serie, die homosexuellen Geschlechtsverkehr zeigt oder explizit andeutet (vgl. Ozark I/2: 49:00, 40:00). Dies entspricht grundsätzlich der drastischen Darstellungsweise der Serie.

Maura Pfefferman, prominentester transsexueller Charakter meines Korpus, lebte vor ihrem Outing langjährig in einer heterosexuellen Ehe. Auch wenn sich Maura bereits während der Ehe als Frau fühlte (vgl. Transparent I/2: 27:10, I/3: 10:46, I/4: 5:07, I/6: 4:57), kann hier nicht von einer homosexuellen Partnerschaft die Rede sein. Interessant in Bezug auf die Auswirkungen von Mauras Outing auf die Familie ist, dass diese durch das Weltmodell und die Charakterkonzeptionen relativiert werden. Natürlich bedeutet Mauras Outing eine Überraschung und eine Umstellung für den Rest der Familie, die eigentlichen Umstände werden allerdings nicht verändert. Die Kinder haben das elterliche Haus verlassen, die Ehe ist bereits geschieden und Shelly Pfefferman wird stets als deutlich dominanter und energischer als ihr emotionalerer Ex-Ehemann dargestellt (vgl. Transparent I/1: 19:00). Die ehelichen Rollenbilder - ein weiblicher und ein männlicher Part - werden somit weiterhin eingehalten. Selbst in der Beziehung zwischen Tochter Sarah und deren Jugendliebe Tammy Cashman nimmt Tammy - bereits durch das Auftreten mit Kurzhaarschnitt und ihre Berufstätigkeit im Gegensatz zu Sarah - eine maskuline Rolle ein. Beide streben nach der Scheidung von ihren Ehepartnern sofort eine Ehe an. So werden wiederum heteronormative Strukturen bekräftigt. Die Negativbewertung, die Sarahs Ehebruch mit Tammy dadurch erfährt, dass sie eine Ehe mit zwei kleinen Kindern bzw. zwei Ehen mit insgesamt drei Kindern gefährdet, ist nur eingeschränkt relevant. Einhergehend mit der positiven Charakterisierung des transsexuellen Outings Mauras erscheint auch Sarahs Handeln mehr als notwendiger Akt der Selbstverwirklichung denn als destruktive Tat.

Für die vier Charaktere, die während der Handlung ihre Homosexualität erkennen oder sich als homo- bzw. transsexuell outen, handelt es sich stets um einen bedeutsamen Moment der Selbsterkenntnis. Kate Messner outet sich zwar nicht öffentlich, entwickelt aber im Zuge von Everything Sucks! ein gewisses Selbstvertrauen bezüglich ihrer sexuellen Orientierung. Der Einbezug Dizzees in die Homo- und Transsexuellen-Szene wird - vor allem durch Einsatz von Musik und Licht - als hochgradig ästhetischer Glücksmoment inszeniert (vgl. The Get Down I/6: 21:00). Maura traut sich zwar zunächst nicht, sich vor ihren Kindern zu outen (vgl. Transparent I/1: 22:40), letztlich kann sie aber mit der Offenbarung eines jahrelangen Geheimnisses eine große Last ablegen und endlich ihre eigentliche Persönlichkeit ausleben, ebenso Sol und Robert in Grace and Frankie. Für Simon 
Burrows stellt sein Outing als Transsexueller ebenfalls eine enorme Überwindung dar, allerdings zugleich einen Akt der Befreiung (vgl. The Romanoffs I/8: 10:08:45).

Bestandteil dieses Prozesses ist meist der Kampf gegen homophobe Tendenzen in der Gesellschaft bzw. das Arrangement mit denselben. So macht sich Emaline Addario über Kate Messners homosexuelle Neigungen lustig (vgl. Everything Sucks! I/2: 0:00). Ihr Schulspind wird mit dem Wort „Dyke“, ein pejorativer Ausdruck für „Lesbe“, beschmiert (vgl. Everything Sucks! I/2: 4:00) und sie muss ein Gespräch belauschen, in dem zwei andere Mädchen behaupten, sie habe AIDS (vgl. Everything Sucks! I/2: 6:00). Abgesehen davon, dass sie sich vor den Reaktionen ihrer Kinder fürchtet, sieht Maura sich danach immer noch mit problematischen Umständen konfrontiert. Davina Rejennae, ebenfalls eine Transsexuelle und eine Freundin Mauras, erzählt ihr, dass sie nach ihrem Outing von ihrer Familie verlassen wurde (vgl. Transparent I/2: 20:00). Als Maura die Damentoilette eines Kaufhauses benutzen will, wird sie von einer Frau als ,pervert“ bezeichnet (vgl. Transparent I/4: 18:30) und das Zusammentreffen mit einem ehemaligen Bekannten gestaltet sich schwierig (vgl. Transparent I/5: 20:00). Selbst unter Transvestiten und Cross-Dressern musste Maura in der Vergangenheit Vorurteile gegenüber Transsexuellen erleben (vgl. Transparent I/8: 13:00, 15:20). Simon Burrows leidet bereits während seiner Beziehung zu Christopher Ming darunter, dass Christopher ihr Verhältnis offensichtlich nur als zeitweilig und nicht ernsthaft betrachtet (vgl. The Romanoffs I/8: 26:48). Bevor er sich als transsexuell outet, erzählt ihm eine ebenfalls transsexuelle Bekannte, dass sie aufgrund ihrer Transsexualität misshandelt wurde (vgl. The Romanoffs I/8: 1:06:20). Sein erstes Auftreten als Candice wird von seiner Stiefmutter Ondine mit großer Irritation entgegengenommen. Sie verweigert ihm zudem die Ohrringe seiner Mutter, da diese immer nur an Frauen weitergegeben würden (vgl. The Romanoffs I/8: 1:08:45).

David Patton hat mit ähnlicher gesellschaftlicher Ablehnung zu kämpfen. Gegen David, einen homosexuellen Klavierlehrer, entwickelt sich von Seiten der Eltern, deren Kinder er unterrichtet, eine regelrechte Hysterie, da das FBI gegen ihn wegen der Anschuldigung ermittelt, er habe einem seiner Schüler Alkohol gekauft (vgl. The Romanoffs I/5). David erfüllt das Klischee des künstlerisch begabten, ästhetisch interessierten und geschwätzigen Schwulen (vgl. The Romanoffs I/5: 38:53) und gibt aus einem unerfindlichen Grund vor, von den Romanows abzustammen, was eigentlich auf die Protagonistin Katherine Ford zutrifft (vgl. The Romanoffs I/5: 37:10). Er geht aber freundlich mit seinen Schülern um und bietet keinen Anlass zu einem Verdacht. Seine Homosexualität an sich genügt also, um ihn zu verdächtigen. 
Betrachtet man die Darstellung homo und transsexueller Charaktere, so lässt sich eine Tendenz hin zu einer heteronormativen Eingliederung dieser Lebensmodelle feststellen. Sei es, dass Homosexuelle nach einer besonders normgerechten Beziehung streben oder sich entsprechend verbreiteter Stereotype besonders feminin oder maskulin verhalten. Diese Stereotypisierung findet nicht in allen Fällen statt. Alle hier genannten Charaktere, mit Ausnahme von David Patton, sind Figuren mit weitgehend individueller Charakterzeichnung. Im Falle von homo- und transsexuellen Protagonist/inn/en steht deren sexuelle Selbstfindung und Integrierung in die Gesellschaft im Vordergrund der Handlung bzw. Charakterentwicklung sowie die gesellschaftlichen Ressentiments, denen sie im Zuge dieses Prozesses begegnen. Adjuvanten-Figuren, die dies bereits hinter sich haben, können von einem schweren Weg berichten. Der Kampf um die eigene Identität und gegen eine ablehnende oder unverständige Gesellschaft wird in der Regel positiv dargestellt. Dass dieser jedoch so prominent verhandelt wird bei gleichzeitiger Abwesenheit gesellschaftlich vollkommen integrierter Homo und Transsexueller, bewirkt eine klare Kennzeichnung homo und transsexueller Charaktere als von der gesellschaftlichen Norm abweichend. Mögen homosexuelle Figuren auch oft positive Figuren sein, so werden sie nach wie vor zentral über durch ihre gesellschaftliche Außenseiterrolle definiert. Die Serien des Korpus verorten diese Figuren folglich weiterhin am Rande der Gesellschaft und nicht in deren Mitte.

\subsubsection{Resümee: Die Diktatur der Rollenbilder}

Die Analyse der Rollenverteilung zwischen männlichen und weiblichen Charakteren in den untersuchten Video-on-Demand-Serien fördert wenig innovative Strukturen zu Tage. Dass weibliche Protagonistinnen innerhalb der untersuchten Weltmodelle zumeist die Rolle der Mutter oder Tochter einnehmen, ist ebenso wenig verwunderlich wie die äquivalente Positionierung männlicher Charaktere als Väter und Söhne. Vor allem dann, wenn die Kernfamilie als Zentrum der Handlung fokussiert wird, kann es innerhalb einer solchen kaum andere Rollen geben. Dennoch ist es auffällig, dass es in den analysierten Formaten keine nennenswerte Anzahl an Mitgliedern der erweiterten Familie wie Großmütter, Großväter, Onkel, Tanten, Cousins oder Cousinen gibt, die explizit in dieser Rolle in Erscheinung treten. Auch wenn Charaktere eine entsprechende Funktion einnehmen, wird diese zugunsten der kernfamiliären Funktion zurückgestellt. Obwohl z. B. Maura und Shelly Pfefferman sowie Grace Hanson Großmütter sind, treten sie vor allem als Mütter in Erscheinung. Bereits hier kann konstatiert werden, dass eine klare Beschränkung auf den engsten kernfamiliären Verband stattfindet. 
Innerfamiliär wird eine lang bekannte Struktur fortgeführt: Männer sind fast ausnahmslos berufstätig und versorgen als Ehemänner und Väter die Familie allein, während Mütter und Ehefrauen klar dem häuslichen Bereich und der Erziehung der Kinder zugeordnet sind. Vor allem in Bezug auf Serien, die in der heutigen Zeit spielen, entspricht dies nicht der US-amerikanischen Lebensrealität. Liberale Tendenzen der jeweiligen Epochen bzw. Abweichungen von der Norm werden marginalisiert oder negativ konnotiert. Die Notwendigkeit, diese geschlechtsspezifischen Rollen einzunehmen, ergibt sich aus den dargestellten Weltmodellen nicht. Daraus ergibt sich der Eindruck eines langlebigen Kontinuums. Die Opferbereitschaft und das Einstehen des Mannes für die Familie sowie der Wunsch der Frau nach Mutterschaft sind als mythische Biologismen angelegt, ebenso der aktive Part des Mannes bezüglich der Anbahnung einer Beziehung. Damit einhergehend sind männliche Charaktere tendenziell emotional zurückgenommen und rational - Eigenschaften, welche die in den Texten als hart und schutzlos dargestellte berufliche Welt ihnen abverlangt. Dies geben sie nur dann auf, wenn die Familie konkret bedroht wird. Weibliche Charaktere dagegen sind deutlich emotionaler und zeigen mehr Empathie, wie es bei der Fürsorge um Heim und Familie als notwendig klassifiziert wird. Besonders abweichende Frauen, die nicht nach Familie, Kindern oder zumindest einer Beziehung streben, bestätigen diese Struktur, da sie als negative Opponenten oder glücklose, angreifbare Figuren dargestellt werden.

In der Jugendphase bzw. dem Leben als Sohn ist es männlichen Figuren erlaubt, emotional und impulsiv zu agieren und konsequent ihre Träume und Wünsche zu verfolgen. Agieren weibliche Charaktere auf diese Art wird dies, vor allem wenn sie keine baldige Paarbindung anstreben, als burschikoses bzw. maskulines Verhalten betrachtet. Hier wird Zurückhaltung erwartet. Mit dem Wechsel in die Ehe wandeln sich die gesellschaftlichen Erwartungen in den Weltmodellen, so dass Männer stets in einer privilegierten bzw. dominanten Position sind.

Außerfamiliäre Frauen, die der Familie in irgendeiner Weise assoziiert werden, lassen sich recht deutlich schematisieren und stehen, handelt es sich nicht um Opponentinnen, häufig im romantischen Interesse anderer zumeist männlicher Charaktere. Eine ähnliche Rollenverteilung lässt sich im Falle der männlichen, außerfamiliären Figuren nicht feststellen. Diese treten in diverseren, häufig professionellen bzw. beruflichen Rollen auf. Im Vergleich zu den weiblichen Charakteren ergibt sich hieraus eine klare Verortung weiblicher Charaktere im amourösen oder sexuellen Bereich. Eine vergleichbare Korrelation zwischen dem Beziehungsstatus weiblicher Charaktere und deren Charakterisierung als Opponentinnen lässt sich bei männlichen Charakteren definitiv nicht feststellen. Ebenso 
wird diesen eher ein Leben außerhalb einer Paarbeziehung zugestanden als weiblichen Figuren.

Sowohl auf emotionaler Ebene als auch aufgrund finanzieller Verfügungsgewalt - und damit zu einem nicht geringen Teil gesellschaftlichen Einfluss - sind weibliche Charaktere nach wie vor der Autorität männlicher Charaktere unterstellt. Dies wird nicht explizit in dieser Form geäußert, lässt sich aber klar aus den Strukturen und Zusammenhängen der analysierten Weltmodelle erschließen. Die Rollenverteilung ist dabei intradiegetisch durchaus problematisch. Die Mehrzahl der Probleme weiblicher Charaktere ergibt sich aus dem häuslichen Bereich, während Männer meist von der Arbeit belastet werden. Weibliche Figuren leiden unter einem Mangel an Selbstwertgefühl, der Einengung in einen zu kleinen und monotonen familiären Raum und vor allem unter der Abwesenheit charakterlicher und gesellschaftlicher Individualität. Männliche Figuren neigen dazu, den Druck, dem sie in der Arbeitswelt ausgesetzt sind, auf negative Weise auf die Familie zu übertragen. Die Grundlage für diese Problematik wird bereits in der Jugendphase gelegt, in der Söhnen eher ein Ausbruch aus familiären Strukturen zugestanden bzw. dieser emphatischer hervorgehoben wird als die Selbstfindungsphase weiblicher Charaktere, die zumeist mit einer raschen Paarbindung einhergeht. Weibliche Charaktere erhalten weniger die Möglichkeit zur Selbstfindung oder legen diese rasch ab, um eine Familie zu gründen. Der Druck, den männliche Charaktere erdulden müssen, wird von einer ,feindlichen', außerfamiliären Außenwelt ausgeübt. Weibliche Problematiken ergeben sich einerseits aus dem Ennui des familiären Lebens, andererseits - und das dominant - aus dem Charakter selbst. Handelt ein Mann aufgrund beruflicher Belastungen destruktiv gegenüber der Familie, so handelt er aufgrund äußerer Zwänge, die originäre Schuld liegt nicht bei ihm. Entsprechende Handlungen weiblicher Charaktere ergeben sich stets aus deren eigener Verantwortung. Männliche Destruktivität, so lässt sich schließen, ist in den Zusammenhängen der analysierten Erzählungen verzeihlicher als weibliche Destruktivität. Die Verfehlungen eines Vaters und Ehemannes werden somit moralisch weniger hart verurteilt als die einer Ehefrau.

Auch bei der Darstellung homo und transsexueller Charaktere verliert das Machtgefälle zwischen männlichen und weiblichen Charakteren nicht seine Gültigkeit, rückt jedoch zugunsten anderer Thematiken in den Hintergrund. Der Prozess der Selbstfindung und der Kampf gegen gesellschaftliche Ressentiments stehen hier im Vordergrund. Vor allem wird durch die Inszenierung der Charaktere deren Existenz am Rande der Gesellschaft deutlich. Zwar werden sie generell als differenziert und positiv dargestellt, bewegen sich aber außerhalb der dominanten Norm und müssen um Akzeptanz und Anerkennung kämpfen 
- ebenso mit dem Außenraum wie mit der eigenen Persönlichkeit und verinnerlichten Wertvorstellungen. Nicht selten streben die Charaktere dementsprechend nach Normalität bzw. Angleichung an konservative und heteronormative Strukturen und damit an zuvor genannte Schemata der männlichen Dominanz und der weiblichen Unterordnung.

Unabhängig von der sexuellen Orientierung der Charaktere halten die analysierten Video-on-Demand-Serien an einer langjährig tradierten, konservativen Rollenverteilung fest. Die Alternativlosigkeit der Rollenbilder und insbesondere der Wunsch der Frauen aus häuslichen Strukturen auszubrechen und darüberhinausgehende Lebensinhalte zu finden ist dabei eine Problematik, die bereits Anfang der 1960er Jahre von der Feministin und Publizistin Betty Friedan in die Kritik genommen wurde: „We can no longer ignore the voice within women that says: ,I want something more than my husband and my children and my home "“ (Friedan 1963: 20, vgl. Friedan 1963: 44). Friedan führt aus, dass in zahlreichen Narrativen der 1950er und 1960er Jahre, Mutterschaft für weibliche Figuren unabdingbarer Teil des „femininen Mythos" (,feminine mystique") ist (vgl. Friedan 1963: 30, 45). Hier zeigen sich deutliche Parallelen zu den analysierten Serien, die eben diese Strukturen fortführen. Somit kann die Familiendarstellung der Video-on-Demand-Serie im Kern als antifeministisch bezeichnet werden. Dieser Antifeminismus ist wohl kaum Produkt einer bewussten politischen bzw. medialen Agenda und reicht nicht mehr so weit, dass Bildung und Berufstätigkeit von Frauen generell abgewertet werden (vgl. Friedan 1963: 49). Vielmehr handelt es sich bei dem von Friedan beschriebenen „feminine mystique“ um ein verhärtetes mediales Dogma, das unreflektiert reproduziert wird. Auch wenn diese Strukturen in der Darstellung der Serien kein Ideal, sondern vielmehr eine Belastung darstellen, werden sie dennoch weiterhin als alternativlos repräsentiert. Der mystifizierte Gedanke der Frau als Mutter und Hausfrau lebt hier fort und die von Friedan geforderte unbedingte Loslösung der Frauen von ihrer entpersonalisierenden und standardisierenden Rolle (vgl. Friedan 1963: 249) wurde auch über 50 Jahre später nicht umgesetzt.

Dabei gibt es prominente Ausnahmen und Formate (u. a. The Marvelous Mrs. Maisel), die versuchen, abweichende Wege zu beschreiten - diese bestätigen jedoch angesichts der Mehrzahl normkonformer Charaktere lediglich die Regel. Die genannten Strukturen werden durch deutliche Bestrebungen relativiert, diese zu dekonstruieren, zu problematisieren und nicht mehr als Ideal darzustellen. Indes bleiben sie in der Tiefenstruktur der Serien verankert und behalten ihren Status als Mythos bzw. als weitgehend alternativlos. 


\subsection{Familiäre Beziehungsmodelle}

Wie über das Verhalten der Charaktere per se werden familiäre Strukturen auch durch die Interaktion zwischen den Charakteren bestimmt. Da sich gewisse Aspekte der Interaktion bereits aus den vorangegangenen Charakteranalysen ergeben, sollen die Beziehungen der Rollen untereinander hier zusammengefasst und gebündelt werden.

Wiederholt werde ich im Folgenden von positiven und negativen Charakterverhältnissen sprechen. Dies sind zugegebenermaßen fluide und wenig präzise Begriffe, eignen sich aber zur Kategorisierung und Unterteilung der jeweiligen Beziehungen. Die Kategorisierung nehme ich dabei mit Blick auf den gesamten Handlungsverlauf des jeweils analysierten Formats vor. Dabei stehen das Verhalten der Figuren zueinander und die Auswirkungen des Charakterhandelns auf andere Charaktere im Vordergrund. Wenn Charaktere sich also vornehmlich im Streit befinden, die Beziehung über lange Zeit von einer Lüge oder von Missbrauch dominiert wird, eine Figur eine andere wiederholt in problematische Situationen bringt und keine tatsächliche Problemlösung erfolgt, ist von einer negativen Charakterbeziehung zu sprechen. Ist das Gegenteil der Fall, stehen die Figuren in einem harmonischen und daher positiven Verhältnis. Es handelt sich dabei stets um eine tendenzielle Unterteilung. Das heißt, dass nicht jeder Handlungsaspekt einer positiven Beziehung positiv sein muss, damit die Beziehung in ihrer Gesamtheit positiv ist. Kann keine klare Kategorisierung vorgenommen werden, wie dies häufig in komplexeren Beziehungen der Fall ist, werde ich von einer Ambivalenz sprechen.

\subsubsection{Eheliche Charakterverhältnisse}

Betrachtet man die Beziehung zwischen den Eheleuten in den analysierten Formaten, so fällt auf, dass die überwiegende Mehrzahl der Verhältnisse eine deutliche negative oder zumindest ambivalente Wertung erhält. Von 26 Verhältnissen erwecken 12 einen intradiegetisch negativen Anschein, 12 sind ambivalent in ihrer Darstellung und nur zwei deutlich positiv. ${ }^{86}$

Die zwei positiven Beziehungen bestehen zwischen Sol und Frankie Bergstein sowie zwischen Sol Bergstein und Robert Hanson. Die eheliche Beziehung zwischen Sol und Frankie endet zwar durch sein Outing, nach wie vor besteht

\footnotetext{
${ }^{86}$ Für die folgenden Angaben vgl. die Tabelle in Anhang 1.1 im elektronischen Zusatzmaterial.
} 
aber eine enge emotionale Bindung. Selbst nach der Trennung spenden sie sich Trost und schlafen im selben Bett (vgl. Grace and Frankie I/1: 9:00). Er will, dass sie möglichst gute Bedingungen bei ihrer Scheidung aushandelt (vgl. Grace and Frankie I/2: 16:00). Das Verhältnis ist von großer Zuneigung und Offenheit gekennzeichnet. Die Beziehung zwischen Robert und Sol ist ebenso recht harmonisch. Es herrscht gegenseitiges Verständnis, Probleme werden ausgehandelt.

Die Negativdarstellung der anderen ehelichen Verhältnisse ergibt sich handlungslogisch entweder aus einer Scheidung, einem Ehebruch oder der Koinzidenz beider Faktoren. Im Fall der Familie Murphy ( $F$ is for Family) oder der Familie Hayward (The Romanoffs I/6) liegen entsprechende Ereignisse nicht vor. Hier besteht ein anderweitiger Konflikt zwischen den Eheleuten. Die Haywards haben unterschiedliche Standpunkte bezüglich der angemessenen medizinischen Behandlung ihres Sohnes, wobei Philipp einer Weiteführung der von Victoria vorangetriebenen fruchtlosen Behandlungsversuche widerspricht. Hier treffen kühle Rationalität und emotionales Agieren aufeinander und sind der Grund für einen massiven Konflikt, der offensichtlich für beide Seiten belastend ist. Frank Murphy wiederum nimmt seine Frau Sue in ihren Ambitionen und Wünschen nicht ernst und beschränkt sie auf ihre Rolle als Hausfrau und Mutter. Eine dennoch vorhandene gegenseitige sexuelle Anziehung und die Liebe zwischen den Eheleuten reicht daher nicht aus, um das allgemein negative Weltbild des Formats aufzuwiegen. In beiden Fällen tritt eine Scheidung nicht ein, da die Haywards wie die Murphys ihr/e Kind/er weiterhin versorgen müssen. In $F$ is for Family lässt sich dies auch auf die genretypische Konsistenz des Weltmodells zurückführen.

Ehebrüche und Scheidungen haben in den analysierten Weltmodellen diverse Ursachen, welche aber im Kern Gemeinsamkeiten aufweisen. Die am wenigsten problematische Scheidung, d. h. die, die mit der geringsten Entfremdung der Ehepartner einhergeht, ist die zwischen Sol und Frankie Bergstein. Deren Ursache sind nicht mangelnde Zuneigung oder ähnliche Faktoren, sondern die bewusste Abkehr des Ehemannes von der Ehe. Robert und Grace Hansons Ehe war bereits vor der Scheidung wenig glückbringend: Beide Ehepartner führen eher eine eingefahrene Beziehung als eine, die tatsächlich auf Liebe oder Zuneigung basiert (vgl. Grace and Frankie I/1: 7:00). Dabei ist folgendes Gespräch kennzeichnend:

Robert: „Let's be honest. Were you ever really happy with me?“- Grace: „I was happy enough. So we didn't have the romance of the century. But I thought we were normal. I thought we were like everybody else. I thought this is live.“- Robert: „And I thought there was more." (Grace and Frankie I/1: 7:00) 
Die Routine, welche Grace als Normalität wahrnimmt, ist ein Grund für Roberts Trennung und seinen Ehebruch mit Sol. Damit ähnelt er anderen Ehemännern, welche die Ehe aufgrund der Einengung in Bezug auf bestimmte Pflichten hinter sich lassen. Auch Joel Maisel (The Marvelous Mrs. Maisel) begeht Ehebruch aufgrund eines Gefühls mangelnder Selbsterfüllung. Hier ist es aber die Ehefrau, welche die Scheidung nutzt, um die Beziehung zu beenden. Joels und Miriams Ehe und die daraus resultierende Familie sind zwar in sich nicht unglücklich, beide Ehepartner empfinden nach wie vor Zuneigung zueinander. Es handelt sich dennoch um ein Produkt gesellschaftlicher Zwänge. Somit stellt die Ehe eine Belastung dar, die außerdem zwischen den Charakteren und deren Selbstverwirklichung steht. Leroy O'Neil, der sich in Everything Sucks! trotz eines gemeinsamen Kindes von Sherry trennt, um seinen persönlichen, aber fruchtlosen Zielen nachzugehen, ähnelt in seinen Handlungen Joel Maisel. Auch Michael Romanoff begeht Ehebruch, um aus der Routine seines Lebens auszubrechen (vgl. The Romanoffs I/2), während George Burrows schlicht aus sexueller Anziehung zu Ondine handelt (vgl. The Romanoffs I/8).

Bei einer durch männliche Charaktere angestrebten Trennung steht in der Regel das Paradigma der Verantwortungslosigkeit und des Wunsches nach rücksichtsloser Selbstverwirklichung im Vordergrund. Ehebruch ist dabei nie eine probate Handlungsweise, egal ob er von der Ehefrau oder dem Ehemann begangen wird. Wenn er die Stabilität der familiären Struktur bedroht, wird er als verantwortungslos und selbstsüchtig dargestellt. Dennoch wird der Ehebruch durch weibliche Charaktere als nachvollziehbar inszeniert, auch wenn er dadurch intradiegetisch nicht entschuldbar wird. Wendy Byrde und Elsa Gardner leiden unter der familiären Einengung und der Ignoranz des Ehemannes. Elsas Ehemann wirft ihr wortwörtlich vor, sich allein über die Rolle als Mutter zu definieren. Eine Trennung vom Ehemann wie in Grace and Frankie, The Marvelous Mrs. Maisel oder Everything Sucks! ist durchaus legitim, solange diese auf einem Ehebruch des Ehemannes basiert. Wenn - wie in Red Oaks - keine Kinder mehr zu versorgen sind und dadurch die Familie als Schutzraum nicht mehr unmittelbar bedeutend ist, ist dies ebenso möglich. Einen Sonderfall stellt The Get Down dar: Hier erwehrt sich Lydia Cruz ihres gewalttätigen und despotischen Ehemannes, dessen Verhalten Ehebruch und Trennung legitimiert.

Am Beispiel von Sue Murphy, aber auch anhand von Elsa Gardner, Sherry O’Neil, Sue Murphy, Wendy Byrde, Judy Myers, Lydia Cruz, Miriam Maisel, Shelly Romanoff, Victoria Hayward, Natalie Burrows und Sarah Pfefferman zeigt sich ein zentrales Charakterisierungselement ehelicher Beziehungen: Zwar sind einige Serien-Ehemänner ebenso unglücklich mit ihrer Ehe, vor allem aber sind es die Ehefrauen, die unter den geschilderten Strukturen leiden. Es ist dabei nicht 
- wie man vielleicht vermuten könnte - die Überpräsenz des Ehemannes und eine gezielte Ausübung patriarchaler Strukturen, welche problematisch ist, sondern deren Absenz. Eigennützige Selbstbezogenheit des Ehemannes, dessen emotionale Abwesenheit oder Kälte, oft eine Konsequenz des harten Arbeitslebens, haben negative Auswirkungen auf die eheliche Beziehung. Die wirtschaftliche Abhängigkeit und die bereits oft erwähnte Rollenbindung tragen ebenfalls dazu bei.

Die Einschätzung von Ehen als ambivalent ergibt sich zum einen aus einer mangelhaften Datenlage, die keine exakte Einordnung zulässt. Dies ist bei Mitch und Mallory Hanson in Grace and Frankie der Fall. Vor allem für Mallory ist das Leben als Mutter zwar nicht stressfrei, es wird aber doch positiv inszeniert. Mitch ist dabei eher absent. Ebenso erfährt man wenig mehr über die Beziehung von Moishe und Shirley Maisel in The Marvelous Mrs. Maisel, als dass es sich wohl um eine routinierte und langjährige Ehe handelt. Julia Wells wird in der vierten Folge von The Romanoffs von ihrem Ehemann zwar mit geringfügiger Herablassung behandelt, doch auch hier lassen sich keine exakten Aussagen über die Qualität ihrer Ehe fällen. Auch über Justin und Ella Hopkins aus derselben Folge lässt sich wenig mehr sagen, als dass der Ehemann häufig geschäftlich absent ist und die Ehefrau ihre häusliche, passive Rolle freiwillig annimmt.

Weitere ambivalente Beziehungen haben deutliche problematische Elemente, die allerdings durch andere Faktoren, aufgewogen ' werden. Zudem liegt in der Regel keine konkrete Gefährdung der familiären Situation vor: Ken Messners Ehefrau ist verstorben bzw. hat Suizid begangen (Everything Sucks!). Die Ehe per se scheint glücklich gewesen zu sein, denn Messner trauert seiner Ehefrau nach. Dies hindert ihn jedoch nicht an dem Versuch erneut eine Partnerin zu finden und somit eine stabilere Situation zu etablieren. Insofern liegt keine Negativcharakterisierung vor. Auch Doug und Fay Getty in Red Oaks lieben sich, obwohl Fay offensichtlich als Nutznießerin den Wohlstand ihres Ehemannes genießt. Abraham und Rose Weissman (The Marvelous Mrs Maisel) führen ebenfalls keine unproblematische Beziehung: Abraham ist gegenüber seiner Ehefrau ebenso ignorant wie gegenüber seiner Tochter, ist aber dennoch keine explizit negative Figur. Beide Ehepartner haben sich mit den Launen des jeweils anderen arrangiert. Beau und Maggie Bennett (The Ranch) empfinden zwar Zuneigung füreinander und Beau wünscht sich - trotz der Scheidung - erneut ein gemeinsames Leben. Maggie zieht es allerdings vor, ihren Freiraum außerhalb der Ehe zu genießen und kann die emotionale Vernachlässigung durch Beau nicht vergessen. Joe und Anka Garner (The Romanoffs I/7) wollen ein gemeinsames Kind adoptieren. Die Beziehung scheint dementsprechend stabil. Dennoch sind die Adoption und die daraus resultierenden Konflikte ein Prüfstein für ihre Beziehung. George und Ondine Burrows 
(The Romanoffs I/8) führen zwar eine in sich glückliche Ehe, diese verliert aber insofern an positiver Grundwertung, da ihr Verhältnis aus dem gewaltsamen Ende von Georges vorheriger Ehe hervorging. Die Ehe von Maura und Shelly Pfefferman (Transparent) endete bereits vor Einsetzen der Handlung. Die Scheidung wurde wohl mit beiderseitigem Einverständnis vollzogen. Zudem befinden sich beide Charaktere nach wie vor in einem Dialog, haben sich also nicht vollkommen voneinander distanziert. Sarah Pfeffermans und Tammy Cashmans Ehe hat zwar die Spaltung ihrer vorherigen Ehen zufolge und ist in sich nicht nur harmonisch, sie stellt aber insbesondere für Sarah eine Befreiung und Selbstfindung dar.

Hier lassen sich also keine klaren Tendenzen ableiten außer einer Bestätigung der Merkmale der Hausfrauen- und Mutterrolle. Das Idealbild der Ehe mit absoluter Harmonie und unzerbrechlicher Zuneigung zwischen den Ehepartnern findet in den Serien des Korpus keine Anwendung mehr. Nur in den seltensten Fällen werden Ehen bzw. die Beziehungen zwischen den Eheleuten klar positiv bewertet. Meist handelt es sich um negative Verhältnisse, die durch einen massiven Konflikt bestimmt werden, der häufig zu Ehebruch, Scheidung oder beidem führt. Ein ebenso großer Prozentsatz an Ehen ist zwar nicht entsprechend problematisch, weist aber Konflikte auf. Während Ehebruch dabei stets negativ und destruktiv gewertet wird, ist Scheidung in einigen Fällen - z. B. aufgrund eines Ehebruchs - ein probates Mittel. Destruktive Handlungen in Bezug auf die Familie sind dann besonders problematisch, wenn die Kinder noch jünger und dementsprechend schutzloser sind. Die Ehe ist folglich ein Raum des Konfliktes, der zwar eindeutig durch Liebe und Zuneigung gekennzeichnet ist - denn den meisten Ehepartnern des Analysekorpus kann eine entsprechende Zuneigung zugesprochen werden -, aber auch deutliche Belastungen mit sich bringt. Ebenso ist sie weiteren äußeren Einflüssen wie dem Arbeitsleben oder dem gesellschaftlichen Erwartungsdruck ausgesetzt. Brechen sich entsprechende Belastungen Bahn, so geschieht dies meist in einem egoistischen Akt. Dieser kann so schwerwiegend sein, dass er zu einem Bruch der Ehe führt, der - tritt er während der Handlung ein - zentrales Thema ist. Die Beziehung zwischen Eheleuten, so die ableitbare Aussage, muss auf gegenseitiger Rücksichtnahme basieren, die zumindest einen Ausgleich zu negativen Aspekten der Ehe ermöglicht. Das Ende einer Ehe und somit einer Familie ist stets ein höchst problematisches Ereignis. 


\subsubsection{Eltern-Kind-Beziehungen}

Für die Einschätzung des Verhältnisses von Eltern zu Kindern bietet es sich zunächst an, die hierarchische Gewichtung der Beziehung zwischen Vätern und Kindern sowie Müttern und Kindern zu betrachten. Im vorliegenden Analysekorpus nehmen im Eltern-Kind-Gefüge 13 Väter und 8 Mütter eine dominante Rolle ein. In sechs Fällen liegt keine Dominanz vor, in fünf Fällen fehlt ein Elternteil, in einem Fall beide. ${ }^{87}$ Die Dominanz eines Charakters lässt sich aus dessen Handlungsrelevanz ableiten ebenso wie aus der intradiegetischen Charakterisierung als familiärer Entscheidungsträger.

In den fokussierten Familien treten allgemein mehr Söhne (30) als Töchter (18) auf, woraus sich wiederum die ungleiche Verteilung der Vater-MutterSohn/Tochter-Beziehungen in der referenzierten Tabelle (vgl. Anhang $1.2 \mathrm{im}$ elektronischen Zusatzmaterial) ergibt. Wie bereits dargelegt, ist die Mutterrolle dabei eine fürsorgliche, während der Vater Kinder und Familie schützt und versorgt. Eine funktionierende moralische Führungsrolle des Vaters, wie sie für Serien der 1950er und 1960er Jahre elementar war, ist dabei selten gegeben.

Weiterhin lassen sich die Gruppen der Kinder in erwachsene bzw. weitgehend selbstständige und noch elementar auf die Eltern angewiesene Charaktere unterscheiden. 21 der 49 Kinder sind dabei der ersteren Gruppe zuzurechnen. Obwohl sich alle Charaktere in entsprechend individuellen Lebenssituationen befinden, auf die bereits in 2.1.2 und 2.2.2 eingegangen wurde, lassen sich Gemeinsamkeiten ableiten. Mallory und Brianna Hanson (Grace and Frankie), Coyote und Bud Bergstein (Grace and Frankie), Joel Maisel (The Marvelous Mrs. Maisel), Miriam Maisel und Noah Weissman (The Marvelous Mrs. Maisel), Greg Moffat (The Romanoffs I/1), Ella Hopkins (The Romanoffs I/4), Simon/Candice und Jack Burrows (The Romanoffs I/8) sowie Sarah und Josh Pfefferman (Transparent) sind dem Elternhaus bereits entwachsen. Alle Charaktere sind berufstätig und daher nicht mehr auf finanzielle oder emotionale Unterstützung ihrer Eltern angewiesen. Sie haben also eine weitgehende Unabhängigkeit von den Eltern erlangt. Die Beziehung zu den Eltern ist in den meisten Fällen ambivalent. Ausnahmen sind die Bergstein-Söhne, deren Familie allgemein harmonisch dargestellt wird und deren Beziehungen zu ihren Eltern sehr positiv sind. Simon bzw. Candice Burrows hatte als Kind eine positive Beziehung zu seiner/ihrer Mutter, die Ablehnung durch den Vater hat Simon/Candice jedoch tiefgreifend traumatisiert und deutlich

${ }^{87}$ Für die folgenden Angaben vgl. die Tabelle in Anhang 1.2 (im elektronischen Zusatzmaterial). Anushka und Greg (The Romanoffs I/1) stellen wie Ezekiel und seine Tante Wanda (The Get Down) Sonderfälle dar. Ich möchte sie allerdings aufgrund einer äquivalenten Beziehung im Folgenden als Mutter und Sohn behandeln. 
negative Auswirkungen auf ihn/sie. ${ }^{88}$ Die weiteren oben genannten Charaktere stehen nicht mehr unter der Bevormundung der Eltern. Ein übermäßiger Einfluss der Eltern auf das Leben der Kinder wird als störend wahrgenommen. So sind Mallory und Brianna Hanson deutlich mit ihrem eigenen Leben beschäftigt und pflegen zurückhaltenden Kontakt mit Mutter und Vater. Joel Maisel und Miriam Maisel geraten nach der Trennung wieder in Abhängigkeit von den Eltern, die u. a. versuchen, die gescheiterte Ehe wiederherzustellen und darüber hinaus direkten Einfluss auf deren Leben zu nehmen. Auch wenn die elterliche Autorität im Szenario der 1950er Jahre größer ist als in Formaten der Jetztzeit, wird dieses Eingreifen von den Kindern als allgemein negativ wahrgenommen. Greg Moffat und Ella Hopkins setzen sich gegen die autoritären Mutterfiguren durch, welche versuchen, ihr Handeln zu beeinflussen, und agieren im Vergleich zu ihren Müttern deutlich rationaler und überlegter. Für Sarah und Josh Pfefferman stellt das Outing des Vaters eine Belastung der eigenen Lebensumstände dar. Vor allem Sarah, die von den drei Kindern der Pfeffermans am gefestigtsten im Leben steht, versucht ihren Vater zu unterstützen.

Skye Getty, David Myers (Red Oaks), Ezekiel Figuero, Mylene Cruz (The Get Down), Ruth Langmore (Ozark) sowie Julian Myers (The Romanoffs I/5) befinden sich auf dem Weg in das Erwachsenenalter. Sie agieren bereits weitgehend selbstständig, sind allerdings noch von den Vorstellungen und Anforderungen ihrer Eltern abhängig. Eine sukzessive Loslösung findet statt, welche häufig - wie im Falle Davids, Ezekiels und Mylenes - mit der Ablehnung der von den Eltern vorgegebenen Strukturen einhergeht. Dies ist nicht gleichbedeutend mit einer vollkommenen Abkehr von den Eltern bzw. einem Zerwürfnis, bedeutet aber stets Konflikte. Im Falle von Mylene und Ruth stellt sich der Vater gegen diese Loslösung und versucht die Autorität aufrechtzuerhalten. Es handelt sich in diesem Fall um einen deutlich negativen, ja brutalen Akt.

Kann eine Emanzipation nicht stattfinden, handelt es sich um eine problematische Situation. Dies ist der Fall bei Sam Dermody (Ozark), Cadillac (The Get Down), Ali Pfefferman (Transparent) sowie Jameson und Colt Bennett (The Ranch). All diesen Charakteren ist es nicht gelungen, sich von der elterlichen Autorität zu lösen (Sam, Cadillac) bzw. ein eigenes, funktionierendes Leben aufzubauen (Ali, Jameson, Colt). Ein entsprechendes Leben wird, insbesondere im Falle der Abhängigkeit von der Mutter, wie sie bei Sam und Cadillac der Fall ist, stets als defizient dargestellt. Die Charaktere befinden sich nicht nur in

\footnotetext{
${ }^{88}$ Die Ablehnung des Vaters scheint dabei darauf zu basieren, dass er als Kind zwischen ihm und seiner zukünftigen Ehefrau Ondine steht. Michael nimmt sich diese Ablehnung sehr zu Herzen: Nach einem Streitgespräch stiehlt er die Medikamente des kranken Vaters und versucht sich umzubringen (vgl. The Romanoffs I/8: 14:07).
} 
einer einengenden Abhängigkeit, sondern können sich unter Einfluss der Eltern auch nicht vollständig entfalten bzw. selbst verwirklichen. Eine Loslösung ist elementarer Bestandteil des Erwachsenwerdens.

Die verbliebenen Eltern-Kind-Beziehungen lassen sich in zwei Gruppen kategorisieren: die Beziehung der Eltern zu adoleszenten Charakteren und die Beziehung der Eltern zu jüngeren Kindern, welche noch unter der absoluten Obhut der Eltern stehen. Die adoleszenten Charaktere des Korpus sind Sam und Casey Gardner (Atypical), Luke O'Neil und Kate Messner (Everything Sucks!), Kevin Murphy ( $F$ is for Family), Charlotte Byrde und Wyatt Langmore (Ozark) sowie Marcus, Ronald, Miles und Yolanda Kipling (The Get Down). Diese Charaktere stehen aufgrund ihres Alters bzw. ihrer Entwicklung und ihrer Lebenssituation unter dem deutlichen Einfluss ihrer Eltern. In jedem Fall leben sie zu Hause unter Aufsicht beider Elternteile oder eines Elternteils. Je älter die Charaktere sind, je näher sie also der Phase der Loslösung stehen, desto eher wird elterliche Autorität oder allgemein elterliches Handeln als störend oder negativ empfunden. Insbesondere bei pubertären Figuren wie Casey Gardner, Kevin Murphy und Charlotte Byrde ist das Verhältnis zu Mutter und Vater gleichermaßen angespannt, da sie zwar einerseits der elterlichen Autorität unterstehen, aber diese andererseits bereits als Einmischung in ihr Leben und ihre Entscheidungsfreiheit verstehen. Je intensiver die Eltern in das Leben ihrer Kinder involviert sind oder je mehr sie zur strengen Ausübung der Autorität neigen, desto problematischer ist diese Phase für beide Parteien. Elsa Gardner versucht sich gegen das Erwachsenwerden ihrer Kinder und damit gegen den Verlust ihrer Mutterrolle zu stellen, ähnlich Sherry O'Neil, die eine Entfremdung von ihrem Sohn befürchtet. Frank Murphy verachtet seinen pubertären Sohn Kevin, der sich wiederholt gegen seine drakonische Autorität auflehnt - eine Quelle ständiger Konflikte.

Bill und Maureen Murphy ( $F$ is for Family), Macklin und Madison Hanson (Grace and Frankie), Jonah Byrde und Three Langmore (Ozark), Henry und Benji Myers (The Romanoffs I/5), Oksana bzw. Katerina (The Romanoffs I/6) und Nicholas Hayward (The Romanoffs I/6) sind zwar unterschiedlich alt (von Kleinkind bis vorpubertär), haben aber alle nicht das Alter erreicht, in dem eine Loslösung von den Eltern angestrebt wird. Allein die älteren Kinder, z. B. Bill, Maureen, Jonah, Three, Henry und Nicholas, haben dabei eine tatsächlich ausgeprägte Persönlichkeit. Elterliche Autorität wird aber nie in Frage gestellt. Der Schutz der Kinder dieses Alters ebenso wie die absolute Bestimmung ihres Lebens stehen dabei im Mittelpunkt der Eltern-Kind-Beziehung, je jünger das Kind, desto deutlicher.

Die Darstellung einer Reduzierung der Intimität zwischen Eltern und Kind mit fortschreitendem Alter und einer zunehmenden Abflachung des Autoritätsverhältnisses folgt einer konventionellen Logik. Doch wovon ist es nun abhängig 
zu machen, ob die Eltern-Kind-Beziehung positiv oder negativ bewertet wird? Einige Faktoren wurden bereits genannt: Negative Verhältnisse können u. a. aufgrund des übermäßig autoritären Auftretens eines Elternteils entstehen. Dies ist bei Frank Murphy, Ramon Cruz und Cade Langmore der Fall. Ebenso begegnet Marty Byrde seiner Tochter mit ignoranter Autorität, nimmt ihre Nöte und Ängste nicht ernst und verfügt über deren Leben. Obgleich es seine Intention ist, die Tochter zu schützen, wird das Vertrauensverhältnis damit beschädigt und Charlotte entfremdet sich sichtlich von ihren Eltern. Auch wenn eine Loslösung von dieser Autorität im Erwachsenenalter nicht erfolgen kann und weiterhin von den Eltern ausgeübt wird, wie bei den Bennett-Söhnen und deren Vater, Fat Annie und Cadillac sowie Sam Dermody und dessen Mutter, ist die Beziehung negativ konnotiert. Besonders problematisch ist auch ein Mangel an Zuneigung zwischen Eltern und Kindern. Dies geht - wie in den vorangegangenen Beispielen - häufig mit einem Übermaß an Autorität einher. Hier nimmt der Wunsch, über die Kinder zu entscheiden, meist überhand. Teils werden Kinder zum Mittel eigene Ziele zu verwirklichen. So stehen für Ramon Cruz, Cade Langmore, Fat Annie und Beau Bennett eigene Bedürfnisse im Vordergrund und nicht das Wohl ihrer Kinder. Es handelt sich folglich um Missbrauchsverhältnisse, um die Unterdrückung einer Persönlichkeitsentwicklung. George Burrows lehnt seinen Sohn aus egoistischen Gründen ab, ohne dass Simon tatsächlich Schuld trägt. Dieser absolute Mangel an Zuneigung hat deutlich negative Auswirkungen auf die Entwicklung des jungen Mannes. Leroy O'Neil und Russ Langmore vernachlässigen ihre Söhne und lassen ihnen nicht genug Aufmerksamkeit zuteilwerden. Dies führt im Falle Luke O'Neils zu einer schmerzhaften Sehnsucht nach einer Vaterfigur, bei den Langmore-Söhnen, die im Gegensatz zu Luke keine Mutter haben, zu Verwahrlosung. Sowohl ein Mangel an Autorität als auch deren Übermaß und vor allem ein Mangel an elterlicher Zuneigung sind eindeutig negative Faktoren.

Demgegenüber stehen ausgeglichene Verhältnisse. Wenngleich der unselbstständige und ehemals drogenabhängige Coyote einen gewissen Störfaktor darstellt, so ist die Familie Bergstein in sich harmonisch. Die Eltern greifen hier nicht mehr in das Leben ihrer erwachsenen Söhne ein. Ken Messner und Sherry O'Neil geben ihren Kindern zwar Zuneigung und haben sich zuvor um eine angemessene Beziehung bemüht, bei Einsetzen der Loslösungsphase ihrer Kinder treten sie jedoch zurück und lassen den Kindern Freiraum zur individuellen Entwicklung. Als positiv werden eine elterliche Vorbildfunktion sowie der Versuch bewertet, Kinder verständnisvoll und mit - je nach Alter - angemessener Autorität in die ,richtige' Richtung zu lenken, wie dies bei Wanda (Ezekiels Tante in The Get Down), Winston und Adele Kipling (The Get Down), Alex Myers und Katherine 
Ford (The Romanoffs I/5) und deren Kindern der Fall ist. In allen vorangegangenen Beispielen sowie bei Maggie Bennett und ihren Söhnen Jameson und Colt (The Ranch), Natalie Burrows bezüglich Samuel und George und Ondine Burrows in Bezug auf deren Sohn Jack (The Romanoffs I/8) zeigt sich, dass es vor allem Liebe und Zuneigung sind, die ein positives Eltern-Kind-Verhältnis definieren.

Ob die Tendenz nun in Richtung einer positiven oder negativen Darstellung geht, ist nicht in allen Fällen ohne Weiteres festzustellen. Hierbei handelt es sich um ambivalente Eltern-Kind-Beziehungen, welche positive Merkmale wie Zuneigung und gegenseitige Fürsorge enthalten, aber auch negative Elemente aufweisen. So versucht Anushka ihren Neffen Greg (The Romanoffs I/1) eindeutig zu ihren Gunsten zu funktionalisieren, dieser begegnet ihr aber nach wie vor mit gelassener Zuneigung und kann sich allgemein durchsetzen. Abraham und Rose Weissmans Versuch, Einfluss auf Miriam Maisels Leben zu nehmen, nimmt bisweilen überhand. Sie kann sich aber behaupten, u. a. indem sie ihren Vater nicht gänzlich ernstnimmt. Victoria Hayward hat zwar per se ein sehr gutes Verhältnis zu ihrem Sohn, agiert jedoch übermäßig protektiv. Im Gegensatz dazu ist der Vater Nicholas Hayward tendenziell zu wenig bemüht, aber mit dem Hintergedanken, seinen Sohn nicht weiteren fruchtlosen Behandlungen auszusetzen. Wendy Byrde setzt sich zwar für ihre Kinder ein, gefährdet sie allerdings durch deren Einweihung in die Geldwäschegeschäfte. ${ }^{89}$

Das Eltern-Kind-Verhältnis bestätigt, wenn auch nicht überdeutlich, die innerfamiliäre Dominanz des Vaters vor der Mutter. Dabei treten Väter häufiger in negativen Rollen auf (9) als Mütter (2), aber auch nahezu ebenso häufig in positiven. Dies ergibt sich aus dem Status des Vaters als Autoritätsfigur und Verantwortungsträger, der oft eine übermäßige Anwendung dieser Autorität mit sich bringt, während die Mutter-Kind-Beziehung als Ort der Wärme und Fürsorge weitgehend unangetastet bzw. frei von scharfer Kritik bleibt. Allgemein existieren nahezu ebenso viel positive wie negative Verhältnisse von Eltern zu Kindern. Der größte Anteil ist jedoch ambivalent. Extreme Ausprägungen wie übermäßige Autorität oder Vernachlässigung der Kinder führen zu einer negativen Beziehung. Eine mangelnde Ausrichtung des Erziehungsstils am Alter des Kindes, also beispielsweise wiederholtes Einwirken auf das Leben bereits erwachsener Kinder, wird ebenso klar negativ bewertet. Grundstein einer jeden positiven Beziehung zwischen Eltern und Kindern ist die gegenseitige Zuneigung und der Respekt vor den Wünschen des jeweils anderen, was auch in der Mehrzahl der ambivalenten Fälle eine Verlagerung ins Negative verhindert. Diese Zuneigung

\footnotetext{
${ }^{89}$ Weitere Beispiele sind der Tabelle in Anhang 1.2 (im elektronischen Zusatzmaterial) zu entnehmen.
} 
ist elementar für den allgemein positiv bewerteten familiären Zusammenhalt. Ein Mangel hat umfassende negative Auswirkungen. Somit bestätigen die analysierten Serien über das Verhältnis der Eltern zu ihren Kindern und umgekehrt die Bedeutung des familiären Zusammenhalts. Das Verhältnis allgemein ist leicht patriarchal dominiert, stellt aber vor allem die Anerkennung der Bedürfnisse und Rechte des Kindes sowie dessen wachsende Selbstständigkeit in den Mittelpunkt. Dies lässt sich, in Verbindung mit den unter 3.2 getätigten Beobachtungen, wiederum als Betonung der Bedeutung von Familie verstehen, denn eine Selbstständigkeit des Kindes führt nach der Logik der Serien im Korpus zu einer erneuten Familiengründung.

\subsubsection{Geschwisterliche Beziehungen}

Geschwisterliche Beziehungen haben in Video-on-Demand-Serien im Vergleich zur ehelichen Beziehung und der Beziehung zwischen Eltern und Kindern eine relativ geringe Bedeutung. Innerhalb meines Korpus zähle ich zwölf relevante Beziehungen zwischen Geschwistern. Dabei ist die Zahl der Brüder mit 21 Figuren deutlich größer als die der Schwestern (9 Charaktere). Allein in zwei Serien dominieren die Schwestern zahlenmäßig: in Transparent (die Pfefferman-Kinder) und in Grace and Frankie (die Hanson-Töchter). Männliche Figuren bestimmen also erneut das Geschehen.

Allgemein wird keine dieser geschwisterlichen Beziehungen explizit negativ dargestellt. Fünf möchte ich als positiv bezeichnen, sieben als ambivalent. In den ambivalenten wie den positiven Fällen herrscht eine gewisse geschwisterliche Konkurrenz, d. h., die Figuren hänseln sich gegenseitig oder pflegen kleinere, aber nie besonders aggressive Streitereien, wie man sie zwischen Geschwistern allgemein als gegeben annimmt.

Insbesondere in den positiveren Beziehungen verteidigen und unterstützen sich Geschwister gegenseitig, besonders in Fragen bezüglich des Umgangs mit den Eltern oder der eigenen Entwicklung. So hilft Casey Gardner ihrem autistischen Bruder nicht nur beim Online-Dating (vgl. Atypical I/1: 5:00), sondern macht sich auch ernsthafte Sorgen, ihn - nach einem Schulwechsel - allein zu lassen (vgl. Atypical I/8: 26:00). Bisweilen ärgert sie sich jedoch über sein Verhalten, beleidigt ihn (vgl. Atypical I/2: 12:00) und hänselt ihn (vgl. Atypical I/4: 4:00). In $F$ is for Family verteidigt Kevin Murphy zwar seinen kleinen Bruder Bill vor einem Schulschläger, schlägt ihn aber gleich darauf selbst (vgl. $F$ is for Family I/1: 13:00). In der gleichen Episode nimmt er zudem die Schuld für einen kaputten Fernseher auf sich, den eigentlich Bill kaputt gemacht hat (vgl. F is for 
Family I/1: 20:00). Kevin zeigt seinem Bruder auch, wie man - um einen Schulverweis zu bestätigen - die Unterschrift des Vaters fälscht (vgl. $F$ is for Family I/5: 4:00). Ebenso lehnt sich Maureen wiederholt gegen ihren größeren Bruder Bill auf (vgl. $F$ is for Family I/2: 11:00), ist aber auch essenziell auf seine Hilfe angewiesen (vgl. $F$ is for Family I/2: 21:00). Als Bill in einen Fluss fällt, rettet Maureen ihm sogar das Leben (vgl. $F$ is for Family III/10: 23:00). Coyote und Nwabudike Bergstein geraten zwar gelegentlich in Streit (vgl. Grace and Frankie I/2: 20:00, I/8: 16:00), aber zugleich unterstützt Nwabudike seinen ehemals drogenabhängigen Bruder und lässt ihn bei sich wohnen (vgl. Grace and Frankie I/2). Die Kipling-Brüder in The Get Down unterstützen sich über die gesamte Serie hinweg und halten untereinander und mit ihrem Freund Ezekiel eng zusammen.

Die genannten Beziehungen werden deutlich positiv bewertet. Sind hier auch Konflikte vorhanden, überwiegt doch die gegenseitige Unterstützung, das Einstehen füreinander. In den ambivalenten Beziehungen besteht ein Gleichgewicht von intensiven Streitereien und einem dennoch vorhandenen Zusammenhalt. ${ }^{90}$ Dies ist der Fall bei Charlotte und Jonah Byrde, die bereits zu Beginn der Serie im Streit präsentiert werden (vgl. Ozark I/1: 7:00). Im Verlauf spielt die Konkurrenz zwischen beiden aber keine unmittelbare Rolle mehr. Zum Abschluss der ersten Staffel argumentieren sie dafür, zu ihrem Vater zurückzukehren, und nehmen somit einen gemeinsamen Standpunkt ein (vgl. Ozark I/10: 1:10:00). Wyatt Langmore hat ebenso kein allzu enges Verhältnis zu seinem Bruder Three und fühlt sich bisweilen gestört von ihm und seinem infantilen Verhalten (vgl. Ozark I/5: 44:00). In echte Konkurrenz treten sie jedoch nie. Colts und Jamesons Beziehung wird von Witzen auf Kosten des jeweils anderen und wenig tiefgehenden Streitereien bestimmt (vgl. The Ranch I/1: 7:00, I/2: 13:00, I/5: 22:00). Dennoch bleiben sie in einer brüderlichen Dynamik und Vertrautheit verbunden (vgl. The Ranch I/2: 14:00, I/5: 25:00). Zwischen den Pfefferman-Kindern in Transparent treten ernsthafte Konflikte zutage. Persönliche Eigenheiten und Lebensentscheidungen der Geschwister werden gegenseitig angezweifelt (Transparent I/6: 4:20, I/10: 13:00). Auch in Hinblick auf finanzielle und materielle Fragen, z. B. wer das Haus des Vaters nach dessen Auszug bekommt (Transparent I/1: 12:00, I/5: 11:00), kommt es wiederholt zu Streitigkeiten. Dennoch gefährden diese nie unmittelbar den familiären Zusammenhalt. Durch die Unterstützung des Vaters bemühen sie sich - wenn auch indirekt - vielmehr um dessen Erhalt. ${ }^{91}$

\footnotetext{
${ }^{90}$ In einigen Fällen haben geschwisterliche Beziehungen keine besondere Relevanz bzw. werden nicht vertieft ausgeführt, weswegen ich sie als ambivalent kategorisieren möchte.

${ }^{91}$ Letztlich sitzt die gesamte Familie versammelt um den Esstisch (vgl. Transparent I/10: 27:00).
} 
Wie unter 2.7 dargelegt, blieben geschwisterliche Verhältnisse in Serien zwar über die Jahrzehnte hinweg im Kern positiv, wurden aber zunehmend konfliktreicher. Die Serien des Korpus folgen diesem Trend. Zusammenhalt und gegenseitige Unterstützung sind nach wie vor ein wichtiger Bestandteil der Verhältnisse und in ihrer Essenz sind die Beziehungen zumindest nie negativ. Diesen positiven Entwicklungen werden stets Konflikte unterschiedlichen Ausmaßes entgegengesetzt. Sie erreichen selten eine ernsthafte Dimension und bewegen sich auf dem Niveau eines geschwisterlichen ,Hickhacks'. In keinem der analysierten Fälle hat das Verhältnis zwischen Geschwistern eine besondere Tiefe. Sie bilden eine gemeinsame Familie, dabei ist die Bindung und Beziehung zu den Eltern von höherer Handlungsrelevanz als die Konflikte untereinander.

\subsubsection{Außerfamiliäre Verbindungen}

Nach der ausführlichen Darlegung außerfamiliärer Beziehungen (vgl. 3.2.1.3, 3.2.2.3) ist eine detaillierte Ausführung an dieser Stelle müßig. Stattdessen werde ich einen globaleren Blick auf die Verbindungen von Familien in die Außenwelt werfen.

Anhand der bereits vorgenommenen Kategorisierung stellt sich heraus, dass zwar eine bedeutende Zahl an eindeutigen Opponenten und Adjuvanten vorliegt, die Anzahl der nicht klar zuzuordnenden Figuren allerdings wiederum hervorsticht. Das Verhältnis zur Außenwelt ist folglich facettenreich und bestätigt die bisher bereits wiederholt implizierte These einer relativ komplexen Darstellung der Figurenverhältnisse in Video-on-Demand-Serien. Bei der allgemeinen Betrachtung der außerfamiliären Verhältnisse springt ins Auge, dass es sich meist um Kontakte zu für sich stehenden Einzelpersonen handelt, die mit eigener Motivation handeln. Staatliche Stellen und Einrichtungen treten nur selten in Gestalt expliziter Personen auf. Bereits genannte Beispiele sind die FBI-Ermittler Roy Petty und Trevor Evans (Ozark), welche - obgleich sie ihre objektiv notwendige Tätigkeit zur Verhinderung von Verbrechen ausüben - eindeutig Antagonisten der Familie Byrde sind. Bei einem Blick auf die weiteren Serien handelt es sich um Figuren mit geringer Tiefe, die über ihre Funktion, nicht über ihre charakterlichen Eigenheiten definiert werden.

In $F$ is for Family treten Polizei bei einer Geiselnahme (vgl. $F$ is for Family II/10: 19:00) und Feuerwehr bei einer Rettungsaktion in Erscheinung (vgl. F is for Family III/10: 21:00). In beiden Fällen erweisen sie sich als unfähig, die Situation 
zu lösen. Frank Murphys Arbeitgeber, ebenso im weitesten Sinne eine außerfamiliäre Autorität, sind durchgehend unfähig und tyrannisch und tragen zu Franks stetiger Belastung bei, welche seine Familie letztlich ebenso erdulden muss.

Doug Getty wird in Red Oaks vom FBI wegen Insiderhandels verhaftet (vgl. Red Oaks I/10: 16:30), was die Familie Getty in eine negative Lage bringt.

In The Get Down stehen Politik und staatliche Organe, schon durch die problematische soziale Herkunft der Mehrzahl der Charaktere, in deren Opposition. Dabei tritt u. a. Ed Koch, 1978 bis 1989 Bürgermeister von New York, als entschiedener Gegner von Kriminalität und Vandalismus und somit auch als Gegner der Charaktere auf, die u. a. selbst Graffitis anbringen.

Miriam Maisel wird bei ihrem ersten Auftritt von der Polizei abgeführt und kurzzeitig inhaftiert, nachdem sie öffentlich ihre Brüste gezeigt hat (vgl. The Marvelous Mrs. Maisel I/1: 46:40). Später muss sie sich einem äußerst konservativen Richter mit sexistischen Tendenzen stellen (vgl. The Marvelous Mrs. Maisel I/3: 18:40).

Der einzige Polizist, der in The Ranch auftritt, ist „Beer Pong Billy“, ein dümmlicher und offensichtlich wenig kompetenter ehemaliger Saufkumpan der Bennett-Brüder (vgl. The Ranch I/3: 23:00).

In der fünften Episode von The Romanoffs ermittelt die Polizei gegen den Klavierlehrer David Patton und bringt somit das Leben der Familie in Unordnung (vgl. The Romanoffs I/5: 10:05). In der siebten Episode müssen sich Joe und Anka Garner einer autoritären Richterin stellen, als sie ein Kind adoptieren wollen (vgl. The Romanoffs I/7: 1:20:19). In den weiteren Serien des Korpus tritt der Staat nie in relevanter Weise in Erscheinung.

Aus den obigen Darstellungen ergibt sich ein deutliches Muster. Treten staatliche Stellen in Video-on-Demand-Serien auf, so entweder als deren Opponenten oder als unfähig zur Problemlösung. Wenn die Charaktere gegen geltendes Recht verstoßen, wie in Ozark oder The Get Down, stellt staatliches Eingreifen stets einen eindeutigen Störfaktor dar. Der Staat ist aber selten ein Opponent mit hoher Handlungsrelevanz. In allen anderen Fällen besteht kein relevanter Kontakt zu staatlichen Stellen, d. h., jegliche Probleme können innerfamiliär bzw. in Kontakt zu den der Familie assoziierten Charakteren gelöst werden.

Hinsichtlich ihrer außerfamiliären Verbindungen erfährt die Familie eine Darstellung als geschlossene Zelle, zu der Charaktere nur dann legitimen Zugang haben, wenn sie in Hinblick auf die Familienmitglieder eine Position einnehmen, welche diesen dienlich ist. Relevante Problemlösungen können niemals außerhalb der Familie oder durch Eingreifen/Einmischen äußerer Stellen erfolgen, sondern müssen in letzter Instanz immer zwischen den Charakteren ausgetragen werden. 


\subsubsection{Resümee: Komplexe Charaktere in simplen Strukturen}

Zusammengenommen bieten die Relationen innerhalb der Familie sowie deren Positionierung nach Außen ein eindeutiges Bild. Zunächst lässt sich eine Dominanz der männlichen Familienmitglieder vor den weiblichen konstatieren, sei es auf Ebene der Eltern oder auf Ebene der Kinder. In der Ehe und bezüglich des Verhältnisses zu den Kindern üben Männer einen größeren Einfluss aus und in der Kindergeneration sind sie häufiger vertreten. Selbst bezüglich der außerfamiliären Charaktere nehmen männliche Charaktere nicht nur eine privilegierte Rolle ein, auch der Staat bzw. gesellschaftliche Institutionen werden - bis auf wenige Ausnahmen - fast ausschließlich durch männliche Figuren repräsentiert.

Die Gewichtung der familiären Verhältnisse ist zudem eindeutig. An oberster Stelle stehen eheliche Bande. Von deren Bestehen hängt die Stabilität der gesamten Familie ab. Es folgen die Eltern-Kind-Relation, wobei die Vater-KindBeziehung negativer gewertet wird als die Mutter-Kind-Beziehung und schließlich die Beziehungen der Geschwister untereinander. Von geringster Bedeutung sind außerfamiliäre Beziehungen. Familien sind also als Pyramiden konstruiert, die eine klare Hierarchie festigen und somit Stabilität gewährleisten. Auch bezüglich der familiären Strukturierung bestätigen sich die unter 3.2 getätigten Aussagen über geschlechtliche Hierarchien.

Trotz der eindeutigen Ausrichtung des Gesamtgefüges auf Stabilität und den Erhalt der Familie sind die Verhältnisse dabei nicht unproblematisch. Wie bereits im Falle von Ozark festgestellt, treten zahlreiche innerfamiliäre wie außerfamiliäre Konflikte auf, welche das Leben der Charaktere bestimmen. Dass familiäre Konflikte in einer Serie auftreten, deren Hauptcharaktere Mitglieder einer Familie sind, ergibt sich logischerweise aus der Erzählung - ohne innerfamiliäre Konflikte könnte kaum Handlung zustande kommen. Ausschlaggebend ist, dass es sich in den analysierten Handlungen meist nicht nur um oberflächliche Anwandlungen oder momentane Zwistigkeiten handelt, sondern um Konflikte, die den Kern des familiären Zusammenlebens berühren und dessen Sinnhaftigkeit in Frage stellen. Dabei ist es allein von der Ernsthaftigkeit der Serie abhängig, wie tief diese Konflikte gehen und wie problematisch deren Lösung ist. In komisch-unterhaltenden Formaten wie Grace and Frankie, The Ranch oder Red Oaks entfremden sich die Charaktere nie so ernsthaft voneinander wie in Serien wie Ozark, The Get Down oder auch dem zynischen $F$ is for Family. Ambivalente Beziehungen dominieren auch in komischen Formaten. In Anbetracht der Dominanz ambivalenter Darstellungen treten klar negative und vor allem eindeutig positive Konstellationen in den Hintergrund. Diese Ambivalenz überdeckt oberflächlich die konservative Strukturierung der familiären Beziehungen. 


\subsection{Familiäre Modelle und deren Wertung}

Aus der Interkation der familiären Rollenmuster und Geschlechterkonstruktionen ergeben sich familiäre Modelle, die ich zusammenfassend betrachten möchte.

\subsubsection{Traditionelle Kernfamilien}

Die Kernfamilie aus Vater, Mutter und Kind/ern nimmt unter allen Familienmodellen des Analysekorpus den prominentesten Status ein. Dabei zähle ich all diejenigen Familien zu diesem Typus, die zu Beginn der ersten Staffel noch bestehen, auch wenn deren Scheidung Thematik der ersten Staffel sein sollte. ${ }^{92}$

Die absolute Mehrzahl der Kernfamilien besteht zusätzlich zu den Eltern aus einem, häufiger zwei oder (selten) mehreren Kindern. Dabei schließe ich diejenigen Ehen mit ein, die innerhalb der Handlung ein Kind adoptieren oder bei denen die Geburt eines Kindes aussteht. Die Ehe zwischen Michael und Shelly Romanoff (The Romanoffs I/2) stellt die einzige Ausnahme dar. Hierbei handelt es sich um eine überaus problematische Beziehung: Michael betrügt Shelly nicht nur, er versucht sogar, sie umzubringen. Eine kinderlose Ehe, welche nicht nach Kindern strebt, stellt folglich eine absolute Ausnahme dar. Kernfamilien mit unehelichen Kindern, also unverheirateten Eltern, existieren im Analysekorpus gar nicht. Zwar treten einige uneheliche Kinder auf, auf die ich später genauer eingehen werde (vgl. 3.4.4), in diesen Fällen sind die Eltern allerdings nie ein Paar.

Das Modell der Kernfamilie unterscheidet sich in seiner Grundstruktur und seinem hierarchischen Aufbau nur geringfügig von dessen Vorbild in den 1950er und 1960er Jahren. In vielerlei Hinsicht hat eine Liberalisierung der Strukturen stattgefunden: Es herrscht weitgehende Gleichberechtigung zwischen den Geschlechtern und Autoritätsgefälle haben sich abgeflacht. Doch diese Liberalisierung ist nur eine oberflächliche bzw. scheinbare. Die männliche Dominanz wird nicht mehr klar auf der Oberflächenebene betont, wie es mit Titeln wie Father Knows Best offensiv getan wurde. Dies bedeutet jedoch nicht, dass Hierarchien nicht im grundsätzlichen Gefüge der Weltmodelle weiterhin beibehalten werden. Sie sind in diesem sogar tief verankert.

Die Kernfamilie der analysierten Serien steht insofern im Kontrast zu den Idealfamilien vergangener Jahrzehnte, dass Konflikte klar zutage treten. Problematische Familiensituationen und der Konflikt der Charaktere mit den ihnen

\footnotetext{
92 Für die folgenden Angaben vgl. die Tabelle in Anhang 1.4 im elektronischen Zusatzmaterial.
} 
auferlegten Rollenbildern führen wiederholt zu massiven Konflikten. Selbst diejenigen Familien, die relativ funktional und harmonisch sind, tragen Konflikte offen aus. Auffällig ist, dass diese Situationen, mögen sie auch höchstproblematisch sein und eine Belastung für die Familienmitglieder darstellen, selten in einer Scheidung der Familie enden. Nur bei drei der 21 Kernfamilien, die ich hier als relevant aufgenommen habe, tritt eine Scheidung ein: eine als Reaktion auf einen Ehebruch (Grace and Frankie), zwei weitere Scheidungen bahnen sich an (Red Oaks, The Marvelous Mrs. Maisel). Zwei der Ehen, in denen ein Ehebruch stattfindet, werden aufrechterhalten, wobei angemerkt werden muss, dass beispielsweise in Atypical der Ehemann erst zum Ende der ersten Staffel vom Ehebruch seiner Frau erfährt und somit kein entsprechender Konflikt stattfinden kann. Die Ehe, Basis der Kernfamilie, wird daher nur in absoluten Extremsituationen aufgelöst. Alternativ ergibt sich die Notwendigkeit einer Trennung/Scheidung aus der Handlung, wie bei der Trennung Graces und Frankies von ihren Ehemännern, was die Basis für die Serie bildet. Bestes Beispiel für den dogmatischen Umgang mit der Familie bleibt dabei Ozark, wo eine Scheidung trotz überhandnehmender Konflikte und dem Ehebruch der Ehefrau nie ernsthaft zur Debatte steht. Die Kernfamilie muss schon allein deshalb erhalten bleiben, weil sie der einzige Ort ist, an dem Probleme des/der Einzelnen adäquat gelöst werden können. Zwar bieten sich außerfamiliäre Adjuvanten gelegentlich als Unterstützer an, eine Problemlösung ist jedoch erst dann ,wertvoll', wenn sie abschließend von der Familie bestätigt wurde. Die Hierarchie der Familie und die klar definierten Rollenmuster, denen die Charaktere untergeordnet sind, bedeuten zudem, dass Charaktere ohne Familie ihre essenzielle gesellschaftliche Funktion verlieren.

\subsubsection{Alleinerziehende und geschiedene Eltern sowie Adoptivfamilien}

Familien mit alleinerziehenden Eltern erfahren eine Charakterisierung als mangelhaft, unabhängig davon, ob nun eine Mutter oder ein Vater die alleinige Erziehung übernimmt. ${ }^{93}$ Die Mehrzahl dieser Familien ist in sich problematisch: Eugenia Dermody (Ozark) und Fat Annie (The Get Down) unterdrücken ihre Söhne und machen diese von sich abhängig. Russ Langmores Söhne verwahrlosen, Cade Langmore instrumentalisiert seine Tochter (Ozark). Ezekiel Figuero leidet - trotz der guten Beziehung zu seiner Tante und Adoptivmutter - unter der Absenz bzw.

\footnotetext{
${ }^{93}$ Für die folgenden Angaben vgl. die Tabelle in Anhang 1.5 im elektronischen Zusatzmaterial.
} 
dem Verlust seiner Eltern (The Get Down). Bei „,The Get Down Brothers“ sucht er nach einer Ersatzfamilie, wobei die Kipling-Brüder als seine Brüder und Shaolin Fantastic als sein Mentor fungieren. Nach dem Tod seiner Mutter ist Simon Burrows seinem lieblosen Vater ausgeliefert (The Romanoffs I/8). Für die Söhne von Beau und Maggie Bennett ist - da beide erwachsen sind - die Scheidung der Eltern nicht mehr unmittelbar problematisch (The Ranch). Für die erwachsenen Pfefferman-Kinder ist die Situation ebenfalls nicht mehr unmittelbar problematisch und die Kernfamilie strebt trotz Scheidung der Eltern und nach dem Outing Mauras wieder zusammen (Transparent). Selbst die sehr positiven Beziehungen zwischen Sherry O'Neil und ihrem Sohn sowie zwischen Ken Messner und seiner Tochter sind insofern defizient, da Kinder und Elternteile den Verlust des jeweiligen Ehepartners bzw. Elternteils als eindeutig problematisch wahrnehmen (Everything Sucks!). Über den Großteil des Serienverlaufes streben sowohl Ken Messner als auch Sherry O’Neil nach einer Partnerschaft. Man kann also darauf schließen, dass sie mit ihrer aktuellen Lebenssituation nicht zufrieden sind.

Nicht alle alleinerziehenden Partnerschaften oder geschiedenen Familien werden grundlegend negativ dargestellt. Dennoch nehmen Figuren ohne Vater, Mutter oder Ehepartner ihre Situation in der Regel als defizient und problematisch wahr und streben dementsprechend danach, sie zu , vervollständigen'. Hieraus lässt sich die Stellung der Kernfamilie als Norm ableiten. Von ihr abweichende Strukturen dienen durch deren Charakterisierung zur Stabilisierung des traditionellen Modells.

\subsubsection{Homosexuelle Partnerschaften}

Homosexuelle Partnerschaften nehmen im gesamten Analysekorpus eine geringe Bedeutung ein. Marcus Kipling (The Get Down) und Nicholas Hayward (The Romanoffs I/8) gehen nur vorübergehende Beziehungen ein, die keine Familienähnlichkeit besitzen. Wie bereits unter 3.2.3 ausgeführt, werden diese Charaktere als etwas ,Besonderes“, d. h. als von der heterosexuellen Norm abweichend, präsentiert. Allein Robert Hanson und Sol Bergstein (Grace and Frankie) sowie Sarah Pfefferman und Tammy Cashman (Transparent) streben eine Heirat an.

Die Beziehungen Roy Pettys in Ozark sind die problematischsten homosexuellen Partnerschaften des Korpus: Die Beziehung zu seinem Ex-Kollegen Evans ist offensichtlich gescheitert, die zu Russ Langmore dient allein als Werkzeug. Eine glückliche Beziehung in der Vergangenheit scheint ebenfalls gescheitert zu sein. Dies ist aber vor allem Pettys soziopathischen Charakterzügen zuzuschreiben, weniger der Tatsache, dass es sich um einen Homosexuellen handelt - obgleich 
sich hier eine ungünstige Korrelation ergibt. Die eine glückliche Beziehung, die Petty führte, ähnelt in ihren Abläufen weitestgehend konventionellen, heteronormativen ehelichen Strukturen. Der positive Fall entspricht folglich der Norm, während alle anderen Beziehungen Pettys außerhalb derselben stehen.

Bezüglich homosexueller Partnerschaften und Beziehungen hat hier eine eindeutige Liberalisierung stattgefunden. Sie werde nicht (mehr) immerzu problematisch und homosexuelle Charaktere nicht (mehr) als grundlegend negativ dargestellt. Die familiären Grundstrukturen bleiben jedoch unangetastet: Sowohl die Inszenierung homosexueller Partnerschaften als abweichend als auch das Streben nach einer baldigen Heirat zur Festigung der Beziehung bestätigen die Norm einer auf ehelichen Banden basierenden Kernfamilie. Die recht dünne Datenlage lässt hier aber kein abschließendes Urteil zu. Fest steht, dass der aufgezeigte Status kein Alleinstellungsmerkmal für die Serien des Korpus ist, sondern mit einer allgemeinen Entwicklung übereinstimmt, wie sie unter 2.7aufgezeigt wurde.

\subsubsection{Freundschaftsverbände und Ersatzfamilien}

Die relevanten Faktoren, über die sich Familie in den Serien des Korpus definiert, sind der Schutz gegen die Außenwelt und das Potenzial, essenzielle Probleme ohne institutionelle Intervention zu lösen. Existieren nun in Serien, welche die biologische Kernfamilie fokussieren, entsprechende Verbände aus Freunden und Vertrauten und erlangen sie eine äquivalente Relevanz?

Zahlreiche außerfamiliäre Charaktere, auch diejenigen, die als Adjuvanten fungieren, können in Hinblick auf die obigen Faktoren nicht als Familie gelten. Auch amouröse Beziehungen, die über einen rein sexuellen Kontakt hinausgehen, zählen nicht dazu. Im Verhältnis einiger Charaktere zu Adjuvanten finden sich dennoch Anklänge an familiäre Relationen: Buddy Dyker (Ozark) rückt dadurch, dass er mit der Familie Byrde ein Haus bewohnt, Jonah als Mentor zur Seite steht und die Familie gegen Del Rios Handlanger verteidigt, in die Nähe eines Familienmitgliedes. Er fungiert als Ersatz-Großvater. Mehr als ein Familienmitglied definieren ihn diese Handlungen jedoch als einen wertvollen Unterstützer der Familie. Dies trifft auch auf Abel Erikson zu, der in der sechsten Episode von The Romanoffs für Nicholas und vor allem dessen Mutter Victoria Hayward ein väterlicher Ratgeber ist. Seine Ratschläge sind dabei weitgreifender und weniger praktisch als die des nüchternen Buddy Dyker. Er gleicht das Defizit aus, das durch die Absenz von Victorias Ehemann entstanden ist. Susie Myerson (The Marvelous Mrs. Maisel) tritt in große Nähe zu Miriam Maisel. Sie motiviert sie dazu, 
sich von den rigiden Strukturen ihrer Familie zu lösen und sich selbst zu verwirklichen. Sie ähnelt einer älteren Schwester, welche sich in anderen Lebensbereichen auskennt als die behütet aufgewachsene Miriam. Julia Wells (The Romanoffs I/3) hat in Daniel Reese eine Art zweiten Ehemann, eine Beziehung neben der Beziehung. Als Vater ihrer Tochter und Ansprechpartner in zahlreichen Situationen ist er in gewisser Weise Teil ihrer Familie. Sex ist im dargestellten Zeitraum keine Komponente der Beziehung, vielmehr scheint es sich um eine enge, wenn auch konfliktreiche Freundschaft zu handeln, die auf eine Affäre zurückgeht. Eine ähnliche Beziehung pflegen Joshua Pfefferman und Rita Holt (Transparent). Joshua begann schon im Jugendalter eine Affäre mit seiner ehemaligen Babysitterin und hat einen gemeinsamen Sohn mit ihr - dies findet er in der letzten Folge der ersten Staffel heraus. Sie ist für ihn ein Fluchtpunkt aus dem familiären Chaos. Joshua besucht Rita in Momenten der Verunsicherung, wobei eine sexuelle Beziehung weiterhin andauert (vgl. Transparent I/4: 13:00). Sein Verhalten lässt an eine ödipale Bindung denken, wobei Rita ein Ersatz für seine eher nüchterne Mutter ist, die wenig Geborgenheit vermittelt.

Die Konstellation eines nicht verheirateten und nicht zusammenlebenden Paares mit gemeinsamem Kind, das in einer anderen Familie aufgewachsen ist, tritt insgesamt dreimal auf. Mylene, Tochter von Lydia Cruz (The Get Down), ist nicht das Kind ihres Ehemannes Ramon, sondern von dessen Bruder Francisco. Sie entscheidet sich gegen Ende der Serie für eine Beziehung mit Francisco, der ihr im Gegensatz zu ihrem drakonischen Ehemann Liebe und Respekt entgegenbringt.

Bei The Get Down handelt es sich prinzipiell um eine Serie, die Freundschaftsverbände mehr in den Mittelpunkt stellt als die Familien der Charaktere: Mylenes Vater unterdrückt sie und hindert sie an der Verwirklichung ihrer Träume. Unterstützung findet sie bei ihren Freundinnen Yolanda und Regina. Gemeinsam beginnen sie ihre musikalische Karriere. Ebenso sucht sich Ezekiel Figuero, dessen Vater und Mutter verstorben sind, enge Verbündete in den Kipling-Brüdern und Shaolin Fantastic. Sie treten als „The Get Down Brothers“ auf und Zeke erklärt sie wortwörtlich zu seinen Brüdern (vgl. The Get Down I/3: 37:00). Shaolin Fantastic ist dabei eine Art Mentor und großer Bruder für Ezekiel. Shaolin Fantastics Beziehung zu Fat Annie ist das negative Gegenstück zu Joshua Pfeffermans und Rita Holts Verhältnis. Fat Annie inszeniert sich selbst als autoritäre Übermutter und pflegt zur gleichen Zeit eine sexuelle Beziehung zu Shaolin. Dieser hat keine Familie und ist somit angreifbar für ihre Manipulationen.

The Get Down stellt im gesamten Korpus eine Ausnahme dar. In den zuvor genannten Beispielen sind außerfamiliäre Charaktere enge Verbündete und Freunde eines oder mehrerer Charaktere und nehmen somit eine quasi-familiäre 
Funktion ein. The Get Down ist im problematischen Milieu der afro- und lateinamerikanischen Unterschicht und zugleich in der Bronx der 1970er Jahre als deren konkret topographischem Extremraum verortet. Defiziente und problematische Familien sind Teil des Topos des afroamerikanischen Milieus, oft einhergehend mit kriminellen Verbindungen. ${ }^{94}$ Dies ist auch in The Get Down der Fall. Die Charaktere suchen, angesichts der eigenen, mangelhaften Situation, nach Kompensation und bilden neue Familien aus Freunden und Vertrauten.

Wenn auch weniger häufig eine Neubildung familiärer Verbände wie in The Get Down stattfindet, so spielen die zuvor genannten Charaktere eine ähnliche Rolle. Sie treten auf, um ,Lücken zu schließen', also um den Protagonist/inn/en in Situationen zur Seite zu stehen, in denen ihr familiäres Umfeld nicht den entsprechenden Ausgleich bieten kann. Sind sie doch von großer Relevanz für das Leben der Charaktere, werden sie doch selten bis nie mit der genetischen oder verwandten Familie gleichgesetzt. Dies liegt in den Formaten des Korpus insbesondere daran, dass - auch in defizienten Situationen - weiterhin stets eine solche Familie besteht. Deren Erhalt oder Rettung steht stets im Mittelpunkt. ${ }^{95}$

\subsubsection{Resümee: Die Kernfamilie als Norm}

Die Serien des Korpus nehmen bei ihrer Abbildung von Familien eine klare Normsetzung vor. Im Zentrum aller möglichen Familienkonstellationen steht die

\footnotetext{
94 In den 1950er Jahren wurde die afroamerikanische Familie oft als negatives Gegenstück zur idealen weißen Mittelklasse gezeigt. Die dargestellten Familien waren matriarchal geprägt, afroamerikanische Männer waren ,,primär durch eine habitualisierte Verantwortungslosigkeit gegenüber ihren Familien gekennzeichnet“ (Dechert 2018: 36) und verließen ihre Familien. „In der US-amerikanischen Öffentlichkeit kursierte dementsprechend weniger das Bild eines afro-amerikanischen Mannes als Familienvater" (Dechert 2018: 36). Zwar differenzierte sich die mediale Darstellung der afroamerikanischen Familie über die Jahrzehnte hinweg und wurde durchaus positiver (vgl. Dates/Stroman 2001: 223). Wie sich in The Get Down zeigt, bleiben bestimmte negative Muster jedoch erhalten. In diesem konkreten Fall ist in Betracht zu ziehen, dass es sich um eine Serie handelt, die nicht heute, sondern in der Bronx der 1970er Jahre spielt, als es sich bei dem Stadtteil in der Tat um einen sozialen Brennpunkt handelte. Dennoch wird nach wie vor eine dominant negative und stereotype mediale und journalistische Repräsentation von (insbesondere männlichen) Afroamerikanern und der afroamerikanischen Familie beklagt, die nicht nur potenziell negative Auswirkungen auf die Außen-, sondern auch auf die Selbstwahrnehmung von Afroamerikanern haben kann (vgl. Donaldson 2015, vgl. Fantini 2016, vgl. Mohdin 2017, vgl. Punyanunt-Carter 2008: 241 ff.).

${ }^{95}$ Die einzige Ausnahme stellt hier Ezekiels Beziehung zu „The Get Down Brothers“ dar. Diese ist relevanter als seine Beziehung zu seiner Adoptivmutter Martha, allerdings liegt dies darin begründet, dass seine eigentlichen Eltern nicht mehr am Leben sind.
} 
traditionelle Kernfamilie und die mit ihr einhergehenden Rollenmuster sowie Geschlechterbilder. Dabei ist diese Form der Familie nicht das einzig mögliche Familienmodell, alternative Konstellationen sind möglich und treten auf. Eine Alternativlosigkeit, wie zu Zeiten der Herausbildung des Modells, ist nicht mehr gegeben.

Signifikanterweise werden alle Alternativmodelle durch ihren Status als Abweichung zur Norm definiert - dies ergibt sich bereits logisch durch die Zentrierung der Serien auf kernfamiliäre Verbände. Selbst positive und funktionierende Konstellationen, z. B. gelingende alleinerziehende Elternschaft oder erfüllende Wahlfamilien aus Freunden, werden entweder durch die Charaktere selbst als defizient wahrgenommen oder entstehen aus einem Defizit. Homosexuelle Partnerschaften, die am deutlichsten von der heteronormativen Kernfamilie abweichen, streben nach Angleichung an diese.

Scheint es also auf den ersten Blick so, dass die Kernfamilie in ihrem Status als Norm ausfranst bzw. durch das Auftauchen von Alternativmodellen an Absolutheit verliert, ist genau das Gegenteil der Fall. Durch die Inszenierung der Alternativen als Abweichung und als defizient, durch das Streben der Figuren nach Angleichung bestätigen Ausnahmen die Regel. In den analysierten Serien kann die traditionelle Kernfamilie nach wie vor als absolute Norm der familiären Modelle gelten. Durch diese Ausnahmen nimmt sie im Vergleich einen höheren Stellenwert ein.

\subsection{Leitparadigmen in der Repräsentation von Familie}

Neben der vorangegangenen strukturellen Analyse der Familienrepräsentation ist es von besonderem Belang zu untersuchen, welche Paradigmen die Serien anhand der dargestellten Familienkonstellationen und damit auch anhand der Protagonist/inn/en vermitteln.

Bei der Analyse des Korpus wurde untersucht, welche Paradigmen gehäuft verhandelt werden, also welche Themengebiete nicht nur in einer Einzelserie, sondern in mehreren Serien des Korpus wiederholt relevant sind. Aufgrund ihrer großen inhaltlichen Nähe wurden einige Paradigmen dabei zu Gruppen gebündelt. Es haben sich fünf zentrale Paradigmengruppen herausgebildet. Dabei handelt es sich um 1. familiäres Leben sowie die Bedeutung und die Funktionen von 
Familie $^{96}$, 2. soziale Schicht, Arbeit und Geld, 3. Sexualität, 4. Alkohol und Drogenkonsum sowie 5. Religion - in absteigender Relevanz.

\subsubsection{Regeln und Werte familiären Zusammenlebens}

Wie Familie in der Video-on-Demand Serie modelliert wird, wurde bereits festgestellt. Nun soll geklärt werden, welche Wertung innerhalb der Weltmodelle vorgenommen wird und welche Merkmale und Funktionen Figuren und Handlung der Familie zuschreiben. Über die Beispiele hinweg lassen sich dabei gemeinsame, wiederkehrende Merkmalszuschreibungen erkennen und bündeln.

Besonders relevant ist die Rolle der Familie als Schutz- und Rückzugsraum, wo das einzelne Familienmitglied Wärme und Fürsorge findet. Dieser Raum steht in Kontrast zu einer bedrohlichen Außenwelt. Obgleich außerhalb des Analysekorpus, möchte ich hier den Trailer zur zweiten Staffel von Atypical heranziehen, der diese Eigenschaft direkt paraphrasiert: „For most mammalian species, survival depends on knowing and sticking with your pack. [...] It's a rough world out there, that's why you need your family." (vgl. Atypical: Staffel 2 (Trailer): 0:00). Hier werden explizit der Gegensatz zwischen Außenwelt und Familie betont und eine Parallele der Familie mit einem Rudel geschaffen. Das Zusammenleben in einer Familie wird als integraler, natürlicher Teil menschlichen Lebens gesetzt, der nicht der persönlichen Wahl obliegt. Menschen, so ist die Argumentation, sind Säugetiere und Säugetiere benötigen ein Rudel - dies ist ein unabänderbares biologisches Dogma. Zum Ende der ersten Staffel betont Sam zudem den Aspekt der familiären Wärme:

Recently, researchers have discovered that when penguins make even the smallest movement together, they create a unique behavioral warming structure. So emperor penguins perform a mass dance to keep warm. [...] One penguin couldn't warm up like that on its own. They do it by being together. (Atypical I/8: 33:00)

Wärme und Schutz sind in der Logik von Atypical, die hier durch den Protagonisten verbalisiert wird, zwei Grundmerkmale bzw. Grundaufgaben der Familie. Schutzfunktion und ,Rudelbildung' stehen dabei insbesondere dann im Vordergrund, wenn sich die Familie in einer Notsituation befindet, sei es wie in Ozark oder in $F$ is for Family, als sich Frank Murphy zusammen mit Frau und Kindern

\footnotetext{
${ }^{96} \mathrm{Zu}$ dieser Paradigmengruppen zählen ebenso die Geschlechterrollen. Da diese bereits zuvor ausführlich thematisiert wurden und hierbei die Blickwinkel der Figuren essenziell zum Tragen kamen, wird an dieser Stelle auf eine Wiederholung verzichtet.
} 
gegen einen Schläger und dessen Vater zur Wehr setzt (vgl. $F$ is for Family I/6: 15:00). Der Mangel an innerfamiliärer Wärme ist in Ozark und $F$ is for Family besonders problematisch. In Ozark ist dies nicht nur auf die angespannte Situation der Familie durch Wendys Ehebruch zurückzuführen, sondern zusätzlich auf ein Eindringen der Außenwelt und deren negativen Einflüssen. In $F$ is for Family ist es Frank, der die Familie durch sein destruktives Wesen unterdrückt. Dennoch wird die Familie in beiden Fällen aufrechterhalten, gerade aufgrund ihrer Schutzfunktion. Wenngleich in den anderen Serien die Bedrohung von außen nicht so konkret auftritt wie in Ozark und $F$ is for Family ${ }^{97}$, sind hier familiäre Wärme, Fürsorge und Rückhalt ebenso von Belang. Die Beziehung der Protagonisten in Everything Sucks! zu ihren Eltern und deren intimes Verhältnis werden nicht nur wiederholt betont, Luke O'Neil erkennt auch am Ende der Serie, dass er nur dank seiner Familie (und seiner Freunde) erfolgreich ein Filmprojekt verwirklichen konnte (vgl. Everything Sucks! I/10: 8:00). Allein durch den Rückhalt ihrer Eltern ist den jugendlichen Charakteren eine freie Entwicklung möglich. In The Romanoffs kommt diese Funktion ebenfalls zu tragen. ${ }^{98}$

In Transparent wie in Grace and Frankie ist die Familie der Raum größter emotionaler Bindung. Maura sucht zuerst bei ihrer Ex-Frau und ihren Kindern Unterstützung für ihre Situation. Im Gegensatz zu allen anderen Beziehungen ist es die Familie, welche trotz aller Konflikte letztlich wieder zusammenfindet und bestehen bleibt. Die Familienmitglieder unterstützen sich in der problematischen Situation gegenseitig. ${ }^{99}$ Charaktere wie Joshua Pfefferman und Mallory Hanson suchen gezielt nach einer eigenen Familie, um ihre Situation zu stabilisieren. In Red Oaks wird die verfahrene Situation in der Familie durch liebevolle Gesten der Charaktere zueinander relativiert.

\footnotetext{
${ }^{97}$ Zeichentricksitcoms neigen zu einer Darstellung der Gesellschaft außerhalb der Familie als besonders chaotisch und von rücksichtslosem Individualismus bestimmt (vgl. Kelsch 2019: 124, 137). Hier stellt $F$ is for Family mit überzeichneten und extrem destruktiven Charakteren keine Ausnahme dar.

${ }^{98}$ Dies ist beispielsweise der Fall, wenn Anushka sich über den Erhalt der Familie und somit implizit auch über das Ende ihrer Isolation freut (The Romanoffs I/1). Olivia Rogers ist ohne Familie schutzlos den Ränken am Set ausgeliefert (The Romanoffs I/3). Katherine Ford (The Romanoffs I/15) sowie Victoria Hayward (The Romanoffs I/6) versuchen ihre Söhne zu beschützen. Simon Burrows zerbricht am Mangel familiärer Wärme (The Romanoffs I/8).

${ }^{99}$ Dies wird in Grace and Frankie besonders am Zusammenhalt von Frankie und Sol Bergstein deutlich. So spendet Sol der verängstigten Frankie nach ihrer Trennung bei einem Erdbeben Trost (vgl. Grace and Frankie I/6: 6:00).
} 
Das enge Zusammenleben in der Familie bedeutet zuweilen eine Bedrohung der individuellen Privatsphäre. Dies ergibt sich einerseits aus dem lokalen Zusammenleben der Charaktere ${ }^{100}$ und andererseits - und das vor allem - aus der Tatsache, dass die Probleme des Einzelnen ab einem gewissen Punkt stets mit allen anderen Familienmitgliedern ausgehandelt werden. ${ }^{101}$ Geheimnisse und Probleme des Einzelnen, so eine durchgehende Regel fast aller Serien des Korpus, werden früher oder später ans Licht kommen. ${ }^{102}$ Dass Familie das Aufdecken intimer Details bedeutet, geht aus der Natur der Narration hervor: Persönliche Details sind notwendige Elemente der Figurencharakterisierung und des Handlungsverlaufes.

Ebenso ambivalent ist die Funktion der Familie als Raum der Erziehung und der persönlichen Entwicklung. Es kann sich dabei um die positiv konnotierte Weitergabe von Werten und Normen handeln, z. B. wenn Alex Myers seinen Söhnen Toleranz gegenüber anderen Menschen beibringen will (vgl. The Romanoffs I/5: 1:06:30). Mit der gleichen Intention - wenn auch deutlich hilfloser - spricht Ken Messner mit seiner Tochter (vgl. Everything Sucks! I/1: 20:00). In The Ranch erzählt Beau Colt wiederholt Geschichten aus seiner Vergangenheit mit dem klaren Ziel, ihm Vernunft beizubringen und seine Entwicklung zu einem ,Mann“ zu unterstützen (vgl. The Ranch I/3: 27:00, I/4: 28:00). Die Erziehungsfunktion gewinnt indes rasch den Charakter einer Zwangsstruktur, wenn an die Jugendgeneration diejenigen Normen weitergegeben werden, unter denen bereits die Elterngeneration litt bzw. leidet. Dies bezieht sich vor allem auf Geschlechternormen, sei es direkt durch Erziehung oder indirekt durch eine Erwartungshaltung, wie sie bereits wiederholt angesprochen wurde. Diesen Zwangscharakter entwickelt Familie auch, wenn die Freiheit eines einzelnen Familienmitgliedes im Dienst der Erziehung und zu dessen vermeintlichem Wohl eingeschränkt wird. Dies ist sowohl bei Charlotte in Ozark der Fall als auch bei Sam in Atypical, als seine Mutter sich gegen Sams selbstständige Entwicklung stellt. Auch Frank Murphy ( $F$ is for Family), welcher seine Kinder in ihrer Entwicklung unterdrückt, Sam

\footnotetext{
${ }^{100}$ Red Oaks: Davids Mutter betritt ohne Anklopfen das Badezimmer, während David in der Dusche masturbiert (vgl. Red Oaks I/4: 1:30). The Ranch: Während Colt mit einer Frau im Bett ist, betritt sein Vater - ebenfalls ohne anzuklopfen - den Raum (vgl. The Ranch I/1: 11:00).

${ }^{101}$ Dies kann u. U. auch Spott provozieren, z. B. wenn ihre Geschwister Ali verspotten, als sie sagt, sie wolle wieder studieren (vgl. Transparent I/6: 4:30).

102 Die Ehebrüche in Atypical, Ozark und The Marvelous Mrs. Maisel, die Homosexualität sowie diverse persönlich Details in Transparent und Grace and Frankie, Judys homosexuelle Neigungen in Red Oaks, Mylenes Clubbesuch ebenso wie ihre Gesangskarriere in The Get Down etc.
} 
Myers, der seinem Sohn in Red Oaks in einen Beruf zwingen, oder Ramon Cruz in The Get Down, welcher die Gesangskarriere seiner Tochter verhindern will, folgen diesem Muster. Durch Nachahmung der Eltern werden zudem problematische Charaktereigenschaften weitergegeben - z. B. Coyotes Disziplinlosigkeit und Briannas Karrierismus in Grace and Frankie oder der beißende Sarkasmus in der Familie Bennett in The Ranch. Auch wenn nur die Auswirkungen der elterlichen Erziehung auf die Kindergeneration unmittelbar zu beobachten sind, ergibt sich logisch, dass entsprechende Strukturen gesellschaftlich und somit auch familiär tradiert sind, d. h., bereits den Eltern eine entsprechende Erziehung zuteilwurde. Für alle Generationen stellt dies ein Hindernis im Rahmen der freien Entfaltung und der persönlichen Entwicklung dar. Die Charakterisierung von Familie als Hindernis der persönlichen Entwicklung ist damit deutlich stärker vertreten als die positive Wertevermittlung. Die Erziehungsfrage ist Teil des klassischen Topos der Familie als Ort des Generationenkonfliktes, wie er u. a. in Serien der 1970er Jahre (z. B. All in the Family) hervortrat.

Die dritte Merkmalszuweisung an die Familie, die ich hier aufführen möchte, ist die Familie als Endpunkt und Legitimation von Beziehungen sowie deren integrale Notwendigkeit für ein gelungenes Leben. Dies wird insbesondere am Beispiel der homosexuellen Beziehungen in Grace and Frankie und Transparent deutlich, in denen die Paare nach möglichst rascher Ehe streben, um ihren Partnerschaften tatsächlich Geltung zu verleihen. Ebenso suchen Grace und Frankie, gleich nach ihrer Trennung, nach einer festen Beziehung. Graces alleinstehende Tochter Brianna befindet sich auf einer ähnlichen Suche. Aufgrund seiner Vaterund Mutterlosigkeit bemüht sich Ezekiel Figuero in The Get Down um eine Ersatzfamilie. Prinzipiell ist das Leben ohne Familie in den Serien des Korpus defizient, da es ohne sie an der oben genannten Schutzfunktion mangelt.

Grundsätzlich ist folglich festzustellen, dass das Familienparadigma hochgradig ambivalent ist. Der tragende positive Aspekt der Familie als Ort der Wärme und der Fürsorge, als Schutzraum gegenüber der Außenwelt wird in nahezu allen Serien als deren tragende Legitimation herangezogen. Er ist derjenige, der in Bezug auf die Familie an sich und von den Charakteren am ehesten verbalisiert und hervorgehoben wird. Die Familie ist ein Rudel, ein Kollektiv, das alternativlos gemeinsam handelt: ,We're a family, so we are... We're making this move as a family." (vgl. Ozark I/1: 32:00). Entsprechend ist die Familie unabdingbar für eine gelungene Existenz und der logische Endpunkt sowie die Legitimation einer festen Beziehung.

In der aus der Beziehung resultierenden Familie werden die Kinder erzogen und Werte vermittelt. Die negativen Effekte der Familie, deren potenzieller Zwangscharakter und der Umstand, dass Wertevermittlung auch die Vermittlung 
negativ-konnotierter Werte und Strukturen ebenso wie problematischer Verhaltensweisen bedeuten kann, ist dabei zwar ein häufiger Effekt des familiären Lebens, wird aber nicht explizit als solcher betrachtet. Hier lässt sich bisweilen eine Diskrepanz der Meinungen der Charaktere bezüglich der Familie und deren tatsächlicher Darstellung erkennen: Figuren halten an der Familie fest, da es sich ebenso um einen sicheren Raum wie um den Raum ihrer sozialen Prägung handelt. Bei Verlust einer familiären Struktur versuchen sie möglichst rasch diesen zu kompensieren. Die Familie wird daher in zahlreichen Situationen als etwas Besonderes und Erstrebenswertes betont, obgleich sie eine Quelle zahlreicher persönlicher Probleme ist. Das Familienparadigma baut so auf einer Doppelstruktur von warmem Schutzraum und kaltem Gefängnis auf.

\subsubsection{Soziale Schicht, Arbeit und Geld}

Wie in der folgenden Tabelle deutlich wird, gehören alle zentralen Familien des Analysekorpus der Mittelschicht an. Dies lässt sich am präsentierten Besitz der Familie, insbesondere deren Wohnort, d. h. großes/kleines Haus etc., festmachen ebenso wie an Kleidung und Gebaren oder Beruf.

\begin{tabular}{|c|c|c|c|}
\hline \multicolumn{4}{|c|}{ Soziale Schichtzugehörigkeit } \\
\hline Serie & Familie & Schicht & Wohnort \\
\hline 1. Atypical & Gardner & Mittelschicht & Vorstädtisches Haus \\
\hline 2. Everything Sucks! & $\begin{array}{l}\text { O’Neil, } \\
\text { Messner }\end{array}$ & Mittelschicht & Vorstädtisches Haus \\
\hline 3. F is for Family & Murphy & $\begin{array}{l}\text { Untere } \\
\text { Mittelschicht }\end{array}$ & $\begin{array}{l}\text { Vorstädtisches Haus } \\
\text { (verwahrlostes } \\
\text { Umfeld) }\end{array}$ \\
\hline 4. Grace and Frankie & $\begin{array}{l}\text { Hanson, } \\
\text { Bergstein }\end{array}$ & $\begin{array}{l}\text { Obere } \\
\text { Mittelschicht }\end{array}$ & $\begin{array}{l}\text { Vorstädtisches Haus } \\
\text { (großzügige } \\
\text { Ausstattung) }\end{array}$ \\
\hline 5. Ozark & Byrde & $\begin{array}{l}\text { Obere } \\
\text { Mittelschicht }\end{array}$ & $\begin{array}{l}\text { Haus mit großem } \\
\text { Grundstück }\end{array}$ \\
\hline 6. Red Oaks & Myers & Mittelschicht & Vorstädtisches Haus \\
\hline 7. Red Oaks & Getty & Oberschicht & Großes Anwesen \\
\hline 8. The Get Down & Figuero & Unterschicht & $\begin{array}{l}\text { Kleine städtische } \\
\text { Wohnung } \\
\text { (sozialer Brennpunkt) }\end{array}$ \\
\hline
\end{tabular}




\begin{tabular}{|c|c|c|c|}
\hline \multicolumn{4}{|c|}{ Soziale Schichtzugehörigkeit } \\
\hline Serie & Familie & Schicht & Wohnort \\
\hline 9. The Get Down & Cruz, Kipling & $\begin{array}{l}\text { Untere } \\
\text { Mittelschicht }\end{array}$ & $\begin{array}{l}\text { Wohnung mittlerer } \\
\text { Größe (sozialer } \\
\text { Brennpunkt) }\end{array}$ \\
\hline $\begin{array}{l}\text { 10. The Marvelous Mrs. } \\
\text { Maisel }\end{array}$ & $\begin{array}{l}\text { Weissman, } \\
\text { Maisel }\end{array}$ & $\begin{array}{l}\text { Obere } \\
\text { Mittelschicht }\end{array}$ & $\begin{array}{l}\text { Große Wohnung } \\
\text { (wohlhabendes Viertel) }\end{array}$ \\
\hline 11. The Ranch & Bennett & Mittelschicht & Farm \\
\hline 12. The Romanoffs I/1 & La Charnay & Oberschicht & $\begin{array}{l}\text { Große Wohnung } \\
\text { (luxuriöse } \\
\text { Ausstattung) }\end{array}$ \\
\hline 13. The Romanoffs I/2 & Romanoff & Mittelschicht & $\begin{array}{l}\text { Haus } \\
\text { (wahrscheinlich } \\
\text { vorstädtisch) }\end{array}$ \\
\hline 14. The Romanoffs I/4 & Wells & $\begin{array}{l}\text { Obere } \\
\text { Mittelschicht }\end{array}$ & $\begin{array}{l}\text { Größere Wohnung } \\
\text { (großzügige } \\
\text { Ausstattung) }\end{array}$ \\
\hline 15. The Romanoffs I/5 & Ford & $\begin{array}{l}\text { Obere } \\
\text { Mittelschicht }\end{array}$ & $\begin{array}{l}\text { Vorstädtisches Haus } \\
\text { (großzügige } \\
\text { Ausstattung) }\end{array}$ \\
\hline 16. The Romanoffs I/6 & Hayward & $\begin{array}{l}\text { Obere } \\
\text { Mittelschicht }\end{array}$ & Luxuriöses Hotel \\
\hline 17. The Romanoffs I/7 & Garner & Mittelschicht & I \\
\hline 18. The Romanoffs I/8 & Burrows & $\begin{array}{l}\text { Obere } \\
\text { Mittelschicht }\end{array}$ & $\begin{array}{l}\text { Vorstädtisches Haus } \\
\text { (großzügige } \\
\text { Ausstattung) }\end{array}$ \\
\hline 19. Transparent & Pfefferman & $\begin{array}{l}\text { Obere } \\
\text { Mittelschicht }\end{array}$ & $\begin{array}{l}\text { Vorstädtisches Haus } \\
\text { (großzügige } \\
\text { Ausstattung) }\end{array}$ \\
\hline
\end{tabular}

Die Schichtzugehörigkeit unterscheidet sich vor allem darin, welchem Bereich der Mittelschicht die Familien zugehörig sind. Familien, die hier der oberen Mittelschicht zugeordnet werden, verfügen über einen höheren Lebensstandard als Angehörige der unteren Mittelschicht. Beide Gruppen sind aber deutlich von der Unterschicht abzutrennen, der Ezekiel Figuero angehört. ${ }^{103}$ Ebenso ist eine Grenze zur Oberschicht zu ziehen, was ein Leben in einer Villa oder einer luxuriösen Wohnung ermöglicht, wie im Falle der Gettys oder von Anushka La Charnay.

${ }^{103}$ Ezekiel lebt in einer sehr kleinen, von Ungeziefer befallenen Wohnung in der Bronx mit seiner Tante und deren Partner (vgl. The Get Down I/1: 3:00). 
Die Zugehörigkeit zur Mittelschicht ergibt sich also daraus, dass weder Reichtum noch Armut besonders betont werden. Diese Familien wohnen - in langer serieller Tradition - in vorstädtischen Einfamilienhäusern, welche an das Ideal der Suburbs der 1950er und 1960er Jahre erinnern. Sofern der Wohnort gezeigt wird, lässt sich daran eine weitere schichtinterne Differenzierung ableiten. ${ }^{104}$ Mit der Zuordnung der Mehrzahl der Familien zur Mittelschicht folgen die analysierten Serien einem anhaltenden Trend in der Seriengeschichte. Während eine Zugehörigkeit zu einem gesellschaftlichen Extrem - also Armut oder Reichtum - stets eigene Themenfelder und Problematiken mit sich bringt und die Charaktere in Distanz zur Mehrzahl der Rezipient/inn/en setzt, erscheint die soziale Mittelschicht nicht nur ein neutraler Raum und bietet ein höheres Identifikationspotential als die Extreme. Hier können familiäre und persönliche Problematiken ohne Kopplung an besondere gesellschaftliche Faktoren verhandelt werden.

In Serien wie Atypical, Everything Sucks!, Grace and Frankie, The Ranch und The Romanoffs ist die Schichtzugehörigkeit nicht relevant. Hier werden soziale Problematiken weitestgehend ausgeblendet. In The Marvelous Mrs. Maisel spielt die Schichtzugehörigkeit der Protagonisten dann eine Rolle, wenn Miriam ihr behütetes soziales Umfeld verlässt. Bei ihrem Besuch im Greenwich Village ist Miriam schockiert von den dortigen Zuständen, die nicht den gediegenen Verhältnissen der Upper-West-Side entsprechen (vgl. The Marvelous Mrs. Maisel I/2: 2:00). Als Susie Myerson ihre Wohnung besucht, ist sie von deren Pracht überwältigt, während Miriam das Umfeld für vollkommen normal hält (vgl. The Marvelous Mrs. Maisel I/22:05). Ober- und Unterschicht erscheinen wie zwei vollkommen voneinander entfremdete Bereiche. Ähnlich verhält es sich für David Myers, als er das erste Mal die Gettys besucht. Das große Anwesen mit Villa, Park und Angestellten ist für David, der bescheidenen Verhältnissen entstammt, eine fremde Welt (vgl. Red Oaks I/2: 7:00). Doug Getty wird in seinem Verhalten gegenüber anderen allgemein als negativer und arroganter Charakter inszeniert, der sich vor allem durch sein Vermögen von anderen abhebt und ihnen bisweilen mit seinem Einfluss droht (vgl. Red Oaks I/1: 9:16, 27:00). Er lebt in der Überzeugung, aufgrund seiner Position über das Leben anderer bestimmen zu können (vgl. Red Oaks I/2: 4:47). ${ }^{105}$ Mit übertriebenem Pathos spricht er von der Arbeit an der Börse und idealisiert diese geradezu als männliche Heldentat (vgl. Red

\footnotetext{
${ }^{104}$ Ausnahmen stellen hier Serien dar, die wie The Get Down, The Marvelous Mrs. Maisel oder einige Folgen von The Romanoffs in einem städtischen Umfeld verortet sind. Die Mehrheit der Serien bleibt allerdings dem vorstädtischen Umfeld verhaftet.

105 Sympathien zu Getty werden aufgebaut, indem er von seinem , Vom Tellerwäscher zum Millionär'-Werdegang berichtet. Er selbst hat sich laut eigener Aussage von einem Handlanger im Country-Club zu einem reichen Mann hochgearbeitet (vgl. Red Oaks I/1: 20:03). Zudem
} 
Oaks I/8: 1:41). Anushka La Charnay, die in einer äußerst luxuriösen Wohnung in Paris lebt, behandelt ihre Angestellten mit äußerster Herablassung. Sie wirkt indes nicht glücklich und lebt einsam und ohne enge Freunde oder Angehörige in der Wohnung, die unübersichtlich und zu groß für eine Person erscheint. Wie David Myers leidet auch Frank Murphy unter seinem Arbeitgeber, der als arroganter und willkürlicher Kapitalist ohne tatsächliches Interesse am Wohl seiner Angestellten auftritt. Er muss ihn aber - trotz dessen tyrannischem Wesen - hofieren, um in seinem Beruf erfolgreich zu sein (vgl. $F$ is for Family I/3: 10:00).

Am deutlichsten tritt das Paradigma der sozialen Herkunft in The Get Down zutage. Bereits in der Eröffnungssequenz der Serie wird die Bronx in einem Rap Ezekiels als Ort der Kriminalität und der Armut charakterisiert (vgl. The Get Down I/1: 0:00). Sich innerhalb des Stadtteils zu bewegen, ist aufgrund von Gang-Kriegen und Vandalismus gefährlich (vgl. The Get Down I/1: 12:00). An Ezekiels Lebensumständen treten die sozialen Problematiken des Stadtteils überdeutlich zutage. Sein Vater erlag den Drogen und seine Mutter wurde versehentlich erschossen (vgl. The Get Down I/1: 24:00). Durch die Brutalität mit der Fat Annie und Cadillac ihre kriminellen Machenschaften betreiben, wird die hochproblematische Lage des Milieus offensichtlicher. Dieses Milieu zu verlassen ist zunächst unmöglich. Nicht nur rutschen zahlreiche Charaktere, wie Shaolin oder in Teilen die Kipling-Brüder, in die Kriminalität ab, auch ist die ausweglose Zugehörigkeit zur Unterschicht tief in den Köpfen der Charaktere verankert. Ezekiels Tante sperrt sich beispielsweise anfangs gegen den Gedanken, er könne auf ein Ivy-League-College gehen (vgl. The Get Down I/2: 21:00). Ezekiel befürchtet zudem den Verlust seiner Freunde bei Verlassen der Bronx, da diese wohl, der Straße' verhaftet bleiben würden (vgl. The Get Down I/6: 33:00), und ist allgemein gelangweilt von seinem Praktikum in einer großen Firma und seiner Bewerbung für Yale (vgl. The Get Down I/6: 1:00), die im Gegensatz zu seinen musikalischen Ambitionen steht. Die extreme Differenz zwischen Ober- und Unterschicht wird deutlich, als er - halb Latino, halb Afroamerikaner (vgl. The Get Down I/7: 2:00) - zu einer Veranstaltung eingeladen wird, die exklusiv für afroamerikanische Yale-Anwärter stattfindet (vgl. The Get Down I/8: 30:00). Durch seine soziale und lokale Herkunft und durch seine Abstammung gehört er in mehrfacher Hinsicht einer sozialen Randgruppe an. Der Weg aus der Armut, aus den problematischen Verhältnissen scheint aufgrund dieser Faktoren, den Vorurteilen ihm gegenüber und aufgrund einer tief verankerten mentalen Zugehörigkeit zu seinem Umfeld schwerlich möglich. Wie sich an Papa Fuertes scheiternden Intentionen zeigt, die

tritt er als Davids Mentor und Gönner auf, was gewisse negative Charaktereigenschaften ausgleicht. 
Bronx in ein lebenswertes Viertel umzugestalten (vgl. The Get Down I/1: 20:00), lässt sich die Ausweglosigkeit auf den gesamten Herkunftsraum übertragen. Arm, so die Botschaft, welche durch die Serie in einer durchaus pathetischen Inszenierung vermittelt wird, bleibt arm und diese Armut zu verlassen ist ein harter Kampf - wenn man sich dabei nicht von seinen ,Wurzeln“ entfremden will.

Die hier aufgeführten Beispiele zeigen, dass sowohl die Zugehörigkeit zur Unterschicht als auch zur Oberschicht, d. h. prinzipiell die Zugehörigkeit zu einem sozialen Extrembereich, negativ konnotiert sind. Armut und Reichtum führen zu einer Entfremdung der betroffenen Personen von dem, was eigentlich essenziell ,wichtig' ist. Familie und Zwischenmenschlichkeit werden durch Arroganz, Gewalt, Drogen, Skrupellosigkeit und die Gier nach Reichtum ersetzt. Die Stellung der Mittelschicht als idealer gesellschaftlicher Bereich wird somit bekräftigt. Dies lässt an die Verortung zahlreicher Soaps wie Dallas oder Dynasty in der Oberschicht denken, die sich gerade aufgrund dessen in ihren Handlungsverläufen von der klassischen Familienserie unterscheiden.

Wie bereits in Bezug auf $F$ is for Family erwähnt wurde, ist der Bereich der Arbeitswelt ebenfalls ein Paradigma, das eng mit der Schichtzugehörigkeit verknüpft ist. Frank Murphy, im familiären Rahmen ein Tyrann, muss in der Arbeit nicht nur unter einem vollkommen unfähigen Vorgesetzten leiden (vgl. $F$ is for Family I/2: 13:00), sondern auch unter der ungerechten Behandlung durch die Kunden (vgl. $F$ is for Family I/2: 22:00). Der Stress in der Arbeit belastet ihn und führt zum negativen Verhalten gegenüber der Familie. Ebenso hat sich Joel Maisel vollkommen von seiner Arbeitsstelle entfremdet. Dies zeigt sich in einem verbalen Ausbruch, kurz bevor er Miriam seinen Ehebruch gesteht:

Joel: „Do you know what I do everyday? Day in and day out, what the actual physical machinations of my job are?“ - Miriam: „No.“ - Joel: „Neither do I. I take meetings. I make phone calls. I shuffle paper around, and I have no idea of what the hell I actually do.“ (The Marvelous Mrs. Maisel I/1 34:26)

Joel hat keinen Bezug zu seinem Beruf, der seinem eigentlichen Wunsch, StandUp-Comedian zu werden, entgegenläuft. Diese Entfremdung führt letztlich zu seinem Ehebruch. Auch am Beispiel Michael Romanoffs, der High-SchoolAbgänger bei der Wahl eines Colleges berät, selbst seine Heimatstadt aber nie verlassen hat und sich deswegen als Versager fühlt, zeigen sich die potenziell negativen Auswirkungen des Berufes bzw. der Arbeitswelt auf das persönliche Leben. Ebenso vernachlässigen Beau Bennett (The Ranch) und Grace und Brianna Hanson (Grace and Frankie) ihre Familien aufgrund ihrer beruflichen Verpflichtungen. Als Teil der Außenwelt, des öffentlichen Raumes, der in Opposition zum 
Privatraum, zur familiären Geborgenheit steht, erfährt die Arbeitswelt - wenn sie explizit thematisiert wird - eine negative Konnotation. Eine explizite Thematisierung bedeutet stets einen Einfluss der Arbeit auf die Familie, d. h. eine indirekte Bedrohung derselben durch Eindringen eines feindlichen Gegenraumes. Dieses Szenario wird dabei vornehmlich anhand männlicher Charaktere ausgehandelt, die in der Regel als alleinige Brotverdiener fungieren, trifft aber gelegentlich - wie man am Beispiel von Grace and Frankie sieht - auch auf weibliche Charaktere zu.

Mit der sozialen Schicht und der Arbeitswelt hängt ebenfalls der Bereich des Geldes zusammen. Dieser tritt auch in Serien auf, welche wohlhabendere Familien zeigen, und erhält dabei ebenso eine negative Konnotation. In Ozark tritt das Geld als Antagonist des Familiären auf. Geld hat destruktive und belastende Auswirkungen auf das Familienleben - meist dann, wenn sich die Figuren dem Streben nach finanziellem Wohlstand bzw. der Geldgier vollkommen hingeben. Das Erwirtschaften von Geld darf also nie Selbstzweck werden. Einen ähnlichen Blickwinkel nimmt Transparent ein. Obwohl alle Pfefferman-Kinder in gesicherten finanziellen Verhältnissen leben, bricht ein Streit angesichts der Frage aus, wer Mauras Haus bekommt (vgl. Transparent I/1: 12:00). Ali leiht sich wiederholt Geld von Maura, die Wahrscheinlichkeit, dass sie es zurückzahlt, ist gering (vgl. Transparent I/1: 13:30). Dies ist für beide Charaktere eine Belastung. Tatsächlich ist sich Maura nicht sicher, ob Ali sie noch mögen würde, wenn sie kein Geld mehr bekäme (vgl. Transparent I/10: 24:00). Später versucht sie vor den anderen Kindern geheim zu halten, dass sie jedes von ihnen finanziell unterstützt. Sie sagt jedem der Kinder, dass sie den anderen nichts von der Unterstützung bzw. den finanziellen Versprechungen erzählen sollen (vgl. Transparent I/6: 1:25, 7:40, 27:00), und errichtet somit eine Art Geheiminis- oder Lügengebäude, was problematische familiäre Konsequenzen wahrscheinlich macht. Im Gegensatz zu ihren Kindern, die sehr vom Geld der Eltern profitieren, bringt Maura wiederholt zum Ausdruck, sich nicht um Geld zu kümmern, sondern eher darum, was „richtig“ sei (vgl. Transparent I/7: 2:00). Ebenso wie in Ozark wird Geld somit als entzweiende Kraft inszeniert, welche die Familie gegeneinander aufbringt und Charaktere geradezu verdirbt. Gleiches gilt für die erste Episode von The Romanoffs, in der Gregs Freundin Sophie vor allem an der Wohnung und dem Besitz Anushkas interessiert ist und ihr sogar indirekt den Tod wünscht, um an das Erbe zu gelangen (vgl. The Romanoffs I/1: 9:26). In The Ranch stellt ein Mangel an Geld eine Belastung für die Familie dar und in Grace and Frankie ein maskulines Machtinstrument, wenn die Ehemänner ihren Ehefrauen die Kreditkarten sperren.

Was Ozark in Bezug auf das Paradigma Geld aussagt, kann auf alle genannten Beispiele übertragen werden. Zusammen mit anderen Faktoren der Außenwelt, 
wie der Arbeit oder einer problematischen Schichtzugehörigkeit, übt es einen konkret negativen Einfluss auf die Einzelcharaktere und auf das Verhältnis der Charaktere zueinander aus. Es stellt eine Belastung dar, die die Figuren in ihrem Handeln negativ beeinflusst oder sie voneinander entzweit. Die Charakterisierung dieser Paradigmen verschärft die Opposition des Privat-Familiären und des Öffentlichen.

\subsubsection{Sexualität}

Einhergehend mit der großen Bedeutung des Beziehungslebens spielt das Paradigma Sexualität eine besondere Rolle. Als Teil der sexuellen Identität ist sie vor allem in Formaten mit homosexuellen Charakteren relevant. Hier steht die sexuelle Selbstfindung im Vordergrund, sei es in der Adoleszenz in Everything Sucks!, im späteren Leben in Transparent (Sarah Pfefferman), Grace and Frankie und Ozark (Russ Langmore) oder bezüglich der geschlechtlichen Identität in Transparent (Maura Pfefferman) und The Romanoffs (I/8, Candice Burrows). Dieser Prozess bringt dabei stets Probleme hinsichtlich des Selbstbildes und der gesellschaftlichen Reaktion mit sich. Die Charaktere haben Angst, als Außenseiter zu gelten bzw. selbst innerfamiliär nicht mehr anerkannt zu werden. Bei jugendlichen und pubertären Figuren ist das Streben nach Sexualität und dem ,ersten Mal' eine bedeutsame Lebensthematik. Dies ergibt sich natürlicherweise aus dem Alter und der Entwicklungsphase der Charaktere. ${ }^{106}$

Die Selbstfindung im Bereich der Sexualität ist integraler Teil der charakterlichen Entwicklung. Auch in späteren, erwachsenen Beziehungen spielt sie eine bedeutende Rolle. In einer Ehe ist sie exklusiv den Ehepartnern vorbehalten. Außereheliche Sexualität ist negativ konnotiert (Atypical, Ozark, The Marvelous Mrs. Maisel, The Romanoffs I/2, I/4, I/8). Modelle wie eine offene oder gar polyamore Beziehung oder die Einbeziehung einer dritten Person in die Sexualität eines Paares sind nicht vertreten. Eine stabile, auf Zuneigung und Liebe basierende Beziehung wird allgemein höher bewertet als körperliche Sexualität. So hat Joshua in Transparent Sex mit zahlreichen wechselnden Partnern und nutzt dies

${ }^{106}$ In Atypical sucht Sam nach einer Freundin und strebt nach ersten sexuellen Erfahrungen. Seine Schwester schläft das erste Mal mit einem Mann (vgl. Atypical I/7: 26:00), ebenso wie Charlotte in Ozark. In The Get Down haben Mylene und Ezekiel miteinander ihren ersten Sex (vgl. The Get Down I/3: 55:00). Auch Luke und seine Freunde unterhalten sich in Everything Sucks! zu Beginn ihres High-School-Lebens über Sex und ihre dahingehenden Möglichkeiten (vgl. Everything Sucks! I/1: 8:00). 
offensichtlich als Kompensation eines emotional defizienten Lebens. Auch Brianna hat in Grace and Frankie einen One-Night-Stand (vgl. Grace and Frankie I/7: 28:00). Beide streben allerdings vor allem nach einer dauerhaften Beziehung. Joshuas Schwester Ali wirkt ohne einen festen Partner ebenfalls isoliert. Der Charakter Abel in The Romanoffs ist offensichtlich gelangweilt vom gelegentlichen Sex mit Frauen und dem Nutzen einer Dating-App (vgl. The Romanoffs I/6: 01:50) und investiert wesentlich mehr Zeit in seine platonische Beziehung zu Victoria Hayward. Sexualität allein ist somit kein Ersatz für eine ernsthafte Beziehung oder eine Ehe. Ozark und $F$ is for Family zeigen sie aber als Bestandteil einer funktionierenden. In beiden Fällen ist sie einerseits Bestätigung der gegenseitigen Zuneigung und trägt andererseits zum Abbau von Konflikten und Spannungen bei. 107

Neben dem Ehebruch geben einige Serien der Sexualität eine ausdrücklich negative Konnotation: In The Get Down bringt Fat Annie Shaolin Fantastic u. a. mittels einer sexuellen Beziehung unter ihren Einfluss. Sie nutzt Sexualität als Mittel der Macht. In der Regel handelt es sich allerdings um Männer, die Sexualität als Zeichen ihrer Dominanz verstehen. Der Tennislehrer Nash inszeniert sich in Red Oaks vor allem über seine vermeintliche Anziehungskraft auf Frauen und trägt allgemein seinen Machismo zur Schau. ${ }^{108}$ Dies wird in diesem Weltmodell insofern relativiert, da Skye Getty durch ihren offenen Umgang mit Sexualität emanzipierte weibliche Dominanz gegenüber dem zurückhaltenden David demonstriert. Vor allem The Ranch inszeniert einen starken Sexualtrieb als Zeichen von Männlichkeit: Colt hatte in der Vergangenheit viele wechselnde Sexualpartnerinnen und Rooster definiert sich über seine sexuellen Kontakte und seinen verantwortungslosen Umgang mit Sexualität.

Allgemein ist Sexualität ein wichtiger Lebensbestandteil der meisten erwachsenen Protagonisten. Wenn sie als Selbstzweck, d. h. als Teil eines hedonistischen Lebenswandels ohne Einbindung in eine Beziehung, dient, ist sie in der Regel Anzeichen für das unglückliche und einsame Leben des Charakters. Findet sie außerhalb einer bestehenden Ehe statt, handelt es sich um eine klare Normverletzung. Neben der sexuellen Selbsterfahrung während der Adoleszenz ist die

\footnotetext{
${ }^{107}$ In $F$ is for Family schlafen Sue und Frank direkt nach einem Streit miteinander und scheinen dadurch im weiteren Verlauf der Episode, ihren Streit beigelegt zu haben (vgl. $F$ is for Family I/5: 17:00).

${ }^{108}$ Nash schläft laut eigener Aussage nur nicht mit den Frauen im Country-Club, da man nie wisse, mit wem sie verheiratet seien, mit wem man sich also anlege (vgl. Red Oaks I/1: 4:40). Er meint zudem, man gehe nur aufs College, um dort Sex zu haben (vgl. Red Oaks I/1: 8:00). Später in der Episode bandelt er, obwohl er verheiratet ist, mit zwei deutlich jüngeren Frauen an (vgl. Red Oaks I/1: 14:15).
} 
eheliche Sexualität die einzige Form der Sexualität, deren Legitimation nicht in Frage gestellt wird. Sie ist nur dann problematisch, wenn sie zur Kompensation und Verdrängung ungelöster Konflikte genutzt wird. Da es vollständig an positiv besetzten Alternativmodellen zur Sexualität innerhalb einer Beziehung mangelt und der konsequente Endpunkt und die Legitimation von Beziehungen in der Logik der analysierten Serien die Ehe ist, kann hier von einer relativ konservativen Vorstellung von Sexualität die Rede sein - relativ deswegen, da voreheliche Sexualität nicht negativ bewertet wird.

\subsubsection{Alkohol- und Drogenkonsum}

Der Konsum von Alkohol und Drogen ist ein selbstverständlicher Teil des Lebens zahlreicher Serien-Charaktere des Analysekorpus. Harte Drogen wie Kokain oder Heroin werden eindeutig problematisiert. In Ozark sind es ein Drogenkartell und das Heroingeschäft der Familie Snell, welche eine tödliche Gefahr darstellen. In Red Oaks gerät der Charakter Wheeler durch den Kokainhandel wiederholt in problematische Situationen (vgl. Red Oaks I/8, I/,9). ${ }^{109}$ Sein Konsum und Verkauf von Marihuana (vgl. Red Oaks I/1: 13:00, I/3: 7:29, I/6: 1:20) trägt zwar zu seiner Charakterisierung als ,Loser ' bei, der ein ungeordnetes Leben führt ${ }^{110}$, ist darüber hinaus aber ein recht gewöhnlicher Teil des gezeigten Weltmodells - selbst der konservative Sam Myers spricht davon, dass es normal sei, im College Marihuana zu rauchen (vgl. Red Oaks I/1: 1:00). In The Get Down ist der Rauschmittelkonsum bis zu einem gewissen Grad Teil der Normalität. Wenn beispielsweise die Kipling-Brüder und Ezekiel wiederholt Alkohol und Marihuana konsumieren (vgl. The Get Down I/3: 8:00, I/3: 29:00, I/7: 12:00) und deutliche Abhängigkeitserscheinungen zeigen (vgl. The Get Down I/9: 32:00), scheint dies kaum problematisch zu sein und schadet den Charakteren trotz ihres jungen Alters nur geringfügig. Viel dramatischer ist der absolute Kontrollverlust von Charakteren wie Cadillac, der im Kokainrausch einen Jungen foltert und schließlich versehentlich erschießt (vgl. The Get Down I/2: 38:00), ebenso wie die Tatsache, dass der jüngste Kipling-Bruder aus Profitgier selbst zum Drogenkurier wird

${ }^{109}$ Sein Love-Interest Misty weigert sich mit ihm zu sprechen, nachdem sie erfährt, dass er mit Kokain dealt (vgl. Red Oaks I/10: 2:19). Das Kokain versperrt ihm auch auf amouröser Ebene seine Möglichkeiten.

110 Tatsächlich muss sich Wheeler um seine Großmutter und seine Geschwister kümmern, die Eltern scheinen abwesend, die Lebensverhältnisse sind eher ärmlich und chaotisch (vgl. Red Oaks I/6: 0:04). Der Drogenkonsum entspringt zudem seiner Zuordnung zu ungeordneten sozialen Verhältnissen. 
(vgl. The Get Down I/8: 19:00). Mylene konsumiert zwischenzeitlich Kokain, um ihre problematische Situation zu ertragen (vgl. The Get Down I/10: 38:00) und ihr Vater begeht im Alkoholrausch Suizid. Während die Rolle von Drogen als Mittel der Entspannung und als soziales Ereignis, z. B. bei Partys oder beim gemeinsamen Beisammensein, normalisiert wird, läuft der totale Kontrollverlust durch Drogen und das absolute Aufgehen im Drogenrausch der Normalität zuwider. Vor allem der kriminelle Drogenhandel, welcher die Charaktere an die Unterschicht bindet und einen gesellschaftlichen Aufstieg verhindert, ist Teil der Grundproblematik des Formats. Hier zeigen sich die scheinbar unüberwindbaren Grenzen zwischen den sozialen Schichten.

Wie in The Get Down nutzen zahlreiche andere Charaktere Drogen als Kompensationsmittel in belastenden Situationen. Vor allem in Grace and Frankie ist dies auffällig. In nahezu jeder Situation, mit der sie nicht zurechtkommt - und darüber hinaus -, konsumiert Grace Alkohol (vgl. Grace and Frankie I/1: 5:00, I/8: 16:00) und/oder Beruhigungsmittel (vgl. Grace and Frankie I/1: 13:00, I/10: 2:00). Auch andere Mitglieder der Familie können unangenehme Lagen kaum ohne Alkohol oder Valium bewältigen. ${ }^{111}$ Der Konsum von Drogen wird nur am Beispiel Coyotes problematisiert, der zeitweilig stark drogenabhängig war und die Beherrschung über sich verlor (vgl. Grace and Frankie I/3: 16:00). De facto ist eine Vielzahl der Charaktere abhängig. Die Ironie dieses Weltmodells besteht darin, dass der massenhafte Konsum von Rauschmitteln soweit legitim ist, solange die Charaktere weitgehend die Kontrolle über sich behalten und niemandem durch ihre Sucht zur Last fallen. Der Konsum alltäglicher Drogen wie Alkohol, Beruhigungsmitteln und Marihuana (vgl. Grace and Frankie I/5: 5:00) wird hier normalisiert und ist vor allem Anlass für humoristische Handlungselemente. Ähnlich verhält es sich in Transparent, wenn sich beispielsweise Sarah Pfefferman und ihr Ehemann ärztlich Marihuana verordnen lassen (vgl. Transparent I/7: 7:00, I/9: 5:50) oder Ali Rauschmittel konsumiert (vgl. Transparent I/2: 25:08), um ihr Leben besser bewältigen zu können. Sarah muss schließlich ihr Marihuana entsorgen, um damit Tammy entgegenzukommen, die davon abhängig war (vgl. Transparent I/9: 2:45). Die Argumentation beider Serien ist im Kern identisch: An einem Einzelbeispiel wird auf die Problematiken der Sucht hingewiesen, während der regelmäßige Konsum von Rauschmitteln einer gesellschaftlichen Normalität entspricht.

${ }^{111}$ Graces Tochter Mallory nimmt wie ihre Mutter in Stresssituationen Beruhigungsmittel (vgl. Grace and Frankie I/2: 12:00). Ein gemeinsames Essen mit ihren Vätern ist für die Kinder kaum ohne Alkohol zu bewältigen (vgl. Grace and Frankie I/3: 17:00). Graces zeitweiliger Freund Guy nimmt das Beruhigungsmittel Ambien, um schlafen zu können (vgl. Grace and Frankie I/11: 1:00), dies führt sogar zu Gedächtnisverlust (vgl. Grace and Frankie I/13: 9:00). 
In The Ranch ist der Konsum von Alkohol ein bestimmender Teil des Lebens, vor allem der männlichen Charaktere. So freut sich Rooster, dass er nach Colts Rückkehr nun regelmäßig mit seinem Bruder trinken kann, weil er so weniger wie ein Alkoholiker wirke (vgl. The Ranch I/2: 14:00). Außerdem sieht er es als normales Verhalten an, sich bis zur Besinnungslosigkeit zu betrinken (vgl. The Ranch I/4: 1:00). Es gibt in der Serie kaum eine Gelegenheit, bei der Beau und seine Söhne in Maggies Bar keinen Alkohol konsumieren (vgl. The Ranch I/6: 22:00). Es scheint auch wenige Alternativen zu geben: Maggie findet in ihrer Bar kein Wasser, als darum gebeten wird, und serviert stattdessen Light-Beer (vgl. The Ranch I/2: 12:00). Besonders Colts Alkoholismus bleibt nicht ohne Konsequenzen: Vollkommen betrunken blamiert er sich bei einem Auftritt in seiner ehemaligen Schule und muss danach von der Polizei nach Hause gebracht werden (vgl. The Ranch I/3: 21:00). Dies ist jedoch eher der jugendlichen Unbeherrschtheit Colts zuzuschreiben, einer seiner Grundeigenschaften, und weniger dem Alkohol per se, welcher Teil des alltäglichen Lebens ist. Er dient den Charakteren zur ,Bewältigung ' von Problemen, aber auch zur Selbstbelohnung nach einem Arbeitstag und ist Teil des Topos des harten Rancher-/Cowboy-Lebens ebenso wie der vermittelten Vorstellung von Männlichkeit.

Der extreme Konsum von Rauschmitteln, gleich welcher Art, wird in Videoon-Demand-Serien tendenziell abgelehnt, vor allem dann, wenn er zum Kontrollverlust führt. Gleiches gilt für den kriminellen Handel mit Drogen. Dahingegen ist der gelegentliche bis regelmäßige Konsum legaler oder gesellschaftlich akzeptierter Drogen wie Beruhigungsmittel, Marihuana und vor allem Alkohol Teil der gesellschaftlichen Normalität. Er wird zwar ab und an Ziel des seriellen Humors und erhält den negativen Beigeschmack der Problemverdrängung und der gesellschaftlich akzeptierten Abhängigkeit, wird allerdings nie tiefergehend sanktioniert. In keinem der Beispiele des Korpus führt übermäßiger Konsum von Rauschmitteln zu einer tatsächlichen Bedrohung der Familie und damit des zentralen und handlungstragenden Raumes. Gegenläufig lässt sich bezüglicher einiger Beispiele argumentieren, dass der gemeinsame Konsum von Alkohol und Rauschmitteln sogar einende und solidarisierende Wirkung haben kann: Die Figuren legen ihre Hemmungen ab und kommen sich näher (vgl. z. B. Grace and Frankie I/1: 27:00, I/4: 4:00, I/5: 5:00; The Ranch I/1: 14:00, I/6: 22:00; Red Oaks I/3: 7:29). Insofern handelt es sich nicht um eine tiefergehende Problematik. 


\subsubsection{Religion}

Das letzte Paradigma ist die Religion und der Umgang der Charaktere mit dieser. Nur in fünf Serien des Korpus ist das Paradigma von annähernder Relevanz. In Ozark handelt es sich bei Pastor Mason Young und seiner Ehefrau Grace um die einzigen relevanten religiösen Charaktere. Mit seinem fast schon naiven Gottvertrauen steht Young im Gegensatz zur kalten und rationalen Welt der Serie. Ein wesentlich negativer Charakter ist Ramon Cruz in The Get Down, dessen verbissene, extreme und konservative Religiosität zur Unterdrückung seiner Familie und zudem zur Ablehnung seines vermeintlich unmoralischen Bruders Francisco führt. Laut Aussage seines Bruders kam Ramon Cruz erst im Gefängnis zum Glauben, nachdem er zwei Kinder in Puerto Rico zurückließ, Kokain konsumierte und fast einen Mann und sein Kind bei einem Autounfall umbrachte (vgl. The Get Down I/6: 3:00). Bevor er sich erschießt, gibt er dem Teufel und nicht sich selbst die Schuld am Verlust seiner Tochter und seiner Ehefrau (vgl. The Get Down I/10: 46:00). Seine religiösen Belehrungen wirken dementsprechend heuchlerisch und als verzweifelter Kompensationsversuch früherer Vergehen.

Die zentralen Familien in Red Oaks, The Marvelous Mrs. Maisel und Transparent sind jüdisch. In Red Oaks wird der gesamte Country-Club von jüdischen Mitgliedern dominiert. Somit ist das Jüdischsein Teil des Alltags und bringt nur geringe besonders hervorgehobene Besonderheiten mit sich. Mit dem Satz „A ,C' is a Jewish ,F"“112 (Red Oaks I/1: 00:34) als Kommentar zu Davids Noten unterstreicht Sam Myers den besonders elitären Anspruch der jüdischen Gesellschaft. Im späteren Serienverlauf findet eine Bar Mitzwa statt (vgl. Red Oaks I/9, die Episode trägt den Titel „The Bar Mitzwah“). Hierbei handelt es sich um ein gewöhnliches gesellschaftliches Ereignis ohne besondere Wertung. In Transparent ist das Judentum unter den Angehörigen der Pfeffermans Anlass zu Scherzen, z. B. über typische jüdische Nachnamen (vgl. Transparent I/1: 7:50). Durch das Auftreten der Rabbinerin Raquel Fein wird das verbreitete Muster einer rein männlichen Priesterschaft im Judentum gebrochen und ein progressives Gesellschaftsbild demonstriert. Keiner der Pfeffermans ist besonders religiös oder in jüdischen Bräuchen bewandert. Religion ist kein integraler Bestandteil ihrer Identität.

Durch die zeitliche Nähe zum Dritten Reich wird das Judentum In The Marvelous Mrs. Maisel häufiger thematisiert. Wiederholt wird auf die Schrecken des Holocaust angespielt, obgleich keiner der Charaktere ihn erlebt hat (vgl. The Marvelous Mrs. Maisel I/1: 00:36, 33:21). Insbesondere brüstet sich Moishe Maisel

${ }^{112}$ In der deutschen Synchronisation: „Eine 3 ist eine jüdische 5.“ 
damit, 194313 Juden aus Deutschland gerettet zu haben (vgl. The Marvelous Mrs. Maisel I/3: 24:30). Darüber hinaus wird das Judentum von den Charakteren zwar gelebt - so ist Miriam schockiert, als sie merkt, dass sie ihr Jom-KippurFasten gebrochen hat (vgl. The Marvelous Mrs. Maisel I/1: 50:33) - allerdings vor allem auf der Ebene gesellschaftlicher Ereignisse, die zu Stand und Ansehen der Familie beitragen. Beispielsweise ist Miriam begeistert, weil der Rabbi zu Gast auf der Jom-Kippur-Feier der Familie sein wird (vgl. The Marvelous Mrs. Maisel I/1: 05:41), und Moishe Maisel inszenierte die Bar Mitzwa seines Sohnes als gesellschaftliches Großereignis (vgl. The Marvelous Mrs. Maisel I/7: 06:30), um Einfluss zu gewinnen. Darüber hinaus ist der Umgang der Charaktere mit dem Judentum pragmatisch: Moishe Maisel lässt an Jom Kippur die Arbeit in seiner Fabrik fortsetzen (vgl. The Marvelous Mrs. Maisel I/2: 11:00). Miriam macht Witze über jüdische Traditionen (vgl. The Marvelous Mrs. Maisel I/6: 16:25), hebt aber auch den elitären Status der jüdischen Gesellschaft hervor. ${ }^{113}$ Die deutlicher zur Schau getragene Religiosität der Maisels und Weissmans hängt sicherlich mit der konservativen Gesellschaft der 1950er Jahre zusammen.

Wie sich also herausstellt, spielt Religion in den Serien des Korpus eine geringe Rolle. Im Rahmen familiärer Festlichkeiten und Zusammenkünfte hat sie bisweilen einen identitätsstiftenden und vereinenden Charakter - die Figuren stehen sich durch Brauchtum und Tradition nahe -, tritt aber aufgrund der weltlichen Orientierung der Charaktere eher in den Hintergrund. In einem jüdischen Umfeld mag sie dabei - aus dem Blickwinkel eines nicht jüdischen Autors - eher auffallen, wird aber in diesen Fällen nicht besonders hervorgehoben. Das ist insofern erwähnenswert, da in Serien wie The Ranch, die ein konservatives Weltbild zeigen, Religion eigentlich erwartbarer Bestandteil der Gesellschaft wäre. Dennoch wird allgemein auf eine Thematisierung der Religion, das Auftreten von Priestern oder den Besuch einer Kirche verzichtet. Dies mag möglicherweise der Fall sein, um das Identifikationspotenzial mit nicht religiösen Rezipierenden aufrechtzuerhalten, u. U. auch, um religiöse Institutionen und Gefühle nicht anzugreifen und somit eine dahingehende Kontroverse zu vermeiden.

\footnotetext{
113 Als ein Mann sie bei einem Auftritt beleidigt und zu ihr meint, sie solle nach Hause gehen und die Küche putzen, antwortet sie: „Oh, Sir, I'm Jewish. I pay people to do that.“ (The Marvelous Mrs. Maisel I/8: 57:50). Sie greift somit ironisch das Klischee des wohlhabenden Juden auf.
} 


\subsubsection{Resümee: Zentrierung des familiären Paradigmas}

Selbstverständlich sind die genannten Paradigmen nicht die einzigen, die in den Serien verhandelt werden. In Atypical steht beispielsweise der Autismus des Protagonisten wiederholt im Vordergrund, wenn auch eher als unterhaltendes Element und Katalysator und Zuspitzung der Handlung denn als tiefergehend verhandelte Problematik. In The Ranch spielen gelegentlich der politische Konservatismus Beau Bennetts sowie der Football eine Rolle - ein Sport, über den sich Colt definiert. Ein Aufgehen in Details, welche Relevanz für ein Einzelformat, aber nicht für das Gesamtkorpus besitzen, wäre indes wenig zielführend. Im Folgenden sollen nun die Ergebnisse bezüglich der Paradigmen gebündelt werden.

Die Paradigmen Alkohol- und Drogenkonsum und Religion sind bezüglich der Familiendarstellung zwar wiederholt auftretende, aber sekundäre Teile der vorgeführten Weltmodelle. Der gemeinsame Konsum von Alkohol und Rauschmitteln kann dabei - neben seiner Anwendung als ,Problemlösung ' - einen einenden und entspannenden Charakter haben. In Hinblick auf die Familie hat Religion ebenso eine vereinende Funktion, diese erfolgt aber vor allem über ihre identitätsstiftenden Eigenschaften. Sexualität ist Teil von Ehe und Beziehung und nur innerhalb dieser legitim. Soziale Schicht, Arbeit und Geld stärken durch ihren negativen und bedrohlichen Einfluss die Opposition von Privatem und Öffentlichem und damit die Bedeutung des familiären Zusammenhalts sowie die Funktion der Familie als Schutzraum.

Es lässt sich feststellen, dass ein Paradigma erst dann besonders relevant wird, wenn es einen direkten Bezug zum familiären Leben aufweist. Je stärker etwas Einfluss auf die Familie nimmt, je relevanter es im familiären Leben der Charaktere und auch bezüglich ihrer Selbstdefinition ist, desto relevanter ist es im Weltmodell der untersuchten Formate. Viele der analysierten Serien setzen vordergründig andere Handlungsschwerpunkte als das Familienleben, z. B. die Drogenkriminalität in Ozark, die Musik in The Get Down, Transsexualität in Transparent oder Autismus in Atypical. Bei diesen und bei allen darüber hinaus verhandelten Paradigmen handelt es sich letztlich allerdings nicht um eigenständige Handlungselemente, sondern allein um Träger der dominanten Familienhandlung. Diese Thematiken stellen die Möglichkeit dar, familiäre Dynamiken aus unterschiedlichen Perspektiven zu thematisieren und die im Kern stets gleiche Handlung zu variieren. Die zuvor genannten Thematiken und scheinbar primären Handlungsstränge sind im Kern nicht mehr als reine „Pseudo-Paradigmen“ ohne eigenständige Relevanz, die der ,nackten' Familiendarstellung unterschiedliche Hüllen verleihen und überdecken, dass es im Kern darum geht, bestimmte 
Werte, Normen und Idealvorstellungen von menschlichem Zusammenleben zu transportieren.

\subsection{Repräsentation von Familie durch Handlungs- und Raumstrukturen}

Mit Ausnahme von $F$ is for Family und The Romanoffs haben die analysierten Formate ausschließlich eine Tendenz zur Fortsetzungsserie. ${ }^{114}$ Bei The Romanoffs handelt es sich um eine Anthologie-Serie, die in jeder Episode eine alleinstehende Geschichte erzählt. Dabei existieren übergeordnete Elemente wie u. a. wiederkehrende Figuren, die auch in anderen Episoden auftreten (vgl. The Romanoffs I/8: 2:20 - hier sieht man Greg Moffat und Sophie aus der ersten Episode am Pariser Bahnhof). Der Charakter einer Anthologie wird vorgeblich über den Aspekt der (behaupteten) Abstammung einiger Figuren von der Zarenfamilie Romanow hergestellt. Dabei handelt es sich um ein Element, das in der Handlung eine untergeordnete Rolle einnimmt. Vielmehr stehen im Mittelpunkt der Serie diverse Familienkonstellationen und Charakterkonflikte mit Familienbezug: eine ungewollte Schwangerschaft, der Konflikt zwischen Mutter und Tochter, die Adoption eines Kindes, ein Sohn, der verstoßen wird etc. Familie ist das übergeordnete und vereinende Paradigma der Serie, weniger die Abstammung vom russischen Zarenhaus. Der Titel The Romanoffs wird insofern ad absurdum gefühlt, da die Figuren - unabhängig von ihrer Herkunft - familiäre Probleme durchleben, die in keinerlei Bezug zur ihrer Ahnenlinie stehen. $F$ is for Family ist als Zeichentricksitcom klassischerweise an der Episodenhandlung orientiert und weniger an übergreifenden Handlungslinien. Allerdings treten auch hier dauerhafte Veränderungen ein, z. B. hinsichtlich der beruflichen Situation der Charaktere, und ein Streit zwischen den Figuren wird nicht zwingend mit jeder Episode beendet.

Serien, die man im weitesten Sinne als Sitcom bezeichnen könnte, wie Atypical, Everything Sucks!, Grace and Frankie, Red Oaks und The Ranch weisen relativ abgeschlossene Episodenhandlungen auf, doch in jedem Fall sind übergeordnete Handlungsstränge vorhanden, die in ihrer Bedeutung die Handlung der Einzelfolgen dominieren. In Atypical steht neben der Beziehungsfindung Sams vor allem der Ehebruch seiner Mutter im Vordergrund. Bei Everything Sucks! handelt es sich um die Adoleszenz der jungen Charaktere und um das Zusammenfinden von deren Eltern, bei Grace and Frankie um die Homosexualität der Ex-Ehemänner

114 Die Handlungsschemata der Serien sind der Untersuchung in Anhang 3. (im elektronischen Zusatzmaterial) angehängt. 
und die daraus resultierenden Konflikte, in Red Oaks um die Loslösung Davids vom Elternhaus und seine amouröse sowie berufliche Entwicklung und in The Ranch um den Konflikt zwischen Beau und Maggie sowie um Colts Selbstfindung auf Berufs- und Beziehungsebene. Dabei wird eine kontinuierliche Entwicklung der Charaktere gezeigt, auch wenn sich diese in ihren Merkmalen nur langsam ändern und weitgehend ihrem (oft überzeichneten) Typus treu bleiben. Die weiteren Serien sind klar als Fortsetzungsserie zu bezeichnen. Hier durchlaufen die Charaktere in einer kontinuierlichen Handlung eine klare Entwicklung.

Wie hier deutlich wird, tendiert die Video-on-Demand-Serie zur Fortsetzungsserie. Traditionell episodal gehaltene Gattungen wie die Sitcom entwickeln einen Trend in Richtung eines narrativen Kontinuums. Selbst die Zeichentricksitcom, die - z. B. in The Simpsons, Family Guy oder South Park - auf eine absolute Unabhängigkeit der Einzelepisoden setzte, löst sich von diesem Schema. Dies lässt sich auch im Netflix Original BoJack Horseman beobachten, das deutliche übergeordnete Handlungsstränge aufweist (vgl. Kelsch 2019: 114 f.). Die Handlungsverläufe lösen sich vom simplen Schema der Ein-Episoden-Handlung mit stabilen Charakteren und wendet sich komplexeren Handlungsverläufen zu. Dies muss nicht in jedem Falle bedeuten, dass die Figuren eine mehr oder weniger drastische Entwicklung durchlaufen, wie dies vor allem in Fortsetzungsserien der Fall ist, gibt einer solchen Entwicklung allerdings deutlich mehr Raum. Selbst ein Zeichentricksitcom-Charakter wie Sue Murphy wandelt sich, indem sie sich gegen ihren Ehemann durchsetzt und einen Beruf ergreift. Frank muss schließlich lernen, damit zurechtzukommen. Der Trend einer gesteigerten Komplexität von Figuren und Handlung, der mit dem sogenannten Quality-TV der 2000er begann, setzt sich in der Video-on-Demand-Serie fort.

\begin{tabular}{l|l}
\hline Handlungsverlauf & \multicolumn{1}{l}{ Auswertung } \\
\hline Serie & $\begin{array}{l}\text { Kinder: Kindheit }>\text { Erwachsensein (durch Adoleszenz) } \\
\text { - Extremraum: Sexualleben } \\
\text { Eltern: Stabiles Familienleben }>\text { instabiles Familienleben }\end{array}$ \\
$\begin{array}{ll}\text { (durch Ehebruch) } \\
\text { - Extremraum: Ehebruch } \\
\rightarrow \text { Störende Faktoren: Adoleszenz, Ehebruch }\end{array}$ \\
\hline Everything Sucks! & $\begin{array}{l}\text { Kindheit }>\text { Erwachsensein (durch Besuch der High-School } \\
+ \text { erste Beziehung) } \\
\text { - Extremraum: Elternschaft } \\
\rightarrow \text { Störende Faktoren: Adoleszenz, defiziente } \\
\text { Familiensituation }\end{array}$ \\
\hline
\end{tabular}




\begin{tabular}{|c|c|}
\hline \multicolumn{2}{|l|}{ Handlungsverlauf } \\
\hline Serie & Auswertung \\
\hline$F$ is for Family & $\begin{array}{l}\text { Klassische Sitcom-Episodenstruktur (mit teilweise } \\
\text { übergreifender Handlung) } \\
\rightarrow \text { Störende Faktoren: Arbeitswelt, Adoleszenz, } \\
\text { Emanzipation der Frau }\end{array}$ \\
\hline Grace and Frankie & $\begin{array}{l}\text { Geordnete Familien- und Rollenverhältnisse > ungeordnete } \\
\text { Familien- und Rollenverhältnisse (durch Outing von Robert } \\
\text { und Sol)>angestrebt: neue Familien- und Rollenverhältnisse } \\
\text { - Extremraum: Homosexualität } \\
\rightarrow \text { Störende Faktoren: Ehebruch, Scheidung (und } \\
\text { dementsprechend defiziente Lebenssituation) }\end{array}$ \\
\hline Ozark & $\begin{array}{l}\text { Relative Sicherheit }>\text { Bedrohung }>\text { relative Anpassung an den } \\
\text { Raum } \\
\text { - Extremraum: Extreme Bedrohung } \\
\rightarrow \text { Störende Faktoren: Arbeitswelt/Geld, Ehebruch }\end{array}$ \\
\hline Red Oaks & $\begin{array}{l}\text { Stabile Familien- und Beziehungsverhältnisse > instabile } \\
\text { Familien- und Beziehungsverhältnisse (durch Auflösung der } \\
\text { Ehe, Emanzipation Davids, Verlieben Davids) } \\
\text { - Extremraum: Normablehnung } \\
\rightarrow \text { Störende Faktoren: Adoleszenz/Loslösung vom } \\
\text { Elternhaus, Ehestreitigkeiten }\end{array}$ \\
\hline The Get Down & $\begin{array}{l}\text { Persönliche Unfreiheit>persönliche Freiheit (durch } \\
\text { Emanzipation von der Familie und sozialen Zwängen }+ \\
\text { aber auch: Einigen Charakteren gelingt keine Emanzipation) } \\
\text { - Extremraum: Persönlicher Erfolg } \\
\rightarrow \text { Störende Faktoren: Soziale/gesellschaftliche Zwänge }+ \\
\text { Kriminalität, defiziente Familiensituation }\end{array}$ \\
\hline The Marvelous Mrs. Maisel & $\begin{array}{l}\text { Gesellschaftliche Norm > Normbruch (durch Joels Ehebruch } \\
\text { + Miriams Stand-Up-Karriere) } \\
\text { - Extremraum: Stand-Up-Comedy } \\
\rightarrow \text { Störende Faktoren: Soziale/gesellschaftliche Zwänge, } \\
\text { Ehebruch }\end{array}$ \\
\hline The Ranch & $\begin{array}{l}\text { Leben außerhalb der Heimat }>\text { Leben in der Heimat (durch } \\
\text { Colts Heimkehr) } \\
\text { - Extremraum: Familie } \\
\rightarrow \text { Störende Faktoren: Defiziente Lebens- und } \\
\text { Familiensituation, unangemessenes Verhalten des } \\
\text { Protagonisten }\end{array}$ \\
\hline The Romanoffs $\mathrm{I} / 1$ & $\begin{array}{l}\text { Instabile Familiensituation (kein Erbe) }>\text { Stabilisierung } \\
\text { durch Erweiterung der Familie } \\
\rightarrow \text { Störende Faktoren: Defiziente Lebens- und } \\
\text { Familiensituation }\end{array}$ \\
\hline
\end{tabular}




\begin{tabular}{|c|c|}
\hline \multicolumn{2}{|l|}{ Handlungsverlauf } \\
\hline Serie & Auswertung \\
\hline The Romanoffs $\mathbf{I} / 2$ & $\begin{array}{l}\text { Instabile Familiensituation (keine Liebe der } \\
\text { Eheleute) > Bruch der Familie } \\
\rightarrow \text { Störende Faktoren: Entfremdung der Eheleute }+ \\
\text { Ehebruch }\end{array}$ \\
\hline The RomanoffsI/3 & $\begin{array}{l}\text { Kein Familienbezug (instabile Situation aufgrund } \\
\text { mangelnden familiären Rückhalts) }\end{array}$ \\
\hline The Romanoffs I/4 & $\begin{array}{l}\text { Erweiterung der Familie }+ \text { instabile } \\
\text { Familiensituation }>\text { Versöhnung und dadurch Stabilisierung } \\
\text { der Familie } \\
\rightarrow \text { Störende Faktoren: Widerstreitende Meinungen zwischen } \\
\text { Mutter und Tochter, Ehebruch }\end{array}$ \\
\hline The Romanoffs I/5 & $\begin{array}{l}\text { Gefährdung der Familie von außen > Tilgung der Gefahr } \\
\rightarrow \text { Störende Faktoren: Bedrohung der Kinder (bzw. } \\
\text {,Eindringling‘ in die Familie) }\end{array}$ \\
\hline The RomanoffsI/6 & $\begin{array}{l}\text { Gefährdung der Familie von innen }>\text { Aufrechterhalten der } \\
\text { Familie } \\
\rightarrow \text { Störende Faktoren: Krankheit des Sohnes, Konflikt des } \\
\text { Ehepaares }\end{array}$ \\
\hline The RomanoffsI/7 & $\begin{array}{l}\text { Versuch der Familienbildung }>\text { Bildung von Familie } \\
\rightarrow \text { Störende Faktoren: Defiziente Familiensituation }(+ \\
\text { Streben nach deren Komplettierung) }\end{array}$ \\
\hline The Romanoffs I/8 & $\begin{array}{l}\text { Eindringen eines Fremdkörpers in die Familie }>\text { Tilgung des } \\
\text { Fremdkörpers bzw. Sanktionierung des Eindringens } \\
\rightarrow \text { Störende Faktoren: Fremdkörper in Familie, Tod eines } \\
\text { Elternteils, Selbstfindung }\end{array}$ \\
\hline Transparent & $\begin{array}{l}\text { Traditionelle Rollenschemata }>\text { Bruch traditioneller } \\
\text { Rollenschemata (durch Transsexualität, aber auch } \\
\text { Homosexualität) } \\
\rightarrow \text { Störende Faktoren: Drastischer Selbstfindungsprozess, } \\
\text { Ehebruch, Defiziente Familiensituationen }\end{array}$ \\
\hline
\end{tabular}

In seiner Betonung des familiären Zusammenhaltes ist der Handlungsverlauf von Ozark im Vergleich zu den anderen analysierten Serien herausstechend. Dass die Handlung der Serien stets aus dem Bruch einer bestehenden familiären Ordnung resultiert, ergibt sich logisch aus deren inhaltlicher Fokussierung auf die Familie.

Eine vollständige oder zumindest weitgehende Wiederherstellung familiärer Stabilität, d. h. eine vollständige Umsetzung des Konsistenzprinzips, findet lediglich in den abgeschlossenen Folgen von The Romanoffs statt. Aufgrund folgender 
Staffeln werden Handlungslinien und Konflikte in den weiteren Beispielen nicht abgeschlossen. In Ozark bleiben die Byrdes innerfamiliär im Konflikt und außerfamiliär bedroht. In Atypical entdeckt Doug Gardner den Ehebruch seiner Frau zum Ende der ersten Staffel (vgl. Atypical I/8: 34:00). Everything Sucks! endet mit der Ankunft von Lukes Vater beim gemeinsamen Essen der Messners (vgl. Everything Sucks! I/10: 24:00) und mündet somit in eine potenzielle Bedrohung der neugefundenen Harmonie. Red Oaks endet mit der Ankündigung Skye Gettys, sie werde nach Paris gehen. Stets bleibt ein großes Potenzial zur Fortführung der Handlung. Auch The Get Down weist, obwohl keine zweite Staffel folgt, einige offene Enden auf.

Der Bruch familiärer Strukturen kann - wie in der obigen Tabelle zu sehen ist - aus unterschiedlichen Faktoren bzw. aus verschiedenen Grenzüberschreitungen resultieren. Dabei handelt es sich in der Regel um einen inneren Antrieb der Figuren, der zu einer ereignishaften Situation führt, also einer Änderung der Familie von innen heraus. Fokussiert die Handlung jüngere Charaktere, handelt es sich bei dieser Grenzüberschreitung meist um den Wandel von der Kindheit zum Leben als Erwachsener. Im Rahmen einer frühen oder fortgeschrittenen Adoleszenz führt die Ablehnung der elterlichen Autorität und das Erwachen sexuellen Interesses bzw. bei älteren Charakteren die Suche nach einer dauerhaften Beziehung zur Loslösung vom Elternhaus. Der logische Endpunkt einer solchen Handlung wäre die vollkommene Abspaltung von den Eltern und der Beginn eines eigenständigen Lebens. Dies findet allerdings in den untersuchten ersten Staffeln so nie statt. Weitere Serien zeigen andere ,Störungen' der geordneten familiären Koexistenz. Dabei spielen vor allem der Ehebruch, Konflikte zwischen Eheleuten und deren Entfremdung voneinander oder der Konflikt eines Charakters mit seiner Rolle innerhalb der Familie, deren aller Konsequenz meist der Ehebruch ist, eine große Rolle. In The Ranch besteht die Handlung vorrangig darin, dass der Protagonist Colt versucht, sich im familiären und erwachsenen Leben zu verorten. Die Handlungen von Grace and Frankie und Transparent basieren auf dem Verlust des konstitutiven Merkmales einiger Hauptcharaktere. Robert und Sol (Grace and Frankie), die zuvor von ihren Familien als heterosexuell wahrgenommen wurden, outen sich als homosexuell. In Transparent stellt sich heraus, dass Maura sich als Frau und nicht als Mann fühlt. Somit ist sie - auf Ebene der Rollenwahrnehmung - nicht mehr Vater, sondern Mutter ihrer Kinder. In den meisten Fällen lassen sich die oppositionellen Räume in etwa mit ,geordnete Familien- und Rollenverhältnisse“ und ,instabile Familienverhältnisse“ bezeichnen oder auf diese reduzieren. Findet die Handlung, wie in The Romanoffs, einen Abschluss, besteht dieser - naheliegenderweise - in der Stabilisierung der Situation: Anushka La Charnay findet, wie ihr Neffe, familiäre Geborgenheit (The Romanoffs I/1). Julia 
Wells verträgt sich mit ihrer Tochter Ella und erfährt, dass diese schon länger weiß, wer ihr leiblicher Vater ist (The Romanoffs I/4). Katherine Ford überwindet ihren Argwohn gegenüber dem Klavierlehrer David Patton (The Romanoffs I/5). Abel Erikson ermöglicht scheinbar eine Versöhnung des Ehepaares Hayward (The Romanoffs I/6) und die Garners adoptieren eine Tochter und ,vervollständigen * ihre Familie (The Romanoffs I/7). Der Endpunkt der Entwicklung ist die Beilegung eines familiären Konfliktes und die Sicherung der familiären Koexistenz. Eine Ausnahme stellen die zweite, dritte und achte Episode dar: In der zweiten Episode zerbricht die desolate Ehe von Michael und Shelly Romanoff, in der dritten Episode spielt Familie gar keine Rolle und in der achten Episode ermordet Simon/Candice Burrows seinen/ihren ,Konkurrenten“ Jack. Diese Episoden stellen dementsprechend Einzelfälle dar. Die Abwesenheit von Familie bzw. deren negativer Zustand wird auf diese Weise stets als hochproblematische Situation gewertet, wodurch deren intradiegetische Bedeutung bestätigt wird.

Auffällig ist, dass die Bedrohung der Familie und deren Destabilisierung nur selten von äußeren Faktoren bedingt wird. Stets kommt zu den äußeren Einflüssen eine Handlung der Charaktere, welche die Familie destabilisiert. In Ozark wird die Familie von einem Drogenkartell bedroht, vor allem aber begeht Wendy Byrde Ehebruch. In $F$ is for Family und The Marvelous Mrs. Maisel werden die Ehemänner von der Arbeitswelt unter Druck gesetzt und handeln gegenüber ihren Ehefrauen und Kindern negativ. Der äußere Einfluss ist dabei den familieninternen Faktoren an Bedeutung untergeordnet. Die Charaktere stehen zwar unter dem Einfluss äußerer Faktoren, doch diesem wird weniger Bedeutung beigemessen als dem konkreten Handeln. Frank Murphys despotisches und ignorantes Verhalten, Wendy Byrdes und Joel Maisels Ehebruch werden mehr fokussiert als deren Ursachen.

Eine Handlung, in der eine äußere Bedrohung der Familie vorliegt - beispielsweise die Jagd durch eine Verbrecherorganisation, die Bedrohung durch Armut, eine Naturkatastrophe oder Ähnliches -, ohne dass schwerwiegende innere Konflikte vorliegen, tritt im Analysekorpus nicht auf. Die Handlung richtet sich eher auf das Handeln und die Geschehnisse innerhalb der Familie aus als auf deren Interaktion mit dem Außen.

In Ozark ist die Hervorhebung des familiären Zusammenhalts herausstechend. Trotz oft dysfunktionaler Verhältnisse lösen sich Familien auch in weiteren Beispielen nicht auf. Der logische Endpunkt ist stets die Sicherung des Zusammenhalts und das Fortbestehen. Die Adoleszenz jugendlicher Charaktere sehe ich hierbei als Ausnahme. Dies ist durchaus bei Grace and Frankie ebenso der Fall, eine Serie, die mit dem Zerbrechen zweier Ehen beginnt. Dieses Ereignis bringt die Familien Bergstein und Hanson und deren Kinder sogar näher zusammen als 
zuvor. Natürlich lässt sich dies als besondere Gewichtung des familiären Zusammenhalts werten, basiert aber - auf einer deutlich profaneren Ebene - vor allem auf dem inhaltlichen Grundkonzept der Serien. Selbst in einer Fortsetzungsserie, in welcher die Charaktere einen Wandel durchlaufen, wäre die vollständige Auflösung eines bestehenden Charakterverhältnisses, das in der ersten Staffel als handlungstragend etabliert wurde, ein narratives Wagnis. Die Konsequenz wäre eine Zersplitterung der Handlung und die notwendige Etablierung weiterer Figuren. Obgleich sich auf der Handlungsebene die Bedeutung der Familie durchaus manifestiert, darf dies angesichts der aus der Gattung Serie resultierenden narrativen Zwänge nicht zu hoch gewertet werden.

Zudem wurde zuvor darauf verwiesen, dass in den Formaten besonders konfliktreiche Familien präsentiert werden, deren unbedingte Aufrechterhaltung fragwürdig erscheint. Familie wirkt dadurch wie ein hohles Dogma, das angesichts aktueller gesellschaftlicher und sozialer Gegebenheiten an Bedeutung verliert. Um den Fatalismus dieser Argumentation zu relativieren, muss betont werden, dass die beständigen und tiefgreifenden Konflikte der Video-on-Demand-Familien ebenso wie der Drang junger Charaktere, die Herkunftsfamilie zu verlassen, narrativ notwendig sind. Ein stabiles Personengefüge zu beobachten, das harmonisch beisammen lebt und in seinen Abläufen absolut funktional ist, ist von geringem Spannungs- und Erzählwert. Selbst in Serien der 1950er Jahre traten in Familien Konflikte auf, wenn auch diese selbstverständlich nicht die Drastik oder Schärfe heutiger Serien aufweisen. Aktuelle erwachsene Rezipierende erwarten - so ist anzunehmen - schwerwiegendere Konflikte zwischen den Charakteren, die über einen alltäglichen Streit hinausgehen. Die Darstellung des Familienparadigmas verläuft daher stets zweigleisig: Einerseits ist ein fiktionales Weltmodell, insbesondere das eines medialen Formates, das auf Publikumswirksamkeit abzielen muss, stets Ergebnis dramaturgischer Überlegungen. Problematiken und Spannungsfelder werden bewusst verschärft. Andererseits tritt im Weltmodell auch das kulturelle Wissen der Medienschaffenden zutage. Welchen Narrationen das größte Identifikationspotenzial und somit die größten Marktchancen beigemessen werden, erlaubt Rückschlüsse auf das Gesellschaftsbild der Produzierenden und ist dementsprechend relevant. Dramatik und damit essenziell auch die Gestaltung der Narration mögen also zur Übertreibung neigen, ähnlich wie die satirische Herangehensweise zahlreicher Sitcoms. Was aber konkret übertrieben wird, verweist umso deutlicher auf existierende Weltbilder sowie Norm- und Wertvorstellungen. 


\subsection{Familienmodelle im Serienkorpus: Die Kernfamilie der Mittelschicht - ein idealisiertes und elitäres Modell}

Zeigen einige Ausnahmen auch alternative Familienmodelle und -strukturen, so präferieren die analysierten Serien doch die traditionelle Kernfamilie und damit einhergehend konservative Geschlechternormen. Weibliche Charaktere sind häufig auf die Versorgung durch männliche Charaktere angewiesen und nur in geringfügigem Maße beruflich emanzipiert. Ihre Bindung an einen männlichen Charakter, in der Regel mit dem Ziel eine Familie zu gründen und Kinder zu bekommen, d. h. das Streben nach Erfüllung einer mütterlichen und fürsorglichen Rolle, erscheint als feststehende biologische Determination. Vollkommen unabhängige Frauen, Frauen, die allein für ihren Beruf leben oder Autoritätspositionen einnehmen, und ebenso alleinstehende Frauen führen entweder ein defizientes Leben oder es handelt sich um Negativcharaktere. Männlichen Charakteren wird eine größere Freiheit bei der Gestaltung ihres Lebens eingeräumt, vor allem wenn sie sich in der Jugendphase befinden, die sich bei weiblichen Charakteren bereits früh auf eine dauerhafte Paarbindung ausrichtet. Männer ergreifen die einflussreicheren sowie finanziell ertragreicheren Berufe und fungieren später als Familienversorger und Väter, d. h. als Autoritätspersonen. Das Autoritätsgefälle ist dementsprechend stets deutlich, selbst wenn es sich bei den dargestellten Beziehungen um vordergründig gleichberechtigte Partnerschaften handelt.

Die auf einer heterosexuellen Ehe basierende Familie ist dabei die absolute Norm und steht im Zentrum aller Formen der Familie und der Partnerschaft. Alles außerhalb der traditionellen Kernfamilie ist in den Serien des Korpus als Abweichung und ungewöhnlich zu betrachten, jedoch nicht unbedingt als illegitim oder negativ. Dies betrifft vor allem homo und transsexuelle Charaktere. Die Kernfamilie ist dabei stets auf den engsten Familienkreis beschränkt, d. h., Großfamilien in der Form des engen Zusammenlebens mehrerer Generationen treten nicht auf. Selbst wenn Hauptcharaktere bereits Großeltern sind, tritt die Enkelgeneration in der Regel in den Hintergrund. Die Charaktere bleiben somit an erster Stelle Mütter und Väter.

Ebenso wie von der erweiterten Familie bleibt die Kernfamilie gegen den öffentlichen Raum hin isoliert. Dies geschieht nicht, weil die Charaktere keinerlei Umgang mit der Öffentlichkeit pflegen würden, sondern dadurch, dass die Kompetenz zur Problemlösung allein im familiären Bereich liegt. Außenstehende Personen können eine beratende oder unterstützende Funktion einnehmen, haben aber keinen direkten Einfluss auf die Entscheidungen, welche die Familie betreffen. Dies gilt insbesondere auch für öffentliche und staatliche Institutionen. Äußere Einwirkung - häufig in Form der Berufs- und Arbeitswelt - ist zumeist 
belastend und negativ. Wird direkt Einfluss genommen, handelt es sich in der Regel um antagonistisches Eingreifen. Die Kernfamilie fungiert dementsprechend als Schutzraum vor ,feindlichen ' Einflüssen, als Raum des privaten Rückzuges, der Geborgenheit und der Sicherheit. ${ }^{115}$

Die auftretenden Familien sind dabei vornehmlich weißer Hautfarbe und gehören der Mittelschicht an. The Get Down, in dem afro- und lateinamerikanische Figuren die Hauptrollen spielen, stellt dabei, auch hinsichtlich der thematischen Schwerpunktsetzung auf soziale Problematiken, eine Ausnahme dar. In Everything Sucks! tritt die teilweise afroamerikanische Familie O'Neil auf. Rassismus wird hier nicht besonders thematisiert. Vielmehr sind die O'Neils wie Nwabudike Bergstein in Grace and Frankie voll inkludierter Teil der sie umgebenden Gesellschaft. Nwabudike fällt als adoptierter Afroamerikaner innerhalb einer vollständig weißen Familie zwar auf, wird aber nicht als abweichend, sondern vielmehr als Vorzeigesohn im Vergleich zum verantwortungslosen Coyote inszeniert, der in die Fußstapfen seines Vaters getreten ist. Der auffällige Name weicht normalerweise dem unauffälligen Spitznamen Bud, ebenfalls ein Anzeichen der Inklusion. Es muss außerdem darauf hingewiesen werden, dass es sich bei den O'Neils um eine unvollständige bzw. vaterlose Familie handelt, also nicht um eine geschlossene Kernfamilie wie in anderen Beispielen. Dennoch sind drei afroamerikanische Charaktere nicht ausreichend, um eine generelle Regel über die Darstellung afroamerikanischer Charaktere in der gesamten Video-on-DemandSerie zu formulieren. Die geringe Zahl entsprechender Figuren macht indes deutlich, dass Menschen afroamerikanischer, lateinamerikanischer oder anderer Herkunft, insbesondere Native Americans oder Amerikaner asiatischer Herkunft, deutlich unterrepräsentiert sind. ${ }^{116}$ Mit der zusätzlichen Beschränkung auf eine eher wohlhabende Mittelschicht engt sich das Gesellschaftsbild weiter ein.

Bezieht man weiterhin die Tatsache mit ein, dass relativ wenige alleinerziehende Eltern auftreten, lässt sich feststellen, dass das präsentierte Bild von Familie

115 In The Marvelous Mrs. Maisel treten, wie in The Romanoffs, Charaktere auf, die erfolgreich ein Leben unabhängig von einer Familie führen. Dies allerdings nur im eingeschränkten Sinne: Miriam Maisel bleibt ebenso von ihrer Familie, d. h. ihren Eltern, abhängig und der alleinstehende Charakter Susie Myerson tritt als gesellschaftlicher Sonderling auf. In The Romanoffs ist Abel Erikson (The Romanoffs I/6) ein gefestigter und beruflich erfolgreicher Charakter. Allerdings ist Erikson offensichtlich einsam und strebt durchaus eine Beziehung an.

1162018 waren 18,3\% der Einwohner der USA afroamerikanischer Herkunft, 13,39\% lateinamerikanischer und 5,91\% asiatischer Herkunft. 60,38 \% der US-Bevölkerung waren weiß. Mit knapp $40 \%$ nehmen Angehörige von Minderheiten also einen durchaus bedeutsamen Teil der US-Bevölkerung ein. Dies lässt die Tragweite von deren Unterrepräsentation deutlicher werden. 
keinesfalls repräsentativ für die US-amerikanische Gesellschaft ist. Vielmehr stützen sich die Serien auf das seit den 1950er Jahren dominante Modell der weißen Mittelschichtsfamilie. Es wird eine Ausblendung und Reduktion von Komplexität auf ein Modell vorgenommen, das in der Realität nur einer relativ elitären gesellschaftlichen Gruppe entspricht.

Die strikte Einhaltung dieser Norm wird insofern auffälliger, da zeitgleich zunehmend vielschichtige Figuren und Handlungsstränge Einzug in die Serien gehalten haben - bereits vor der Video-on-Demand-Serie, aber durch diese noch vermehrt. Dementsprechend sind die dargestellten Familienverbände ausgesprochen konfliktreich, von der Harmonie der 1950er Jahre kann keine Rede mehr sein. Wie in Ozark erweist sich die Familie als zu tief im medialen Bewusstsein verankerter Mythos, als dass eine Auflösung oder rasche Umbildung erfolgen könnte. Die Repräsentation alternativer Lebensformen und vor allem deren Inszenierung als legitim und der traditionellen Familie gleichwertig wird von der Dominanz des Familienmythos nahezu erstickt. Das Ideal der Kernfamilie mag zwar kein Ideal mehr sein, dennoch bleibt es ein mediales Dogma und ein essenzieller Mythos. Selbstverständlich ergibt sich das unbedingte Festhalten an der Familie auch aus narrativen Zwängen der untersuchten Serien, die Narration verbietet allerdings keine Alternativen zur Kernfamilie bzw. zur vorliegenden Darstellungsform. Zudem entspringt die Verortung in einer nahezu exklusiv weißen Mittelschicht keinerlei narrativem Zwang, eher noch einem normativen.

Komplexe und ambivalente Figurenkonstellationen und Handlungssituationen werden in einfache und eindeutige Weltmodelle eingefügt, die ihren Ursprung in einer Zeit haben, deren serielle Modelle allgemein simpler und weniger vielschichtig konzipiert waren. Hier bestätigt sich die bezüglich Ozark bereits ausgeführte These des medialen Familienmythos, der im Inneren der Weltmodelle angelegt, aber für die Charaktere nicht mehr funktional ist. Aus narrativer Sicht ist das Aufeinanderprallen der Realität des Weltmodells und dessen innerer Normsetzungen äußerst reizvoll: In sich konfliktreiche Weltmodelle bieten Ansatzpunkte für komplexe und reizvolle Handlungslinien. Die analysierten Serien speisen sich daher gerade aus dem Konflikt widerstreitender Strukturen, zwischen tradierten, eindimensionalen Modellen und moderner Mehrdimensionalität.

Aus gesellschaftlicher Sicht erscheint die Konsequenz dessen allerdings problematisch. Schließlich werden hier auf massenmedialer Ebene idealisierte Weltmodelle bzw. Lösungsstrategien perpetuiert, die nicht mehr zeitgemäß sind. Vor allem aber versperren konservative Geschlechter- und Rollenbilder ebenso wie die Setzung der heteronormativen Kernfamilie als absolute Norm den Blick auf alternative Verhaltens- und Lebensweisen wie offene oder polyamore Beziehungen, unverheiratete Paare mit Kindern, die bewusste Entscheidung für ein 
Leben ohne Kinder oder als Single. Solange diese nicht medial aufgegriffen und populärkulturell ,normalisiert` werden, werden bestimmte Aspekte des menschlichen Zusammenlebens weiterhin als außerhalb der Norm stehend wahrgenommen werden. Das zunehmende Auftreten etwa transsexueller Charaktere und homosexueller Partnerschaften lässt zwar auf eine Entwicklung in Richtung einer breiteren Gesellschaftsrepräsentation schließen, auch wenn diese im besten Falle langsam, wenn nicht sogar schleppend verläuft. Diese Repräsentation bedeutet allerdings keinesfalls eine tatsächliche Vielfalt oder Inklusion entsprechender Modelle, sondern lediglich das Aufgreifen aktueller Entwicklungen. Es ist nicht nur die Zahl, sondern auch die Art und Weise der Darstellung, die relevant ist. Diese betont nach wie vor Abweichung und Andersartigkeit und propagiert die Anpassung an heteronormative, traditionell-konservative Strukturen.

Open Access Dieses Kapitel wird unter der Creative Commons Namensnennung 4.0 International Lizenz (http://creativecommons.org/licenses/by/4.0/deed.de) veröffentlicht, welche die Nutzung, Vervielfältigung, Bearbeitung, Verbreitung und Wiedergabe in jeglichem Medium und Format erlaubt, sofern Sie den/die ursprünglichen Autor(en) und die Quelle ordnungsgemäß nennen, einen Link zur Creative Commons Lizenz beifügen und angeben, ob Änderungen vorgenommen wurden.

Die in diesem Kapitel enthaltenen Bilder und sonstiges Drittmaterial unterliegen ebenfalls der genannten Creative Commons Lizenz, sofern sich aus der Abbildungslegende nichts anderes ergibt. Sofern das betreffende Material nicht unter der genannten Creative Commons Lizenz steht und die betreffende Handlung nicht nach gesetzlichen Vorschriften erlaubt ist, ist für die oben aufgeführten Weiterverwendungen des Materials die Einwilligung des jeweiligen Rechteinhabers einzuholen.

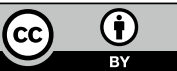

